Aus dem Landkrankenhause Cassel I.

\title{
Über die Entstehung der Hirnblutung bei dem Schlaganfall.
}

Von

\author{
Prof. Dr. Rosenblath.
}

(Mit 4 Photographien und Tafel I/IV.)

Inhaltsübersicht.

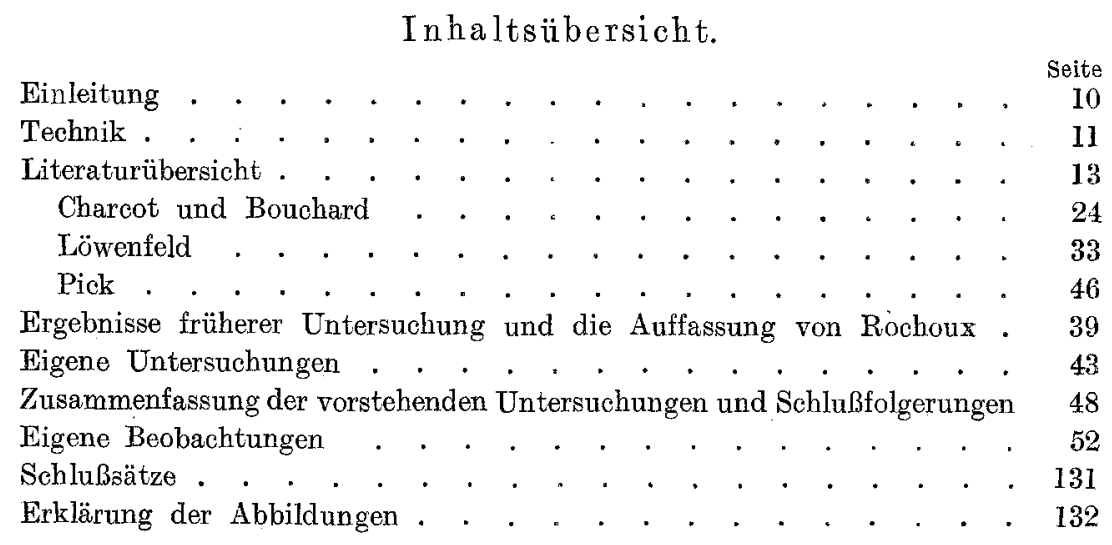

\section{Einleitung.}

Unter allen Lehren, die die Schulmedizin über die Entstehung innerer Krankheiten vorträgt, ist vielleicht keine, die so einfach und verständlich erscheint, wie die von der Entstehung der Hirnblutung bei dem Schlaganfall. Eine Hirnarterie reißt plötzlich, das Blut strömt unter entsprechendem Druck aus ihr aus und zertrümmert das umgebende Nervengewebe. Es war wohl die Plötzlichkeit, mit der ein Mensch scheinbar inmitten völliger Gesundheit durch den Hirnschlag gefällt werden kann, die den Gedanken an eine übermächtige, wie ein heftiger Schlag auf den Kopf wirkende Gewalt nahelegte und dieser hat in der deutschen wie griechischen Wortbildung, die den Vorgang bezeichnet, seinen unverkennbaren Ausdruck gefunden. Es war somit nur natürlich, daß sich die anatomische Forschung über die Ursache der Apoplexie zunächst dem Verhalten der Hirnarterien zuwandte, und in der Tat wurden schwere Erkrankungen dieser Gefäße, die ein 
Nachgeben und selbst ein jähes Zerreißen wohl verständlich machen konnten, gefunden. Nimmt man hinzu, daß der Hirnschlag öfter solche Personen befällt, die einer Steigerung des Blutdrucks, sei es vorübergehend bei körperlichen Anstrengungen oder Gemütsbewegungen, sei es dauernd bei chronischer Nierenentzündung, ausgesetzt waren, so gewinnt diese ganze Erklärung an Wahrscheinlichkeit.

Trotzdem ist diese Betrachtungsweise einseitig und oberflächlich. Sie nimmt stillschweigend an, daß die Hirnsubstanz lediglich mechanisch geschädigt werde, obwohl niemand ihr Verhalten näher untersucht hat. Mit der Frage nach ihrem Schicksal beginnen aber alsbald die Schwierigkeiten für die mechanische Auffassung. Ist es denn überhaupt wahrscheinlich, daß unter der Wirkung ausströmenden Blutes eine ganze Hirnpartie in einen blutigen Herd verwandelt werden könnte, dessen Ränder mit der umgebenden Wand, wie meist der Fall, fast gar keinen Zusammenhang mehr haben ? Sollte man nicht vielmehr erwarten, daß sich das Blut, die Hirnsubstanz vielfach zerklüftend, zwischen den Fasermassen der Marksubstanz durchwühlte und breite Brücken von erhaltener Nervensubstanz in dem Herde stehen ließe. Hat jemand versucht, ob sich an der Leiche durch Einspritzung von Flüssigkeit in das Hirn ein Bild erzeugen läßt, das eine, wenn auch nur entfernte Ähnlichkeit mit dem apoplektischen Herde hat? Was wird aus der angeblich mechanisch zertrümmerten Hirnsubstanz? Für die heutige Technik müßte ihr Nachweis leicht sein. Wie verhalten sich die Gefäße, die, soweit ihr Reißen nicht die Blutung veranlaßt hat, ebenfalls mit dem zerstörten Hirngewebe zerrissen werden sollen? Auch die alten Fragen nach dem Wesen der Gefäßerkrankung, die den Blutaustritt bewirkt, nach der Bedeutung, die den sogenannten Miliaaneurysmen zukommt, haben eine befriedigende Lösung noch nicht gefunden. Solche Uberlegungen bildeten den Anlaß zu der folgenden Untersuchung.

\section{Technik der Untersuchung.}

Jahrzehnte hat man sich zur Untersuchung des apoplektischen Herdes nur der Zupfpräparate bedient, indem man den Herd breit eröffnete, den Inhalt vorsichtig ausspülte und nun die der Wand häufig anhaftenden flottierenden Fortsätze ablöste und gefärbt oder ungefärbt auf den Objektträger brachte. Bei diesem Vorgehen konnte nicht einmal über den Zustand der Gefäße ein übereinstimmendes Urteil gewonnen werden. Bequemer wurde dieser Weg durch Pick gestaltet, der die 
betreffenden Hirnteile stundenlang mit physiologischer Kochsalzlösung im Schüttelapparat behandelte und so die Gefäße des apoplektischen Herdes isolieren konnte. Beide Methoden habe ich nur soweit angewendet, um mir ein eigenes Urteil über die Präparate, die sich mit ihnen gewinnen lassen, zu bilden. Sie sind für eine Untersuchung, die die Gefäße nicht isoliert betrachten, sondern in ihrer Beziehung zum umgebenden Gewebe studieren und auch den Inhalt des apoplektischen Herdes nach Möglichkeit in die Betrachtung einbeziehen will, nicht brauchbar. Die Anwendung der Schnittechnik bietet heute für die Objekte dieser Art keine unüberwindliche Schwierigkeit mehr.

Die Gehirne wurden daher in der Regel im ganzen auf 2-3 Tage in Formalinwasser eingelegt, meist, nachdem sie in die Hemisphären zerlegt waren und Brücke mit Kleinhirn. abgetrennt war. Wenn die Arterien mit Leimmasse injiziert waren, so mußte das Gehirn für einige Stunden unzerlegt in das Formalin gebracht werden. Immer wurden nach 2-3 Tagen die Hemisphären in dicke frontale Scheiben zerschnitten und der apoplektische Herd möglichst nur an seinen Polen eröffnet. Von diesen wurde dann eine Scheibe zum Teil zu Gefrierschnitten verwendet, zum Teil in Alkohol gebracht und den gebräuchlichen Färbungen unterworfen. Alles übrige wurde in Müllersche Flüssigkeit gelegt, die nach meinen Erfahrungen immer noch die beste Schnittkonstistenz gibt. Für die Anfertigung von großen Utbersichtsschnitten, die die ganze Hemisphäre umfassen, ist das von Bedeutung. Nach etwa 6 Wochen ist die Konsistenz so, daß man die Stücke mit dem Hirnmesser in glatte, etwa daumenbreite Scheiben zerlegen kann. Für die Markscheidenfärbung sind sie reif, nachdem sie nochmals 6 Wochen in Müllerscher Lösung gelegen haben. Längeres Einlegen hat keinen Vorteil.

Für die Anfertigung der großen Ubersichtsschnitte habe ich mich nur der Zelloidineinbettung bedient. Dabei bin ich kurz verfahren und habe die Stücke in das dünne Zelloidin nicht länger als 8 Tage gelegt. Die Apathysche Terpineoldurchtränkung der Zelloidinblöcke fand ich auch für die Anfertigung der Utbersichtsschnitte häufig sehr vorteilhaft. Die Schnitte fallen meist feiner aus, als sie nach dem alten Verfahren gemacht werden können. Nur frische Blutergüsse sind auf diese Weise nicht schneidbar.

Von mehreren großen Mikrotomen, die ich im Laufe der Jahre benutzte, befriedigte mich das Reichertsche am meisten. Nur gestattet es, wenigstens in der mir zur Verfügung. stehenden Ausführung, 
die Schnittführung mit querstehendem Messer nicht. Ich habe daher den Mechaniker C. Betting in Göttingen veranlaßt, ein Mikrotom herzustellen, mit dem man unter Flüssigkeit oder trocken und mit beliebiger Messerstellung schneiden kann.

Einen Teil der Hirne habe ich von den Gefäßen der Basis aus mit Leimmasse injiziert. Hier und da erleichtert das Verfahren die Auffindung nekrotischer, schwer erkennbarer Gefäße in den Herdwandungen. In Gefäße, welche inmitten der Blutergüsse selbst lagen, drang die Injektionsmasse meist nicht ein. Ich verfolgte aber bei der Einspritzung noch einen anderen Zweck. Aus der gesunden Hemisphäre der Gehirne wurden nach Formalinhärtung fingerdicke Scheiben besonders aus der Gegend der Sylvischen Grube der Aufhellung nach Spalteholz ${ }^{\mathbf{1}}$ ) unterworfen. Man kann auf diese Weise die Verästelung der Arteria media so gut zur Anschauung bringen, daß man erwarten darf, nicht zu kleine Aneurysmen sehen zu können. Der durch den Krieg herbeigeführte Mangel an einigen zu der Aufhellung nötigen Materialien beschränkte die Zahl der so untersuchten Hirne bisher auf sechs. Es mag hier kurz erwähnt sein, daß ich ein einem Aneurysma gleichendes Gebilde niemals gesehen habe.

Versuche, durch Eintreiben von Injektionsmasse in die Hirnsubstanz eine Zertrümmerung derselben zu bewirken, mißlangen voll, ständig. Sticht man eine Nadel einfach durch die Rinde in das Markso läuft die eingespritzte Flüssigkeit an der Nadel glatt zurück und breitet sich zum Teil in den Maschen der Spinnewebhaut aus. Das Resultat wird nicht besser, wenn man zunächst innerhalb einer Arterie eindringt und durch diese dann in das Hirn einsticht. Auch kam ich nicht besser zum Ziele, wenn ich zunächst hochprozentiges Agar einspritzte und dasselbe dann gerinnen ließ, in der Hoffnung, daß es der dann durch die wieder frei gemachte Nadellichtung eingespritzten Flüssigkeit den Rücklauf verlegen würde. Es gelingt auf diese Weise nicht, einen Hirnherd zu schaffen, der mit einem apoplektischen eine entfernte Ähnlichkeit hätte.

\section{Literaturübersicht.}

Werfen wir zunächst einen Blick auf die Literatur und sehen wir uns die Schilderung an, die von dem Hirnbefund bei Schlaganfall ge-

I) Über das Durchsichtigmachen von menschlichen und tierischen Präparaten. Leipzig 1911. 
geben zu werden pflegt. Es ist zwecklos hierbei weiter zurückzugehen als in das vorige Jahrhundert. Wer sich für die früheren Arbeiten interessiert, findet eine ausführliche historische Darstellung bei Löwenfeld.

Diet11) unterschied im Jahre 1846 vier Formen, unter denen der apoplektische Herd auftreten kann. Er besteht:

1. Aus einzelnen punkt- und striemenförmigen Blutaustritten, wobei die dazwischen liegende Hirnsubstanz normal geblieben ist.

2. Aus zahlreichen kleinen Blutaustretungen, wobei die Hirnsubstanz vielfach verletzt und breiartig weich geworden ist.

3. Aus einem großen, durch den Zusammenfluß mehrerer kleiner Blutaustretungen gebildeten Blutextravasate, das zertrümmerte Hirnsubstanz in sich enthält und von solcher umgeben ist.

4. Aus einem großen, durch Vergrößerung eines einzelnen kleinen Blutextravasates mittels fortgesetzter Blutung gebildeten Blutaustrittes, der in seinem Innern keine beigemischte Hirnsubstanz enthält (S. 240).

Für Dietl beruht die Pathogenie der Apoplexie auf rein physikalischen Momenten (S. 275). So bestimmt diese Ansicht vorgetragen wird, so vergeblich sieht man sich nach dem Nachweis der GefäBruptur oder nach dem der zertrümmerten Hirnsubstanz um. Der Autor hat offenbar keinen Zweifel daran, daß der Sachverhalt so gestaltet sein müsse und daher sucht er gar nicht nach Beweisen.

Ein Jahrzehnt später sagt Rokitansky²) in seinem Lehrbuch der pathologischen Anatomie: „Die Gehirnhämorrhagie besteht in der Extravasation von Blut in das Parenehym des Gehirnes, womit die Entstehung einer dem Maße der Blutung entsprechenden Laesio continui der Gehirntextur gegeben ist, welche meist augenscheinlich als eine vielfache Zertrümmerung, Zerreißung, Quetschung der Gehirnmasse auftritt.

Der anatomisehe Befund bietet mancherlei Verschiedenheiten dar. Einmal findet man die Gehirnsubstanz an einer Stelle von verschiedenem Umfang von punkt- oder striemenförmigen Extravasaten dunkelrot gesprengelt oder gestriemt. Die Extravasate sitzen seitlich an den feinen und kapillären Gefäßen oder umfassen dieselben, oft in großen Strecken, ringsum, sind zum Teil in der Adventitia enthalten. Die zwischenbefindliche Gehirnsubstanz hat ihre normale Farbe und Konsistenz behalten und erseheint dem unbewaffneten Auge bloB auseinander gedrängt - Apoplexia capillaris.

Das andere Mal ist die Anzahl jener Extravasate beträchtlichex, sie stehen dichter, die zwischenliegende Marksubstanz ist von Imbitition eines diluierten Blutrots gelblich gefärbt; sofort fließen die Extravasate unter sich zusammen, die Gehirnsubstanz erscheint ziemlich glejchmäßig

1) Anatomische Klinik der Hirnkrankheiten. Wien 1846. S. 239-289.

2) 3. Aufl. Wien 1855. Bd. 2, S. 443. 
suffundiert, rot, dabei gelockert, feuchter, vielfach zertrümmert, zu einem roten Brei zerquetscht. Endlich findet sich eine von zertrümmerter und gequetschter Hirnsubstanz begrenzte Kluft vor, welche das Extravasat einschließt - apoplektischer Herd.

Der apoplektische Herd geht ohne Zweifel häufig aus einer sogenannten Kapillarapoplexie hervor - sein Inhalt ist ein Extravasat, welches einen entsprechenden Anteil zertrümmerter Hirmsubstanz in sich aufgenommen hat. Er entsteht aber auch unzweifelhaft sehr oft aus einem einzelnen kleinen Extravasat, indem sich dieses mittels fortgesetzter Blutung eines ansehnlichen Gefäßes vergrößert und die Hirnsubtanz mit vielfacher Zertrümmerung auseinander drängt" (Bd. 2, S. 443).

Über den Inhalt des apoplektischen Herdes und die Wand desselben finden sich auch in der weiteren. Darstellung nur wenige Zeilen. Das Blut schließt Trümmer der destruierten Gehirnsubstanz ein oder es ist von dieser Beimengung frei. Die mannigfachsten Verschiedenheiten gibt der Grad und die Art seiner Gerinnung. Über die Wand heißt es noch: ,Sie bildet eine rote, zu einem feuchten Brei zerquetschte Hirnsubstanz. In umfänglichen Herden hängen zottige Trümmer derselben in die Höhle hinein. Weiter nach außen hin sind gewöhnlich kleine, an Zahl mit der Entfernung abnehmende Blutaustritte zugegen."

Unter den Ursachen der Hirnblutung nennt Rokitansky Hyperämien, Erkrankungen des Herzens und der Lungen und Gefäßkrankheiten. Erweiterung der kleinen und kapillaren Gehirngefäße, Fettmetamorphose und Verknöcherung derselben.

Es ist von großem Interesse, daß Rokitansky auch größere Blutungen aus zusammenfließenden Kapillarapoplexien hervorgehen läßt, wenn es auch für die rasch tötenden großen Blutungen die Zerreißung eines ansehnlichen Gefäßes annimmt. Daß der Inhalt des Herdes zum Teil aus zertrümmerter Hirnsubstanz besteht, wird nicht weiter bewiesen. Wie immer, gründet sich diese These nur auf den Augenschein, wahrscheinlich vornehmlich auch auf den Befund der zottigen Wand des Herdes.

Um dieselbe Zeit gab Hasse ${ }^{1}$ ) eine ausführliche Darstellung des Befundes bei der Apoplexie. Auch er unterscheidet zwei Hauptformen, den eigentlichen apoplektischen Herd und die kapilläre Apoplexie. Es findet sich meist nur ein Herd, niemals wohl mehr als zwei oder drei. Bei den ganz großen Herden, die eine ganze Hemisphäre zertrümmern, ist es nicht unwahrscheinlich, daß eine mit Erweichung der Hirnsubstanz selbst verbundene Erkrankung vorausging. Die Form des Herdes hängt davon $a b$, ob bloß Zerreißung und Zertrümmerung der Hirn-

1) Krankheiten des Nervenapparates. Virchow, Spezielle Path. u. Ther. 1855, Bd. 4, Abt. 1. 
substanz bei dem Blutaustritt erfolgte oder ob es auch zu einer Auseinanderdrängung der Gewebe in der Richtung der Hirnfaserung gekommen ist. Solche hat er nach außen vom Seh- und Streifenhügel und im Kleinhirn nach den Brückenschenkeln hin gesehen.

Der frische apoplektische Herd ist ausgefüllt von einem lockeren, schwarzroten Blutgerinnsel. Niemals sah er an demselben eine isolierte Ausscheidung von Faserstoff. ,Sehr häufig bemerkt man schon mit bloßem Auge eine Beimischung von zertrümmerter, ganz erweichter und mehr oder minder von Blutfarbstoff durchtränkter Hirnsubstanz. Da, wo die Blutaustretung die Hirnsubstanz auseinandergedrängt hat, findet sich der Cruor ganz frei von jeder Vermischung mit Hirnsubstanz. Öfters gelingt es bei vorsichtiger Lösung und Abspülung des Gerinnsels mittels eines Wasserstrahles den Zusammenhang desselben mit einem oder ein paar Büscheln feiner Hirngefäße zu erkennen, an welchem es wie an einem Stiele anhängt. Es ist wohl niemals mit Sicherheit die Berstung eines größeren Gefäßes innerhalb des Gehirnes nachgewiesen worden. Dagegen lassen sich auffallende Veränderungen kleiner Arterienzweige oft in sehr großer Verbreitung konstatieren, so daß es nicht sowohl die Verletzung eines einzigen Gefäßes als vielmehr diejenige einer ziemlichen Zahl sehr kleiner Arterien ist, welche die Blutung liefert" (S. 376).

„Die Wandungen des frischen Herdes bestehen aus ungleichmäBig erweichter, mehrfach zerrissener Hirnsubstanz, deren Fetzen und Trümmer in das Extravasat hineinragen und sich abgelöst damit teilweise vermengen. Eine gelblichrote Färbung durchdringt die erweichte Hirnmasse in der Ausdehnung von einer oder ein paar Linien. Da, wo der Herd von in der Richtung ihrer Faserung auseinandergedrängter, nicht zerrissener Hirnsubstanz begrenzt wird, sind die Wandungen mehr glatt, gleichmäßig, weniger erweicht und nicht so sehr von Blutfarbstoff imbibiert. Ein Wasserstrahl auf dieselben löst keine Trümmer und Fetzen ab (S. 377).

Bei der kapillären Apoplexie finden sich hirsekorngroße Blutungen in erweichtem Gewebe. Die Auffassung, daß aus der Verschmelzung solcher kleiner Blutungen große hervorgehen können, wird erwähnt, aber ein eigenes Urteil darüber nicht abgegeben.

Für Hasse unterliegt es keinem Zweifel, daß die Apoplexie durch Gefäßruptur zustande kommt. Aber im Gegensatz zu anderen Autoren, die an eine Zerreißung gröberer Arterien denken, ist es für ihn nicht zweifelhaft, „daß es sich in beinahe allen Fällen um eine Läsion der kleinsten Gefäße handelt" (S. 381).

Diese Autoren und auch alle folgenden nahmen wohl als selbstverständlich an, daß der Umfang des durch die Blutung zerstörten Bezirkes meist größer ist, als dem Versorgungsgebiet des zerrissenen GefäBes entspricht. Ziehen ${ }^{1}$ ) macht hierzu die Bemerkung, es sei zu

1) Ebstein-Schwalbe, Handbuch der praktischen Medizin Bd. 3. 
beachten, ,was gewöhnlich übersehen wird, daß außer dem mechanischen Effekt der Blutung auch die Absperrung der Blutzufuhr von dem durch das zerrissene Gefäß ernährten Bezirk den Untergang vieler Elemente herbeiführen muß. Da sich der von dem ausströmenden Blut. zerstörte und der seiner Blutzufuhr beraubte Bezirk keineswegs decken, so kommt also $\mathrm{zu}$ der hämorrhagischen Zerstörung stets noch eine ischämische hinzu. Auf die letztere ist auch die umgebende Erweichung zum Teil zu beziehen."

Der Herd selbst besteht nach Ziehen aus einer breiigen Masse, welche aus zertrümmerter Hirnmasse und ausgetretenem Blut gemischt ist und die Blutung erfolgt durchweg aus der Zerreißung nur eines kleineren arteriellen Gefäßes mit Aneurysmenbildung.

Hier begegnet man einmal dem Versuch, die Veränderungen in der Randzone des apoplektischen Herdes zu erklären. Aber er muB an dem Umstande scheitern, daß die erweichte Zone meist nicht nur an einer beschränkten Stelle der Peripherie des Herdes gefunden wird, sondern, daß sie den ganzen Herd mehr oder weniger vollständig umgibt und die übergroße Mehrzahl der apoplektischen Herde ja viel größer ist, als dem Versorgungsgebiet einer kleineren Himarterie entspricht.

Wenn als sicher angenommen wurde, daß der apoplektische Herd lediglich durch mechanische Kraft, die Gewalt des ausströmenden Blutes, geschaffen wird, so muß auch die Form des Herdes aus mechanischen Ursachen erklärbar sein. Man dürfte erwarten, daß die Herde von etwa gleicher Größe in einer bestimmten Hirngegend meist auch eine bestimmte Form darbieten müssen. Aber im Sinne dieser Erklärung finden sich nur dürftige Andeutungen, die sich teilweise sogar direkt widersprechen. So hält Monakow ${ }^{1}$ ) die graue Substanz für widerstandsfähiger gegenüber der Blutung, während Wernicke²) dasselbe von der weißen behauptet.

Wichtige Gesichtspunkte treten bei dieser mechanischen Auffassung von der Entstehung der Hirnblutung in den modernen Darstellungen unserer Lehrbücher nicht weiter hervor. Die Auffassung, daB die Himsubstanz in dem apoplektischen Herde durch die Gewalt des ausströmenden Blutes zertrümmert wird, gilt als selbstverständlich und

1) Gehirnpathologie. Nothnagels Handbuch der speziellen Path. u. Ther. Wien 1905.

2) Lehrbuch der Gehirnkrankheiten. 1881. Bd. 2. 
wird meist gestïtzt durch den Hinweis auf die Beschaffenheit der Herdwand, die abgerissene Gewebsfetzen und Gefäße erkennen lasse. Weniger bestimmt wird das von dem Inhalt des Herdes vorgetragen, der nach einer Auffassung, wie sie z. B. Wernicke vertritt, lediglich aus Blut, nach anderer aus Blut und zertrümmerter Nervensubstanz besteht. Der letztere Vorgang kann wieder in verschiedener Weise in die Erscheinung treten. Es können einmal größere Teile des Gehirns durch die Blutung aus ihrem Zusammenhang gelöst werden. So gibt in dem Kaufmann schen $^{1}$ ) Lehrbuch die Abbildung 581 einen Frontalschnitt durch ein apoplektisches Gehirn wieder, in dessen Ebene der Sehhügel ganz von seiner Umgebung durch die Blutung abgeschält ist. Solche Vorkommnisse werden selten sein. Außerdem aber begegnet man der Auffassung, daß der Inhalt des apoplektischen Herdes einen blutigen Hirnbrei darstellen könne, aber man vermißt hier durchaus nähere Angaben, die eine wirkliche innige Mischung aus Blut und Hirnteil glaubhaft machen können. Und jedenfalls findet sich niemals ein Bericht über den Versuch, das Hirngewebe in diesem Brei mikroskopisch nachzuweisen.

Die Figur 580 desselben Lehrbuchs gibt noch einen Horizontalschnitt durch ein apoplektisches Gehirn wieder, in dem der Streifenhügel durch den Insult zerstört ist. Hier gestattet der Vergleich mit der gesunden Hemisphäre gut die erhebliche Schwellung zu erkennen, die die kranke Hälfte in der Herdregion erlitten hat. Auch dieser Vorgang ist von Bedeutung und merkwürdigerweise für die mechanische Entstehung des apoplektischen Herdes nicht verwertet worden.

Sieht man sich nun nach Berichten über den. Nachweis geplatzter Arterien oder auch von Venen in solchen Herden um, so erhält man auffälligerweise gar keine positiven Angaben. Man ist gewohnt, daß bei anderen tödlichen. Blutungen, z. B. der Lunge, des Magens, des Ösophagus, des Darmes, der Obduzent nach der Quelle der Blutung sucht und hier wird das Suchen, wenn auch keineswegs ausnahmslos, von Erfolg begleitet sein. Bei der Apoplexie verbält es sich entschieden anders. Schon Abercrombie ${ }^{2}$ ) und später Hasse haben dieses Suchen für au ssichtslos erklärt und in dieser Auffassung hat die neuere Zeit augenscheinlich nichts geändert. Uber etwaige bessere Erfolge, die die Anwendung mikroskopischer Technik hier bietet, wird an anderer Stelle zu sprechen sein.

1) Lehrbuch der speziellen path. Anatomie. 4. Aufl. Berlin 1907.

2) Über die Krankheiten des Gehirns und Rückenmarks. Deutsch von De Blois. Bonn 1821. 
Faßt man alles zusammen, so sieht man, daß die mechanische Auffassung von der Entstehung der Apoplexie zwar allgemein und nahezu unbestritten ist, daß sie aber nur wenige Stützen hat. Unter diesen ist die wesentlichste die Beobachtung, daß die Wand der apoplektischen Herde öfter eine unebene und fetzige Wand hat und daß unter Umständen in dem blutigen Inhalt dieser Herde Teile anscheinand zertrümmerter Hirnsubstanz nachweisbar sind. Man wird zugestehen, daß dieser Beweis für die mechanische Entstehung der Herde nicht zwingend ist, denn Gewebsreste, mehr oder weniger verändert, findet man auch in Herderkrankungen der verschiedensten Organe, bei denen lediglich chemische Kräfte wirksam waren. Ich erinnere an solche Befunde bei Lungenabszeß und Lungengangrän, an jau.chige Prozesse im Unterhautzellgewebe und zwischen den Muskeln, in denen man hier und da Reste von Faszien findet, und an die Pankreasnekrose. Der Vergleich mit dieser ist besonders naheliegend, da das nekrotische Gewebe so stark mit Blutungen durchsetzt sein kann, daß der Anblick zu der Bezeichnung Pankreasapoplexie geführt hat. Trotzdem hat hier noch niemand an eine primäre Zerreißung einer erkrankten Arterie gedacht, sondern allgemein wird hier die Blutung als ein mehr nebensächlicher Vorgang betrachtet.

Als eine weitere wichtige Stütze der mechanischen Auffassung ist seit langer Zeit der Umstand betrachtet worden, daß in sehr zahlreichen Fällen von Apoplexie die Hirnarterien ausgesprochen sklerotisch gefunden wurden.' Zwar wird dieser Befund keineswegs ausnahmslos erhoben und es ist auch vielfach darauf hingewiesen worden, "daß nicht ohne weiteres klar ist, warum ein, wenn schon sklerotisches, aber doch verdicktes Gefäß leichter reißen soll, als ein normales, aber die nicht wegzuleugnende Tatsache des häufigen Zusammenvorkommens von Schlaganfall und Sklerose der Hirngefäße ist zum Ausgangspunkt der Forschungen über die feineren Vorgänge in dem Gehirn des Schlagflüssigen geworden, und diese Forschungen haben so wichtige Tatsachen klargestellt, daß wir uns mit ihnen vor allem beschäftigen müssen.

Die Aufnahme anatomischer Forschung in der Neuzeit hatte nach und nach die Einsicht gebracht, daß die Apoplexie die Folge eines Blutaustrittes in das Gehirn sei und Morgagn $\mathrm{i}^{1}$ ) suchte bereits nach den Ursachen des Blutergusses. Er schloß, daß die großen Höhlen, die man beim Schlagfluß sieht, plötzlich entstehen müssen, denn er sah nie

1) De causis et sedibus morborum. U̇bersetzt von Königsïörfer. 1771. 
kleine Anfänge des Leidens, obwohl er solche Gehirne oft in kleine Scheiben zerlegte. Die rasche Entstehung kann er sich am besten mit dem Platzen einer Pulsadergeschwulst erklären, obwohl er eine solche nie gefunden hat. Er erwähnte wohl die Krankengeschichte eines Greises, der in den letzten Lebensjahren zwei Pulsadergeschwüre an den Händen bekam, und als dieser an einem Schlage starb, nahm Morgagni an, daß das Reißen einer Pulsadergeschwulst im Gehirn stattgefunden hätte. Er fügt aber hinzu: ,Weil sein Leichnam nicht ist geöffnet worden, so weiß ich nicht, ob ich recht oder unrecht gemutmaßt habe."1)

Jedenfalls hält er die allmähliche, unmerkliche oder auch plötzliche Ausweitung der dünnwandigen Hirngefäße und ihre plötzliche Zerreißung für die gewöhnliche Ursache der Hirnblutung, wenn er auch zuläßt, daß noch andere Verderbnisse der Gefäße zu deren Zerreißung führen mögen. Man sagt nicht zu viel, wenn man ausspricht, daß diese Gedanken Morgagnis in der ganzen späteren Forschung weitergewirkt haben. Das Suchen nach Aneurysmen im Gehirn des Apoplektikers ist seitdem um so ernsthafter und methodischer betrieben worden, je feiner die Untersuchungstechnik entwickelt wurde.

Zunächst allerdings lag besonders in Deutschland die wissenschaftliche Forschung noch brach, und als sie allmählich einsetzte, war sie anfänglich nur ein Arbeiten mit Begriffen, die nicht aus der lebendigen Erfahrung abgezogen waren. Diesen Tiefstand wird man am deutlichsten in dem kleinen Buche von Burdach ${ }^{2}$ ) erkennen, das die Auffassung über den Schlagfluß im Beginn des vorigen Jahrhunderts wiedergibt, den Kollaps und die Kompression des Gehims als die Ursache der Apoplexie bezeichnet und auch nicht ein Sektionsprotokoll enthält. Erst die Zeit von Kölliker ${ }^{3}$ ) und Virchow brachte neues Leben.

Der erste untersuchte die Leiche eines 75 jährigen Potators, der eine Apoplexie wenige Stunden überlebt hat. Er fand im linken Streifenhügel einen mit roten Punkten übersäten Herd. Mikroskopisch entsprachen diese Punkte blutgefüllten Blasen, deren scharf konturierte Wände als Fortsetzungen feiner Gefäße, Venen und Kapillaren, deutlich erkennbar waren. Im Anschluß daran bespricht er die Apoplexia capillaris und die falschen Aneurysmen der kleinsten Hirnarterien. Diese entstehen „nach vorhergegangener Zerreißung der Tunica media et intima durch einen

1) l. c. S. 83 , 3. Brief.

2) Burdach, Die Lehre vom Schlagfhn. Leipzig 1806.

3) „Ưber blutkörperchenhaltige Zellen“. Zeitschr. f. wissenschaftl. Zoologie. 1849. Bd. 1. 
Bluterguß zwischen Media und Adventitia, durch welchen die letztere blasen- und schlauchförmig oder auf lange Strecken abgehoben wird" (S. 264). (Dazu ist freilich zu bemerken, daß die Zerreißung der inneren Gefäßwand weder durch die Abbildung, noch durch die Beschreibung belegt oder auch nur wahrscheinlich gemacht wird.) Zerreißt nun an solchen Stellen die Adventitia, so kommt es zu kapillärer oder auch größerer Apoplexie. Der Erguß in der Adventitialscheide kann sich zurückbilden, das Gefäß annähernd normal werden oder obliterieren und dann entsteht im Umkreis durch Ernährungsstörung des Nervensystems eine Erweichung.

Zur weiteren Studie in dieser Richtung wurde durch Kölliker Pestalozzi ${ }^{1}$ ) angeregt. Für diesen Autor ist es von vornherein feststehend, daß Krankheiten der Gefäßwandungen die wichtigste Bedingung für die Entstehung der Blutung bilden. Trotzdem sei aber das Verhalten der Gefäße nur wenig studiert. Auch seien die Gefäße, deren Bersten die Blutung setzt, zu klein für die makroskopische Untersuchung. Das Mikroskop müsse helfen. Die Technik der Untersuchung wird nicht erwähnt, sie besteht aber jedenfalls in der Anfertigung von Zupfpräparaten ohne Heranziehung von Färbungen, die zu jener Zeit noch nicht gebräuchlich waren.

So untersucht er fünf Fälle von Apoplexie, ganz frische wie auch ältere Blutungen. An Venen und Kapillaren fand er keine Veränderungen und an Arteriē nur an solchen, die noch drei Häute erkennen ließen. Die gröBeren Gefäße glichen länglichen Blutkoagulis und fanden sich auch oft im Zusammenhang mit wirklichen Extravasaten. „Erst die weitere Untersuchung lehrte, daß die vermeintlichen Blutkoagula von einer deutlichen Haut umgeben waren, und wenn durch Zusatz von Wasser oder durch Kompression der Inhalt der Schläuche etwas entfernt worden war, sah man im Innern derselben, mehr oder weniger weit von der äußeren Haut entfernt, das eigentliche Gefäßrohr, die Intima und Media ohne die geringste Erweiterung verlaufen" (S. 17). Diese Aneurysmen waren selten auf einen kleinen Teil des Gefäßes beschränkt, sondern meist im ganzen Verlauf des GefäBes, soweit es isoliert und unter das Mikroskop gebracht werden konnte, sichtbar. Der Durchmesser der Erweiterung war dann auf lange Strecken ziemlich glejchmäßig und betrug höchstens das Drei-, Vierfache des inneren Lumens bei solchen schlauchförmigen Erweiterungen. An den Teilungsstellen sah er blasenförmige Erweiterungen mit 6-7 facher Vergrößerung des Durchmessers. „Manchmal war das Gefä $\beta$, d. $h$. diese äußere Haut geborsten, während die inneren Häute unzerstört durch das Koagulum gingen. Manchmal fehlte auch jede Spur der äußeren Membran bei unverletzter innerer. Mit Abbildungen ist die Arbeit nicht ausgestattet.

Entgegen späteren Verwertungen; die sie gefunden hat, als erbringe sie den Nachweis der Blutungen aus Aneurysmen, ist festzustellen, daß der Vorgang der Zerreißung der

1) Über Aneurysmata spuria der kleinen Gehirnarterien und ihrem Zusammenhang mit der Apoplexie. Diss. Würzburg 1849. 
Adventitia sowohl wie der Media und Intima nur angenommen, aber keineswegs bewiesen wird. Wie das Blut in den Adventitialraum kam, wird nicht dargetan, und das Bersten oder Geborstensein der äußeren Gefäßhülle wird nur aus dem Umstande geschlossen, daß diese äußere Hülle an manchen, in die Blutung eintauchenden Gefäßen nicht mehr nachweisbar ist. Auch die Ursache des angenommenen Platzens der Adventitia wird nicht angegeben, sondern nur gesagt, daß die mechanische Erweiterung derselben allein dieses Platzen nicht verständlich macht.

Es ist somit zweifellos, daß diese beiden Arbeiten zuerst die Anfüllung von Adventitialscheiden mancher Arterien im Gebiete der Hirnblutung beschrieben haben, wie man sie heute am Schnittpräparat leicht nachweisen kann. Aber dieser Vorgang ist mehr nebensächlich und er erklärt die Entstehung der Hirnblutung noch nicht.

Aneurysmen und aneurysmenähnliche Bildungen an den Hirngefäßen waren in der Folge nun oft Gegenstand der Untersuchung. Virchow ${ }^{1}$ ) sah bei Hirnapoplexien mehrfach ähnliche Gebilde wie Kölliker und Pestalozzi. Er bezeichnete sie als Aneurysma dissecans. Er hebt hervor, daß die strukturlose Adventitia dabei von dem inneren Gefäßmantel abgehoben sei, ohne daß an den inneren Häuten eine Ruptur zu sehen war, und er fügt hinzu, daß diese Form auch artefiziell durch das Ausziehen des Gefäßes oder durch den Druck des Deckglases hervorgebracht werden kann.

Die Gesamtheit der Veränderungen, die er an Hirngefäßen - ohne Beziehung zum Schlaganfall - fand, faßt er unter folgenden Rubriken zusammen:

1. Die einfache Ektasie; die in einer allgemeinen und gleichmäßigen Erweiterung des GefäBes besteht.

2. Die variköse Ektasie, bei der das ganze Gefäß, aber ungleichmäßig, erweitert ist.

3. Die ampulläre Ektasie, die vorher schon Cruveilhier unter dem Namen Aneurysme sous l'aspect d'ampoule im Gehirn bei Schlaganfall beschrieben hatte. Er versteht darunter eine partielle, lokale Grefäßerweiterung. Sie kann jede Änderung in der Struktur der Gefäßhäute vermissen lassen, oder es kann eine Atrophie der Ringfaserhaut nachweisbar sein. In der Ektasie fand er manchmal eine Ansammlung von mehrkernigen Rundzellen. Diese Aneurysmata vera totalia fand er in der Pia alter Leute ohne Beziehung zu einer bestimmten Krankheit und er hält es für möglich, daß sie eine Anlage für die Apoplexie schaffen.

4. Die kavernöse Ektasie, die zu unserem Thema keine Beziehung hat.

In einer späteren Notiz kommt Virchow ${ }^{2}$ ) nochmals auf Telangiektasien im Gehirn zurück, indem er sie mit denen der Nävi vergleicht

1) Virchows Archiv 1851, Bd. 3. ,Über die Erweiterung kleinerer Gefäße."

2) Virehows Archiv: UUber Naevi vasculosi des Gehirns. 1864. Bd. 30, S. 272. 
und annimmt, daß sie von längerem Bestande, vielleicht angeboren sein könnten.

Ưber ähnliche Befunde berichtet HeschI ${ }^{1}$ ) im Jahre 1865. Er schrieb die Gebilde als kleine, meist dichtgedrängte Punkte von dunkelroter Farbe, zwischen denen die Substanz des Hirnes, meist der Brücke leicht rötlich imbibiert ist. Die Größe des erkrankten Gebietes wechselt zwischen Hanfund Haselnußgröße. Meist besteht nur ein Herd, manchmal zwei, sehr selten zahlreiche. Außer den Aneurysmen der Gefäßchen besteht bis auf die rote Färbung der umgebenden Hirnsubstanz keine Veränderung, besonders keine Erweichung. Im allgemeinen kommt das Leiden nicht vor dem 40. Jahre vor, wird aber im späteren Alter auch nicht häufig. Über die Bedeutung der Erkrankung äußert sich Heschl nicht und sagt auch nichts über den etwaigen Zusammenhang mit Apoplexie. Aus einer tabellarischen Übersicht über 16 Fälle geht aber hervor, daß zwei mit Blutung kompliziert waren.

Im Jahre 1867 beschrieb Paulickiª) einen Befund, den er an einer weiblichen Leiche einer Siechenhaus-Patientin erhob, über deren Leiden nichts mitgeteilt wird. An den basalen Hirnarterien fanden sich drei kleine Aneurysmen, deren größtes erbsengroß war und von denen eins geplatzt war. Kleinere stecknadelkopfgroße Aneurysmen fanden sich in der Umgebung noch mehrere vor. Außerdem sah man an zahlreichen Stellen, besonders der Großhirnhemisphären und zum Teil dicht unter der Oberfläche punktförmige blaue Stellen, die sich mit der Nadel herausheben ließen. Mikroskopisch waren es bläschenförmige Gebilde, die mit einem ab- und zuführenden Gefäß zusammenhingen. Die Wandungen dieser Säckchen ließen eine fibrilläre Grundsubstanz mit eingestreuten Spindelzellen erkennen, während Elemente von Muskelfasern und ein innerer Zellenbelag nicht mit Sicherheit nachweisbar waren. Im rechten Streifenhügel waren zwei ältere apoplektische Narben.

Über die Arbeiten von Paget ${ }^{3}$ ), Wedl ${ }^{4}$ ), Moosherx ${ }^{5}$ ) und Todd ${ }^{6}$ ) über fettige Degenerationen der Gefäße braucht hier nicht näher berichtet zu werden, weil da augenscheinlich nicht allein wirklich degenerative Veränderungen beschrieben wurden, sondern auch Ansammlung von Fett in der Lymphscheide, wie sie bei den verschiedensten Zuständen und auch wohl normalerweise vorkommt. Außerdem beziehen sich diese Beobachtungen nur zum Teil auf die Apoplexie. So findet sich unter Moosherrs 21 näher mitgeteilten Beobachtungen nur ein einziger Schlaganfall mit Blutung in die Gehirnsubstanz.

1) Die Kapillaraneurysmen im Pous Varoli. Wiener Abd. Bd. 15, II.

2) Mehrfache kleine Aneurysmate an den Basilararterien des Gehirns und in der Gehirnsubstanz. Deutsche Klinik 1867, Bd. 19.

3) London, medical Gazetie 1850.

4) Grundzüge der pathol. Histologie. Wien 1854 .

5) U̇ber das pathologische Verhalten der kleineren Hirngefäße. Diss. Würzburg 1854.

6) Clinical lectures on paralysis etc. London 1854. 
Weitaus den größten und nachhaltigsten Einfluß auf die ganze Lehre von der Bedeutung der Hirnaneurysmen für die Apoplexie hat die Arbeit von Charcot und Bouchard ${ }^{1}$ ) ausgeübt.

Diese Autoren begrenzen ihre Aufgabe dahin, daß sie die hämorrhagischen Entzündungen der Dura und die meningealen Blutungen, ebenso wie die Aneurysmen der basalen Arterien, von der Untersuchung ausschließen. Die bislang beschuldigten Ursachen der Apoplexie, der gesteigerte Blutdruck im Schädel, die Konsistenzverminderung des Hirngewebes und die Verminderung der Widerstandskraft der Gefäße infolge einer Wanderkrankung, wie Arteriosklerose und fettige Degeneration, reichen zur Erklärung der. Hirnhämorrhagie nicht aus. Diese wird aber erklärt durch das Vorkommen von Aneurysmen an den kleinen, intrazerebralen Arterien. „Ces anévrysmes, qui existent le plus souvent en grand nombre dans le cerveau des individus qui succombent à l'apoplexie sanguine, qui se développent lentement, successivement, précèdent l'attaque d'un temps variable, souvent fort long, et d'enfin, en se rompant sous l'influence de quelque cause occasionelle, ils déterminent l'épanchement qui va former le foyer apoplectique. A ces anévrysmes nous avons donné le nom d'anévrysmes miliaires." (S. 112). Dabei wird erwähnt, daß diese Aneurysmen schon von Virchow; Gull, Meynert, Heschl beschrieben, aber nicht in ihrer Bedeutung erkannt wurden.

Die Gefäßveränderungen wurden zunächst nur an den Hirnen alter Leute gefunden und dementsprechend lautete der Schluß zunächst: Die senile Hirnblutung ist die Folge des-Berstens der Hirnaneurysmen. Später aber wurden dieselben Bildungen auch an den Hirnen jüngerer Leute gefunden, die einer Hirnblutung erlegen waren. Dabei ist nur die Einschränkung zu machen, daß natürlich nicht alle Hirnblutungen durch diese Aneurysmen bedingt sind. Es scheiden alle traumatischen Blutungen, die bei Erweichungen und bei Thrombosen, ebenso wie die bei manchen Infektionskrankheiten, aus.

Die Verfasser untersuchten im ganzen 77 Fälle von Apoplexie, meist alte Leute der Salpetrière. Bei alten Leuten ohne Hirnblutung fanden sie die Aneurysmen nicht. Ihre Untersuchungen bestätigen die statistischen Angaben von Heschl, wonach die Miliaraneurysmen vor dem 40. Jahre sehr selten sind, aber mit zunehmendem Alter häufiger geworden. Von der Arteriosklerose gilt das' gleiche. Trotzdem ist diese nicht die Ursache der Aneurysmen. Beides kommt nur oft zusammen

1) Nouvelles recherches sur İ pathologie de l'hémorrhagie cérébrale. Archives de physiologie normale et pathologique. Paris 1868, T. 1. 
vor. Die Arteriosklerose ist eine Endarteriitis, die Miliaraneurysmen aber entstehen aus einer Periarteriitis. Diese ist diffus. Sie findet sich nicht nur an den kleinen Arterien, die eine miliare Ektasie tragen. Sie ist ausgebreitet auf das ganze System der kleinen intrazerebralen Gefäße und ist manchmal begleitet von einer Wandatrophie der großen Arterien an der Basis.

Der arteriitische Prozeß beginnt in der Lymphscheide der kleinen intrazerebralen Gefäße und führt zu einer Kernvermehrung, wobei die Kerne dem Typus der Gliazellen entsprechen und stark färbbar sind. Die Adventitia verdickt sich, wird längsstreifig und die spindeligen Kerne des Bindegewebes vermehren sich. Wie es scheint, kommt es unter dem Einfluß dieser Vorgänge zu einer Atrophie der Muscularis. An den Stellen dieser Atrophie weitet sich das Gefäß da aus, wo die Adventitia noch nicht verdickt ist. So kommt es zur Bildung der Miliaraneurysmen. An der Intima beobachtet man nur Kernvermehrung.

Beide Veränderungen, die periarterielle Sklerose und die Miliaraneurysimen, fanden sich bei Individuen mit frischen oder alten Blutungen. Manchmal fehlten die Miliaraneurysmen, wo die Sklerose sich fand. Diese Gehirne waren für die Entwicklung der Miliaraneurysmen vorbereitet.

Die geschilderten Veränderungen fanden sich auch an den Gefäßen der Pia und der Basis, außerhalb des Schz̈dels aber nie.

Alle diese Miliaraneurysmen sind mit bloßem Auge sichtbar. Ihre Größe schwankt zwischen 0,2-1 mm. Sie hängen in kugeliger Gestalt einer Arterie an, die eine Dicke bis etwa $0,25 \mathrm{~mm}$ hat. Ihre Farbe ist rot, violett oder schwärzlich, die Konsistenz je nach der Beschaffenheit der Wand weich oder hart.

Sie finden sich fast an allen Teilen des Gehirnes, aber entsprechend dem hauptsächlichen Sitz der Blutungen besonders im Streifenhügel, Sehhügel, dem Markweiß der Hemisphären, dem Kleirihirn und den Großhirnwindungen. Beim Abziehen der Pia sieht man sie oft auf den Windungen. Manchmal sind sie leicht aus dem Hirngewebe, das sie umgibt wie ein. Schüsselchen, herauszunehmen, manchmal haften sie an. Oft sieht man sie in der Substanz der Windungen durchscheinen. Thre Häufigkeit wechselt von einigen wenigen bis zu etwa 100 .

Schwieriger ist es, die Miliaraneurysmen in den frischen Blutherden und deren Wandungen zu finden. Man muß zunächst - und dies ist die einzige Angabe, die die Autoren über die von ihnen befolgte Technik machen - die Höhle von dem. Blutkuchen reinigen. Dazu darf man weder das Blut an den Wänden des Herdes mit dem Skalpell noch mit einem Wasserstrahl behandeln. Man eröffnet den Herd breit, läßt den Inhalt herausschlüpfen, legt das Gehirn in öfter zu wechselndes Wasser, um so durch vorsichtiges, häufiges Ablaufenlassen des Wassers aus dem Gefäß die noch der Wand anhaftenden Reste des Blutkuchens zu entfernen. Nach einiger Zeit kann man so eine ziemlich große Zahl von blutigen Massen isolieren, die an der Herdwand flottieren oder ihr durch fadenförmige Gefäße anhaften. Diese muß man mikroskopieren. Die folgenden Zeilen lauten wörtlich übersetzt: „Man muß ihrer eine gute 
Zahl nachsehen, bis man endlich ein Aneurysma findet. Die Mehrzahj sind nichts als Bruchstücke des Blutkuchens, welche die geborstenen Gefäße kappenförmig umschließen; aber endlich findet man einige, die man das Gefäß durch die fibrinösen Massen verfolgend, sich plötzlich ampullenförmig erweitern sieht, die im Inneren noch Blut enthalten, in einem Teile ihres Umfangs aber gespalten sind und man stellt dann fest, daß die bloßgelegte oder vielmehr von dem Erguß injizierte Hülle in gleicher Weise zerrissen ist, so daß ein Zusammenhang besteht zwischen dem Blutkuchen des Herdes, dem, der die Hülle gespannt hält und endlich demjenigen, der in dem Aneurysma eingeschlossen ist. Man sieht, die mikroskopische Untersuchung, die übrigens nur mit schwacher Vergrößerung ausgeführt werden darf und die für die Erkennung der vom Herde entfernt liegenden Aneurysmen unnütz wäre, wird unerläßlich, wenn man diejenigen aufsuchen will, die den Erguß hervorzubringen vermochten" (S. 124). Dieser Beschreibung sind einige Abbildungen beigegeben.

Am isolierten Aneurysma sieht man bei stärkerer Vergrößerung, daß die Wand ohne Grenzlinie sich in die Häute des Gefäßes fortsetzt. Aber diese Häute sind nicht mehr unterscheidbar. Die Muskelschicht fehlt im Bereich der Erweiterung vollständig, so daß äußere und innere Haut sich berühren und selbst miteinander verschmelzen. Eine Scheidung ist dann nicht mehr möglich. Man sieht nur eine einzige Membran, an deren Oberfläche zahlreiche Kerne liegen. Ebenso kann die Lymphscheide mit der Wand des Aneurysma verschmelzen. Das Aneurysma kann obliterieren und die Wand kann sich verdicken durch Proliferation der Adventitia. Auch das umgebende Gewebe kann kernreicher werden.

Die meisten Miliaraneurysmen sitzen isoliert an der Arterie. Die Autoren teilen ihre Fälle in drei Rubriken. Die erste enthält 25 frische Apoplexien, bei denen keine älteren Herde bestanden. In allen Fällen sind, allgemein gesprochen, Miliaraneurysmen an den kleinen Hirnarterien nachgewiesen. Von besonderer Wichtigkeit ist aber doch, ob sie auch in den Wandungen des Herdes gefunden sind. Da ist nun bemerkenswert, daß das nur in 16 Fällen, das sind 64 Proz. zutrifft oder, wenn man die später erwähnten frischen Apoplexien Nr. 73-77 mit einem positiven Befund hinzunimmt, in 56 Proz. Noch wichtiger ist, daß nur zweimal, im Fall 1 und 25, ein oder mehrere Aneurysmen geplatzt vorgefunden wurden.

Die zweite Gruppe umfaßt die Fälle 26-41. Hier bestehen neben frischen Blutungen noch ältere. Hier sind die M.-A. im unmittelbaren Bereiche frischer Herde in 8 . Fällen, also in 50 Proz. erwähnt. Nur in 1 Fall -27 - wird erwähnt, daß 2 M.-A., die an einer kleinen Arterie saßen, geplatzt waren und daß ihr Blut in Zusammenhang mit dem des Blutherdes stand.

Die dritte Gruppe, Fall 42-72, umfaßt nur ältere Herde. Hier steht die nahe Beziehung der M.-A. zu dem Herd nur in 6 Fällen $=19$ Proz. fest. Die Autoren äußern sich nicht darüber, ob diese relative Seltenheit etwa mit Rückbildungsvorgängen in den M.-A. zu erklären wäre, wodurch diese unkenntlicher und schwerer nachweisbar würden. 
Die besprochene Arbeit hat einen großen und noch fortwirkenden Einfluß auf den Gang der Forschung gehabt und es liegt mir fern, ihre Bedeutung verkleinern zu wollen. Aber die Entstehung des blutigen Herdes wird keineswegs restlos durch sie erklärt. Wenngleich in allen 77 untersuchten Fällen irgendwo im Gehirn die M.-A. nachgewiesen sind, so ist der Nachweis im Herde selbst auch bei frischen Blutungen keineswegs immer gelungen. Auch ist ihre Zahl durchschnittlich nicht so groß dargetan, daß die Entstehung einer großen Blutung ohne weiteres verständlich würde. Meist wird nur angegeben, daß M.-A. in dem Herde gefunden sind. Manchmal wird gesagt, daß mehrere nachweisbar waren und nur selten ist von einer großen Zahl die Rede. Bei dem großen Fleiße, der zweifellos auf die Untersuchung verwandt wurde, ist das von Bedeutung, denn man wird nicht zugeben können, daß der Nachweis von einem oder auch zwei M.-A. die Entstehung einer großen Blutung völlig verständlich machen könnten. Dazu kommt nun weiter, daß nur ausnahmsweise ein sogenanntes geplatzes M.-A. gefunden wurde, dem ja eine unbestreitbare Bedeutung für den Austritt des Blutes zukommen würde. Vergegenwärtigt man sich aber, wie diese Präparate hergestellt wurden, wie das ganze Organ erst in vielfach gewechseltes Wasser gelegt und Quellungszuständen ausgesetzt wurde, daß dann das Präparat selbst oft nicht ohne mechanische Mißhandlung hergestellt werden kann, so wäre eine genauere Beschreibung gerade dieser Befunde und besonders eine Stiitze durch naturgetreue Abbildungen recht erwünscht. Die letzteren sind aber mehr schematisch und wirklich nicht genügend. Die Schwierigkeit liegt freilich in der Sache selbst und die spätere Forschung hat zur Genüge dargetan, daß durch Zupfpräparate überhaupt keine eindeutigen Bilder erlangt werden und die Natur der sog. M.-A. so nicht klargestellt werden kann.

Für dieRichtigkeit der Charcotschen Befunde trat in Deutschland zuerst Zenker ${ }^{1}$ ) ein. Auf der Leipziger Naturforscher-Versammlung 1872 führte er folgendes aus: Während bisher die spontane Hirnblutung. auf Arteriosklerose der feineren Arterien und die dadurch bedingte größere Zerreißlichkeit bezogen wurde, wobei man besonders an Verfettung und Verkalkung der Intima dachte, lehren Charcot und Bouchard, $\mathrm{da} B$ in der Bildung kleiner Aneurysmen ohne Beziehung zur Arteriosklerose das wesentliche der Ätiologie der Blutung zu suchen sei. Zenker hat seit Jahren alle ihm vorkommenden Fälle von Schlaganfall

1) Ửber die Pathogenese der spontanen Hirnhämorrhagie. Tageblatt der Versammlung Deutscher Naturforscher und Ärzte. Leipzig 1872. 
untersucht und in allen Fällen, in denen er die genügende Zeit und Sorgfalt auf die Untersuchung verwenden konnte, fand er die Aneurysmen entweder nur in der Wand des Herdes oder auch in anderen Stellen des Gehirns. Sie sind nicht zu verwechseln mit den längst bekannten dissezierenden Aneurysmen, sondern șie sind umschriebene, durch sämtliche Arterienhäute begrenzte Erweiterungen der kleinen Gefäße. Ihre Größe schwankt vom eben Sichtbaren bis zu Stecknadelkopfgröße. Sie sind bald vereinzelt, bald in enormer Zahl durch das ganze Gehirn verstreut. Der gewöhnliche Gang ist nun der, daß zunächst die inneren Arterienhäute bersten und durch Blutaustritt unter die Adventitia ein Aneurysma dissecans entsteht. In dieser Weise kann der Zustand längere Zeit bestehen, oder es kann sogar eine Rückbildung mit Hinterlassung eines pigmentierten Knötchens eintreten. Anderseits kann auch die Berstung der äußeren Haut und damit der Eintritt der Hirnblutung erfolgen.

Im Gegensatz zu Charcot läßt Zenker die M.-A. durch Arteriosklerose entstehen, indem die Intima der kleinen Gefäße dieselben Veränderungen durchmacht; die von den großen längst bekannt ist. Allerdings können M.-A. vorhanden sein, ohne daß an den basalen Hirngefäßen irgend erhebliche sklerotische Veränderungen nachweisbar sind. Aber mikroskopisch findet sich an den M.-A. an den Arterien, denen sie aufsitzen, ,stets eine eigentümliche Veränderung der Innenhaut, die ganz der unebenen hügeligen. Verdickung entspricht, welche das wesentliche Moment bei der Sklerose der größeren Arterien bildet. Die Innenhaut erscheint deutlich verdickt, eigentümlich glänzend, wie aufgequollen und etwas ungleichmäßig schattiert. Oft, aber durchaus nicht konstant, finden sich darin auch reichliche Fetteinlagerungen." (S. 160.) Damit betätigt sich für Zenker die alte Auffassung, daß die Disposition zur spontanen Hirnblutung in der Sklerose der Hirnarterien gegeben ist.

Dazu wäre nur zu bemerken, daß Zenker zwar die Sklerose der Intima kleiner Arterien, die M.-A. trugen, nachgewiesen $\mathrm{zu}$ haben glaubt, daß sie aber anderen kleinen Gefäßen der Herdwand eben nicht immer nachgewiesen ist. Es wäre aber sehr merkwürdig, wenn ein Leiden, das die Basis für die Entwieklung der Aneurysmen abgeben soll, nicht weiter verbreitet als gerade an den die Aneurysmen tragenden Gefäßen gefunden werden kann.

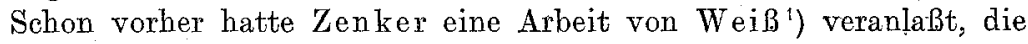

1) Zur Pathogenese der Gehirnhämorrhagie. Diss. Erlangen 1869. 
dem gleichen Gegenstand gewidmet ist. Dieser beschreibt eine einen Tag alte Apoplexie in dem Gehirn eines 62 jährigen Geisteskranken. Der walnußgroße Herd fand sich im rechten Stirnhirn. Außerdem war die Marksubstanz mit einigen kleinen, grauen Flecken durchsetzt (angeblich enzephalitische Herde). In den Streifenhügeln fanden sich ,sehr zahlreiche, unregelmäßige, mit gallertartigem Bindegewebe ausgefüllte Lücken“. Die Arterien der Basis und der Hirnoberfläche waren ausgesprochen sklerotisch.

Auf der Oberfläche der Windungen und in den Furchen, auch auf Durchschnitten fanden sich nun schwarzgraue Flecken. Sie sind von Stecknadelkopf- bis Erbsengröße. Die. kleineren, scharf begrenzt, lassen sich mit der Messerspitze leicht von der Umgebung lösen und hängen mit einem Crefäß zusammen. Die größeren sind von einer Pigmentinfiltration der benachbarten Hirnsubstanz umgeben. Diese Körner sind Aneurysmen. Die Untersuchung der kleineren zeigt folgendes: Die Hülle besteht zunächst aus der Adventitia. Die kann verdickt und deutlich längs gefasert oder unverdickt sein und dann sind die Kerne vermehrt. Die Media ist im Bereiche der Ausweitung geschwunden und die Muskelkerne sind nicht mehr nachweisbar. Die Intima legt sich hier an die Externa an und würde mit ihr untrennbar verschmelzen, wenn nicht zwischen beiden eine ziemlich breite, fein netzförmige, sehr stark glimmerartig glänzende Schicht erkennbar wäre. Die Endothelkerne können gewuchert sein.

Die größeren Aneurysmen von braunroter oder schwarzer Farbe lassen sich ohne anhaftende Hirnsubstanz nicht aus der Umgebung lösen. Streift man diese mit der Pignentschicht ab, so kommt ein fast strukturloser Kern zutage. An den Polen, den Übergängen in das gesunde Gefäß, unterscheidet man noch verdickte Adventitia. Auf der Höhe der Ausbuchtung ist weder von dieser noch von den anderen Häuten etwas zu erkennen. Ältere geborstene Aneurysmen sind nicht selten. „Man sieht an ihrem Scheitelpunkt die umhüllenden GefäBhäute deutlich durchsetzt durch einen breiten Pigmentstreifen, der sich außerhalb des Sackes in einer diffusen Pigmentinfiltration des umgebenden Hirngewebes verliert. Der breite Pigmentstreifen stellt die Verbindung zwischen den Pigmentkörnern im Aneurysmasack mit den Körnern und Hämatoidinkristallen außerhalb her" (S. 22).

Von einigen über hanfkorngroßen Aneurysmen wird gesagt, daß man bei einem etwas kräftigen Druck auf das Deckglas eine der Lymphgefäßscheide entsprechende Schicht zum Platzen bringen kann und daß man dann im Zentrum sehr deutlich ein kleines Aneurysma sehen kann, von dem aus ein Bluterguß unter die Lymphscheide erfolgt ist. Diese ist soweit abgehoben, daß sie erheblich verdünnt ist. An einem solchen Präparat ist dann auch ein Riß in der Intima gefunden. Der Zweifel, der für den Leser besteht, ob dieser Riß nicht durch den Deckglasdruck gemacht wurde, wird nicht beseitigt. Jedenfalls wird über etwaige Reaktionserscheinungen in der Umgebung des Risses nichts gesagt. Auch sind der Arbeit keine Abbildungen beigegeben.

Die Gefäße des apoplektischen Herdes selbst scheint der Verfasser 
nach der Charcotschen Methode untersucht zu haben. Er meint, daß die bisherige Untersuchung es schon sehr wahrscheinlich mache, daß auch dieser Herd durch M.-A. entstanden sei. Aber hier wird die Schilderung noch summarischer. „Man sah die Aneurysmen ganz umgeben von einem Blutgerinnsel, unter dem sie erst bei leichtem Druck mit einem Deckgläschen zum Vorsehein kamen. Man konnte an ihnen die Rißstelle ganz deutlich sehen, aus welcher ein Blutgerinnsel hervorragte, das mit dem außerhalb des Aneurysma geronnenen Blute in Verbindung stand" (S. 25).

Weiß nimmt mit Charcot an, daß die Periarteriitis allein zur Aneurysmenbildung führen kann, weil sie eine Atrophie der Media bedingen soll. Der Druck des Blutes soll dann die Ektasie bewirken. Aber er legt doch Wert darauf, daß in seinen Fällen eine "Skleröse Endarteriitis" bestand, die sich durch die Bildung der glimmerartigen Schicht kundgab.

Die ganze Darstellung bietet der Kritik mehrfache Angriffspunkte. Über die angeblich nachgewiesenen Risse in der Aneurysmenwand will ich weiter kein Wort verlieren. Aber ist es nicht sehr auffallend, daß Aneurysmen zahlreich durch das ganze Gehirn verbreitet waren, daß gerade diese nur minimale Blutungen oder Pigmentierungen hervorgebracht hatten, $\mathrm{da} B$ aber die viel weniger sicher nachgewiesenen Veränderungen der Gefäße in dem apoplektischen Herd nun eine walnußgroße Höhle geschaffen haben sollen? Die Sklerose wird aus der Einlagerung einer glänzenden Schicht zwischen Intima und Adventitia geschlossen, die sich aber nur in den sogenannten Aneurysmen findet. $\mathrm{Ob}$ sie auch an anderen kleinen Hirngefäßen vorhanden war, wird nicht gesagt. Mit Charcot nimmt der Autor an, daß die Periarteriitis zu der Aneurysmenbildung führt. Unter dieser Periarteriitis ist wohl nur die Kernvermehrung und etwa die fibrilläre Verdickung der Wand verstanden. Warum daraus ein Aneurysma werden soll, bleibt für die heutige Auffassung dunkel.

So findet sich auch bei Roth1) die Ansicht vertreten, daß weder Peri- noch Endarteriitis die Aneurysmen hervorbringe, sondern daß eine Erkrankung der Media, durch die die Muskelfasern verdickt und glasig werden, das Wesentliche des Prozesses sei.

Auch Arnd t ${ }^{2}$ ) beschreibt ein Gehirn von einer 60 jährigen verblödeten Frau, das mehrere apoplektische Insulte, Pachymeningitis interna haemorrhagica, Leptomeningitis chronica, Atrophie der Windungen und Atherom der Arterien aufwies, die zum Teil aneurysmatisch erweitert waren und frische Thromben enthielten. Im rechten Sehhügel lag ein haselnußgroßer Erweichungsherd. Zu ihm lief eine rabenfederkieldicke Arterie, deren zahlreiche Äste alle mit Zotten besetzt waren, die büschelförmig anhaften. Mikroskopisch. hält der Autor diese Bildung für ein Endotheliom der Lymphwege. Außerdem aber fanden sich in Erweichungsherden der Linsenkerne Veränderungen der Arterien vor. Die Adventitia war stark verdickt und spindel- oder kugelförmig erweitert. Im Innern fanden sich viel Körnchenzellen. Die Muskelschicht war nur an stärkeren Aneurysmen atrophisch.

1) Schweizerisches Korrespondenzblatt 1874 .

2) Aus einem apoplektischen Gehirn. Virchows Archiv 1878, Bd. 72. 
Die Kapillaren waren hyalin verquollen und als unförmige kolbige Gebilde in der Herdwand nachweisbar.

Der Wert der Arbeit von Eichler ${ }^{1}$ ) wird durch den Umstand beeinträ,chtigt, daß dieser Autor gar nichts über seine Untersuchungstechnik sagt. Das wäre um sc nötjger gewesen, als unter den vier Fällen zwei sich befinden, von denen ihm nur die seit Jahren in Chromlösung aufbewahrten Gehirne zur Verfügung standen. Außerdem untersuchte er zwei frische Gehirne. Die ersten Fälle stammten einmal von einem 72 jährigen Geisteskranken, an dessen Gehirn chronische Pachymeningitis hydrocephalus, zahlreiche enzephalitische Narben und ein Aneurysma der Carotis cerebralis gefunden wurde. Der zweite Fall bezog sich auf einen 62 jährigen Mann mit zahlreichen kleinen Erweichungsherden in Gehirn und einem großen in der linken Hemisphäre. Außerdem bestand Thrombose der A. cerebri profunda sin. und Leptomeningitis chron. Bei beiden Nierenatrophie. Von beiden Gehirnen berichtet die Sektionsdiagnose zahlreiche M.-A. des Gehirnes.

Außerdem untersuchte dex Autor zwei frische Gehirne, deren eins von einer 74 jährigen Frau stammend Blutungen in Brücke, Kleinhirn und linkem Seitenventrikel und mehrere ältere Narben im linken Streifenbügel aufwies. Die Arterien waren stark atheromatös. Das vierte Gehirn stammte von einer 77 jährigen Frau, in deren Gehirn sich Erweichungsherde im Streifenhügel und enorme Arteriensklerose fand.

Demnach hätte überhaupt nur in dem dritten Falle ein blutiger Schlaganfall vorgelegen.

In der Schilderung der gröberen Verhältnisse der M.-A. schließt sich Eichler an Charcot an. Mikroskopisch dagegen läßt er den Prozeß mit fettigem Zerfall der Gefäßendothelien beginnen. An diese schließt sich nach außen eine dicke, homogene Schicht und leicht gekörnte Zellen ähnlich weißen Blutkörperchen, die zum Teil fettig zugrunde gehen. Diese Veränderung der Intima soll die Ursache der Aneurysmenbildung sein. Degeneriert die Intima einseitig, so wird auch die Ektasie auf diese Seite beschränkt bleiben. Erkrankt der ganze Querschnitt, so wird die Ektasie spindelförmig.

Das zweite Stadium der Aneurysmenbildung wird gekennzeichnet durch enorme Wucherung der Intima, allmählich Atrophie der Muskelschicht und Wucherungsprozesse zwischen dieser und der Adventitia.

Die Adventitia leidet weniger und mehr sekundär. An der Eintrittsstelle in das Aneurysma wird sie abgehoben. Es kommt hier zu Stauung und Ansammlung von Lymphzellen und weiterhin zu Bindegewebswucherung.

An der Intima kann es noch zur Verkalkung und zum Verfall in glänzende Kugeln kommen, über die nichts weiter gesagt wird. Die Aneurysmen können bersten, was bei kleinen nicht für gefährlich angesehen wird. Die größeren aber, „,bei denen die Intima dünn, die Muskularis häufig voll-

I) Zur Pathogenese der Gehirnhämorrhagie. Deutsch. Archiv f. klin. Med. 1878, Bd. 22. 
kommen atrophiert, die Entwicklung von Bindegewebe im Adventitialraum sehr gering ist, sind als die gefährlichsten Bildungen, deren Bersten die stärksten Blutungen verursacht, zu betrachten".

Diesen Prozeß hält Eichler für identisch mit dem der Arteriosklerose. Die Bedeutung einer Periarteriitis für die Entstehung der M.-A., wie Charcot wollte, lehnt er ab.

Eichlers Befunde beweisen schon deshalb nicht viel für die Genese der Apoplexia sanguina, weil eine solche offenbar nur in einem Falle vorlag. Wir erfahren auch gar nichts darüber, ob etwa die Aneurysmen in der Wand des blutigen. Herdes sich von denen unterschieden, die er aus anderen Hirnteilen, sei es den nicht blutigen Erweichungsherden, sei es aus gesunder Hirnsubstanz isolierte. Wir erfahren nur, daß er aus den frischen Hirnen eine große Zahl, 3-400, M.-A. isolierte.

Auch bleibt es vollkommen zweifelhaft, ob wirklich geplatzte Aneurysmen beobachtet sind und deren Beziehung zu einem Bluterguß festgestellt worden ist. Jedenfalls erscheint dem Leser die Berechtigung des ersten Leitsatzes am Schlusse der Arbeit zweifelhaft, welcher besagt: Die primäre idiopathische Hirnhämorrhagie verdankt ihre Entstehung dem Bersten miliarer Aneurysmen der kleinen Hirnarterien.

Von den weiteren Leitsätzen seien nur noch zwei hervorgehoben, welche lauten: Die dissezierenden Aneurysmen sind scharf von den M.-A. zu trennen. Sie sind einfache Hämatome der Gefäßwand und nie Ursache, sondern Folge einer Hirnhämorrhagie. - Ebenso sind die Kapillarektasien von M.-A. zu trennen. Erstere sind den Telangieektasien anderer Organe gleichzustellen und kommen wie diese angeboren vor.

Rindfleisch ${ }^{1}$ ) nimmt als Ursache der Hirnhämorrhagie eine fettige Usur der Gefäßwand an. Aneurysmenbildung im Sinne Virchows findet statt. „Die Gefäße sind in weite schlaffe Schläuche verwandelt; von den histologischen Elementarteilen der Wand und deren Anordnung in drei Schichten ist kaum noch eine Andeutung vorhanden. Statt der inneren und mittleren Haut bemerkt man eine nicht eben große Anzahl platter Kerne, welche durch Duplizität der Kerne und die bekannten Einkerbungen und Einschnürungen auf einen stattfindenden Teilungsvorgang schließen lassen. Endothelium, Intima und Media sind also durch einen nachweisbaren Wucherungsvorgang zugrunde gegangen, mit ihnen aber und namentlich mit der Media gerade derjenige Bestandteil der Gefäßßand, welcher vor allen ihre Fähigkeit, aus der Spannung in Kontraktion überzugehen und so dem Drucke des Blutes Widerstand zu leisten, garantiert. Die Gefäßwand, über das normale Maß ausgedehnt, weicht endlich an einzelnen Stellen auseinander und der Blutaustritt erfolgt."

Die Arbeit von Kromeyer ${ }^{2}$ ) mag kurz besprochen werden, obwohl sie sich auf ein Paralytikergehirn bezieht und eine Hirnblutung überhaupt nicht vorlag. Die Sektion der Leiche, deren Alter und Geschlecht nicht

1) Lehrbuch der patholog. Gewebelehre. 4. Aufl. 1878.

2) Über miliare Aneurysmen und kolloide Degeneration im Gehirn. Diss. Bonn 1885. 
angegeben ist, wurde von $\mathrm{Köster} \mathrm{gemacht.} \mathrm{Die} \mathrm{Hinter-} \mathrm{und} \mathrm{Seitenstränge}$ des Rückenmarks fanden sich grau entartet. Die Pia des Gehirns verdickt und ödematös. Arterien an der Basis zeigten nur Spuren von Atheromatose. Defektstellen an der Rinde des Vorder- und Hinterlappens. An der Unterstelle des Schläfenlappens eine große Anzahl braunatrophischer Stellen. Härtung kleiner Stücke in Alkohol. Die Gefäße der gehärteten Rinde rissen beim Abziehen der Pia ab, und starrten als steife Stränge hervor. Mikroskopisch waren an einzelnen Stellen die ganzen Gefäßwandungen in homogene, zerklüftete Schollen umgewandelt, die die Dicke der normalen Arterienwand um das 2-10 fache übertrafen. An anderen Stellen sind Kerne der Intima umgeben von durchsichtigen homogenen Massen sichtbar. Wieder an anderen ist nur die Externa homogen verklumpt. Diese Massen werden durch Karmin nicht gefärbt, wurden mit Jod gelb, von Essigsäure und Kalilauge nicht angegriffen und daher als Kolloid bezeichnet. Manchmal läßt sich erkennen, daß der Degeneration eine zellige Wucherung in der Gefäßwand vorausging.

In der grauen Rinde fanden sich Aneurysmen, auf die die Charcotsche Schilderung paßte.

Von mehreren englischen Arbeiten dieser Periode ist die von Turner ${ }^{1}$ ) hervorzuheben. Fr untersuchte mit Karmin gefärbte Zupfpräparate, die er in Balsam einschloß. Die an sich guten Abbildungen zeigen das eine mit aller Deutlichkeit, daß diese ganze Technik für die Beurteilung der aneurysmenähnlichen Bildungen, die Turner beschreibt und abbildet, nicht ausreichend ist. Gerade an den hier interessierenden Stellen wird die Struktur der Gefäßwand so undeutlich, daß die Beurteilung unmöglich wird. Wichtig ist die Feststellung Turners, dab nicht allein Periarteriitis, sondern auch wirkliche Arteriitis mit zelliger Infiltration der Gefäßwand im Bereiche der M.-A. besteht.

Der Autor trennt den hier in Betracht kommenden destruierenden Prozeß der Gefäßwand von der Sklerose.

Eine gründliche Bearbeitung hat der Gegenstand durch Löwenfeld $^{2}$ ) erfahren. Neben vielen anderen Hirnen untersuchte er 17 Apoplexien mit frischen und älteren Herden. Die Technik bestand ganz vorwiegend in der Anfertigung von Zupfpräparaten. Die Gefäße wurden entweder dem frischen Gehirn oder Stücken, die in sehr verdünnter Lösung von Kaliumbichromat mazeriert waren, entnommen. Sie wurden entweder in schwacher Essigsäure untersucht oder nach Färbung mit den gebräuchlichen Farbstoffen, von denen besonders dünne Bismarckbraunlösung empfohlen wird, in Wasser auf den Objektträger gebracht. Von Schnitten wurde weniger Gebrauch gemacht. In jedem

1) Arteries of the brain from cases of cerebral hemorrhage. Transactions of the pathol. society of London 1882, Vol. 33 .

2) Studien über Ätiologie und Pathogenese der spontanen Hirnblutungen. Wiesbaden 1886.

Deutsche Zeitschrift f. Nervenheilkunde. Bd. 61. 
Falle von Hirnblutung sind mehrere hundert Präparate entnommen, und zwar sowohl aus den Wandungen des apoplektischen Herdes als auch aus anderen Hirnteilen.

Die Schilderung der Befunde beginnt mit den Veränderungen der Intima, die zu fleckförmigen. Verdickungen und zur Bildung starklichtbrechender Plaques führen kann. Hie und da liegen diesen Bildungen Rundzellen an. Sie können fettig zerfallen unter Bildung von feinkörniger Masse oder von Fettkugeln. Auch Verkalkung kommt vor. Dabei ist eine Wucherung der Endothelien erkennbar, die sich in Zügen anordnen. Diese Veränderung findet sich in Arterien jeden Kalibers bis zu den Übergangsgefäßen hin. Neben dieser fleckförmigen Entartung findet sich noch eine, die sich diffus über kleinere oder größere Gefäßabsshnitte erstreckt. Sie präsentiert sich in breiten cder schmäleren homogenen oder faserigen stark lichtbrechenden Zügen in der Intima. Gerade diese Veränderungen sind auch am Schnittpräparat studiert und die beigefügten Abbildungen, besonders die Querschnitte, sowie die weitere Beschreibung lassen keinen Zweifel, daß Verfasser dièse Prozesse mit Recht der Arteriosklerose zuteilt. Außerdem wird noch einer granulösen Degeneration der Intima gedacht, die bei Betrachtung der Veränderungen der Muskularis eine nähere Beschreibung findet.

An der Muskelschicht wird neben der einfachen und der fettigen Entartung eine granulöse Degeneration beschrieber. Sie kann isoliert, herdweise und diffus auftreten. Im ersten Stadium quillt die Muskelfaser auf, kann das Vielfache einer normalen Faser erreichen und gewinnt ein stärkeres Lichtbrechungsvermögen. Die Kerne verschwinden und die ganze Masse wird feinkörnig. Die feinkörnige Beschaffenheit kann teilweise oder ganz in eine grobkörnige übergehen, womit zugleich eine Abnahme des Lichtbrechungsvermögens einhergeht. Bei F̈̈rbung mit Bismarckbraun heben sich die verschieden gekörnten Partien voneinander ab, indem die grobkörnige rot bis braun, die feinkörnige glasig aufgequollen und lichtgelb erscheint. Die körnigen Massen einzelner Fasern können miteinander verschmelzen und es kann zu einem gänzlichen Untergang der Muskelschicht kommen. Die Anordnung der Körnerhaufen quer über die Gefäßachse erinnert dann noch an den Ursprung dieser Massen. Die Intima kann an dem Zerfall teilnehmen und die Zerfallsprodukte können durch den Blutstrom weiter gespült und in die kleineren Gefäße getrieben werden, die dann bis zur Verstopfung angefüllt sein können. Diese Erkrankung soll isoliert und herdweise besonders an gröberen, diffus dagegen an kleinen und kleinsten Gefäßen vorkommen. Bei dieser Erkrankung bleibt die Intima nur geschont im Anfangsstadium des Prozesses. Kommt es aber zum Zerfall der Muskelfasern in einiger Ausdehnung, so geht die Längsstreifung der gefensterten Haut verloren und die Endothelien verschwinden oder zerfallen lkörnig. Die isolierte und herdförmige Entartung der Muskelschicht kann sich mit Atheromatose der Intima verbinden.

Die Körner haben mit Fett nichts zu tun. Behandlung mit Äther 
verändert sie nicht. Auch Amyloidreaktion geben die glänzenden Massen nicht.

Die granulöse Degeneration ist kein seltenes Vorkommnis an Gehirngefäßen. Verfasser fand sie nicht nur bei Apoplexie, sondern auch sonst bei bejahrten Individuen.

Eine weitere Entartung besteht in den fibroiden oder bindegewebigen Umwandlungen der Gefäßwand, bei der entweder nur die Muskelschicht oder auch die anderen in eine feinfaserige, gleichartige Masse verwandelt werden. Dabei kann die Lichtıng der Gefäße stark verengt oder aufgehoben werden. $\mathrm{Ob}$ dabei wirklich echtes Bindegewebe gebildet wird, läßst Verfasser unentschieden.

Diese Degeneration findet sich hauptsächlich an den Gefäßen der Pia, der basalen Ganglien und des Hemisphärenmarkes.

Den geschilderten Entartungen verwandt ist eine weitere, durch die mittlere und innere Haut in einen stark glänzenden Strang verwandelt wird. Die äußere Haut wird zu einer mattweißen, schwäch längs gestrichelten Masse, die in ihren Massen entweder der Adventitia entspricht oder diese enorm bis um das Zehnfache des Umfangs übertrifft. Dabei können Verschmächtigungen und Anschwellungen dicht hintereinander liegen und so dem Gefäß ein sehr eigenartiges Aussehen geben.

Relativ am seltensten erkrankt die Adventitia. Die Kerne können vermehrt sein. Dabei ist zu bemerken, daß die Zahl derselben schon in normaler Weise erheblichen Schwankungen unterliegt. Löwenfeld nimmt daher nur da, wo eine beträchtliche Zunahme vorliegt, eine pathologische Vermehrung an. Zu dieser kann dann eine feinfaserige Verdickung kommen. Die veränderte Adventitia kann mit der umgebenden Glia verschmelzen. Die Kerne können schwinden, auch durch fettige Degeneration zugrunde gehen. Die äußere Haut kann auch Erweiterungen erleiden, so daß sie bei diffuser Ektasie das Gefäß wie ein weiter Sack umschließt. Anderseits kann auch umschrieben eine blasige Ausstülpung beobachtet werden. Selbst zahlreiche beeren- und zottenartige Ausstiilpungen kommen vor. Diese Veränderungen an der Adventitia können sich mit fibroider Entartung der Innenhäute verbinden. Auch eine der hyalinen ähnliche Degeneraticn der Adventitia vorzugsweise an kleinen und kleinsten Gefäßen wurde manchmal beobachtet.

Der Inhalt des adventitiellen Lymphraumes in den ektatischen Partien besteht aus Fett und Pigmentmassen, Fettkörnchenzellen, weißen und roten Blutzellen. Besonders die letzteren häufen sich in umschriebenen oder, diffusen Ektasien an, so daß ein Aneurysma dissecans entsteht, und solche Bildungen können vielfach an Arterienstämmchen gefunden werden. Verfasser bespricht bei dieser Gelegenheit die Auffassung der Autoren, wonach solche Blutungen durch Zerreißung der Innenhäute entstehen sollen. „Aber“, fügt er hinzu, ,den Riß, der hier vorhanden sein soll, hat noch niemand gesehen" (S. 62). Er selbst nimmt an, daß der Blutaustritt entweder durch Diapedesis oder durch kleinste Kontinuitätstrennungen in den sehr verdünnten und atrophischen Innenhäuten, wie er letztere fleckweise im Bereiche der Ektasien gesehen hat, zustande kommt. 
Daß an solchen dissezierenden Aneurysmen die Adventitia platzen und daß so eine Blutung in das benachbarte Hirngewebe erfolgen kann, steht für den Autor außer Zweifel.

Eine Teilerscheinung der Veränderungen, die die Arterien in apoplektischen Gehirnen darbieten, bilden nun die Miliaraneurysmen. Einleitend unterscheidet Löwenfeld unter den Ausbauchungen des Gefäßrohres 6 Formen. 1. Geringe umschriebene Ausbuchtungen der Gefäße an den Teilungsstellen gelten als normal. 2. Ähnliche multiple, hintereinander gelegene Ausbuchtungen der inneren Häute, an denen die äußere nicht teilnimmt, gelten als Ausdruck wechselnden Muskeltonus, indem stellenweise Fasern der Muskelschicht paretisch sein sollen. 3. Umgekehrt sollen streckenweise vorkommende Kontraktionen der Muskelschicht den Eindruck der Ektasie benachbarter machen, deren Tonus nicht verändert ist. Da soll es sich um eine Art Leichenstarre der Gefäßmuskeln handeln. 4. Finden sich umschriebene Ausbuchtungen ohne erkennbare Änderung der Wandstruktur. 5. Solche mit nachweisbarer Veränderung der Wandstruktur. 6. Diffuse, meist über größere Gefäßstrecken sich ausdehnende Erweiterungen, überwiegend mit Erkrankungen der inneren Häute. Als M.-A. werden nur die unter 4 und 5 aufgeführten betrachtet, wobei die erstere ein Initialzustand der unter 5 aufgeführten sein sollen. Die strenge Abgrenzung gegen 2 mache Schwierigkeiten.

Die M.-A. sind von sehr verschiedener Größe, von mikroskopischer Kleinheit bis zur Linsengröße, doch sind die Extreme selten. In den Fällen, in denen sie überhaupt in größerer Anzahl auftreten, überwiegen die kleinen, deren Durchmesser etwa eine Drittellinie groß ist, erheblich und zu ihrer sicheren Unterscheidung ist mindestens die Lupe erforderlich. Löwenfeld fand diese Bildungen vorwiegend in der Wand der apoplektischen Herde und nur höchst selten an den Gefäßen der Pia und innerhalb der Windungen des Großhirnes.

Die Gestalt der M.-A. ist wechselnd. Die Kugelform wird am häufigsten, dann die Spindel-, und dann die Sackform gefunden.

Was die feineren Verhältnisse der Wand angeht, so kommt Ausbuchtung aller drei Häute vor bei intakter Struktur, ein ziemlich seltenes Vorkommnis. In anderen Fällen findet sich einfache Atrophie der Muskelschicht verknüptt mit Verdickung der Intima. Dabei ist die Atrophie gewöhnlich am ausgesprochensten auf der Höhe der Ektasie. Oft findet sich eine schwere Errkrankung der Muskelschicht in Form der granulösen Degeneration, so daß nur noch Körnerhaufen die untergegangene Muskelfaserung anzeigen und auch die Intima kann in derselben Weise zugrunde gehen. Die Wand dieser M.-A. wird dann nur von der äußeren und der gefensterten Haut gebildet. Die angrenzenden Getäßabschnitte sind dabei gewöhnlich ebenfalls im Zustand fortgeschrittener granulöser Degeneration und der abführende Gefäßabschnitt ist mit Zerfallsmassen vollgestopft. Diese Form der M.-A. kommt besonders an kleinen und kleinsten Gefäßen vor. Atheromatöse Veränderungen fehlen in der Regel.

Weiter findet sich in M.-A. eine fettige Zerstörung der Muskelschicht. Die Intima kann daran teilnehmen. Doch kommt an ihr auch eine Wuche- 
rung des Endothels vor. Bei weitem die meisten dieser M.-A. weisen atheromatöse Verdickung der Intima auf. Sie kann in eine solide äußerst lichtbrechende Masse übergehen, die mehr oder minder die Lichtung des Gefäßes einengt.

An einer erheblichen Anzahl, offenbar älterer Aneurysmen bemerkt man folgendes Verhalten: Sie sind makroskopisch undurchsichtig. Mikroskopisch ist die Ausbauchung mit feinkörniger, undurchsichtiger Masse ausgekleidet mit eingelagerten feinen. Fettropfen und stark lichtbrechenden Platten (ähnlich Cholestearinkristallen). Die einzelnen Häute sind nicht mehr zu unterscheiden. Weder Längsstreifung der Intima noch Muskelkerne sind erkennbar. Die Wand des Aneurysma ist von einer einzigen Hülle gebildet und nur zuweilen bewahrt die Adventitia ibre Selbständigkeit. Die Muskulatur ist meist durch einfache oder fettige Entartung zugrunde gegangen. Die Adventitia kann erhalten sein, aber öfter verschmilzt sie mit den inneren Häuten. Die Wand der M.-A. kann mit gelöstem Blutfarbstoff imbibiert sein.

Neben den M.-A. findet sich in apoplektischen Gehirnen noch eine diffuse Ektasie, eine Erweiterung eines größeren, über $1 \mathrm{~cm}$ betragenden Gefäßabschnittes, an der alle drei Häute teilnehmen. An einem Teile solcher Ektasien kann es zur Bildung von M.-A. kommen. Die Intima kann diffus oder in Plaquesform verdickt sein. Die Muskelschicht ist fettig odex granulär degeneriert.

Die Entstehung der Miliaraneurysmen anlangend, so lehnt Löwenfeld die ursächliche Bedeutung der Arteriosklerose ab. Man findet hochgradige Sklerose der Gefäße ohne Aneurysmenbildung und an vielen Aneurysmen zeigt die Intima keine sklerotischen Veränderungen. Er beschuldigt als eigentliche Ursache 1. Jokale Blutdrucksteigerung, die nur selten von Bedeutung sein soll, etwa bei peripherem Verschluß eines Gefäßes, und 2. lokale Gefäßwanderkrankungen, wodurch die betreffenden Teile dem Blutdruck weniger Widerstand leisten. Zu diesen Erkrankungen rechnet er die Atheromatose nicht, da ja die verdickte Intima die Widerstandskraft des Rohres eher erhöhen als herabsetzen müsse. Da man ferner Aneurysmen auch an Gefäßen findet, deren Wandung für die heutigen Hilfsmittel keine nachweisbare Veränderung zeigt, so muß man annehmen, daß entweder unerkennbare Veränderungen vorliegen oder daß vasomotorische Störungen eine Rolle spielen.

Die Venen können an diesen Erkrankungen teilnehmen und ihre inneren Lagen fettig und granulär degenerieren. Die zelligen Elemente können spurlos verschwinden. Auch können Media und Intima in eine untrennbare feinfaserige Hülle verschmelzen. Mit dieser kann auch die Adventitia verschmelzen. Sie kann aber auch erhalten sein und seltener Kernwucherung aufweisen. Auch hebt sie sich wohl in diffuser oder umschriebener Erweiterung ab und der Adventitialraum kann dann mit Fett und Pigmentmassen oder auch mit roten Blutzellen ausgefüllt sein. Niemals sah der Autor in diesem letzeren Falle einen Riß der Innenhäute.

Auch an den Kapillaren kommt fettige und hyaline Degeneration vor und sie können ebenfalls an der granulösen Degeneration der Arterien 
und Venen teilnehmen. Dabei können auch die Kerne beträchtliche Vergrößerung und körnigen Zerfall erleiden.

Wenn die geschilderten Veränderungen auch nicht alles enthalten mögen, was überhaupt an den Hirngefäßen bei Apoplektikern vorkommen mag, so glaubt der Autor doch alles Wesentliche damit beschrieben $\mathrm{zu}$ haben. Von Bedeutung ist nun, daß er diese Befunde nicht nur in Fällen von Apoplexie erhob, sondern auch in einer großen Zahl von Gehirnen, bei denen das Bestehen einer Disposition zu einer Blutung angenommen werden durfte, bei denen also alte Erweichungsherde bestanden oder in Gehirnen sehr alter Leute, in denen M.-A. nachweisbar waren. Es war nun noch den Unterschieden nachzugehen, die die Gefäßbefunde in den einzelnen Fällen von Hirnblutung boten.

Da zeigt sich zunächst, daß sich die Gefäßveränderungen am reichlichsten in der Wand der apoplektischen Herde oder deren nächster Nachbarschaft finden. Doch gibt es hier Verschiedenheiten, indem manchmal kaum ein normales Gefäß sich auffinden läßt, manchmal unveränderte Gefäße sich in größerer Anzahl finden. Das letztere trifft namentlich für kleinere Herde zu.

Bedeutender sind die Differenzen noch in den weit von den Herden abliegenden Partien. Man kann hier einerseits unter 20 untersurhten Präparaten ein einziges völlig intaktes, anderseits unter 40-50 Präparaten ein einziges mit deutlicher Veränderung finden. Von Interesse ist weiter der Umstand, daß man nicht selten an einem Stämmchen mit zahlreichen Verzweigungen ein einzelnes Ästchen erkrankt, anderseits aber auch unter zahlreichen erkrankten ein vereinzeltes intaktes findet.

Was die Häufigkeit des Vorkommens der einzelnen Degenerationsprozesse angeht, so steht die fettige Degeneration an erster Stelle, die an der Muskelschicht keinmal gänzlich vermißt wurde. Dann folgt die einfache Atrophie und beide kombinieren sich unter Umständen an ein und demselben Gefäß. An dritter Stelle steht die granulöse Degeneration, die sicher nur an 10 von 17 apoplektischen Gehirnen gefunden wurde, und in erheblicherer Ausdehnung bestand sie nur in einem dieser Fälle. Sie wurde übrigens auch in nicht apoplektischen Gehirnen aufgefunden.

Die Erkrankung der Intima entspricht im allgemeinen der der Muskelschicht nach Häufigkeit und Ausdehnung. Nur kommt öfter noch die A theromatose hinzu.

Die Erweiterung der Adventitia war entsprechend dem Grade der Erkrankung der Innenhäute verschieden häufig. Wucherung der Kerne und streifige Verdickung fehlte wohl in keinem Falle gänzlich.

M.-A. wurden in keinem Falle gänzlich vermißt. Thre Zahl war aber sehr schwankend. In dem einen Falle waren, trotz mühsamster Untersuchung des ganzen Gehirns" nur wenige auffindbar, in anderen wurden 50 und darüber ohne besondere Anstrengung entdeckt. Noch größer waren die Differenzen im Vorkommen diffuser Ektasien. Diese Form wurde in einigen Beobachtungen gänzlich vermißt und war in der Mehrzahl der Fälle nur sehr sparsam vertreten. In zwei der Apoplexien aber 
fand sie sich in der Wand der Herde in sehr großer Anzahl. Soweit sich erkennen läßt, ist dieser Befund lediglich auf den apoplektischen Herd beschränkt, was von keiner der anderen Erkrankungen gesagt werden kann.

Dissezierende Aneurysmen fanden sich in der Minderzahl der Fälle und nur einmal in größerer Zahl in der Wand des Herdes. Sie waren meist abgerissen und von keulenförmiger Gestalt, das breitere abgerissene Ende war dem Herde zugekehrt.

Löwenfeld bestreitet, daß sich, wie Charcot annimmt, bei der Apoplexie stets eine Periarteriitis an den Gefäßen des ganzen Hirnes fände. Wahrscheinlich sei manches als pathologisch gedeutet, was noch in den Bereich des Normalen gehört.

Auch die Auffassung Turners, der eine entzündliche Erweichung der Gefäßwände annimmt, kenntlich an Rundzellenanhäufung in der Adventitia, wird abgelebnt.

Der letzte, hier interessierende Abschnitt des Löwenfeld schen Buches behandelt den Ausgangspunkt der Blutung. Charcot und Bouchard lehren, daß lediglich die M.-A. als Quelle der Hirnblutung beim Schlaganfall anzusehen sind. Für diese Auffassung führen sie an: 1. das konstante Vorkcmmen in Gehirnen mit Spontanblutungen und 2. das konstante Vorkommen von M.-A. in den Wandungen apoplektischer Herde. Dazu ist zu bemerken, daß erkrankte, aber nicht aneurysmatische Gefäße ebenso vorbereitet zu Hämorrhagie sein können wie die M.-A. Bei der zweiten These ist zu bedenken, daß das Extravasat größerer Blutungen nicht einheitlichen Ursprungs sein wird. Das aus einem geborstenen Gefäß ausströmende Blut zertrïmmert Gehirnsubstanz, eröffnet also auch zahlreiche Gefäße, so daß gar nicht gesagt werden kann, ob ein aufgefundenes geplatztes Aneurysma primär oder sekundär eröffnet ist. Weiterhin aber ist die Charcotsche Behauptung, daß in der Wand eines jeden apoplektischen Herdes konstant geborstene M.-A. nachweisbar seien, unrichtig. Die eigene Arbeit Charcots beweist das nicht und auch die Untersuchungen Löwenfelds sprechen dagegen. Speziell weist dieser hier auf seinen Fall 14 hin, der nach Charcotscher Methode untersucht, keine geborstenen M.-A., wohl aber geborstene Gefäße ohne Aneurysmen erkennen ließ. Auch fand er hier in der Wand des großen Herdes einen über erbsengroßen Bluterguß vor, der gehärtet und an Schnitten sorgfältig untersucht, nichts von M.-A. erkennen ließ, obwohl das Gefäß, aus dem die Blutung stammen mußte, in den Schnitten vorlag. Die ausschließliche Quelle der Blutungen kann daher in den M.-A. nicht gesucht werden.

Die einfache, die fettige und die granulöse Degeneration sind nach Löwenfeld in gleicher Weise geeignet, die Arterien in den Zustand zu bringen, der eine Vorbedingung der Ruptur ist. Auch die Sklerose wird in gleicher Weise wirken können. Man darf nicht annehmen, daß die Verdickung der Wand, welche diesen Prozeß begleitet, einen Schutz gegen Zerreißung bietet, da man sich schon beim Isolieren solcher Gefäße von deren Brüchigkeit überzeugen kann.

Auch das Zerreißen von erkrankten Venen kann Blutergüsse bewirken. 
Das Vorkommen von dissezierenden Aneurysmen an denselben sowie der Umstand, daß hie and da Einlagerung von Hämatoidinkristallen in die Venenwand gefunden wird, spricht dafür. So werden die kleinen und kleinsten Extravasate, die man bei Apoplexien findet, wohl zum Teil zu erklären sein.

Durch die Löwenfeldschen Untersuchungen sind somit zahlreiche Befunde nachgewiesen, von denen ich die wichtigen kurz zusammenfasse. Es gibt an der Gefäßwand apoplektischer Gehirne schwere Ernährungsstörungen, die sich als einfache, fettige und granuläre Degeneration darstellen. Besonders die letztere beginnt mit einer Homogenisierung der Media und dem gänzlichen Untergang der Muskelfasern. Ist dieser Prozeß nicht zu beschränkt, so nimmt auch die Intima und die Elastika daran teil. Sie verschmelzen in eine glänzende Masse und werden dann körnig oder faserig umgewandelt. Auch die Adventitia kann an dem Prozeß teilnehmen. Der nämliche Vorgang kann auch Venen und Kapillaren zerstören.

Die M.-A. sind eine Teilerscheinung dieser Veränderungen und lassen ähnliche Degenerationen der Wand erkennen, kommen aber auch an unveränderten Gefäßen vor. Die Blutung erfolgt durchaus nicht nur aus M.-A. Sie kommt aus den degenerierten Gefäßen zustande, entweder durch Diapedesis oder durch kleinste Kontinuitätstrennungen der entarteten Wand.

Auffallend ist, daß Löwenfeld, wenigstens für die Entstehung größerer Blutungen, der sekundären Zerreißung von Gefäßen, die durch die Gewalt des ausströmenden Blutes zustande kommt, eine große Bedeutung beimißt, während seine Untersuchungen für eine solche Annahme keine tatsächliche Unterlage liefern. Er so wenig wie einer seiner Nachfolger hat versucht, die zertrümmerte Hirnsubstanz in frischen Fällen nachzuweisen. Auch wird nicht gesagt, ob auf diese Weise nur kranke oder auch gesunde Gefäße zum Zerreißen gebracht werden können.

Die Bedeutung der mitgeteilten Degenerationen der Gefäße erfährt nun dadurch eine Einschränkung, daß sie nicht einzig und allein in den apoplektischen Herden und deren nächster Nachbarschaft, sondern hier nur am reichlichsten vorkamen. Außerdem waren sie in den entfernteren Teilen dieser Hirne und auch in solchen, die von Blutungen zwar frei waren, aber doch als disponiert für die Apoplexie angesehen werden durften, nachweisbar.

Marchand $\left.{ }^{1}\right)$ kommt in dem Artikel Arterien im Eulenburgschen

1) Eulen burg, Real-Enzyklopädie. 3. Aufl. Wien und Leipzig 1894. 
Handbuch auch auf die M.-A. der kleinen Hirnarterien zu sprechen, ohne die Apoplexie allgemeiner zum Gegenstand seiner Ausführungen zu machen. Wenngleich es Aneurysmen ohne Artericsklerose gibt und die Arteriosklerose ohne Aneurysmenbildung verlaufen .kann, so ist die Kombination beider doch eine so gewöhnliche Escheinung, daß man das Aneurysma als eine der wichtigsten und schwersten Folgeerscheinungen der Arteriosklerose bezeichnen kann. Er beschreibt dann die kleinsten, nur mikroskopisch sichtbaren Aneurysmen der Gehirnarterien als wirkliche Ausbuchtungen der Arterienwand, welche offenbar die Folge von Degeneration der Muskelfasern im Anschluß an sklerotische Veränderungen der Intima sind. „Die Verdickung der Gefäßwand, welche in der Bildung einer strukturlosen Masse besteht, wölbt sich stark nach außen vor und greift auch auf die Adventitia über; stellt somit eine Art Arteriitis nodosa dar. Das Lumen des Gefäßes beteiligt sich anfangs bei der Ausbuchtung, doch wird dasselbe, abgesehen von der starken Verdickung der Wand, noch beeinträchtigt durch Thromben; der ganzen Masse kommt eine gewisse Brüchigkeit zu, welche leirht zu Rupturen, besonders an der Grenze des Knötchens führt" (S. 252).

Davon ist die Ansammlung von Blut in den Lymphscheiden der kleinen Gefüß口, wie sie sich oft in der Umgebung größerer Blutergüsse findet, wohl zu scheiden. Ein isoliertes Aneurysma, aus dem Linsenkern stammend, und Querschnitte durch ein solches werden abgebildet.

Gegen die Auffassung Löwenfelds über die Aneurysmen wendet sich Eppinger1), der in einer größeren und allgemeineren Arbeit über Aneurysmen auch die der Hirnarterien untersucht. In diesen kommen fettige, hyaline und kolloide Degenerationen vor und solche mit Kalk und Pigmentablagerungen. Die Gefäße können bei der fettigen Degeneration spindelige Auftreibungen zeigen. Die Elastika ist dabei erhalten, das Lumen mehr verengt als erweitert, wenn hyaline Quellung dazukommt. Das sind aber nach Eppinger keine Aneurysmen. Die granulöse Degeneration Löwenfelds bestätigt er, faßt sie aber als eine Kombination von fettiger und kalkiger oder fettiger und kolloider Degeneration auf. Auch diese hat mit Aneurysmenbildung nichts zu tun. Auch die Arteriosklerose lehnt er als ätiologisch nicht von Bedeutung ab.

Die Periarteriitis ist von Bedeutung für embolisch-mykotische Aneurysmen, wie sie Eppinger in einem besonderen Kapitel beschreibt und er fügt hinzu, daß diese Periarteriitis auch an Aneurysmen der Gehirnarterien vorkomme, daß man aber etwas anderes meine, wenn man von den M.-A. des apoplektischen Gehirnes spreche. Er gibt zu, daß die von Charcot, Eichler, Löwenfeld beschriebenen Bildungen jeder finden kann, der einen apoplektischen Herd im Gehirn sorgfältig auswäscht und untersucht. Aber die so gefundenen Bildungen sind keine Aneurysmen. „Ich gewann immer mehr die Anschauung, daß eigentlich nur konventioneller Weise, wegen Mangel an einer entschiedenen Charakteristik des Aneurysma überhaupt, von miliaren Aneurysmen gesprochen wird" (S. 551).

1) Pathogenesis der Aneurysmen. Archiv f. klin. Chir. 1887, Bd. 35, Suppl. 
Die in den apoplektischen Gehirnen zu findenden Gefäßveränderungen scheidet Eppinger 1. in Aneurysmata dissecantia. Die Löwenfeld sche Beschreibung and Abbildung werden als trefflich anerkannt; 2. in solide Anschwellungen oder Verdickungen mehr oder weniger streng umschriebener, obturierter Abschnitte der Lymphräume. Daß sich daran eine chronische Periarteriitis anschließt als reaktive Entzündung, ist sehr natürlich. So entstehen aneurysmenähnliche Bildungen. Am gefärbten und aufgehellten Präparat sieht man das Gefäß durch diese knctigen Bildungen hindurchgehen; 3 . in adventitielle Verdickungen umschriebener Art und von homogener oder hyaliner Natur, auf dem Querschnitt von halskrausenartiger Beschaffenheit.

Die Arbeiten Löwenfelds und Eppingers veranlaßten Zenker ${ }^{\mathbf{1}}$ ) zu einer erneuten Stellungnahme auf der Wiesbadener NaturforscherVersammlung. Entgegen Löwenfeld sieht er in dem M.-A. die einzige Quelle der Blvtung bei dem Schlaganfall. Er gibt zu, daß diese Bildungen nicht immer auffindbar seien und meint, daß ein vereinzeltes M.-A., das durch sein Bersten eine Blutung veranlaßt habe, sich naturgemäB dem Nachweis entziehen werde.

In der Diskussion, die neue Gesichtspunkte sonst nicht brachte, bemerkte Thoma mit Recht, daß manche Meinungsverschiedenheiten nur die Folge der nicht genügenden Schärfe der Definition dessen sei, was man als Aneurysma zu betrachten habe.

Löwenfeld ${ }^{2}$ ) hat dann Eppinger gegenüber seine Ansicht vertreten, ohne indessen neues Material vorzubringen und ohne auch auf. den Kern einzugehen, der in Eppingers neuer Definition des Aneurysma liegt. Von Interesse ist hier seine Feststellung: ,Der Zufall kann dem Untersucher eine Mehrzahl von Gehirnen mit Blutherden nacheinander in die Hände führen, in welchen sich selbst bei mühsamstem tagelangem Suchen immer nur einige Exemplare von M.-A. entdecken lassen" (S. 1525).

In diesem Meinungsaustausch hat danin schließlich Eppinger ${ }^{3}$ ) nochmals das Wort ergriffen, um hervorzuheben, daß er eine neue Definition des Aneurysma geschaffen hat. Danach ist dieses ,,eine streng umschriebene Ausweitung der Lichte einer Arterie, deren Wandung kontinuierlich, mindestens mittels einer Schicht, in die der Ausweitung übergeht, wobei aber immer am Eingang zu der Ausweitung die Elastika ganz und gar und plötzlich unterbrochen oder abgerissen erscheinen muB. In der Wand des Aneurysma muß sonach die Elastika fehlen. Am Eingang zu dem Aneurysma müssen die Enden der abgesetzten Elastika erwiesen werden" (S. 406). Demnach gehören nicht zum Aneurysma, die einfache Ektasie, in deren

1) Versammilung Deutscher Naturforscher u. Ärzte, Wiesbaden 1887. Tageblatt, S. 273.

2) Zur Lehre von den Miliar-Aneurysmen des Gehirns. Wiener med. Woch. 1887, Nr. 47.

3) Die miliaren Hirnarterienaneurysmen. Virchows Archiv 1888, Bd. 3. 
Wandungen sich sämtliche veränderten oder unveränderten Schichten der Wand nachweisen lassen, das Aneurysma dissecans und spurium.

Nach dieser Definition erkennt Eppinger als Aneurysma an:

1. Das kongenitale Aneurysma. Es kann an Gehirnarterien vorkommen. Die Miliaraneurysmen Charcots sind aber auf das Kriterium des Verhaltens der Elastika nicht untersucht. Vielleicht kann der eine oder andere Fall hierher gerechnet werden.

2. Die parasitären Aneurysmen. Die Arosionsaneurysmen der Lungenarterien in Kavernen gehören dahin. Auch verfügt Eppinger über sechs Fälle von embolisch-mykotisehen Aneurysmen, die unter dem Bilde der multiplen M.-A. an den Hirnarterien verliefen.

3. Die traumatischen Aneurysmen.

Was man nach Charcot konventionell als Aneurysma betrachtet, hält Eppinger für Ektasien.

Von den Löw en feld schen Abbildungen, die M.-A. wiedergeben sollen, betrachtet er einen Teil als Ektasien mit unveränderter, einen anderen Teil als solche mit veränderter Wand. Speziell die Figuren 19 und 20, die am meisten nach Aneurysmen aussehen, hält Eppinger nicht für sicher deutbar. Diese Gefäße hätten nur durch Zerlegung in Serienschnitte eine klare Beurteilung möglich gemacht. Dem kann man nur zustimmen und die Bemerkung hinzufügen, daß die Abbildungen der Autoren überhaupt um so vieldeutiger werden, je mehr sie die Existenz des Miliaraneurysma und besonders des geborstenen erweisen sollen.

Es ist auffallend, daß die nächsten zwei Jahrzehnte, in denen die mikroskopische Technik die größte Entwicklung erfuhr, keine Arbeit brachten, die den Gegenstand mit moderner Technik und an Schnittpräparaten untersucht hätte. Die alte $\mathrm{Charcotsche} \mathrm{Technik} \mathrm{wird}$ wieder verwandt und dementsprechend kein neuer Gesichtspunkt gewonnen.

Stein 1 ), der unter Leitung von Bollinger und Schmauß arbeitete, beschreibt 6 Fälle von Apoplexie. Viermal bestand Atheromatose der Hirnarterien, zweimal war Lues wahrscheinlich. Nicht ein einzigesmal fand Stein, ,trotz größter Sorgfalt der Untersuchung", ein typisches M.-A. Das ist um so wichtiger, als Stein lauter ganz frische Blutungen untersuchte. Nur eine war 5 Tage alt. Sehr oft aber fand er in den Zupfpräparaten Gefäße, deren Lymphscheiden mit Blut oder Detritus ausgefüllt waren. Er nimmt an, daß diese Lymphscheiden im Blutherd zerreißen und sich von da aus füllen, daß also nicht eigentliche dissezierende Aneurysmen vorliegen.

Er schließt, daß M.-A. seltener sind als bisher angenommen wurde und daß sie nicht die große Rolle bei Gehirnblutungen spielen, die ihnen früher zugeteilt wurde.

1) Beitrag zur Ätiologie der Gehirnblutungen. Deutsche Zeitschr. f. Nervenheilkunde 1895, Bd. 7. 
Noch eine weitere Arbeit von Pöhlmann ${ }^{1}$ ) folgte aus dem Pathologischen Institut von München. Er untersuchte 15 Fälle von Apoplexien, Herz- oder Nierenkrankheiten. Es ist nicht ersichtlich, ob alle Fälle Hirnblutungen darboten. Er bediente sich der Charcotschen Untersuchungsmethode. Färbungen wurden nur dann in Anspruch genommen, wenn es nötig war, degenerative Prozesse zu spezialisieren. Einbettungen ergaben ihm kein brauchbares Resultat. Von den M.-A. scheidet er die diffusen zylindrischen Ektasien, ferner die seheinbaren Erweiterungen zwischen zwei kontrahierten Strecken einer Arterie und schließlich die umschriebenen Blutungen in der Umgebung des Gefäßes, durch die dieses ohne Veränderung des Lumens hindurchzieht. Alle anderen Gefäßerweiterungen, mit drei Häuten umgrenzt, faßt er als Aneurysma auf und ordnet sie in Gruppen, je nach dem Zustand der Wand. In ihr fand er zunächst die fettige Degeneration der Media und die hyaline, nicht aber die körnige und kolloide. Die Mehrzahl der Aneurysmen ließ auch Veränderungen der Intima erkennen. Sie war verdickt, glänzend aufgequollen, mit oder ohne Fetteinlagerung. Auch körnige stark lichtbrechende Einlagerungen kamen vor, während an solchen Stellen die Muskelschicht atrophisch oder fettig entartet oder in eine gelblich glänzende, körnige Schicht verwandelt war.

Veränderungen der Intima waren stets mit solchen in der Media verbunden. Die Adventitia war bei diesen Formen unverändert.

Bei einer anderen Gruppe von Aneurysmen, die er für älter hält und zum Teil für Endstadien erklärt, findet er die Häute zu einer einzigen verschmolzen. Diese gemeinsame Hülle kann dann glasig, kalkig oder fettig entartet sein.

In dem Streite der Autoren über den ursprünglichen Sitz und die Natur des pathologischen Prozesses an den Gefäßen nimmt Pöhlmann keine bestimmte Stellung ein, lehnt aber die Arteriosklerose als ätiologisch bedeutend für den histologischen Prozeß ab. Die Periarteriitis Charcots hat er nie gesehen. Dagegen ist für ihn jeder Prozeß, der die Widerstandsfähigkeit der Media schädigt, auch dauernde Blutdruclssteigerung, ererbte und erworbene Konstitutionsanomalie von Bedeutung.

Wenngleich die Arbeit, etwas einseitig, die M.-A. zum Gegenstand der Untersuchung macht, so ist doch ihr Hauptresultat, wonach es eine eigenartige Erkrankung der kleinen Hirngefäße gibt, die zu einer schweren Entartung der ganzen Gefäßwand mit Verschmelzung ihrer Schichten führt, von Bedeutung, womit frühere Untersuchungen bestätigt werden.

Eine Arbeit von Bruns ${ }^{2}$ ) sei hier nur kurz erwähnt, da nicht klar ist, ob hier eine gewöhnliche Apoplexie beschrieben wird oder ob ein isoliertes echtes Aneurysma durch sein Platzen eine größere Blutung hervorgerufen hat.

Es handelt sich um einen 41 jährigen Mann, der ein Schädeltrauma erlitten hatte und rasch an einem apoplektischen Insult zugrunde ging.

1) Ủber Miliaraneurysmen des Gehirns. Diss. München 1908.

2) Ein Fall von Spätapoplexie nach Trauma. Dextsche med. Wochenschr.1901. 
Die Sektion ergab: Gefäße an der Basis zart. Im rechten Seitenventrikel ein hübnereigroßer Blutklumpen. Streifenhügel und vorderer Sehhügel rechts zertrümmert. Durch vorsichtiges Abspülen gelingt es, in der Höhle eine kleine Arterie freizulegen, ,welche die durch den Bluterguß ausgefüllte Höhle durchquert und "durch die Zertrümmerung der sie umgebenden weichen Gehirnmasse isoliert worden war. Während dieses Gefäßchen bei seinem Aus- und Eintritt in die noch erhaltene Gehirnsubstanz nahezu fadendünn erscheint, ist der freigelegte Abschnitt auf die Strecke von $1 \mathrm{~cm}$ spindelförmig aufgetrieben und mißt in seiner dicksten Stelle etwa $2 \mathrm{~mm}$ im Durchmesser. Das Lumen des Aneurysma ist mit geronnenem Blute erfüllt, die Wandung zeigt einen feinen queren Einriß. Eine genaue Untersuchung der übrigen in dieser Gegend verlaufenden Arteriolen läßt keinerlei krankhafte Veränderungen an ihnèn erkennen" (S. 636).

Das Herz war nicht hypertrophisch, die Nieren normal. Eine mikroskopische Untersuchung hat offenbar nicht stattgefunden.

Wenn auch die übrigen Arteriolen im Bereiche der Blutung als verändert angegeben wurden, so ist doch nicht wahrscheinlich, daß ein so kleines Aneurysma wie das beschriebene als alleinige Quelle der Blutung in Betracht kommen könnte. Indessen ist der Fall für die vorliegenden Zwecke nicht weiter verwertbar, da eben die milkroskopische Untersuchung fehlt.

v. Monakow ${ }^{1}$ ) kommt auf Grund eigener Untersuchungen und der Literatur zu dem Resultate, daß weitaus die häufigste und vielleicht die einzige sichere Ursache für die spontane Hirnblutung in der Berstung von M.-A. gesucht werden muß. Die Bildung der letzteren beginnt mit einer Entartung der Muskularis; ein endarteriitischer Prozeß ist zur Bildung der M.-A. nicht notwendig.

Auch Monakow scheidet von den M.-A. die dissezierenden Anewrysmen und nimmt an, daß diese entstehen, indem Blut durch Diapedesis in den Adventitialraum oder aus benachbarten größeren Blutherden eindringt. Betreffs der Technik sagt er: „Gießt man vorsichtig Wasser auf den Herd und läßt denselben einige Zeit unter Wasser stehen, dann gelingt es, durch sachte Abspülung die Rupturstelle des M.-A. zu finden und außerdem noch eventuell andere M.-A. zu treffen. Viel sicherer lassen sich die M.-A. an Serienschnitten nachweisen. Gewöhnlich sieht man da sehr verschiedene Formen und von sehr verschiedener Größe. Das Gewebe in der Umgebung eines M.-A. ist eine Strecke weit degeneriert. Die Rupturstelle eines M.-A. habe ich indessen an Schnittpräparaten von einem Blutherd mit Sicherheit nicht auffinden können" (S. 1122).

Wenn es wirklich so ist, daß die M.-A. an Serienschnitten viel sicherer nachweisbar sind als am Zupfpräparat, so ist njcht zu begreifen, warum der Autor nicht eine beweisende Abbildung bringt. Unter den Figuren, auf die verwiesen wird, findet man statt dessen aber nur die immer wieder-

1) Gehirnpathologie. Nothnagels Handbuch der spez. Path. u. Ther. 2. Aufl. Wien 1905, Bd. 9, I. 
kehrenden schematischen Zeichnungen Charcots und zwei eigene Abbildungen, die jedenfalls von Zupfpräparaten stammen.

Auffallenderweise scheint auch v. Monakow anzunehmen, daf das Platzen eines einzigen M.-A., worunter nach Charcot Gebilde mit einem Durchmesser bis zu $1 \mathrm{~mm}$ verstanden werden, genügt, um eine größere Blutung hervorzurufen und eine umfangreiche Zertrümmerung der Hirnsubstanz zu bewirken.

Eine erneute Untersuchung hat $\mathrm{Pick}^{1}$ ) der hier interessierenden Frage zuteil werden lassen. Er tindet es befremdend, daß in dieser wichtigen Frage und bei der Häufigkeit des einschlägigen Materials nach einem 50 Jahre währenden Streite noch keine Einigung erzielt worden ist. Die Schuld sieht er in erster Linie in der Untersuchungstechnik, die seit Charcots Zeiten keine Fortschritte gemacht hat. Pick veranlaßte daher Ellis, auch mit Hilfe der Schnittmethode die Frage zu untersuchen. Zugleich wurden auch Gefäße aus mazeriertem Material isoliert und untersucht. Über die gewonnenen Resultate berichtet Pick das Folgende:

Die Untersuchung stützt sich auf 30 Fälle von Apoplexie. Pick unterscheidet zunächst Scheinaneurysmen. Diese können vorgetäuscht werden durch umschriebene Parese oder Kontraktion der Muskelschicht an Arterien. Weiter kommen dissezierende Aneurysmen vor, die sich durch Deckglasdruck künstlich erzeugen lassen. Schließlich finden sich Ausfüllungen der zirkumvaskulären Räume mit Blut, zelligem oder homogenem Material.

Miliaraneurysmen wurden von Ellis in 20 Fällen isoliert. Thre Menge schwankte bei den einzelnen Gehirnen zwischen 2 und 20, die Größe zwischen 0,5 und $4 \mathrm{~mm}$. In 4 Gehirnen fanden sich rupturierte Säckchen von 1,5-8 mm Durchmesser. $16 \mathrm{mal}$ wurden Aneurysmen in Schnitten gefunden. Die rupturierenden Aneurysmen sind meist übermiliare, selbst erbsengroße Bildungen. $\mathrm{Ob}$ aus miliaren Aneurysmen umfängliche und tödliche Blutungen erfolgen können, bezweifelt Pick.

Mikroskopisch steht in diesen Bildungen in exster Reihe die arteriosklerotische Verdickung der Intima. Die Media kann sekundär erkranken und es kommt zu Atrophie, fettigem und körnigem Zerfall und Nekrose. Eine primäre Atrophie, hyaline oder kolloide Degeneration der Media wurde nicht beobachtet, auch keine primäre Erkrankung der Adventitia. Weiterhin kann es zur Ruptur der Intima, Durchtritt von Blut, Aufblätterung der Muskulatur der Media und Blutaustritt zwischen Media und Adventitia kommen. Solche dissezierende Aneurysmen können mikroskopisch als M.-A. imponieren.

Weder im Schnitt noch im isolierten, dann eingebetteten und geschnittenen miliaren oder übermiliaren Aneurysma ließen sich wahre, d. h. von der ursprünglichen, wenn auch veränderten GefäBwand umgebene Aneurysmen feststellen. Sie erweisen sich vielmehr, ,soweit nicht dissezierende Formen vorlagen,

1) Über die sogenannten miliaren Aneurysmen der Hirngefäße. Berliner klin. Wochenschr. 1910. 
nach den einwandfreien Schnittserien als Aneurysmata spuria: als extramurale Hämatome, begrenzt durch Fibrin, verändertes Hirngewebe und ganz undeutlich gewordene Elemente der zerrissenen Gefäßwand. Diese falschen Aneurysmen wiederum entstehen teils durch die Ruptur atherosklerotisch veränderter kleiner Blutgefäße ohne vorgängige Dissektion der Häute, wohl öfter aber aus einem primär vorgebildeten dissezierenden Aneurysma"s (S. 329).

Manche dissezierende Aneurysmen mögen erst durch die tödliche Apoplexie selbst gebildet sein, wie auch durch die Blutung Gefäße der Hirnsubstanz zertrümmert werden und damit eine neue Quelle der Blutung eröffnet wird. Die tödliche Apoplexie erfolgt entweder unmittelbar durch GefäBruptur oder, anscheinend häufiger, durch Ruptur eines falschen, übermiliaren oder noch größeren Aneurysma.

Eine wichtige and bei anderen Autoren nicht zu findende Beobachtung lasse ich wörtlich folgen: „Auffällig und besonders zu notieren ist in allen Fällen die außerordentlich geringe Reaktion des Hirngewebes in der Umgebung der falschen Aneurysmen im Sinne einer erheblichen Abkapselung und Wandbildung um die Aneurysmensäckchen, der Mangel von bedeutenden Organisationen und hämatogenen Pigmentierungen der äußersten Schichten. Da nicht wahrscheinlich ist, daß gerade alle diese Schnitte durchgängig jüngere Stadien der Aneurysmata spuria aufweisen sollten, so scheint mir dieser Befund darauf zu deuten, daß gemeinhin die Lebensdauer der einmal gebildeten falschen Aneurysmen in der Hirnsubstanz bis zum Eintritt der tödlichen Hämorrhagie eine nur kurze ist" (S. 382).

In der Tat, dieser Mangel einer reaktiven Entzündung ist mit der Annahme, daß diese aneurysmenähnlichen Bildungen längeren Bestand gehabt haben sollten, ganz unvereinbar. Wie unvollkommene Aufschlüsse die ausschließliche Untersuchung der Zupfpräparate gibt, erkennt man eben daraus, daß keiner der zahlreichen Untersucher vor Pick diesen Umstand erkannt und gewürdigt hat.

Nach diesen Feststellungen hat Pick seine Untersuchungen noch fortgesetzt und gefunden, daB sich der GefäBbaum apoplektischer Gehirne gut isolieren läßt, wenn man das durchblutete Hirngebiet in physiologischer Kochsalzlösung stundenlang im Schüttelapparat ausschüttelt. Nicht durchblutete Hirnteile lassen sich nach Mazerierung in dünner Chromlösung ebenso behandeln. Pick konnte so achtmal in 11 Fällen die Quelle der Blutung nachweisen und zwar fünfmal schon durch mikroskopische Besichtigung. „Dreimal war mikroskopische Kontrolle für die verdächtige Rupturstelle, die nadelfein sein kann, nötig" (S. 383).

Die mit der Schüttelmethode gefundenen Frgebnisse faßt Pick so zusammen:

1. Die tödliche Hämorrhagie war stets nur aus größeren, zum mindesten übermiliaren Aneurysmen, zuweilen aus mehrfachen, rupturierten Aneurysmen erfolgt.

2. Für die eigentlich miliaren Aneurysmen ließ sich in keinem der Fälle eine Ruptur, in keinem eine Beziehung zur Genese der Blutung nachweisen. 
3. Die histologische Untersuchung der M.-A. erwies diese, soweit nicht zirkumskripte Blutanhäufungen im zirkumvaskulären Lymphraum, also falsche dissezierende Aneurysmen vorlagen, entweder als dissezierende Aneurysmen oder als Aneurysmata spuria. Die mikroskopisch untersuchten übermiliaren, rupturierten Aneurysmen waren gleichfalls Aneurysmata spuria.

Aber auch mit Hilfe der Schüttelmethode gelang es nicht, ausnahmslos Aneurysmen zu isolieren. Es ergab sich daraus für den Autor eine dualistische Auffassung der Blutungen, daß nämlich die tödliche Hämorrhagie auch aus einem aneurysmafreien rupturierten atherosklerotischen BlutgefäßB erfolgèn kann.

Im Gegensatz zu anderen Untersuchungen nimmt Pick die Arteriosklerose als die eigentlich ursächliche Gefäßerkrankung bei dem Schlaganfall an.

Interessant ist weiter eine Mitteilung von $\mathrm{Weber}^{1}$ ), der über multiple, punktförmige Blutungen im Gehirn, besonders bei Potatoren berichtet. Dabei sind die Wände der mittleren und kleineren Arterien und anch die Kapillaren hyalin entartet, die Wandungen verdickt und aufgeblättert. Zwischen den einzelnen Lamellen finden sich rote und weiße Blutzellen. Der Prozeß beginnt mit einer Wucherung der Gefäßwandzellen und zwar der äußeren Schichten. Das umgebende Hirngewebe ist aufgelockert und die Glia in Wucherung begriffen. M.-A. waren dagegen nicht nachweisbar.

Fassen wir die Resultate dieser seit einem halben Jahrhundert der Entstehung der Apoplexie gewidmeten Forschung kurz zusammen. Sie ging von der Idee Morgagnis aus, daß die spontane Himblutung durch das Platzen von Anewrysmen bedingt ist und sie ist bis auf den heutigen Tag von dieser Idee geleitet worden. Weitaus die wichtigste Errungenschaft dieser Arbeiten war die Auffindung jener Gebilde, die Charcot als Miliaraneurysmen bezeichnete. Die wirkliche Natur dieser Bildungen blieb indessen zweifelhaft und wurde um so zweifelhafter, je mehr sich die mikroskopische Technik entwickelte. Seit den wichtigen Untersuchungen von Pick sind sie als echte Aneurysmen nicht mehr anzuerkennen.

Mochten diese Bildungen aber gedeutet werden, wie man wollte, sie genügten nicht ohne weiteres, um die Entstehung des apoplektischen Herdes zu erklären. Von den früheren Forschern hat niemand ein zerrissenes M.-A. wirklich überzeugend aufweisen können. Die schematischen Abbildungen Charcots können als Beweismittel nicht gelten,

1) Hyaline Gefäßerkrankung als Ursache multipler miliarer Hirnblutung. Neurol. Zentralblatt 1901, S. 1063 und Deutsche med. Wochenschr. 1901, Vereinsbeil., S. 64 . 
wenn man sich auch Jahrzehnte mit ihnen begnügt hat in der Hoffnung, daß diese Lücke seiner Forschung später ausgefüllt werden würde. Das Zupfpräparat ist aber zur Entscheidung dieser Frage überhaupt ungeeignet. Einem so gewonnenen Präparat gegenüber, das ein geplatztes Aneurysma demonstrieren soll, wird stets der Einwand bleiben, daß der demonstrierte Riß ein Artefakt sei. Dieser Einwand wird natürlich ebenso Präparate treffen, die mit der Schüttelmethode Picks gewonnen sind. Eine weitere Schwierigkeit lag in dem Umstande, daß M.-A. auch in Hirnteilen gefunden wurden, die frei von Blutungen waren, ja auch in Hirnen, die überhaupt keine Blutungen enthielten. So entwickelte sich eine Lehre, die eine andere Schädigung der Gefäße als Quelle der Blutung betrachtete und die Aneurysmen nur nebenher gelten ließ.

Als eine solche Schädigung galt von alters her die Arteriosklerose. Sie machte die Entstehung einer Hirnblutung schon verständlich, da sie ja an den Gefäßen des Gehirnes ungemein häufig nachgewiesen war und die Gefäße augenscheinlich brüchig werden ließ. Allein, so oft auch die Sklerose an den Gefäßen des Schlagflüssigen gefunden werden mochte, es bleiben doch Fälle genug, bei denen sie fehlt und bei denen doch große Hirnblutungen das Leben vernichten. Es war daher ein Verdienst, besonders von Löwenfeld, eine schwere Degeneration der Hirngefäße nachgewiesen zu haben, die von der Sklerose zu scheiden war und als hauptsächliche Ursache der Blutung betrachtet werden konnte. Die einzelnen Formen dieser Entartung stellen sich dem Autor zwar nicht als wechselnde Form eines einheitlichen histologischen Prozesses dar, aber diese einzelnen Formen, wenn auch nicht in ihrer Gesamtheit, kehren seitdem bei allen Autoren wieder. Neben einer einfachen und fettigen Atrophie schneidet Löwenfeld eine granulöse Degeneration der kleinen Arterien ab, die zu einer Verschmelzung der einzelnen Wandschichten, oft auch zu einer glasigen oder fibroiden Umwandlung führt. Auch an Venen und Kapillaren findet er ähnliche Veränderungen und die Bildung von aneurysmenähnlichen Veränderungen verliert demgegenüber an Bedeutung.

Über die Ursache dieser Umwandlungen hat Löwenfeld kein Urteil abgegeben und es bleibt auch dahingestellt, ob die Mannigfaltigkeit seinerBefunde auf getrennte Krankheitsprozesse zu beziehen ist, oder ob sie vielmehr unter wechselnder Form der Erscheinung einem einheitlichen pathologischen Geschehen angehört. Ist man doch versucht, bei einem klinisch und anatomisch so einheitlichen Bilde, wie es der blutige Schlaganfall bietet, auch eine einheitliche Ursache zu vermuten. 
Indessen hat die spätere Forsehung über diese Frage keine Klarheit gebracht, ja diese Frage nicht einmal gestellt. Eine andere Seite des ganzen Problems wurde durch die Arbeit von Pick beleuchtet. Ihm gelang unter der Anwendung der Schnittechnik der Nachweis, daß die sogenannten M.-A. keine echten. Aneurysmen sind. Besonders aber mit dem Nachweis, daß diese aneurysmenähnlichen Bildungen ganz augenscheinlich kurzlebige Erscheinungen sind, daß ihrer Umgebung die Zeichen länger bestehender Gewebsreaktionen völlig fehlen, bringt diese Arbeit einen ganz neuen Gesichtspunkt, der über die bisher gewonnenen Resultate hinausweist.

Wenn nun diese aneurysmenartigen Bildungen erst kurz vor dem apoplektischen Insulte akut entstehen, so bleibt die Frage nach den Bedingungen ihrer Bildung noch offen. Die nähere Beziehung zu der Arteriosklerose, die Pick annimmt, ist noch nicht aufgeklärt und bleibt schon deshalb unverständlich, da ja solche Bildungen in anderen Organen, deren Gefäße oft der Sklerose verfallen, niemals gefunden werden. Auch die Entstehung größerer Blutergüsse ist für die Fälle noch unaufgeklärt, in denen zwar zerrissene M.-A. nachgewiesen sind, die Offnungsstellen aber von geringer Größe, unter Umständen nur nadelfein, waren.

Wie man sieht, gehen alle diese Arbeiten von der Auffassung Morgagn is aus, daß ein oder auch mehrere Gefäße, gleichviel wie verändert, platzen und die Hirnmasse mechanisch zertrümmern. Nur wenig beachtet findet sich daneben noch eine andere, von $R o c h o u x^{1}$ ) vertretene Ansicht. Roch ou x war ein Arzt, der in der Literatur seiner Zeit und der der Vorzeit wohl bewandert war, speziell auch die Schriften Morgagnis kannte und der ein reiches Krankenmaterial verarbeitet und zahlreiche Sektionen ausgeführt hatte, als er im Beginn des vorigen Jahrhunderts sein Buch über den Schlaganfall erscheinen ließ. Er stützt seine Ausführungen auf 25, auch durch die Autopsie kontrollierte Fälle von Schlaganfall, ungerechnet zahlreiche verwandte Beobachtungen mit und ohne Sektion.

Er unterscheidet bei dem Schlaganfall wechselnde, akzidentelle Läsionen, die Veränderungen der Dura und Verhärtungen der Gefäße und konstante Läsionen. Diese letzteren bestehen in dem Bluterguß und in der Läsion der Hirnsubstanz. Das Blut liegt in Kavernen, deren Wandungen sehr weich und in einer Ausdehnung von 1-2 Linien lebhaft rot gefärbt sind. Diese Wandungen sind ungleich, an der Innenseite

1) Recherches sur l'apoplexie. II. Edition. Paris 1833. 
sichtlich zerrissen und mit flottierenden Fetzen besetzt. An die innere, rote Schicht schließt sich nach außen eine gelbgrüne, die sehr weich ist und nach außen unmerklich in das normale Gewebe übergeht. Zwischen dieser äußeren und der inneren roten Schicht liegt offter noch eine dritte, blaßgelbe, von 2-4 Linien Dicke, mit einer großen Zahl von kleinen, stecknadelkopfgroßen Blutungen. Rochoux meint, daß die meisten Ärzte seiner Zeit die äußere Schicht als Entzündungsfolge betrachten, daß aber diese Ansicht nicht zulässig sei. Sie ließe sich vertreten bei Fällen, bei denen das Leben tagelang nach dem Insult erhalten geblieben wäre; sie sei unmöglich, wo sie sich in ganz frischen Apoplexien fände, die das Leben in einigen Stunden beendet haben. Letztere Beobachtungen wiesen darauf hin, daß eine organische Läsion der letzten Katastrophe vorausging. Wenn man dagegen sage, daß sich ein solcher Prozeß durch gar kein Krankheitssymptom anzeige, so sei zu erwidern, daß z. B. der Lungentuberkel, wie viele andere organische Schädigungen, sich auch symptomenlos entwickle, bis plötzlich die Blutung eintritt. Ähnlich sei der die Hirnblutung vorbereitende Prozeß zu denken, den er als ramollissement hémorrhagipare bezeichnet.

Rochoux wendet sich dann gegen die Autoren, die die Blutung aus Veränderungen der Arterien ableiten. Daß solche sich häufig finden, leugnet er nicht, aber sie sind gewöhnlich beschränkt auf die großen Gefäße und steigen nicht auf die Kapillaren hinab, und gerade diese seien es ja, deren Zerstörung die Blutung der Apoplexie hervorbringt. Es ist aber unmöglich, die Affektion der Kapillaren von der des zugehörigen Gewebes zu trennen. Die wirkliche Natur dieses Vorganges ist unbekannt. Man darf nur sagen, daß eine entzündliche Erweichung nicht in Frage kommt, da diese der Heilung fast unzugänglich sei, während die apoplektische Erweichung offenbar zur Heilung neige. Den Vorgang des Zerreißens der Gefäße gibt Rochoux zu, aber er definiert die Apoplexie als ,,une hémorrhagie par rupture, suite d'une alteration du tissu propre de l'encephale" (S. 159). Diese Ansichten sucht Rochoux in den Epikrisen der Fälle seiner Kasuistik im Einzelnen zu begründen.

Darin ist vor allem ein Gedanke, der heutzutage ohne weiteres der Kritik anheimfällt. Man kann das Géhirn nicht mit der Lunge, vergleichen und annehmen, daß sich in ihm ein irgend umfangreicher Prozeß unbemerkt entwickeln könne, wie etwa ein Tuberkel in der Lunge. Tuberkel sind wohl meist in der Anlage recht kleine Gebilde. Ein die A poplexie vorbereitender Erweichungsvorgang wird aber von Rochoux 
größer vorgestellt, als der schließlich eintretende Blutherd. Er könnte nur ganz selten bei entsprechender Lokalisation, etwa im vorderen Mark eines Stirnlappens, und bei geringem Umfang symptomenlos sich entwickeln. Schon deshalb ist die Annahme, daß der Blutung irgend ein dieselbe vorbereitender Prozeß lange vorausgehen könnte, abzuweisen. Ferner bringt Roch oux keinen Beweis für seine Behauptung, daß die Blutung nicht aus den Arterien, sondern aus den Kapillaren stammt. $\mathrm{Daß}$ Arterien zerstört werden, kann heute als bewiesen angenommen werden. $O b$ dasselbe mit Kapillaren geschieht, blieb ungewiß und war mit der nun einmal früher üblichen Untersuchungstechnik nicht festzustellen. Möglich und selbst wahrscheinlich ist eine solche Schädigung der Haargefäße aber sicherlich.

Als wichtig aber läbt sich aus Rochoux' Ausführungen der Gedanke sondern, daß die Hirnsubstanz möglicherweise nicht allein mechanisch durch das aus zerrissenen gröberen Gefäßen ausströmende Blut zertrümmert wird, daß sie vielleicht primär miterkrankt und daß dementsprechend um den blutigen Herd noch eine Zone erkrankten Gewebes gefunden wird. Man kann schon sagen, daß gerade diese Zone bisher nicht die Würdigung gefunden hat, die sie möglicherweise verdient und daß sie, wenn überhaupt, nur nebenher erwähnt wird. Selbst von den kleinen Blutungen, die sich oft so reichlich in der Umgebung des großen Herdes finden, ist meist nicht die Rede, und doch sollte man meinen, daß gerade ihre Untersuchung, die ja leichter ausführbar als die des großen Herdes ist, ein Licht auf die Entstehung des ganzen Vorganges werfen könnte. Statt dessen hat man bisher meist angenommen, daß diese kleinen Hämorrhagien mechanisch zu erklären seien und daß sie Kreislaufstörungen in der Umgebung des großen Herdes ihre Entstehung zu verdanken hätten. Es wird sich zeigen, inwiefern der Grundgedanke von Rochoux für eine neue Auffassung der Pathogenese der Apoplexie verwertbar ist.

Eigene Beobachtungen.

Erste Becbachtung. Zwei Stunden alte Blutung.

Adam K., 52 jähriger Arbeiter, wird abends am 8. XII. 1915 sterbend in das Krankenhaus gebracht. Die später vernommenen Angehörigen schildern ihn als früher gesund. Er hatte bis zum Nachmittag, wie gewöhnlich gearbeitet, geriet dabei in einen Wortstreit, wurde taumelig und brach bewußtlos zusammen. So fand ihn ein herbeigerufener Arzt vor, dem der harte Puls auffiel. Zwei Stunden später trat der Tod ein.

Bei der am anderen Morgen vorgenommenen Sektion fand sich die 
Dura stark gespannt, die Windungen abgeplattet. Die Gefäße der Basis zeigen nur geringe Verdickung. Bei Durchtrennung des Balkens gleiten aus dem Seitenventrikel der linken Hemisphäre einige weichgeronnene Blutklumpen. Doch zeigt sich, daß dieses Blut zum Teil aus dem angeschnittenen blutig erweichten Streifenhügel stammt. Das durch einen Frontalschnitt eröffnete Hinterhorn ist kaum erweitert und frei von Blut.

Die Lungen, besonders die rechte, ödematös. Auf dem Epikard einige Schwielen. Die rechte Kammer ein wenig dilatiert, die linke nicht verdickt. Die Aortenklappen zart, an den Mitralsegeln leichte Verdickungen. In der aufsteigenden Aorta leichte Intima-Verfettungen.

Die Milz atrophisch. Die Nieren von gewöhnlicher Größe. Die Oberfläche glatt, die Kapsel aber nicht leicht abziehbar.

Diagnose: Frische Apoplexie der linken Hemisphäre, Lungenödem.

Frontalschnitte der gehärteten Hemisphäre zeigen, daß der ganze Kopf des linken Streifenhügels durch die Blutung zerstört ist, die in den Ventrikel durchgebrochen ist. Daneben zeigt sich in dieser Ebene eine scheinbar selbständige Blutung in der Spitze des Schläfenlappens, die aber weiter hinten mit der ersten zusammenfließt. Der ganze Herd erreicht in der Gegend der Frontalebene des hinteren Balkenabschnittes sein Ende, wo er ziemlich nahe dem Ventrikel sich hinzieht (s. Fig. 1-3).

\section{Mikroskopische Untersuchung.}

Feine Schnitte aus der Gegend des kaudalen Endes des Blutergusses zeigen die Herdwand nur wenig blutig imbibiert. Hie und da hat sie eine etwas wabige Beschaffenheit. Mit stärkerer Vergrößerung untersucht, findet sich ein großer Teil der kleinen Gliazellen verändert. Das sonst kaum erkennbare Protoplasma ist an Masse erheblich vermehrt und gibt der Zelle eine rundliche oder ovale Gestalt. Hie und da sendet dieser Zelleib auch protoplasmatische, plumpe Ausläufer aus. Die Kernstruktur wird manchmal deutlich, und mehrfach sah ich eine einer Knäuelfigur ähnelnde Anordnung des Chromatins. Oft ist das Protoplasma ausgesprochen azidophil. Auffälligerweise sind es gerade die in der Nähe kleinster Blutergüsse liegenden Zellen, deren Protoplasma sich mit Eosin oder Pikrinsäure ähnlich wie ein Erythrozyt färbt.

Übrigens finden sich die gleichen runden azidophilen Elemente in unmittelbarer Nähe der kleinen BlutgefäBe und nahe dem Bluterguß oft ziemlich zahlreich. Auch die fixen Elemente der Wandung der kleinen Gefäße und Kapillaren sind hier manchmal zweifellos vermehrt. Ferner finden sich auch Nester von kleinen Zellen mit runden, gelappten, pyknotischen Kernen im Gewebe der Randschicht.

Feine nach Pal gefärbte Schnitte aus denselben Regionen lassen deutlich erkennen, daß in der Grenzschicht gegen die blutige Zone hin die Zahl der Markfasern schon geringer wird und daß normale Fasern kaum noch auffindbar sind. In den kleinen Blutungen und der blutigen Randschicht selbst nimmt ihre Zahl noch weiter $a b$, und man kann deutlich sehen, wie sie zum Teil auffallend blaß gefärbt, zum Teil in tropfigem Zerfall begrifien sind. 
Von dem Blutkoagulum selbst, von dem einige Teile für sich aufbewahrt waren, ließen sich bei der spröden Härte, die diese Objekte annahmen, keine feinen Schnitte gewinnen.

Das Studium der zahlreichen feinen Schnitte aus verschiedenen Stellen der Wand des Blutergusses brachte viele interessante Stellen über das Verhalten der kleinen Arterien zur Anschaunng, von denen einige hier beschrieben werden sollen. In mehreren Schnitten, die die Wandung eines durch die Blutung geschaffenen Spaltes umfassen, findet sich eine kleine Arterie auf dem Längsschnitt. Sie stellt sich als keulenförmiges

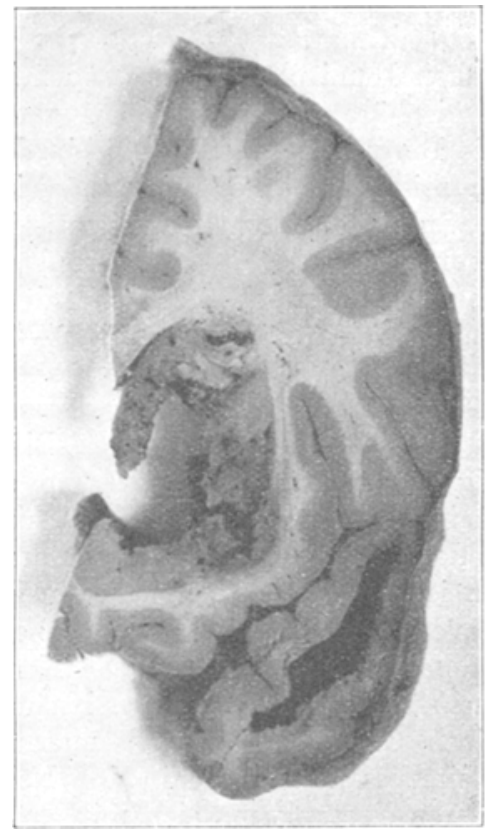

Fig. 1.

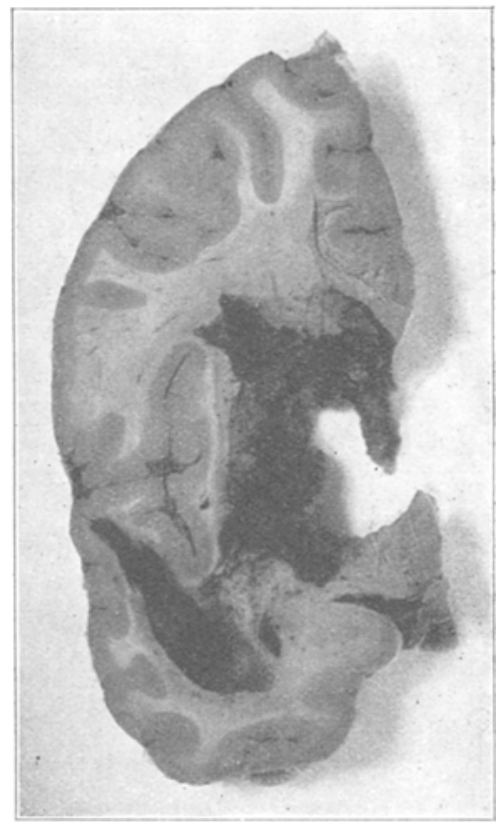

Fig. 2.

3-4 mm langes Gebilde dar, das zum kleineren Teile und mit seinem angeschwollenen Ende in den Spalt, in dem sich beim Zerlegen des Hirnes nur noch wenig Blut befand, hineinragt. Die Breite der Arterie beträgt im Gewebe und da, wo sie noch annähernd normal ist, nicht ganz $0,1 \mathrm{~mm}$ (gemessen mit dem Zeißschen Okularmikrometer). Die keulenförmige Anschwellung mag den 4-5 fachen Durchmesser haben. Die allgemeinen Verhältnisse werden am besten durch einen Blick auf die Abbildungen, (Fig. 4 und 5) veranschaulicht werden. Im einzelnen sei folgendes hervorgehoben. Das Gefäß ist um so besser erhalten, je weiter es von dem durch die Blutung geschaffenen Spalte entfernt ist. In diesem Teiil sind alle drei Schichten der Wand erkennbar. Die Intima ist mit gut gefärbten 
Endothelzellkernen besetzt. An der Media sind die Kerne der Muskelfasern leicht zu sehen, und von ihr hebt sich die Adventitia mit ibren am Giesonpräparat rot gefärbten Zügen gut ab. Nur ist sie kernarm und macht einen homogenen und gequollenen Findruck. Die ganze Arterie ist von einem Mantel von roten Blutkörperchen umhüllt, der, wenn auch nicht überall, gegen die Umgebung scharf abgegrenzt ist. An vielen Stellen hat man den Eindruck, daß diese Grenze durch ein zartes, mit spärlichen Kernen besetztes Häutchen gebildet wird. Da nun, wo die kleine Arterie in die kolbige Anschwellung übergeht, wird zunächst die Schichtung der Wand undeutlich. Die Externa verschwindet ganz, Media und Intima

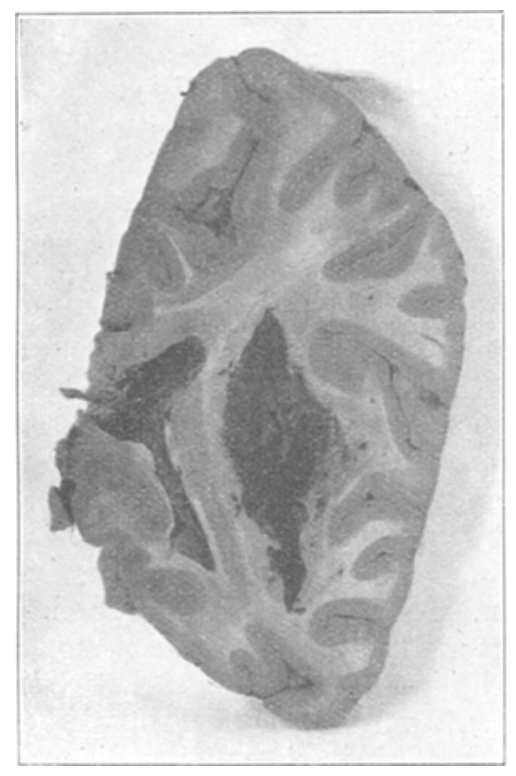

Fig. 3.

verschmelzen miteinander und werden ununterscheidbar. Die Kerne des Gewebes verschwinden und Infiltratzellen treten in und an der Wand auf. Schließlich verschwindet die Wand ganz oder setzt sich nur noch in Form feiner strukturloser Fasern in die kolbige Anschwellung fort, die aus krümeliger oder blutiger Masse besteht, in den Spalt frei hervorragt und meist von einer feinen Haut überkleidet ist, die wohI als Rest der Lymphscheide des Gefäßes zu deuten ist (vgl. Fig. 4 und 5). Auch am Präparat mit Elastika-Färbung ist die Auffassung der Wand bei dem Übergang in die kolbige Anschwellung erkennbar (Präparat 50 und 51).

Auch an anderen Präparaten finden sich gerade in der blutig erweichten Randschicht schwer veränderte Gefäße, deren Reste manchmal nur noch an den undeutlich wahrnehmbaren Kernen der Muskelschicht erkannt 
werden können (Präparat 67 und 68). Interessant ist an diesen Schnitten, wie auch an anderen hie und $d a, d a ß$ in der blutig erweichten Zone fleckweise, im ganzen nur selten, Stellen auftreten, die ganz homogen aussehen, nur vereinzelte Kerne und gar keine rote Blutkörperchen enthalten und sich mit Eosin diffus färben. Bei genauem Zusehen findet man aber manchmal ein feines Gefäß oder auch mehrere mit oft schwer erkennbaren Wandungen hindurchziehen.

Auch in Zonen der Randschicht, die der blutig erweichten Region unmittelbar anliegt, die selbst nicht mehr durchgehends schwer verändert, aber noch von kleinen Blutungen hie und da durchsetzt ist, findet man dieselben Veränderungen der Arterien. Auch hier sind sie nur nachweisbar in denjenigen Gefäßen, die zu den kleinen, meist Stecknadelkopfgröße nicht überschreitenden Blutungen in enger räumlicher Beziehung stehen. So finde ich in den Präparaten 72-78 ein kleines GefäB auf dem Querschnitt, etwa einen Millimeter von dem Rande des apoplektischen Herdes gelegen und selbst in eine kleine Blutung eingebettet. Keines dieser Präparate läßt an dem Gefäßdurchschnitt mehr als die Andeutung einer Struktur erkennen. Fast alle Gewebskerne fehlen und auch Orceinfärbung macht nur an einer kurzen Strecke einen feinen Zug elastischer Fasern deutlich. Infiltration mit Rundzellen fehlt fast vollkommen. Der Inhalt des Gefäßes wird von unveränderten Blutkörperchen gebildet. Neben diesem Durchschnitt findet sich noch ein kleinerer, kaum noch deutlich abgrenzbarer. Der das Ganze umgebende kleine Bluterguß hat keine scharfe Umgrenzung, sondern dringt unregelmäßig und mit kleinen Blutspritzern in das Nervengewebe ein.

Sehr lehrreich waren auch die Schnitte einer Reihe, die leider nicht als Serie aufgelegt waren, und die eine kleinste isolierte Blutung in der Herdwand enthielten. Ich hatte von einem Block eine größere Zahl von Schnitten abgehoben und sie in zwei Schalen aufgefangen. Als ich dann in einigen einen wichtigen Befund erhoben hatte, legte ich alle noch vorhandenen Schnitte auf, von denen aber inzwischen einige verloren gegangen waren und ordnete sie in einer Reihe, die nach dem Verhalten eines Gefäßes und anderen Merkmalen der natürlichen Reihenfolge entsprechen mußte. In dieser wird zunächst eine wenig veränderte kleine Arterie im Querschnitt inmitten eines etwa stecknadelkopfgroßen Blutergusses sichtbar. In den folgenden Präparaten liegt neben diesem Gefäßdurchschnitt ein unregelmäßig rundliches membranöses Gebilde, das von lymphoiden Zellen vielfach durchsetzt ist und immer mehr einem nekrotischen Gefäßwandteil ähnelt. Mit diesem Gebilde, das zunächst getrennt liegt, fließt an einem weiteren Schnitt die Wand der erstgenannten Arterie zusammen. Die letztere öffnet sich in einem weiteren Schnitt und die Wand der noch erhaltenen Arterie geht kontinuierlich in die nekrotische Membran über. Dann fällt die Wand der bisher zum Teil unveränderten Arterie völlig der Nekrose anheim, so $d a B$ in zwei weiteren Schnitten nur unbedeutende Reste der Wand nachweisbar sind, immerhin aber mit einzelnen noch erkennbaren Muskelfasern.

Schließlich bleibt nur noch ein rundliches strukturloses körniges Ge- 
bilde übrig, dessen Zugehörigkeit zu einem Gefäß überhaupt nur aus der Betrachtung mehrerer Schnitte erschlossen werden kann (Präparate 99 bis 100). Drei wichtige Phasen dieses GefäBverlaufes sind in den Abbildungen dargestellt (Fig. 6-8).

In Schnitten von einem anderen Block (Schnitt 83-86) fand ich ebenfalls in der nur durch kleine Blutungen geschädigten Randzone des Herdes eine längsgeschnittene Vene, die an einer Stelle eine Aussackung der Wand von unregelmäßiger spindeliger Gestalt hat. Auf der Höhe dieser Ektasie ist die Wand zerstört und weder Endothel noch Adventitia, die an allen anderen Stellen gut erhalten sind, nachweisbar. Fin krümeliger, thrombusartiger Inhalt, der statt des Blutes den Inhalt der Vene bildet, dringt hier durch die zerstörte Wand bis an die Außenseite des Gefäßes. In der Nähe dieser: Stelle liegt im Gefäß ein Haufen von Rundzellen, Lympho- und Leukozyten, die auch in spärlicher AnzahI die Wand durchsetzen.

Auch an anderen Schnitten ist die Homogenisierung und Verquellung kleiner Arterien, die innerhalb kleiner Blutungen der Randzone des apoplektiscben Herdes liegen, öfter zu beobachten. Manchmal verschwindet selbst in diesen feinen Schnitten die Wand derartig, daß man sie übersehen würde, wenn nicht ein Thrombus, der sich scharf von dem umliegenden Gewebe abhebt, auf den Gefäßrest aufmerksam machte.

Wie in anderen Fällen, so war es auch hier nicht möglich, eine deutliche Fibrinfärbung in den Blutergüssen zu erhalten. Nur in einer Gruppe von Präparaten ließ sich der Faserstoff, in Fäden eine nekrotische Gefäßwand durchsetzend, darstellen.

Die Übersichtsschnitte bieten ziemlich zahlreiche Stellen, an denen die beschriebenen Veränderungen der Gefäße studiert werden können, wenn auch an den dickeren Präparaten manche Feinheiten nicht mit gleicher Sicherheit beurteilt werden können. Vielfach ist der Übergang eines degenerierten Gefäßes in einen rundlichen, körnigen, völlig nekrotischen Körper erkennnbar, der offenbar nichts ist, als die abgestorbene und blasig aufgetriebene Gefäßwand. So zeigen mir die Schnitte 12-13 innerhalb einer kleinen Blutung im Gebiete des Balkenschnabels eine kleine Arterie auf dem Querschnitt, die zunächst nur undeutlich in ihrer Struktur und von Rundzellen durchsetzt ist, dann aber in den folgenden Schnitten an einer Stelle ihrer Wandung mit einem runden körnigen, nekrotischen Gebilde verschmilzt.

Überzeugender noch sind wieder Präparate, die den gleichen Befund an längsgeschnittener Arterie bieten. Sie liegt gleichfalls im Balkenschnabel in der Nähe des großen Blutergusses und in einer kleinen Blutung, die das ganze Gefäß umscheidet. Die Arterienwand ist an den Muskelkernen noch fast überall kenntlich, wenngleich die einzelnen Schichten der Wand nicht ïberall mehr unterschieden werden können.

An der einen Seite geht dies Gefäß nun in den Schnitten 14, h-14, i in ein rundes, scharf begrenztes, ebenfalls von einem rundlichen Bluterguß umgebenes Gebilde über, das von feinkörnigem Aussehen ist und ungefärbt geblieben ist. Der Durchmesser des Gebildes mißt $0,18 \mathrm{~mm}$, das zuführende Gefäß hat ungefähr den dritten Teil dieses Durchmessers. 
Nicht immer läßt sich der Übergang einer erkrankten Arterie in dem nekrotischen Teil mit derselben Deutlichkeit wie hier verfolgen. Da ich meist bei den großen Schnitten nicht lückenlose Serien auflegte, so kann ein ausfallender Schnitt gerade die charakteristische Stelle enthalten. In anderen Präparaten ist die Arterienwand auch ferner von dem ektatischen und nekrotischen Teil derartig verändert, daß sie mehr oder weniger unkenntlich wird. Trotzdem war doch noch in einigen Präparaten, die den proximalsten Teil der großen Blutung in Frontalschnitten fassen, der Zusammenhang mit genügender Sicherheit klarzustellen. Hier sieht man eine feine Arterie längsgeschnitten dem Rande der Blutung zustreben. Ihre Wand ist im ganzen und besonders die Intima streifig verdickt. Ihre Kerne weniger gut als die der Muskelschicht darstellbar, das Ganze von einem frischen Bluterguß scheidenförmig umhüllt. So zieht das Gefäß zu einem keulenförmigen, körnigen, ungefärbten Gebilde hin, das an querem Durchmesser die Arterie um etwa das Vier- bis Fünffache übertrifft und selbst etwas über $1 / 2 \mathrm{~mm}$ im Durchmeessr hat. Dieses Gebilde ist an der einen Seite offenbar mit einer Membran bekleidet und endet mit seinem nicht mehr scharf begrenzten Teile in dem apoplektischen Herde. Nicht überall haftet ihm Blut an.

Immerhin wollen solche Stellen gesucht sein. Häufig sind sie nicht, und ibre Auffindung gelingt am leichtesten daher in den großen Übersichtsschnitten. Öfter findet man die Gefäße mit partiell oder gleichmäßig nekrotischer Wand auch an der Grenze von apoplektischem Herd und stehen gebliebenem Gewebe. Manchmal kann man sehen, daß ein in die Höhle hineinragendes Gefäß in dem Teile, der im Gewebe steckt, noch relativ gesund ist, während es im Bereich der großen Blutung oder der durch sie geschaffenen Höhle seine Struktur einbüßt.

Dabei sind die Veränderungen die schon wiederholt geschilderten. Meist findet sich eine homogene Quellung der ganzen Wand, so daß die einzelnen Schichten ununterscheidbar werden. Nanchmal färbt sich diese gequollene Wand intensiv mit Eosin, manchmal lehnt sie Farbstoffe ab. Thrombenbildung und kleinzellige Infiltration der Wand können fehlen oder vorhanden sein. Nur ganz selten sind in den kleinen Blutungen oder in den Randpartien der großen Blutung Gefäße, die keine schwerere Veränderung erkennen lassen. In der Tiefe der großen Blutung fand ich keine Gefäße. Wo man sie in den kleinen Blutungen oder den Randpartien der großen Hämorrhagie findet, da tragen sie arteriellen Charakter. Eine Vene oder Kapillaren sind nur ganz ausnahmsweise nachweisbar.

Die beschriebenen Veränderungen beschränken sich durchaus auf Gewebe, das in die Blutungen einbezogen ist oder in nächster Nachbarschaft derselben liegt.

Arteriosklerotische Prozesse spielen in diesem Falle nur eine ganz untergeordnete Rolle. Die Äste der Cerebri media, in deren Bereich die Blutung ja lag, liegen in zahlreichen Übersichtsschnitten vor. Sie lassen nur ausnahmsweise eine umschriebene beetartige Verdickung der Innenhaut erkennen.

Lipoide Substanz in Form von Körnchenkugeln ließ sich innerhalb 
der kleinen Blutungen, meist in der Umgebung kleiner Gefäße nicht selten nachweisen. Meist lagen diese kugeligen Gebilde in kleinen Haufen beisammen.

Die Nieren wurden an einer Anzahl von Schnitten untersucht. Es fand sich eine chronische Entzündung, kenntlich durch kleine von der Kapsel ausgehende Schrumpfungszïge und verödete Glomeruli. Auch hier war die Arteriosklerose an den Schlagadern nur gering.

Auch die rein topographischen Verhältnisse des Blutergusses sind von Interesse. Sucht man die Quelle der Blutung da, wo sie ihre größte Ausdehnung hat, so wird man die weitere Ausbreitung in den Schläfenlappen und den Hinterhauptslappen schwer verstehen. Der Streifenhügel war an der Stelle der größten Ausdehnung blutig erweicht, und der Ventrikel eröffnet. Warum erschöpfte sich die Blutung nun nicht rasch, indem sie die Hirnhöhlen mit dem ausströmenden Blut erfüllte. Der Vorgang wird nicht verständlicher, wenn man die Quelle der Blutung neben dem Hinterhorn sucht. Auch hier würde rätselhaft bleiben, wie sich das Blut in den Schläfenlappen einerseits und die basalen Ganglien anderseits einwühlen konnte, ohne sich vorher durch Einbruch in den Ventrikel oder in die Sylvische Grube, der es recht nahe kommt, zu erschöpfen. Ein Blick auf die beigegebenen Photographien der frontal durchschnittenen Hirnscheiben bringt ohne weiteres diese Verhältnisse zur Anschauung (Fig. 1-3).

\section{Zusammenfassung und Beurteilung.}

Ein 52jähriger Arbeiter, der an einer chronischen Nierenentzündung litt, die ihm Beschwerden noch nicht gemacht hatte, starb rasch an einer Blutung in die linke Hemisphäre, die in den Ventrikel durchgebrochen war. Makroskopisch bei der Sektion wie am Schnittpräparat ließ sich nur eine geringe Arteriosklerose nachweisen.

Die nachweisbaren schweren GefäBveränderungen betrafen vor allem die feineren Arterien und diese lediglich im Bereiche der Blutung und deren unmittelbarer Nachbarschaft. Sie bestehen in einem Undeutlichwerden und Verschwinden der Gewebsstruktur der Wandung. Die Kerne verlieren ihre Färbbarkeit und entziehen sich gänzlich dem Nachweis. Häufig sind diejenigen der Muskelfasern noch erkennbar, wenn die der Intima und Externa schon geschwunden sind. Auch das elastische Gewebe wird frühzeitig vernichtet. Häufig, aber nicht immer, tritt eine starke Quellung der homogen gewordenen Wandschichten, die miteinander untrennbar verschmelzen, ein. Diese gequollene und homogen gewordene Wand verhält sich Farbstoffen gegenüber verschieden, indem sie entweder Färbung ablehnt oder sich mit saueren Farbstoffen tingiert. Die Lichtung kann unverändertes Blut enthalten oder Thromben. Kleinzellige Infiltration der Wand ist nicht selten. Eine noch 
schwerere Degeneration der kleinen Arterien führt zur Bildung aneurysmenartiger kolbiger Anschwellungen derselben. Die Vernichtung der Wandelemente ist hier so vollkommen, daß niemand beim Anblick eines Schnittes, der diese kolbigen Gebilde für sich allein enthält, sie würde richtig deuten können. Nur wenn ein glücklicher Zufall diese Gebilde längsgeschnitten und im Zusammenhang mit dem zuführenden Gefäß zur Anschauung bringt, wird eine sichere Deutung möglich. Aber auch dann noch wird nicht jeder derartige Befund eindeutig sein. Erst die Vergleichung vieler Präparate, in denen sich solche veränderte Arterien finden, wird zur richtigen Erkenntnis führen. Von besonderem Interesse sind Bilder, wie sie in Fig. 4 und 5 wiedergegeben sind. Sie werden von vielen zweifellos als abgerissene Arterien, oder allgemeiner gesagt, als mechanisch geschädigte Gefäße betrachtet werden und sind jedenfalls früher so gedeutet. Aber dieser Erklärung stehen doch Bedenken entgegen. Die Wand dieser Arterie endet nach dem Bluterguß und der kolbigen Anschwellung zu doch nicht so plötzlich, wie man das bei einem Abriß zu erwarten hätte. Man erkennt, daß die Wand um so schwerer verändert ist und in ihrer Struktur um so undeutlicher wird, je näher sie dem apoplektischen Herde kommt. Dann geht sie völlig unter oder verschwindet in allen Schnitten. Wäre sie abgerissen, so müßte sie schon völlig quer abgetrennt sein. Wie kann man sich aber ein völliges Abreißen einer Arterie durch die Gewalt des Blutes denken? Auffällig bleibt auch für die mechanische Erklärung, daß ein so zartes Gebilde, wie die Lymphscheide, nicht mit abgerissen ist, sondern daß diese das eigenartige kolbige Gebilde, das der zerstörten Schlagader aufsitzt, wenn auch nicht völlig umschließt. Dieses kolbige Gebilde könnte für die mechanische Auffassung nur ein nebensächliches Gerinnungsprodukt sein. Dagegen spricht aber die an allen solchen Präparaten wiederkehrende runde oder ovale oder kolbenförmige, immer aber allseitig oder doch am größten Teil der Oberfläche scharfe Begrenzung. Sie wäre bei einem Gerinnungsprodukt unverständlich, und wenn man sagen wollte, daß diese Begrenzung eben durch die Lymphscheide hervorgebracht werde, obwohl eine solche nicht überall nachweisbar ist, so bleibt die Schwierigkeit, zu erklären, wie dieses äußerst zarte Gebilde einer Kraft regelmäßig widerstehen soll, die die ganze übrige Gefäßwand, Muskularis und Elastika zerreißt.

Indessen wird die ganze mechanische Erklärung unmöglich bei Präparaten, die diese Bildungen in den kleinsten isolierten Blutungen aufweisen, wie sie spritzerförmig oder rundlich in der Umgebung der 
großen Blutung liegen. Ich glaube nicht, daß jemand annehmen wirâ, daß in einer so kleinen Blutung eine Gewalt wirksam werden könnte, die zum totalen Abreißen einer, wenn auch kleinen, so doch derbwandigen Arterie stark genug wäre. Und wenn man das doch annehmen will, so müßten die abgerissenen Fetzen der Wand doch auffindbar sein. Die Reste der Gefäßwand, die in der Fig. 7 sichtbar sind, könnten möglicherweise als ein abgerissenes Stück in Anspruch genommen werden, aber doch nur, wenn dieses Präparat für sich allein, nicht im Zusammenhang mit den benachbarten Schnitten, betrachtet wird. Die Entstehung dieses ganzen aneurysmenartigen, nekrotischen Gebildes ist mechanisch überhaupt nicht zu erklären, wohl aber für die Annahme, daß eine chemisch wirkende Schädlichkeit die Gefäßwand ihrer charakteristischen Elemente beraubt hat.

Wir sehen an zahlreichen Schnitten, daß die Arterien einem ganz eigenartigen Prozesse unterworfen sind. Gerade der vorliegende Fall macht klar, daß die Sklerose zu ihm keine notwendige Beziehung hat, denn diese war, wenn auch hier und da nachweisbar, weder ausgebreitet noch schwerer Natur. Lediglich im Bereiche des apoplektischen Herdes sind dagegen die Schlagadern in einer der Arteriosklerose fremden Weise verändert. Zuerst erfährt die innere und mittlere GefäBhaut eine Quellung. Wird sie hochgradiger, so wird die Wand zugleich homogen unter Verschwinden der Kerne und des elastischen Gewebes.

Dabei können die Konturen nach innen und außen noch glatt und scharf sein, wenngleich der innere oft durch Thrombenbildung, der äußere durch dicht anliegendes Blut verwischt wird. Wird der Prozeß aber noch hochgradiger, so verschwinden die Begrenzungen der Wand, ebenso wie die homogene Beschaffenheit oft; sie wird feinkörnig, verschwindet in der Blutung oder wird selbst da unkenntlich, wo die Betrachtung weder durch angelagertes Blut, noch durch eingelagerte Rundzellen erschwert wird. Dieser Zerstörungsprozeß kann ganz umschrieben kleine Teile der Wand ergreifen, oder er kann den ganzen Querschnitt betreffen. So kann eine Arterie spurlos in einem Bluterguß verschwinden und, wie sich an feinen Schnitten sehr wohl feststellen läßt, nicht etwa nur durch Blut verdeckt werden. Ebenso sah ich öfter, daß ein umschriebener Abschnitt nur einer Seite eines längs geschnittenen Gefäßes alle Struktur verliert und in eine körnige Masse sich verwandelt, die weder nach dem Lumen noch nach außen hin noch eine scharfe Begrenzung hat.

Unter besonderen, durchaus noch nicht klaren Verhältnissen, kommt 
es zux Bildung von aneurysmenartigen Ausbuchtungen der Gefäßwand. Ich verstehe hierunter nicht die Blutungen, die durch Erguß unter die Lymphscheiden der Gefäße die mannigfaltigsten Formen hervorbringen. Das ist ein mehr nebensächlicher Befund. Vielmehr Interesse verdienen die vorher eingehend beschriebenen rundlichen oder kolbigen Anschwellungen, die ich nur an Arterien kleinen Kalibers fand, und die nur an schon auch anderweit schwer veränderten Gefäßen gefunden werden. Sie stellen sich also so dar, dab eine kleine Arterie, deren Wandungselemente schon unkenntlich geworden sind, in ein kolbiges Gebilde übergeht, das an Größe das zuführende Gefäß um ein Mehrfaches übertrifft. Dieses Gebilde ist öfter von einer Membran überzogen, deren Zusammenhang mit der Lymphscheide hier und da nachweisbar ist. Es ist feinkörnig, im übrigen ganz strukturlos und enthält nur blutige oder körnige Massen mit einigen Rundzellen.

Diese aneurysmenähnlichen Gebilde können in der Wand des großen Blutherdes liegen und frei in die durch den Insult geschaffene Höhle hineinragen. Sie können aber auch in den kleinen Hämorrhagien vorkommen, die sich wohl immer in der Wand des großen Herdes finden.

In der Hauptsache können diese Bildungen wohl nur aus nekrotischer Arterien wand bestehen, wenngleich eingeschlossenes Fibrin dabei beteiligt sein mag.

Es ist klar, daß diese Bildungen mit Aneurysmen im heutigen Sinne nichts zu tun haben. Wohl aber nehme ich an, daß sie dieselben Gebilde sind, die seit Charcot wiederholt in Zupfpräparaten aus den Wänden apoplektischer Herde isoliert und bei der unvollkommenen Technik für Aneurysmen gehalten wurden.

Wie schon Charcot und andere diese Gebilde in einzelnen Hirnen zahlreich, in anderen vereinzelt oder gar nicht fanden, waren sie auch in meinen Fällen nicht überall nachweisbar und nur in dem vorliegenden häufiger. Man darf schon daraus den Sehluß ziehen, daß sie für die Entstehung der Blutung keine Bedeutung haben. Diese ist abhängig von der schweren Entartung des Gefäßsystems, die stets nachweisbar ist, auch wenn diese besondere aneurysmenartige Bildung vermißt wird.

Auch in der vorliegenden Beobachtung war mir der Gedanke unabweisbar, daß innerhalb des Blutergusses das gesamte Gewebe zugrunde gegangen sein muß. Dieser Vernichtung fällt auch das gesamte Kapillarnetz und die dünnwandigen Venen anheim. Fast nirgends sind von ihnen Reste in den kleinen Blutungen oder in dem großen Herde erkennbar. Wohl aber gelang, wenn auch nur selten, der Nachweis, daß. 
auch die Venenwand ähnlichen nekrotisierenden Prozessen unterworfen ist wie die Arterien.

Aus dem Gesagten ergibt sich, daß es unrichtig ist, wenn man für die kleinen Blutungen in der Nachbarschaft der großen eine besondere Entstehung annimmt, sie etwa durch Stauungen, die durch den großen Bluterguß bedingt sein sollen, erklären will. In ihnen finden sich dieselben Veränderungen, wie in dem großen Herde, und das ist für die ganze Auffassung des Leidens von Bedeutung.

Auch abgesehen von diesen kleinen Blutungen war das Gewebe, welches den großen Herd umgibt, nicht unverändert. Zweifellos waren die Markfasern allgemein geschädigt und im Zerfall, während an den Elementen der Glia progressive Veränderungen kenntlich waren.

\section{Zweite Beobachtung. Etwa 2 Stunden alte Blutung.}

Frau B., 42 Jahre alt. Sie litt seit vielen Jahren an Kopfweh. und schon vor 2 Jahren wurde ein Blutdruck von $200 \mathrm{~mm} \mathrm{Hg}$. festgestellt. Sie legte sich am 1. Januar 1915 ohne Klagen zu Bett und sprach noch um 11 Uhr mit dem Ehemann. Um 12 Uhr hört dieser ein Stöhnen, findet die Pat, mit herabhängendem oberen linken Lid, nicht bewußtlos, aber unvermögend zu sprechen. Bald trat Erbrechen ein und um 1/2 Uhr nachts der Tod.

Bei der nach 10 Stunden vorgenommenen Sektion waren die basalen Hirnarterien in mäBigem Grade sklerotisch, die Brücke geschwollen und weich. Beim Abtrennen der Hirnschenkel wurde eine blutige Erweichung sichtbar. Ausgesprochene Hypertrophie der linken Herzkammer. Klappen und aufsteigende Aorta intakt. Die Nieren kaum verkleinert. Die Kapsel hie und da adhärent. Die Rinde schmal.

\section{Mikroskopische Untersuchung.}

Die gehärtete Brücke war mit ihrem frischen Bluterguß für die Mikrotomtechnik ein schwieriges Objekt. Doch ließen sich neben kleinen feinen Schnitten etwa 80 brauchbare Übersichtsschnitte herstellen.

Sie zeigen einen rundlichen Bluterguß, der kaudal fast bis zum Brückenende, proximal noch etwas über das Brückengebiet hinausreicht, indem er sich auf die Hirnschenkel fortsetzt. In einer Frontalebene, die etwa der Mitte des 4. Ventrikels entspricht, erreicht er seine größte Ausdehnung, so daß er einen Durchmesser von 2,5-3 cm erreicht. Das ventrale Gebiet ist weniger beteiligt als die Haube, und lateral ist die Blutung überall noch von einer Schicht nervöser Substanz überzogen. Der Ventrikelboden ist auf eine kleine Strecke zerstört, und in der mäßig erweiterten Hirnhöhle liegt eine Blutung.

In der Umgebung der großen Blutung liegen, im ganzen spärlich, kleinere Hämorrhagien. Eine hat an einer Stelle, die proximal von dem 
Durchbruch in den Ventrikelboden liegt, die eine Hälfte des Ventrikelbodens auf eine Strecke hin hämorrhagisch infiltriert, ohne in den Ventrikel durchzubrechen. Man kann gut die Schwellung erkennen, die durch die Blutung bewirkt ist.

Am Pal-Präparat sieht man im Bereiche der Blutung vielfach Markfasern und Reste von solchen. Allgemein liegen sie dichter an den peripheren Teilen des Herdes, wo sie sich vielfach in Bündeln in das Blut einsenken. Sie sind hier meist intensiv gefärbt, wenn auch manchmal in tropfigem Zerfall begriffen. Die Tropfen können reihenweise, einer zerfallenden Markscheide entsprechend, angeordnet sein oder auch regellos liegen. Spärlicher sind die Reste in den zentraleren Teilen des Herdes und finden sich als Häufchen von Tropfen oder auch noch als schwer erkennbare, blaß gefärbte Fasern. Gar nicht selten bilden Blutkörperchen und solche Faserreste ein inniges Gemisch, immer aber mit Vorwiegen des Blutes. Man hat durchaus nicht den Eindruck, daß diese Marktrümmer dem entsprechen, was an Markmasse untergegangen ist.

Ein Teil der Gefäße hat sich auch innerhalb der Blutung erhalten und zeigt lediglich erhebliche sklerotische Veränderungen. Vielfach aber werden Zeichen des Zerfalls der Gefäßwand in wechselnder Stärke kenntlich. Die Wand bleibt als Ganzes etwa noch erkennbar. Aber ihre Schichtung ist nicht mehr deutlich, sie hebt sich von der Umgebung nicht mehr $a b$ und scheint mit dieser zu verbacken. Im Lumen, sowie in den Wandungen, können sich Rundzellen ansammeln. Ein schwer verändertes Gefäß läßt sich an mehreren Übersichtsschnitten durch die Brücke verfolgen. Es stellt sich als ein im ganzen rundlicher Durchschnitt dar, in den seitlich ein kleinerer Gefäßabschnitt einmündet. Nirgends ist hier mehr als eine Andeutung von Wandstruktur zu entdecken, die sich nur selten in einer streifigen Schichtung bemerkbar macht. Gewebskerne sind überhaupt nicht mehr nachweisbar. Meist wird die innen liegende Blutsäule nur von einer homogenen oder leicht körnigen, breiten Wand umschlossen, die sich mit Eosin gefärbt hat und eine ziemlich lebhafte Infiltration mit Leukozyten zeigt. Es läßt sich nicht sicher entscheiden, ob der größere Gefäßdurchschnitt als Hauptstamm und ein kleinerer als abgehender Ast zu deuten ist, oder ob ersterer nur ein aneurysmenähnlicher Anhang dieses letzteren ist.

Aneurysmenähnliche Bildungen fand ich an einer anderen Stelle. So liegen mir 7 Übersichtsschnitte vor, die ein und dasselbe von der Basis in die Brücke und den Bluterguß sich einsenkende eigentümliche Gebilde von keulenförmiger Gestalt enthalten. Es ist eine auf dem Längsschnitt getroffene Arterie, die relativ gesund in das Hirn eintritt. Rasch verliert sie ihre scharfe Begrenzung nach außen, während sie scheidenförmig von einem schmalen Bluterguß umfaßt wird. Media und Intima bleiben zunächst noch gut erkennbar. Im weiteren Verlaufe aber verschwinden die Kerne rasch, die inneren Gefäßhäute bilden nur noch eine homogene Masse. Zugleich schwillt die umgebende Bluthülle stark und keulenförmig an, grenzt sich aber gegen den umgebenden Bluterguß noch scharf $a b$, an vielen Stellen augenscheinlich durch eine feine Haut, die 
der ursprünglichen Adventitia des zuführenden Gefäßes zu entsprechen scheint. In diesem keulenförmigen Bluterguß verschwindet das nekrotische Gefäß spurlos (Fig. 9).

Bemerkenswert ist weiter, daß die Übersichtsschnitte nur eine mäßige Erweiterung des 4. Ventrikels und des Aquäductus zeigen, und jedenfalls ist es zu einer irgend erheblichen Blutung in diese Hirnhöhle nicht gekommen, obwohl ein nicht ganz kleiner Teil des Hirnhöhlenbodens blutig erweicht ist. Zudem kann man sich überzeugen, daß ein Teil des scheinbar frei ergossenen Blutes nur der nekrotische und blutig infiltrierte Ventrikelboden selbst ist. In den hinteren Teilen des 4. Ventrikels liegt dessen Boden nur ein Streifen Blutes an, der auf Frontalschnitten eine Dicke von $2 \mathrm{~mm}$ nicht übersteigt.

Feinere Schnitte aus Teilen des hämorrhagischen Bezirks lassen noch einige Besonderheiten erkennen. Zunächst ist festzustellen, daß in den blutigen Partien, wenigstens in deren zentraleren Teilen, meist auch in den peripheren, Nervengewebe nur sehr spärlich erkennbar ist. Meist sieht man nur Blutzelle an Blutzelle. Vom Glianetz ist keine Andeutung da und auch die Gliakerne fehlen, oder sind sicher nicht in zu erwartender Zahl vorhanden. Ein großer Teil der nachweisbaren Kerne stammt aus dem. Blute und ist gelapptkernig. Trotzdem kann man hie und da feststellen, daß Gewebsreste vorhanden sind. So sieht man manchmal ein ganz oder teilweise nekrotisches kleines Gefäb in diesem Gebiete und auch Ganglienzellen sind nicht so selten in den blutigen Partien nachweisbar. Sie sind niemals unverändert, sondern verklumpt und oft nur noch an der allgemeinen Form als solche erkennbar, sowie an dem Umstand, daß Zwischenstufen von der gesunden bis zur schwer veränderten Zelle sichtbar sind, wenn man die Gebiete mustert, in denen die graue Brückensubstanz aus dem gesunden Gewebe in das blutige übergeht. Dabei ist erwähnenswert, daß auch die Ganglienzellen, die unmittelbar am Rande auch kleinerer Blutungen gelegen sind, häufig nicht normal sind. Sie verlieren in dieser Grenzzone oft die Unterscheidbarkeit von Kern, Kernkörperchen und Protoplasma und färben sich mit sauren Farbstoffen.

Bemerkenswert sind auch Stellen im Bereich der Blutungen, die fast homogen geworden sind, nur wenig rote Blutzellen enthalten, aber doch hie und da ein kleines, schwer erkennbares Gefäß oder eine degenerierte Ganglienzelle enthalten. Sie sind manchmal von kleinen Lücken durchsetzt, ähnlich älteren Erweichungsherden, können aber bei dem Fehlen aller Gewebsreaktionen nur frisch entstanden sein.

Nach Markresten suchte ich in zentraleren Gebieten der Blutungen vergeblich in diesen kleineren, feinen Schnitten.

In den Nieren fanden sich sichere, wenngleich nicht häufige Veränderungen, bestehend in verödeten Glomeruli und solchen mit streifig verdickten Kapseln. Die Arterien der Grenzschicht zwischen Rinde und Mark zeigten eine zum Teil starke Verdickung der Intima. 


\section{Zusammenfassung und Beurteilung.}

Auch der Wert dieser Beobachtung liegt darin, daß eine ganz frische Blutung untersucht werden konnte, bei der die Reaktion des Gewebes auf den apoplektischen Insult noch ganz in den Anfängen geblieben sein mußte. Ferner war ein großer Teil der Brücke zerstört, und an einer nicht ganz kleinen Stelle war der Boden des 4. Ventrikels in die blutige Erweichung einbezogen. Trotzdem war, wie ich das oft beobachten konnte, in die Hirnhöhle nur ganz wenig Blut ausgetreten, ein Verhalten, das jeden überraschen muß, der annimmt, daß solche Blutungen aus einem oder einigen wenigen gröberen Gefäßen erfolgen, und daß das ausströmende Blut lediglich durch mechanische Gewalt das Hirngewebe zertrümmert. Sollte man doch erwarten, wenn nicht zufällige Umstände hemmend eintreten, daß das ganze Höhlensystem des Hirnes vollblutet. Aber davon war nichts zu sehen. Natürlich könnte gerade an der Durchbruchsstelle in die Hirnhöhle eine rasch einsetzende Blutgerinnung der weiteren Ergießung Einhalt tun. Deshalb sei hier erwähnt, daß ich auch in diesem Falle in Schnitten mit Fibrinfärbung zwischen den roten Blutzellen der Hämorrhagie Fibrin meist gar nicht nachweisen konnte. Da bekannt ist, daß diese Färbungen hier und da versagen können, so lege ich auf die Einzelbeobachtung nicht allzuviel Gewicht.

Von Interesse war weiter das Verhalten der Markfaserung innerhalb der Blutung an $\mathrm{P}$ al-Präparaten. Ich bestreite nicht, daß zahlreiche Stellen mit der Annahme einer bloß mechanischen Schädigung der Nervenfasern vereinbar sind. Besonders in der Randschicht der Blutung entsteht vielfach der Eindruck, daß Faserbündel nur mechanisch auseinandergedrängt sind. Im übrigen ist meist nicht festzustellen, ob in der blutigen Zone zwischen den Bündeln noch untergegangene Fasern liegen müssen. Darüber läßt sich ein Urteil nur gewinnen bei solchen. Brückenblutungen, in denen die Zerstörung einseitig sitzt und Schnitte durch das ganze symmetrische Organ aus dem Vergleich der intakten und der hämorrhagischen Hälfte ein Urteil zulassen, ob die Gesamtmasse der sichtbaren Fasern auf beiden Seiten etwa gleich sein mag. Diese Prüfung war hier nicht möglich. Jedenfalls aber läßt sich sagen, $\mathrm{da} \beta$ in den zentraleren Teilen der Blutung doch vielfach Stellen auffindbar sind, die nicht allein auf mechanische Schädigung der Fasern schließen lassen. Den Zerfall der Fasern in kleine und kleinste Marktröpfchen mag man noch mechanisch erklären. Der Umstand aber, daß in den tieferen Teilen der Blutung die Markreste vielfach blaß gefärbt 
und schattenhaft aussehen, weist auf eine chemische Schädlichkeit. Auch findet man nicht selten Stellen, in denen Faserbündel in die Tiefe der Blutung eintauchen, die keinen tropfigen Zerfall erkennen lassen, sondern im ganzen ihre Färbbarkeit verlieren und als schattenhafte Bänder hinziehen. An anderen Stellen sieht man die Abblassung der Faser und den Zerfall in feine, kaum noch färbbare Tröpfchen gemeinsam. Es ist durchaus zuzugeben, daß bei der Beurteilung dieser Präparate Vorsicht walten muß. Oft färbt sich das Blut nach $\mathrm{Pal}$ so intensiv, daß seine Entfärbung nur mit gleichzeitiger Entfärbung der Markfaser erreicht werden kann. Solche Schnitte sind natürlich für die hier interessierende Frage unbrauchbar. In den hier benutzten Schnitten war jedenfalls die Färbung in den von der Blutung nicht betroffenen Teilen des Gewebes tadellos.

Berücksichtigt man diese, an vielen Stellen der Blutung nachgewiesenen Markreste, so weisen schon sie darauf hin, daß bei der Apoplexie Nervengewebe und Blut innig gemischt vorgefunden wird. Der Gedanke, daß die aus einem größeren zerrissenen Gefäß hervorschießende Blutmasse das Gewebe einfach zertrennt und in seiner Mitte eine lediglich aus Blut bestehende Höhle bildet, findet in solcher Beobachtung. keine Stütze. Der gelegentliche Befund an Gefäßen, und zwar auch an solchen kleinsten Kalibers, spricht ebenso dagegen.

Von den Erkrankungen der Gefäße hebe ich hier nur noch einmal hervor, daß die Arteriosklerose an den intrazerebralen Gefäßen hochgradig war. Die Arterien waren innerhalb wie außerhalb der Blutung erkrankt. Die Verdickung der Intima war mehrfach so hochgradig, daß ein vollkommener oder nahezu vollkommener Verschluß eines Lumens gefunden wurde, und oft hatte ich den Eindruck, daß diese hochgradige Verdickung der Wand ein Gefäß vor der völligen Zerstörung innerhalb der Blutung bewahrt oder wenigstens das völlige Unkenntlichwerden der Wandungen verhindert hatte. Denn unveränderte gröbere oder feinere Gefäße, besonders Venen und Kapillaren, waren innerhalb des Herdes nur ganz ausnahmsweise nachweisbar.

Ziemlich reichlich aber sah man Arterien mit schwer veränderten Wandungen, deren Erkrankung durchaus nicht einfach als sklerotisch aufgefaßt werden konnte. Sie macht sich überall kenntlich in einer Verwischung der feineren Struktur der Arterienwand. Intima und Media verlieren ihre Kerne, werden homogen und verbacken miteinander. Oft sind sie mit Rundzellen durchsetzt, oft ist das Lumen durch thrombusartigen Inhalt verschlossen und häufig wird das Gefäß von einem 
Leukozytenmantel umschlossen. Überhaupt findet man bei näherem Zusehen innerhalb solcher Leukozytenansammlungen fast ausnahmslos Reste, die nur auf abgestorbene Gefäßwand zu beziehen sind. Die Adventitia ist öfter erhalten und ist dann von dem Gefäß meist durch einen Blutergu $B$ abgehoben.

Besonders muß auch in diesem Falle hervorgehoben werden, daß diese schwere Degeneration der Gefäßwände sich nur an Arterien innerhalb der Blutung oder in unmittelbarer Nähe derselben findet.

Von besonderem Interesse waren mir die Präparate, deren eins durch die Fig. 10 veranschaulicht wird. Eine kleine Arterie längs geschnitten dringt von der Peripherie aus in die Basis der Brücke ein. Sie wird nekrotisch und verschwindet in einem keulenförmigen Bluterguß, der noch von einem augenscheinlich präformierten Gebilde umfaßt wird. Das ganze Gebilde ist dadurch von seiner Verbindung mit dem umliegenden Gewebe so weit getrennt, $\mathrm{da} ß$ man den Eindruck hat, es hätte sich am frischen Organ als Zupfpräparat darstellen lassen, und dann würde zweifellos der Beschauer ein Objekt vor sich gehabt haben, das vollkommen mit dem übereinstimmte, was Ch arcot und seine Nachfolger als Aneurysmen beschrieben und abgebildet haben.

Tch habe eingangs erwähnt, daß in diesem Falle die Wassermannsche Reaktion positiv gefunden wurde. Die Annahme, daß die Brückenblutung durch eine syphilitische Affektion, eine spezifische Erkrankung der Gefäße oder eine Encephalitis syphilitica veranlaßt sęi, lag daher nahe. Indessen konnte weder an den Häuten noch im Gewebe oder an den Gefäßen eine spezifische Bildung gefunden werden. Die Arteriosklerose war an manchen Gefäßen sehr hochgradig und bis zum Verschluß eines ganzen Lumens durch Wucherung der Intima führend. Sie wies aber keine besonderen Merkmale auf. Es ist daher unzulässig, den Fall aus der Reihe der übrigen herauszunehmen und ihn betreffs der Ätiologie der Blutung anders zu beurteilen.

Dritte Beobachtung. 4 Stunden alte Blutung.

Franz Ey., 36 Jahre alt, Maler aus Cassel.

Im Jahre 1900 soll er Bleivergiftung durchgemacht haben. Im Februar 1912 häufige Klagen über Müdigkeit. In demselben Jahre erlitt Pat. einen Schlaganfall und lag einige Zeit in einem hiesigen Krankenhause. Näheres ist darüber nicht zu erfahren. Seit jener Zeit bestehen Klagen über Kopfweh, Schwindel und allgemeine Mattigkeit. Zeitweilig trat Erbrechen auf. 
Am. Tage der Aufnahme, am 18. IV. 1914 zwischen 9 und $10 \mathrm{Uhr}$ morgens, fiel Pat. plötzlich bewußtlos zusammen. Bald nach 12 Uhr wurde er in das Landkrankenhaus gebracht, wo er um $3 / 41$ Uhr starb.

Eine summarische Untersuchung ergab: Vollkommene Bewußtlosigkeit. Stertoröse, zuweilen aussetzende Atmung. Erbrechen während der Untersuchung. Pupillen mittelweit. Keine sichere Reaktion auf Lichteinfall. Stark beschleunigter, regelmäßiger Puls. Blutdruck $240 \mathrm{~mm} \mathrm{Hg}$. Urin mit Katheter entnommen, enthält reichlich Eiweiß und im Sediment wenig hyaline und granulierte Zylinder. Untersuchung von Herz und Lunge bei der geräuschvollen Atmung nicht ausführbar. Die Reflexe in Ordnung. $O b$ eine Lähmung bestand, konnte nicht sicher festgestellt werden. Das Phänomen des breiten Beines war nicht vorhanden.

Die am anderen Morgen vorgenommene Sektion ergab: Gehirn blutreich. Die Hemisphären wurden im ganzen mit der an den Hirnschenkeln abgetrennten Brücke in Formalin gelegt. Dabei zeigte sich auf dem Brückendurchschnitt ein Bluterguß.

Hypertrophie der linken Hexzkammer. Alte Mitralstenose. Leichte fleckförmige Verfettung in der Intima der Aorta thoracica. Hypostase in beiden unteren Lungenabschnitten. Schrumpfnieren.

\section{Mikroskopische Untersuchung.}

Bei der Zerlegung des erhärteten Gehirnes fand sich in der linken Hemisphäre eine große apoplektische Zyste. Sie lag dem Sehhügel lateral an. Von dieser Hemisphäre wurden nur einige Übersichtsschnitte angefertigt. Der Seitenventrikel ist hier erheblich erweitert, von der apoplektischen Höhle nur durch das Epithel geschieden, das gut erhalten ist. Die gröberen Äste der mittleren Hirnarterie tragen vielfach eine streifigzellig verdickte Intima. Die Höhle selbst wird von einem grobmaschigen Netze feiner, oft gefäßtragender Bündel eingenommen. Maschen sowohl wie Scheidewände sind außerordentlich zellreich. Die Zellen haben überwiegend den Charakter der Körnchenzellen und tragen häufig noch fein verteiltes Blutpigment. Auch die äußere Wand der Höhle, die aus faseriger Glia gebildet wird, ist sehr zellreich. Nekrotische Gefäße sind nicht auffindbar.

Durchschnitte durch die erhärtete rechte Hemisphäre zeigten einen Bluterguß, der von dem vorderen Ende des Streifenhügels bis in die mittleren Partien der inneren Kapsel reichte. Der Seitenventrikel ist nicht wesentlich erweitert, seine ventrale und laterale Wand aber in die Erweichung einbezogen. Er ist mit blutigen Massen locker erfüllt. Hinterund Unterhorn sind wenig erweitert und enthalten auch nur wenig blutige Massen. Etwas stärker erweitert ist der Aquädukt, der prall mit blutiger, beim Zerlegen der Brücke in Scheiben, herausschlüpfender Masse erfüllt ist. Die Hirnblutung setzt sich auf die Brücke durch den gleichfalls hämorrhagischen rechten Hirnschenkel fort. Diese Brückenblutung ist aber nicht mehr kompakt, sondern in kleinen Flecken und Spritzen derart angeordnet, daß fast jeder Querschnitt ein abweichendes Bild gibt. Diese 
kleinen Blutungen sitzen in der Haube. Nur vereinzelte ganz kleine Blutungen finden sich auch im Fuß. Eine der blutigen Erweichungen kommuniziert mit der Wasserleitung, deren Wand hier an einer kleinen Stelle zerstört ist.

Betrachtet man Übersichtsschnitte der Brücke, nach Pal behandelt und mit Alaunkarmin nachgefärbt, mit freiem Auge oder der Lupe, so fällt zunächst eine Veränderung im Gebiet des rechten Bindearmes auf. Sie besteht in einer Aufhellung des Gewebes durch Ausfall markhaltiger Fasern in der Umgebung der kleinen Blutungen dieses Gebietes, und diese Feststellung wird durch den Vergleich mit der nur wenig von Blutungen durchsetzten Partie der anderen Bindearmfaserung in dem symmetrischen Organ sehr erleichtert. In den dichten Blutungen selbst ist das Verhalten der markhaltigen Fasern nicht sicher festzustellen, doch scheint ihre Färbung vielfach gelitten zu haben. In der nächsten Umgebung sind die Fasern vielfach verunstaltet. Die beschriebenen Veränderungen sind in den proximaleren Brückenteilen ausgeprägter, als in den kaudaleren, nehmen also im ganzen nur einen kleinen Bezirk ein.

Sowohl in Übersichtsschnitten als kleinen und feineren Schnitten von der Brücke lassen sich schwere Gefäßveränderungen feststellen. Die Arteria basilaris und auch ihre Verzweigungen zeigen hie und da sklerotische Prozesse der Intima, im ganzen mäßigen Grades.

Daneben finden sich, und zwar nur in Beziehung zu den hämorrhagischen Stellen, schwere regressive Ernährungsstörungen an den Gefäßwänden. An vielen kleinen Arterien ist weder eine Intima noch eine Adventitia deutlich zu erkennen. Die Muskelschicht ist verquollen, während die Kerne noch erkennbar bleiben. Öfter sind diese Gefäße von Thromben verschlossen, die vorwiegend aus lymphozytären und leukozytären Elementen bestehen. Hie und da bleibt auch das Lumen eines Gefäßes noch für Blut durehgängig, während ringförmig der kaum noch erkennbaren Gefäßwand ein Wall von Rundzellen anliegt. Manchmal durchsetzen Rundzellen auch die erkrankte Gefäßwand und diese kann so homogen und undeutlich werden, daß sie inmitten der Blutung kaum auffindbar sein würde, wenn nicht eben die auffällige Rundzellenansammlung auf das Gefäß aufmerksam machte.

In den Präparaten vom Großhirn sind die geschilderten Gefäßveränderungen in ähnlicher Weise vorhanden. Auch hier hält sich die Arteriosklerose im ganzen in mäßigen Grenzen. Sklerotische Gefäße finden sich zuweilen auch innerhalb der hämorrhagischen Partien und hie und da findet man einen Gefäßdurchschnitt, der neben den arteriosklerotischen Veränderungen den nekrotischen Prozeß der Wand zeigt. So ist eine Stelle von Interesse, wo der Durchschnitt einer gröberen Arterie an der einen Seite die wohlerhaltene Gefäßwand mit stark gewucherter Intima zeigt, während an der anderen Seite die Wand stark verquollen und jeder Struktur beraubt, von roten und weißen Blutzellen durchsetzt ist.

An den großen Übersichtsschnitten durch die rechte Hemisphäre mit dem blutigen Herd zeigt sich hie und da, daß auch die Umgebung des letzteren noch geschädigt ist. Das Pal-Präparat enthält hier am Rande 
des apoplektischen Herdes und ziemlich tief in die Marksubstanz hinein Felder, die lichter gefärbt sind, als der Norm entspricht. Die noch darstellbaren Fasern sind vielfach degeneriert und enthalten keulen- und flaschenförmige Partien.

Erwähnenswert ist die Art, wie die Blutung an diesen großen Schnitten sich gegen die Wand des Herdes absetzt. Da, wo diese Blutung den größten Umfang hat, hat sie sich meist von der Wand zurückgezogen, und die Grenze zwischen erhaltenem Gewebe und Blutung kann ganz scharf und fast völlig glatt sein, ohne daß also Zotten von Gewebe und Gefäßen in die apoplektische Höhle hineinragen. An anderen Stellen ist die von dem umliegenden Gewebe gebildete Wand blutig infiltriert.

Ich erwähnte schon, daß die ventrale und laterale Wand des vorderen Seitenventrikels in die blutige Zerstörung einbezogen ist. In dieser Gegend sucht man vergeblich nach abgehobenen Epithelien.

Das kaudale Ende des apoplektischen Herdes ist so gestaltet, daß die kompakte Blutung in zahlreiche kleine und kleinste Hämorrhagien zersplittert wird, so daß auf dem Durchschnitt ganz das Bild der Encephalitis haemorrhagica vorliegt.

An feinen Schnitten vom Rande apoplektischen Herdes findet man öfters kleine Arterien inmitten der Blutung, die an dickeren Schnitten sich leicht verbergen. Sie sind hyalin gequollen, oft nach van Gieson oder mit Eosin leuchtend rot gefärbt. Meist ist die Intima noch für sich erkennbar und so stark verdickt, daß das Gefäß völlig verschlossen ist.

Manchmal sind auch Muskelkerne nachweisbar. Rundzelleninfiltrate können in solchen Gefäßwänden vorhanden sein oder fehlen.

In der den apoplektischen Herd umgebenden. Hirnsubstanz finden sich oft sogenannte Aneurysmata spuria. Am schönsten präsentieren sie sich auf den Längsschnitten, wo man nicht selten eine Lymphscheide prall mit Blut gefüllt von dem Gefäß abgehoben sieht. Man kann da alle bekannten Formen dieser Aneurysmen, kugelförmige, zylindrische, rosenkranzförmige usw. beobachten.

In feinen Schnitten durch Teile des für sich eingebetteten Blutergusses in den Streifenhügel lassen sich fast nirgends Reste des ursprünglichen Gewebes auffinden. Nur ganz selten trifft man auf eine kleinste Insel von Hirngewebe, das dann eine mehr homogene mit einzelnen Gliakernen ausgestattete Masse darstellt. Nirgends läßt sich eine Gliafaserung mit Sicherheit erkennen. Fast nirgends sieht man soviel Kerne, wie man sie in einem bloß mit Blut infiltrierten Nervengewebe erwarten dürfte. Nirgends sieht man die Reste einer Kapillare, etwa Endothelien. Auch von gröberen Gefäßen venöser Natur habe ich nichts auffinden können. Ausschließlich Arterien mit den beschriebenen Degenerationen trifft man hie und da in der blutigen Masse an.

Diese kleinen und feineren Schnitte wurden natürlich auch der Markscheidenfärbung unterworfen. Auch von Nervenfasern ist in diesen Präparaten auffallend wenig nachweisbar und gut erhaltene überhaupt nicht. Ein Teil ist zwar intensiv schwarz gefärbt, aber unregelmäßig knollig auf dem Längsschnitt gestaltet. Ferner finden sich Marktropfen und weiter 
äußerst blaß gefärbte tropfige, keulen- oder flaschenförmige Gebilde, die so durchscheinend sind, daß sie nur schwer zwischen den roten Blutzellen auffindbar sind. Nach Marchi behandelte Schnitte geben weniger gute Bilder, da die roten Blutzellen hie und da einen Farbenton annehmen, der ihre Unterscheidung von Markresten erschwert.

In der Umgebung des Blutergusses ist die Glia meist etwas verändert. Die feinfaserige Beschaffenheit ist einer mehr klumpigen gewichen. Hie und da sind die Kerne vermehrt und zwar sind es protoplasmaarme Rundzellen mit mehreren pylknotischen kleinen runden Kernen, die hauptsächlich diese Kernvermehrung bedingen. Nicht nur in der nächsten Umgebung der blutigen Partien sind die Gliazellen oft verändert. Ihr Protoplasma hat zugenommen, hat runde oder längliche Form und läßt hie und da auch zarte Ausläufer erkennen. Die Kerne sind entweder gleichmäßig gefärbt oder auch mit erkennbaren Chromatinfäden ausgerüstet.

Die Nieren waren hochgradig verändert. Von der Kapsel aus drängen sich rundzellenreiche, zum Teil auch bindegewebige Züge zwischen die Harnkanälchen und legen sich um die Glomeruli. Diese selbst haben häufig streifige und verdickte Kapsel und sind manchmal völlig verödet. Das Epithel der Drüsenkanälchen hat stark gelitten.

\section{Zusammenfassung und Beurteilung.}

Auch hier handelt es sich um einen Schlaganfall, der in ganz kurzer Zeit, in nicht 4 Stunden, das Leben vernichtete, nachdem Patient zwei Jahre vorher schon einmal eine leichtere Apoplexie erlitten hatte. Er hatte als Maler mit Bleifarben gearbeitet und früher eine Bleivergiftung durchgemacht. Der Blutdruck war von enormer Höhe, $240 \mathrm{~mm}$ $\mathrm{Hg}$, der Urin war eiweißhaltig und die Sektion ergab Schrumpfnieren und Verdickung der linken Herzkammer.

Nicht ohne Interesse ist die alte apoplektische Zyste in der linken Hemisphäre. Sie war etwa von Walnußgröße, lag dem Seitenventrikel eng an und war von ihm nur durch eine papierdünne Wand, das Ependym und das Epithel geschieden. Nimmt man an, daß diese Zerstörung lediglich durch die mechanische Kraft ausströmenden Blutes eingeleitet wurde, dann ist schwer zu verstehen, warum diese Gewalt nicht die dünne Scheidewand zum Ventrikel durchbrach und frei in die Hirnhöhle ausströmte.

Das Hauptinteresse aber bot die frische Blutung der anderen Hemisphäre, der von den vorderen Partien des Streifenhügels bis zum Hirnschenkel reichte und sich mit diesem noch auf die Haube der Brücke fortsetzte. Schon diese Art der Ausbreitung ist, wenn man sie unter dem mechanischen Gesichtspunkte des Blutaustrittes aus einem geplatzten Gefäß betrachtet, nicht zu verstehen. Die Hauptquelle der 
Blutung würde man da suchen, wo der Herd seine größte Ausdehnung erreicht, also im vorderen Streifenhügel. Dazu würde passen, daß sich das auströmende Blut hier durch blutige Erweichung der Hirnsubstanz den Ventrikel eröffnet hat. Warum erschöpfte sich aber nun die Gewalt des ausströmenden Blutes nicht, indem sie das Höhlensystem des Gehirns ad maximum mit Blut erfüllte? Statt dessen war der nur mäßig erweiterte Seitenventrikel mit ziemlich wenig Blut erfüllt, während Hinter- und Unterhorn nur eine ganz geringe Erweiterung erfahren hatten, und das ausströmende Blut nahm seinen Weg in der Hirnsubstanz kaudal weiter und verbreitete sich durch den. Himschenkel bis in die Brücke. Auch das kaudale Ende der Blutung weist nicht auf ein mechanisches Geschehen. Die kleinen Blutungen sind hier nicht spritzerförmige Ausläufer der großen Blutung, sondern sie sind nur als selbständige Herde aufzufassen. Und gerade hier, wo die mechanische Gewalt als erschöpft gedacht werden muß, die das Blut aus den Gefäßen der großen Blutung trieb, ist der Aquädukt relativ erheblich erweitert, offenbar weniger, weil auf seine Wände ein starker Druck von innen gewirkt hätte, sondern mehr, weil sie in eine Erweichung einbezogen war, die sich auch in der Umgebung der kleinen, der Wand der Wasserleitung anliegenden Blutungen geltend machte und so die Widerstandsfähigkeit des Gewebes auch geringem Druck gegenüber herabsetzte.

Wenn ferner die mechanische Kraft ausströmenden Blutes den Seitenventrikel eröffnet hatte, so war zu erwarten, daß das abgehobene Epithel irgendwo in den großen Ubersichtsschnitten aufgefunden wäre. Gewiß, es sind keine Serienschnitte angefertigt, aber die Zahl der Schnitte ist doch nicht ganz gering. Auf die in Rede stehende Region entfällt ein Dutzend. Sie zeigen nirgends eine Abhebung des Epithels in Streifen oder Fetzen, sondern ein allmähliches Undeutlichwerden des Epithelbelags, da, wo er den gesunden Boden verläBt und in die blutige Erweichung eintaucht.

Schließlich ist auch noch die Art, wie der apoplektische Herd gegen die Umgebung sich abgrenzt, der Erwähnung wert. An vielen Stellen weist die Wand des Herdes wohl die zottige Beschaffenheit auf, die in der Literatur oft genug erwähnt ist. An anderen Stellen ist aber die Grenze ganz scharf und glatt, wie sie eine Fläche, die ihre Entstehung einer Gewebstrennung durch die Kraft wühlenden. Blutes verdankt, kaum haben kann.

Es zeigt sich nun weiter, daß die Schädigung des Gewebes vielfach 
über die Wand des apoplektischen Herdes ausgebreitet war. Ziemlich tief in die Marksubstanz hinein zeigte das Pal-Präparat hier und da bei der Betrachtung mit unbewaffnetem Auge Aufhellungen, die durch Faserausfall bewirkt waren. Die noch darstellbaren Fasern waren vielfach degeneriert und enthielten die bekannten Formen der zerfallenden Markscheide.

Teile des blutigen Herdes waren für sich gehärtet und geschnitten. Das Verhalten der Markfasern in diesen Präparaten war mit einer bloß mechanischen schädigung ebensowenig vereinbar wie das eben geschilderte Verhalten der Marksubstanz. Vielfach lagen hier zwischen den roten Blutzellen Marktröpfchen, die intensiv nach Pal gefärbt waren. Man kann allenfalls noch sagen, daß solche aus zerrissenen Markscheiden auslaufen mochten. Ein Teil dieser Tropfen war aber schlecht gefärbt, und zwar mit Übergängen bis zur Unkenntlichkeit. Die mechanische Erklärung versagt bei der Deutung dieser Gȩ́ilde. Dasselbe gilt von jener Stelle in dem rechten Kleinhirnbindearm, wo auch zwischen den kleinen Blutungen die Faserung vielfach ausgefallen ist, und zwar so, daß Zerfallsprodukte überhaupt nicht nachweisbar sind.

Dahin gehört auch, daß die Glia in feinen Schnitten durch den Bluterguß weder mit ihren Kernen noch mit ihrem Fasernetz darstellbar war. Wohl liegen da zwischen den roten Blutzellen vielfach Kerne vom Charakter etwa der kleinen Lymphozytenkerne, die also ganz wohl zu Gliaresten gehören könnten. Das Verhalten zu einem Gewebe ist nicht erkennbar, und so muß unentschieden bleiben, ob sie ganz oder teilweise mit dem Blute ausgetreten sind oder Gewebsreste darstellen. Das Eine aber ist sicher: In ihrer Zahl entsprechen sie nicht annähernd dem, was erwartet werden müßte, wenn man sich die Menge der in einem Gesichtsfelde normalerweise sichtbaren kleinen Gliazellen vergegenwärtigt. Der Schluß, daß Kerne färberisch undarstellbar geworden sind, ist nicht abzuweisen.

Vollkommen analog verhalten sich an diesen Schnitten die kleinen Gefäße. Wo bleiben die Reste zerrissener Kapillaren und Venen? Nirgends findet sich ihre Spur in den feinen Schnitten, nichts von Wandelementen, nichts von Endothelien. Nur hie und da ist auch in den zentraleren Teilen der Blutung eine kleine Arterie der Zerstörung entgangen. Die Veränderungen an den Arterien sind wieder zwieschlächtiger Natur. Uber das ganze Gehirn verbreitet finden sich arteriosklerotische Prozesse in mäßiger Stärke. Sklerotische Arterien sind: auch hie und da innerhalb der Blutung noch nachweisbar, ent- 
weder so wie in dem ganzen Gehirn, oder kombiniert noch mit nekrobiotischen Vorgängen. Diese letzteren aber finden sich ausschließlich an den Arterien der Blutung oder deren unmittelbarer Nachbarschaft. Sie bestehen im leichteren Falle in einer Homogenisierung der Intima und Media, während die Kerne noch darstellbar bleiben können. Die Schwere der Degeneration ist gekennzeichnet durch ein völliges Homogenwerden der Wandung, ein Verquellen der einzelnen Schichten, die ununterscheidbar werden und alle Kerne und jede Andeutung von Struktur verloren haben können. Das Lumen kann Leukozytenthromben enthalten und die Wand kann von Rundzellen reichlich durchsetzt sein, die sich an anderen Stellen nur vereinzelt vorfinden.

Vierte Beobachtung. 6 Stunden alte Blutung.

Postschaffner Karl S., 40 Jahre alt. Hat oft an Rheumatismus gelitten und erkrankte am 20. I. 1913 an einer Angina. Am Vormittag des 24. I. geht er in die Stadt, um eine Besorgung zu machen, wird dabei ohnmächtig und bald in völlig bewußtlosem Zustand dem Krankenhause zugebracht, in dem er gegen 4 Uhr nachmittags stirbt. Die Körpertemperatur betrug $40^{\circ}$.

Bei der am anderen Morgen vorgenommenen Sektion fand sich starke Hypertrophie der linken Herzkammer und geringe schwielige Verdickung des vorderen Mitralsegels. Die rechte Niere kleiner als die linke. Kapsel beiderseits adhärent. Oberfläche höckerig. Auf dem Durchschnitt fleckige Uratablagerungen.

Mäßige Arteriosklerose der Gefäße an der Hirnbasis. Mäßiger Hydrocephalus internus. Frische Blutung in der Brücke.

Die vorausgegangene Angina und das hohe Fieber legten den Gedanken an einen entzündlichen Prozeß nahe. Bei der Sektion wurden daher Stückchen aus Milz und Brücke auf Glyzerinagar gebracht. Sie blieben steril.

Mikroskopische Untersuchung.

Nierenschnitte zeigten eine hochgradige interstitielle chronische Nephritis mit streifiger Verdickung vieler Glomeruluskapseln, Verödung von Glomeruli und Rundzelleninfiltration, die sich hie und da von der Kapsel in die Tiefe der Rinde erstreckte.

Übersichtsschnitte durch die gehärtete Brücke zeigen, daß fast das ganze Organ von einer Blutung eingenommen ist, die zentral gelegen, fast überall noch von einem Mantel erhaltener Nervensubstanz umgeben ist. Nur nach dem 4. Ventrikel hin ist auf einem kleinen Bezirk die bedeckende nervöse Schicht in den Prozeß der blutigen Erweichung einbezogen. Ebenso ist der Boden des Aquäduktes in seinem hinteren Teil blutig erweicht. Dabei ist der Ventrikel keineswegs erweitert, auch in seine Lichtung nirgends Blut ergossen. Er ist im Gegenteil spaltförmig verengt, wenigstens in seinen vordersten Abschnitten. Etwas weiter 
nach hinten entsteht bei flüchtiger Betrachtung allerdings der Eindruck, daß in den wenig erweiterten Ventrikel Blut ergossen ist. Bei näherer Betrachtung sieht man aber, daß die ganze Mitte des blutig-nekrotischen Hirnhöhlenbodens von den lateralen Partien, die ihre gewöhnliche Lage beibehalten haben, losgelöst ist und daß lediglich diese blutig-nekrotischen Partien den Boden der Hirnhöhle bilden. Das Epithel ist nur über den lateralen Partien gut erhalten. Nach der Mitte hin verliert es allmählich seine Färbbarkeit und wird unkenntlich. Öfter sind diese Partien des Ventrikelbodens mehr nekrotisch als blutig, obne Struktur und Gewebskerne, dafür aber mit zahlreichen Leukozytenkernen durchsetzt.

Es ist bemerkenswert, daß von diesem Teile der Blutung, die mit der Hauptmasse des Blutergusses in den kaudaleren Teilen der Brücke zusammen fließt, eine freie Blutung in den 4. Ventrikel nicht erfolgt ist.

Die Hauptmasse der Blutung hat die gesamte Haube und fast den ganzen Fuß vernichtet. Kleinere Blutungen liegen nur wenige in der Randschicht. Eine etwas umfangreichere, etwa erbsengroße, liegt im rechten Bindearm. Ringform haben die kleinsten Blutungen nicht.

Nur an den ventralen Partien grenzt sich der Bluterguß geradlinig von dem gesunden Gewebe ab. An anderen Stellen ist die Begrenzung ganz unregelmäBig, indem feine Blutstreifen vielfach noch in das umgebende Gewebe hineingreifen. Die zentraleren Teile der Blutung aber geben ein fast homogenes Bild. Reste von Gewebe sind mit Ausnahme der noch zu besprechenden wenig zu sehen. Selbst die Zahl der sichtbaren Kerne entspricht kaum dem, was man von Resten bloß mechanisch zertrümmerter Glia exwarten dürfte.

Besonderes Interesse verdienen die Gefäße. Da ist zunächst auffallend, daß innerhalb dèr Blutung feinere Gefäße und Kapillaren überhaupt nicht erkennbar sind, wenigstens nicht in den zentraleren Partien des Blutergusses. Auch in den Randschichten sucht man ganz vergeblich nach Kapillaren. Eher trifft man hier auf feinere Arterien. Gröbere Arterien finden sich auch in der Mitte des Blutergusses hie und da.

Diese Arterien sind sämtlich verändert. Während aber ein Teil nur die sklerotischen Zeichen aufweist, die auch an den Gefäßen außerhalb der Blutung vielfach bestehen, läßt ein anderer Teil Besonderheiten erkennen. Manche sind durch frische Leukozytenthromben verschlossen und sehr häufig findet sich eine oft starke Durchsetzung der Wand mit Leukozyten und Lymphozyten. Sie kann herdweise so stark werden, daß in dem infiltrierten Gebiet jede Struktur der Wand verschwindet. Weiter kommt eine hyaline Quellung der Wand vor, in der Media und Adventitia meist ganz aufgeht. Sie verschmelzen untrennbar miteinander und nur hie und da bleibt noch ein Muskelfaserkern sichtbar. Eher erhalten sich noch Reste der Intima. Diese ist dann an einigen Endothelzellen noch kenntlich, während die beiden äußeren Wandschichten zu einer homogenen mit Eosin färbbaren Masse verquollen sind. Die Quellung aller Schichten kann so hochgradig sein, daß die Lichtung des Gefäßes völlig verschwindet. Infiltration mit Rundzellen solcher Gefäße kann 
sich damit verbinden oder fehlen. Die äußere Begrenzung solcher Gefäße ist häufig unscharf.

Weiter finden sich Gefäßwände, die in eine homogen streifige Masse verwandelt sind, die Farbstoffe nicht annimmt, Kerne des Gewebes nicht oder nur vereinzelt erkennen läßt, aber von Wanderzellen reichlich durchsetzt ist.

Hier ist noch ein Wort über die arteriosklerotischen Veränderungen der Arterien am Platze. Hie und da liegen inmitten des Blutergusses kleine Arterien, deren Lumen durch eine Intimawucherung völlig geschlossen ist, ohne daß sich regressive Veränderungen erkennen ließen. An der Arteria basilaris, die in den Schnitten meist erhalten ist, sind die sklerotischen Veränderungen viel weniger bedeutend und haben nur eine mäBige Einschränkung der Lichtung duroh Intimaverdickung hervorgebracht.

Von großem Interesse sind weiter die mit Alaunkarmin nachgefärbten Pal-Präparate. Stellen, die die Deutung einer mechanischen Zertrümmerung der Nervenfasern inmitten des Blutergusses nahe legten oder gar als allein zulässig erscheinen ließen, sind kaum vorhanden. Vor allem ist in dem ganzen Bluterguß und besonders in den zentralen Teilen desselben nur recht wenig von Marksubstanz zu sehen. Selten ist eine kleine unregelmä8ig begrenzte Insel von einigermaßen erhaltenem Gewebe in der Blutung stehen geblieben. Die Glia ist dann, wie es scheint, leidlich erhalten, wenigstens die Kerne sind noch dargestellt, die Markscheiden aber nur blaß gefärbt.

An der transversalen Brückenfaserung kann man verfolgen, daß vielfach längsgeschnittene Bündel in die Blutung eintreten. Sie sind oft noch gut gefärbt. Aber je tiefer sie in die Blutung eintauchen, um so schmächtiger werden die Bündel, und um so blasser wird die Färbung. In den zentralsten Gebieten der Blutung sind meist Fasern nicht nachweisbar.

Eine ziemlich dichte Blutung liegt im Bindearm der einen Seite, so daß eine direkte Vergleichung mit der gesunden Seite möglich ist. Der Querschnitt des hämorrhagischen Faserzuges ist verbreitert. Die Nervenfasern scheinen gut erhalten und machen hier den Eindruck, daß sie nur mechanisch auseinander gedrängt sind durch die zwischengelagerten Blutzellen.

\section{Zusammenfassung und Beurteilung.}

Es ist im Vorstehenden schon erwähnt worden, daß bei dem Beginn des Leidens mit einer Halsentzündung und seinem Verlauf mit hohem Fieber der Gedanke an eine rasch verlaufende Pyämie mit Hirnblutung auftauchte. Daß im Verlaufe einer septischen Erkrankung Hirnblutungen vorkommen können, ist so bekannt, daß ich hier nicht weiter darauf einzugehen brauche. Aber ich selbst habe auch eine stürmisch verlaufende Staphylokokken-Infektion bei einem jungen Mensehén beobachtet und beschrieben ${ }^{1}$ ), der nur einen Tag krank war und an einer

1) Deutsche Zeitschr. f. Nervenheilluude, 1914, Bd. 50. Zur Path. der Encephalitis acuta, Fall I, S. 343 . 
massigen Blutung in die Hirnhöhlung starb. Hier ließen sich in Schnitten aus dem hämorrhagischen Gebiete der Ventrikelwand Staphylokokken sowohl im Gewebe wie in den krankhaft veränderten Gefäßen nachweisen.

Die Erinnerung an diesen Fall veranlaßte mich, gleich bei der Sektion Kulturen auf Glyzerin-Agar aus Milz und Brücke anzulegen. Sie blieben steril. Ebenso waren in Hirnschnitten, die mit Methylenblau gefärbt waren, keine Spaltpilze nachweisbar. Der Gedanke an eine infektiöse Erkrankung ließ sich also nicht weiter stützen und auf der anderen Seite wurde die Annahme einer gewöhnlichen Apoplexie durch den Leichenbefund mit der starken Hypertrophie der linken Herzkammer und der chronischen Nierenentzündung fast selbstverständlich.

Die Hirnblutung hat das Leben des Patienten in 5-6 Stunden vernichtet. Dieser sehr rasche Verlauf machte auch dieses Gehirn und seine Untersuchung gerade für den vorliegenden $Z$ weck besonders wertvoll. Was sich histologisch hier nachweisen ließ, das mußte durch den die Apoplexie bedingenden Vorgang selbst hervorgerufen sein. Jede ausgiebigere Entwicklung sekundär sich anschließender und reaktiver Prozesse war durch den raschen Tod ausgeschaltet.

Wie es meist zu sein pflegt, war das Gewebe, welches die frische Blutung enthielt, spröde geworden und nicht leicht zu behandeln. Besonders bei den Übersichtsschnitten durch die Brücke mitsamt der Blutung mußte ich mich mit Schnitten von $40-50$ Mikren begnügen. Sie waren aber auch so vollkommen brauchbar.

Prüft man diese Schnitte nun von dem Gesichtspunkt aus, ob mechanische Gewalt des aus geborstenen Gefäßen ausströmenden Blutes die Veränderungen schaffen konnte, die hier vorliegen, so ist folgendes zu beachten: Die blutige Erweichung der Brücke liegt im allgemeinen in den zentraleren Partien. Nur dorsalwärts ist der Boden des Aquäduktes und des 4 . Ventrikels in der Erweichung einbezogen. War diese Erweichung Ausdruck einer mechanischen Zertrümmerung des Gewebes, so ist nicht zu verstehen, warum die Blutung damit zum plötzlichen und völligen Stillstand kam, warum sie nicht vielmehr die Hirnhöhle prall erfüllte. In Wirklichkeit fehlt jede Erweiterung der Hirnhöhle. Sie besteht scheinbar nur an einer Stelle, wo ein Teil des nekrotischen Ventrikelbodens sich von den zentralen erweichten Partien abgehoben hat und in der erweiterten Hirnhöhle als freie Blutung zu liegen scheint. Der Sachverhalt wird klar, sobald man die betreffenden Übersichtsschnitte nicht nur mit freiem Auge betrachtet. Er würde 
aber unaufgeklärt geblieben sein, wenn man die gehärtete Brücke nur in Scheiben zerlegt und makroskopisch betrachtet hätte. Mikroskopisch ist erwähnenswert, daß manche Partien dieses Gebietes mehr nekrotisch als blutig sind und $d a ß$ in ihnen zahlreiche Leukozytenkerne nachweisbar sind. Dabei ist zu erwähnen, daß auch an Gefäßen, besonders an solchen, deren Wand ganz oder teilweise der Nekrose verfallen ist, solche Rundzelleninfiltrationen gefunden wurden.

In einem so frischen Blutherd sollte man nun, der herrschenden Auffassung er tsprechend, die Trümmer des vor kurzem zerstörten Gewebes finden. Aber dem ist nicht so. In den zentralen Teilen der Blutung finden sich gar keine Gefäße, weder Arterien noch Kapillaren, noch Venen. Und das, was man von Arterien in den mehr peripheren Teilen der Blutung findet, trägt nirgends Spuren einer mechanischen Schädigung. Mit den Markscheiden verhält es sich ähnlich. In der Mitte des hämorrhagischen Herdes ist von ihnen viel weniger erkennbar, als man in mechanisch zertrümmertem Gewebe erwarten müßte. Sie senken sich bündelweise von der Peripherie in die Blutung, werden hier schmächtiger, die einzelne Faser verdünnt sich und hie und da hat ihre Fürbbarkeit offenbar gelitten. In kleineren Blutungen, in der Umgebung der großen wie in der des kleinen Bindearmes, haben die markhaltigen Fasern dagegen oft in erkennbarer Weise überhaupt nicht gelitten. Sie scheinen nur durch das Blut in Bündel zerspalten und auseinandergedrängt.

Die Glia ist ein zu schwer zu behandelndes Objekt, als daß sie in größeren Schnitten gut zur Darstellung gebracht werden könnte. Jedenfalls ist aber an van Gieson-Präparaten innerhalb der Blutung nirgends ein Faserwerk darstellbar, das als Gliarest gedeutet werden könnte. Auch muß hervorgehoben werden, daß die Zahl der Kerne, die überhaupt in dem blutigen Gebiete sichtbar sind, meist sehr erheblich hinter dem zurückbleibt, was man bei einer nur mechanisch geschädigten Glia zu erwarten hätte.

Sehr wichtige Veränderungen bieten nun noch die Arterien dar. Während sie in der Brücke außerhalb der Blutung meist nur streifigzellige Verdickung der Intima darbieten mit mäßiger Einengung des Lumens, so findet man hie und da innerhalb der Blutung kleinere Arterien, die stärker sklerotisch sind und bei denen sogar es zu einem völligen Verschluß der Lichtung durch Wucherung der Intima gekommen ist. Aber die ganz chronische Veränderung dieser Gefäße, auch wenn solche in dem blutig erweichten Gebiete gefunden werden, ist sehr 
wenig geeignet, als Quelle der Blutung beschuldigt zu werden. Der Verschluß eines Gefäßes durch einen sklerotischen Prozeß ist ein ganz allmählich eintretendes und länger vorbereitetes Ereignis. Eine urplötzlich einsetzende. Blutung kann dadurch nicht erklärt werden.

Viel eher können da die schweren regressiven Metamorphosen herangezogen werden, die an anderen Gefäßen nachgewiesen wurden. Bei ihnen kommt es zu einer Homogenisierung der Gefäßwand, infolge deren die einzelnen Wandschichten ihre Kerne verlieren, ununterscheidbar werden und miteinander verschmelzen. Meist scheint der Prozeß an den äußeren Häuten einzusetzen, so daß zunächst Adventitia und Media ihre Struktur einbüßen und miteinander verquellen, während die Intima noch erkennbar bleibt. In anderen Fällen ist auch diese mit den anderen Schichten zu einer hyalinen oder homogenen Masse verschmolzen. Dann ist auch meist die äußere Begrenzung der Wand unscharf geworden.

Es kommen auf diese Weise Bilder zustande, deren Deutung mir zunächst große Schwierigkeit machte. Erst das Auffinden von Stadien, die alle möglichen Übergänge von leichterer und schwererer Degeneration der Gefäße darboten, dann der Umstand, daß selbst auf dem Querschnitt nicht immer das ganze Gefäß erkrankt ist, sondern noch stellenweise die Struktur erkennbar ist, ermöglichten die Deutung. Außerdem wird die Auffindung der Gefäßreste durch die Rundzellensammlung erleichtert, die oft in und um die abgestorbene Wand stattgefunden hat. Es ist eine bemerkenswerte Tatsache, daß diese Rundzelleninfiltrate nur da vorkommen, wo entweder erkrankte Gefäße liegen oder Dinge, die mit großer Wahrscheinlichkeit als Reste untergegangener Gefäßwände zu deuten sind. Im übrigen Gewebe kommen wohl einmal in nekrotischen Partien Lympho- und Leukozyten vor, aber sie treten doch nicht in dichteren Schwärmen auf. Dementsprechend fanden sich auch hie und da Leukozytenthromben, welche die ganze Lichtung eines Gefäßes verschlossen und diese sowohl als die Rundzelleninfiltrate der Gefäßwände fanden sich ausschließlich in den Gefäßen der blutigen Zone, nicht in der gesunden Umgebung, und nur an Gefäßen, deren Wand die Zeichen schwerer Degeneration bot. In weniger ausgeprägter Weise als an den Gefäßen und nur an umschriebener Stelle war an dem Epithel des 4. Ventrikels ein Absterben zu beobachten.

Aus dem Vorstehenden sei hier nur der Schluß gezogen, daß in dem blutigen Herde einer vollkommen frischen Apoplexie nirgends 
sichere Spuren einer stattgehabten Zertrümmerung des Gewebes durch mechanische Gewalt aufgefunden wurden.

Fünfte Beobachtung. 14 Stunden alte Blutung.

Johannes F., 64jähriger Invalid aus Cassel. Aufg. den 30. V. 1914, gest. den 18. IX. 1914.

F. litt seit Jahren an Asthma und erlitt im Herbst 1913 einen Schlaganfall mit linksseitiger Lähmung mit allmählicher Besserung. Am Tage vor der Aufnahme plötzlich Schwindelanfälle mit Zuckungen in der linken Körperhälfte und Lähmung des linken Armes.

Er wird mit klarem Sensorium in das Krankenhaus eingeliefert. Die Zunge weicht ein wenig nach links ab. Andeutung von linksseitiger Fazialisparese, sonst aber keine Lähmung. Zeitweilig Zuckungen in der linken Gesichtshälfte. Die Sprache ist etwas undeutlich, aber verständlich. Im Augenhintergrund Reste alter Chorioiditis. Reflexe in Ordnung.

Herz ohne Befund. Blutdruck $180 \mathrm{~mm}$ Hg. Diffuse zähe Bronchitis. Der Urin frei.

Pat. konnte bald aufstehen und war dauernd außer Bett. Er war immer kurzatmig ohne asthmatische Anfälle. Die chronische Bronchitis blieb unverändert. Der Blutdruck, der oft gemessen wurde, blieb dauernd hoch, wenn auch schwankend zwischen $175-230 \mathrm{~mm}$ Hg. Der letztere Wert wurde unmittelbar vor dem tödlichen Anfall gemessen.

Am 17. IX. nachmittags ging Pat. zum Klosett und stieß dort bald einen Hilferuf aus. Der hinzueilende Wärter fand ihn mit der rechten Seite gegen die Wand gelehnt und mit schwer verständlicher Sprache klagend, daß ihm schlecht geworden sei. Kurze Zeit därauf wird Pat. benommen. Der Puls war verlangsamt. Eine Lähmung der Extremitäten konnte nicht sicher festgestellt werden. Bald wurde die Atmung aussetzend und am anderen Morgen gegen 6 Uhr trat der Tod ein.

Die am selben Morgen vorgenommene Sektion ergab:

Dickes Schädeldach. Adhärente Dura. Die weiche Hirnhaut nicht verdickt. Die Gefäße an der Basis frei von Verdickungen. An einzelnen Stellen, über dem Wurme des Kleinhirns und über dem unteren Scheitelläppchen kleine blutige Infiltrate in der Pia. Gehirn wird mit Leimmasse injiziert und im ganzen eingelegt. Die Lungen gebläht, an einigen Stellen verwachsen. In den Bronchien überall zäher Schleim. Das Herz dickwandig. Der linke Ventrikel $1,5 \mathrm{~cm}$, der rechte $0,9 \mathrm{~cm}$ dick. Aortenklappen zart, an den Mitralsegeln nur geringe Verdickungen. Auch die aufsteigende Aorta enthält nur einzelne gelbe Flecken. Auch in der Aorta thoracica et abdominalis nur vereinzelte gelbe beetartige Erhebungen.

Die Nieren kaum verkleinert. Kapsel ziemlich gut abziehbar. Die Oberfläche nicht höckerig. Die Nebennieren klein.

Mikroskopische Untersuchung.

Das gehärtete Gehirn wurde in Frontalscheiben zerlegt. Die linke Hemisphäre ließ, abgesehen von mäßiger Erweiterung der Höhlen, nichts 
Auffallendes erkennen. In der rechten ist das Hinterhorn stark erweitert und längs seines oberen und lateralen Randes zieht ein alter Erweichungsherd hin, der vorn bis zur Vereinigung von Hinter- und Unterhorn, hinten bis fast an das Ende des Hinterhorns reicht.

Die frische, hier interessierende Blutung, sitzt der Hauptsache nach im Kleinhirn und zwar vorwiegend im Mark der linken Hemisphäre. Thr proximalster Teil zerstört den Bindearm, hat einen Erguß in den mäßig erweiterten 4. Ventrikel gesetzt und greift auf das benachbarte linke Kleinhirn über. Den größten Umfang hat die Blntung etwa in der Frontalebene der Trigeminuswurzel, wo fast die ganze Markmasse der linken Kleinhirnhemisphäre hämorrhagisch ist. Kaudalwärts wird der Umfang der Blutnng im linken Kleinhirn rasch kleiner, fließt aber durch den Wurm auf das Mark der anderen Hemisphäre, wo die Blutung indes nur geringe Ausdehnung erreicht. Eine kleine isolierte Blutung von etwa Kirschkerngröße liegt in diesen Ebenen noch dem rechten Nucleus dentatus medial an.

Das proximale Ende der Blutung spaltet sich in zwei Teile, von denen der laterale in den Markleisten der linken Kleinhirnhemisphäre, der mediale im Bindearm derselben Seite liegt. Auf dem Frontalschnitt ist die lange Achse des Ovals des Bindearmes nahezu transversal gestellt und in den Ventrikel hineingewölbt, dessen Lumen dadurch seitlich eingeengt wird. Blut ist in diesen hier nicht ergossen. Stärker erweitert ist der Ventrikel in seinem mittleren, weniger in den kaudaleren Abschnitten. Dabei sind allerdings die Grenzen des ursprünglichen Ventrikels nur in den nicht hämorrhagischen Teilen gut erkennbar. Der Boden ist nirgends in die Zerstörung einbezogen, meist auch die rechte laterale Wand erhalten. Die linke laterale Wand ist vollkommen zerstört und die blutig erweichten Massen legen sich tief in den Ventrikel hinein. Bei Betrachtung mit bloßem Auge würde man sie lediglich für Blut balten. Mikroskopiseh aber zeigt sich, daß in dem Blute kleine Arterien liegen. Nur in dem kaudalen $\mathrm{Ab}$ schnitt des Ventrikels, nahe dem Calamus scriptorius, liegt reines Blut um die Schlingen des Plexus.

Die weiter hirnwärts im Ventrikel liegenden Massen dagegen enthalten neben Gefäßen, wie das Pal-Präparat ausweist, reichlich nervöse Substanz. Deformierte Fasern, in Bündeln oder durch Blut auseinandergedrängt, sind reichlich sichtbar und ebenso zahlreiche Marktropfen. An manchen dieser Gebilde fällt auf, daß sie sich außerordentlich blaß färben.

Auch von der grauen Substanz, z. B. vom Nucleus dentatus, sind Teile durch die Blutung aus ihrer Verbindung gelöst. Ebenso sieht man Teile der Körnerschicht des Wurmes in der Blutung liegen.

Von Bedeutung ist noch das Verhalten der Wand des apoplektischen Herdes. Er stellt sich meist als eine gleichmäßig blutige schmale Schicht dar, von der sich die Hauptmasse der Blutung zurückgezogen hat. Nach außen davon folgt eine, am Pal-Präparat aufgehellte Schicht der Marksubstanz von wechselnder Dicke von einem bis mehrere Millimeter. In ihr sind die Fasern spärlich, meist sehr schmal, manchmal in feinste Tropfen zerfallen. Auch ist das Gewebe etwas wabig. 
In dieser Schicht, seltener über sie hinaus, finden sich kleinste Blutungen, die zum Teil ringförmig sind. In ihrem Bereiche ist von markhaltigen Fasern in der Regel nichts zu erkennen.

Schwere Veränderungen finden sich an den Gefäßen. Die Arterien sind häufig in mäßigem Grade sklerotisch. Die Intima ist streifig und zellig verdickt. Das ist sowohl an den Arterien der Pia wie an den intrazerebralen und auch an solchen, die innerhalb der Blutung selbst sich finden, nachweisbar. Daneben aber besteht eine Veränderung, die nur in der Blutung selbst oder in dem die Blutung nahe umgebenden Gewebe nachweisbar ist. Zunächst sind viele kleinere Gefäße dieses Gebietes durch Leukozytenthromben verschlossen und auch die Wandung von Rundzellen durchsetzt. Fast immer ist dann auch die Wand selbst verändert, in ihrem Bau undeutlich geworden und gegen die Umgebung schwer abgrenzbar. Häufig ist an solchen Gefäßen nicht mehr mit Sicherheit zu sagen, ob sie dem venösen oder arteriellen System zuzuzählen sind.

Die Wandzerstörung ist an anderen Arterien deutlicher ausgesprochen. Außerordentlich charakteristisch lag sie an 5 benachbarten Schnitten vor, die Kleinhirn und Oblongata in der Höhe der Oliven und die Blutung ziemlich in ihrer größten Ausdehnung umfassen. Sie bringen offenbar ein und dieselbe Arterie auf verschiedenen Durchschnitten zur Anschauung. Eine grobe Arterie ist längs getroffen und spaltet sich in drei $\ddot{A s t e . ~ D i e ~}$ Wandung ist streifig homogen geworden. Die einzelnen Schichten sind nicht mehr unterscheidbar. Nur selten ist ein Endothel- oder Muskelfaserkern erkennbar. An vielen Stellen färbt sich diese Wand mit Eosin gut, meist da, wo auch eine zellige Infiltration, die auch an allen übrigen Teilen vorhanden ist, besonders stark ausgeprägt ist. Wäre dies Gefäß nicht prall mit Injektionsmasse gefüllt, so würde es leicht übersehen werden können. Meist ist in der Umgebung so hochgradig veränderter Arterien ebenfalls eine beträchtliche zellige Infiltration vorhanden.

Nierenschnitte weisen eine mäßige Sklerose der gröberen Arterien und spärliche verödete Glomeruli auf.

\section{Zusammenfassung und Beurteilung.}

Ein älterer Mann litt seit Jahren an Bechwerden, die auf chronische Nierenentzündung zu beziehen waren. Sein Blutdruck war hoch und er hatte vor einem Jahre schon einen Schlaganfall mit linksseitiger Lähmung erlitten. Während des Krankenhausaufenthaltes wurde er wieder von einem Schlaganfall betroffen, der das Leben etwa in 14 Stunden vernichtete. Die Sektion konnte sehr bald nach dem Tode gemacht wreden und das Gehirn wurde von der Basilararterie aus injiziert. Es ist von Interesse, daß von dieser Injektionsmasse im Bereiche der großen frischen Blutung, die im Kleinhirn gefunden wurde, nichts aus den Gefäßen heraustrat. Nur in einer kleinen, im rechten Nucleus dentatus gelegenen Blutung war ein kleines Extravasat der Injektionsmasse 
entstanden, wie man es gelegentlich auch sonst an injizierten gesunden Organen findet.

Die frische Blutung hatte also einen großen Teil der linken Kleinhimhemisphäre zerstört und war auch an mehr umschriebener Stelle durch den Wurm auf die andere Hemisphäre des Kleinhirns gelangt. Der rechte Bindearm war in seiner Form erhalten, aber blutig erweicht und geschwollen, in den Ventrikel hineingepreßt. Dieser selbst.war hier eher verengt als erweitert, und obwohl nun die ganze.linke laterale Wand des mittleren 4. Ventrikels in die blutige Erweichung einbezogen war, so lag doch nur ganz wenig Blut in dieser Hirnhöhle, und auch dieses nur an dem kaudalen Ende. Was sich sonst an Inhalt des Ventrikels fand, erwies sich keineswegs als Blut, wie man bei makroskopischer Betrachtung wohl annehmen konnte, sondern als blutige Hirnmasse.

Das ging schon aus Präparaten mit Kernfärbung hervor, die inmitten der blutigen Massen teils sklerotische, teils nekrotische Arterien erkennen ließen. Weiter aber zeigte sich, daß Reste der Körnersehicht und des rechten Nucleus dentatus in diesen Massen lagerten und ferner wurden am Pal-Präparat auch reichlich markhaltige Nervenfasern daselbst angetroffen. Sie sind mit dem Blute innig gemischt und liegen hie und da noch in Bündeln oder meist in mehr vereinzelten Fasern. Viele dieser Fasern sind schwer verändert und im tropfigen Zerfall begriffen. Sie sind meist intensiv gefärbt, so daß sie zwischen den dichten Blutmassen gut erkennbar bleiben. Andere allerdings sind auffallend blaß und schwer auffindbar.

Diese blutige Hirnmasse ist also von der lateralen linken, zum Teil auch von der oberen Wand des Ventrikels in diesen hineingedrängt, so daß auch dieser T'eil der Himhöhle nicht erweitert ist. In der Höhe der Fazialiswurzel kann man noch vollkommen ein mit Epithel bekleidetes kleines Stück der Ventrikelwand erkennen, das von den blutig erweichten Massen nach rechts hineingedrängt und selbst ein Teil dieser veränderten Hirnsubstanz, nun der normalen rechten Ventrikelwand, die hier durch den Bindearm gebildet wird, dergestalt gegenüber liegt, daß nur ein sagittaler Spalt von etwa $1-2 \mathrm{~mm}$ Breite übrig bleibt.

Sehen wir nun zu, wie sich dies Verhalten mit der mechanischen Auffassung von der Entstehung der Apoplexie verträgt. Der Befund einer blutigen Masse, die vom Kleinhirn abgelöst und in den 4. Ventrikel hineingedrängt ist, einer Masse, in der Blut und nervöse Substanz stellenweise innig gemischt sind, ist natürlich mit dieser alten Auf- 
fassung wohl vereinbar. Zwar nicht so, daß man an das Zerreißen eines einzigen groben Gefäßes zu denken hätte, von dem aus das Blut die Hirnsubstanz unterwühlt und zerrissen hätte. Da wäre eine Zerteilung der Hirnmasse in so winzige Massenteile, wie sie hier vorliegen, nicht wohl denkbar. Noch weniger könnte man verstehen, wie diese Blutung in der Substanz des einen Bindearmes sich proximal weiter verbreitet hat, ohne hier wieder in den Ventrikel durchzubrechen, von dem die hämorrhagische Partie nur durch eine schmale Zone intakten Gewebes geschieden bleibt. Will man solchen Schwierigkeiten entgehen, so muß man schon annehmen, daß sehr zahlreiche kleine Gefäße gerissen seien und die Blutung so von vornherein an zahlreichen Stellen des apoplektischen Herdes einsetzte. Dann ließe sich eher verstehen, daß eine Blutung eine Strecke weit im Zuge einer Faserung, wie der des Bindearmes, bleiben mag, ohne durchzubrechen, und die innige Mischung von Hirnmasse und Blut wäre nicht auffallend.

Aber gerade der Umstand der Mischung von Blut und Nervensubstanz bringt eine weitere Schwierigkeit. Diese liegt in dem Verhalten des apoplektischen Herdes zu der umgebenden Wand. Nebme ich an, daß ein solcher Herd durch Bersten eines gröberen Gefäßes, Ausströmen von Blut unter hohem Druck und Auseinanderreißen der Hirnsubstanz entsteht, so begreift man allenfalls, daß die Blutung überall ohne Verbindung zu dem umliegenden Gewebe ist. Man würde höchstens erwarten, daß man eben die Spuren der Durchreißung an dem Gewebe der Herdwand fände, daß besonders die Gefäße in den Herd hineinragten. Tatsächlich spielen auch diese zu erwartenden Gebilde in der Literatur eine große Rolle, wo sie als feine zottenähnliche Bildungen vielfach beschrieben wurden. Der Inhalt solcher Herde, soweit er mit der Wand keinen Zusammenhang hat, besteht dann nur aus Blut. Wird man, wie im vorliegenden Falle, zu der Annahme gedrängt, daß die Blutung aus zahlreichen kleinen Gefäßen hervorgegangen sein muß, so wäre zu erwarten, daß noch breite Brücken erhaltenen Gewebes zu der blutigen Masse hinzögen, die den Inhalt des Herdes bildet. Es wäre ja schwer verständlich, wie in dem Hirn die Blutungen nun gerade so sich anordnen sollten, daß eine Sequestration des blutigen Herdes mit fast völliger Loslösung seiner Substanz von der Umgebung stattfinden sollte.

Dies letztere ist nun aber, wie ich aus meinen zahlreichen Übersichtsschnitten entnehmen darf, tatsächlich eingetreten. Fast überall ist der Inhalt des apoplektischen Herdes von der Wand losgelöst und 
durch eine Lichtung von einem oder mehreren Millimeter Breite geschieden. Nur an einer verhältnismäßig kleinen Stelle fließt der blutige Inhalt mit der blutigen Wand des Herdes zusammen, ohne daß aber auch hier aus der gesunden Hirnsubstanz Gewebszüge in die Blutung hineinzögen.

Betrachtet man nun die blutige Herdwand, so ist sie meist glatt. Sie sendet nur wenig Vorsprünge nach dem Inneren zu. Diese blutige Schicht ist von wechselnder Stärke, meist sehr fein und nicht einmal $1 \mathrm{~mm}$ stark. Sie ist mikroskopisch meist gleichmäßig blutig, nur selten von markhaltigen Fasern durchzogen.

Von großer Bedeutung für die Auffassung des ganzen Prozesses ist die nun weiter nach außen folgende Schicht. Sie ist nicht immer vorhanden, aber an vielen Stellen nachweisbar und charakterisiert durch einen zweifellosen Faserausfall. Dieser kommt weniger durch einen tropfigen Zerfall der. Markscheiden zustande, sondern durch ein völliges Verschwinden der Fasern, das schon makroskopisch durch eine weit lichtere Färbung des Pal-Präparates an dieser Stelle gegenüber der weiteren Umgebung sich kennzeichnet. Die mechanische Auffassung der Apoplexie könnte sagen, daß ja auch die Wand des Herdes noch mechanisch verletzt'werden kann. Das ist gewiß zuzugeben. Aber dann müßten die Markmassen, wenn auch deformiert, doch da sein. Bei dem akuten Verlaufe der Krankheit können sie noch nicht beseitigt sein. Die Fasern sind aber eben zu einem großen Teil nicht mehr nachweisbar. Den Fingerzeig zur Erklärung dieses Verhaltens gibt die Struktur der kleinen, zum Teil ringförmigen Blutungen, die in dieser aufgehellten Schicht nicht selten liegen. In ihrem Bereiche sind nur selten Nervenfasern und noch seltener Marktrümmer zu finden: Es bleibt gar keine andere Deutung übrig als die, daß sie einem Prozesse chemischer Umwandlung verfallen sind, durch den ihr färberischer Nachweis aufgehoben wird. Dementsprechend zeigen die Präparate in dieser Schicht auch hie und da einen deutlich wabigen Bau, der an anderen Stellen nicht vorhanden ist.

Dazu kommt nun, daß auch an den Arterien Veränderungen nachgewiesen sind, die nur als nekrotische gedeutet werden können. Ein Teil der verdickten Arterien widerstand diesem Prozeß. Sowohl in den blutigen Massen selbst, wie in der Herdwand sind hie und da sklerotische Gefäße mit gut gefärbten Kernen erkennbar. Aber von Venen und Kapillaren ist nirgends etwas zu erkennen, außer an solchen Stellen, wo noch erhaltene Gewebspartien, von ihrem Boden losgelöst, in die 
blutigen Massen hineingedrückt sind. Es ist ja auch wohl möglich, daß das aus zerstörten Gefäßen ausströmende Blut eine zertrümmernde Wirkung auf das Gewebe entfaltet hat. Aber das scheint mir nach dem Dargelegten außer Zweifel: Mechanische Kräfte genügen nicht, um die nachgewiesenen Veränderungen zu erklären. Chemische Kräfte haben mitgewirkt oder vielmehr sie haben an dem Zustandekommen des apoplektischen Herdes den Hauptanteil.

\section{Sechste Beobachtung. 2 Tage alte Blutung.}

Herr L., 44 Jahre alt, erkrankte am 24. I. 1916, nachdem er vorher immer gesund gewesen war, mit heftigem Kopfschmerz und Erbrechen. Am 25. I. wurde er benommen und die Sprache wurde lallend. Bei der Aufnahme am 26. I. war der fettleibige Mann tief benommen. Die Pupillen reagierten. Der Augenhintergrund war frei. Eine Lähmung ließ sich nicht feststellen. Die Sehnenreflexe auslösbar. Der.Tod trat am selben Tage ein.

Bei der am 27. I. ausgeführten Sektion fand sich der hintere Teil der linken Kleinhirnhemisphäre blutig erweicht und nahezu von zerfließender Beschaffenheit. Es konnte daher nur ein Teil dieser Kleinhirnhälfte zur Untersuchung konserviert werden. An dem übrigen Gehirn, den Häuten und den Gefäßen war nichts Auffallendes. Auch in Brust- und Bauchhöhle, besonders an Lunge und Herz normale Verhältnisse. Die mikroskopische Untersuchung der Nieren ist leider versäumt worden.

\section{Mikroskopische Untersuchung.}

Die Untersuchung geschah teils an kleineren feinen Schnitten, teils an Übersichtsschnitten durch Oblongata und Kleinhirnhemisphären. Sie mußte sich bei den angegebenen Verhältnissen auf die Wand des ausgefallenen blutigen Herdes beschränken, die sowohl von Rinden- als Marksubstanz der linken Kleinhirnhemisphäre gebildet wurde. Dabei zeigt sich, daß diese Wand des apoplektischen Herdes durch hämorrhagisches Nervengewebe gebildet wird, in dem die kleinen Blutungen vielfach zusammenhängende Streifchen bilden, die sich mit Vorliebe zwischen Rinde und Körnerschicht hinziehen.

Die gröberen Arterien der Pia sind zum Teil gesund, zum Teil besonders $\mathrm{da}$, wo sie sich in die Tiefe der Windungen einsenken, schwer verändert. So liegt mir in einigen Präparaten eine längsgeschnittene Arterie dieser Art vor, die so schwer verändert ist, daß sie vielleicht übersehen worden wäre, wenn sie sich nicht durch mehrere, in die Rinde eintretende, von ihr abgehende Seitenäste Ieichter erkennen ließe. Die Wandung dieser Arterie ist nicht an allen Stellen von dem anliegenden Blut zu scheiden. Thre Lichtung ist angefüllt von wenig gefärbten, zusammengesinterten roten Blutzellen. Die Wandschichten sind miteinander verbacken und völlig ununterscheidbar. Der Gefäßcharakter ist nur noch erkennbar an blaß gefärrbten Muskelfaserkernen, die in gewöhnlicher Lage noch ziemlich reichlich er- 
kennbar sind. Von diesem Gefäß gehen nun eine Anzahl Seitenäste $a b$, die leichter erkennbar sind, wenigstens in ihrem Ursprung. Die Wand hebt sich nach außen und innen deutlich ab, wenngleich auch hier die einzelnen Schichten nur schwer zu scheiden und die einzelnen histologischen Elemente undeutlich sind. Auch ist die Wand vielfach von einer körnigen Beschaffenheit. Sie wird an mehreren Ästen im weiteren Verlauf ganz unkenntlich, indem sie in dieser körnigen Masse untergeht. Da, wo diese in die Rinde eintauchenden Äste ganz unkenntlich werden, sind sie meist ziemlich reichlich von Leukozyten durchsetzt. Auch der Inhalt solcher schwer veränderten Gefäßabschnitte besteht hie und da aus dichten Leukozytenmassen. Solche schwer degenerierte Gefäße fanden sich in ziemlich großer Anzahl und immer in hämorrhagischem Gewebe. Auch in Teilen der nicht blutigen Rinde oder Körnerschicht nahe der Blutungen sah ich vielfach weniger intensiv veränderte kleine Gefäße.

Selten fand ich kleine Gefäße mit homogener und bis zum Verschwinden des Lumens gequollener Wand. Die Lymphscheide war dann abgehoben und mit schwer kenntlichen Erythrozyten gefüllt. Sie lagen nur in blutigem Gewebe.

An Präparaten mit Fibrinfärbung zeigen sich nicht selten kleinere Arterien in der hämorrhagischen Zone, deren Wand von Faserstoff durchsetzt ist. In den Blutungen selbst läßt sich nur selten Fibrin nachweisen.

An Pal-Präparaten erkennt man häufig, daß innerhalb der kleinen Blutungen, die sich im Nervenmark finden, die Zahl der Markfasern zweifellos vermindert ist. Fast immer sind einige Fasern auffindbar und ziehen unverändert durch die Blutung. Ihre Zahl reicht aber nicht annähernd an die der nicht blutigen Umgebung. Auch hat man nirgends den Eindruck, daß etwa die Fasern durch die Blutung auseinander getrieben sind, daß sie etwa bogenförmig die kleinen Blutungen umzögen. Sie nehmen im Gegenteil dicht am Rande der kleinen Hämorrhagien denselben Verlauf wie die in weiterem Abstand ziehenden Fasern.

An einigen Übersichtsschnitten begrenzt das Kleinhirnmark einén größeren Spalt, der durch den Ausfall des blutig erweichten Gewebes entstanden ist. Schon dem unbewaffneten Auge am Pal-Präparat fällt auf, daß dieser Teil der Markschicht blasser gefärbt ist als der entsprechende der anderen unveränderten Hemisphäre. Mikroskopisch zeigt er tropfigen Zerfall der Fasern. Dabei ist er nur sehr spärlich mit kleinsten Blutungen durchsetzt.

Die Übersichtsschnitte zeigen auch gut die Anordnung der kleinen Blutungen, die die Kleinhirnwindungen nahe dem großen Blutherde durchsetzen. Man sieht hier öfter eine Gruppe von Windungen, die in ihrer Form noch erhalten, während die feinere Struktur fast völlig zerstört ist. Mit freiem Auge sieht eine solche Partie wohl vollkommen hämorrhagisch aus, Mit der Iupe erkennt man zahllose kleinste punkt- oder streifenförmige Blutungen, die am dichtesten meist in dem feimen Piafortsatz stehen, der sich zwischen Windungen einsenkt. Von hier aus verbreiten sie sich in die Rinde und besonders auch zwischen Rinde und Körnerschicht und werden in der letzten sowie in den Markleisten wieder seltener 
und kleiner. An manchen. Stellen sind diese kleinen Blutungen offenbar ganz zusammengeflossen. Das Gewebe ist dann sehr brüchig geworden und im Schnitt ausgefallen.

Die kleinen Blutungen sind überall kompakt. Ringblutungen habe ich nicht gesehen.

\section{Zusammenfassung und Beurteilung.}

Ein 44jähriger Mann erlag innerhalb 3 Tagen einem Schlaganfall. Ein guter Teil des hinteren Abschnittes der linken Kleinhirnhemisphäre war blutig erweicht und von so zerfließender Konsistenz, daß der Herd nicht zu erhalten war. Die Veränderungen der Herdwand bestätigen die früheren Beobachtungen. An den kleinen Arterien fanden sich schwere regressive Veränderungen mit Ansammlung von Blutzellen in den Wandungen und deren Umgebung. Auch das Nervenmark war in der Herdwand geschädigt und offenbar nicht oder nicht allein durch mechanische Einflüsse.

Von besonderem Interesse war der Fall, weil er einen deutlichen Hinweis auf die Entstehung des großen Herdes aus kleinsten Blutungen gab. Ein Teil der Herdwand wurde durch schwer veränderte Kleinhirnwindungen gebildet. Diese waren an manchen Stellen noch vollkommen in ihrer Form erhalten und selbst in ihrer Schichtung aus Rinde, Körnerschicht und Markleiste wohl erkennbar. Dabei waren sie aber von sehr zahlreichen, kleinsten, dichtstehenden rundlichen oder streifenförmigen Blutungen durchsetzt. An anderen Stellen flossen diese kleinen Blutungen zusammen oder es hatte wenigstens den Anschein, daß sie zusammengeflossen seien. Man darf daraus wohl schließen, daß auch der große Herd, der sich ja für die Untersuchung nicht konservieren ließ, auf die nämliche Weise entstanden war. Jedenfalls wäre es gezwungen, für die große Blutung eine andere Ätiologie anzunehmen, als für die zahllosen kleinen erkennbar.war. Die schwere Alteration des Gewebes in Form von GefäBzerstörung und Zerfall des Nervenmarks ist nachgewiesen. So würde es nur geșucht sein, wenn man für die große Blutung einen anderen Vorgang, etwa das Zerreißen eines größeren Gefäßes und mechanische Zertrümmerung der Hirnsubstanz durch das ihm entströmende Blut annehmen wollte.

Siebente Beobachtung. Blutung, 3 Tage alt.

Frau P., 48 Jahre alt. Aufgenommen den 16. II., $\dagger$ den 18. II. 1915. Machte im Vorjahr einen Schlaganfall durch, von dem sie sich nur 
schwer erholte. Es bestand rechtsseitige Lähmung. In der Folge erlitt sie durch einen Fehltritt einen rechtsseitigen Knöchelbruch.

Am gestrigen Vormittag zweiter Schlaganfall mit vollkommener Bewußtlosigkeit.

Befund: Tiefer Sopor. Keine Reaktion auf Nadelstiche. Konjugierte Ablenkung der Augen nach rechts. Zyanose, stertoröse Atmung und Zeichen von Lungenödem. Gespannter, beschleunigter Puls.

Bei der am Todestage ausgeführten Sektion fand sich das Herz kaum vergrößert. An der Aorta nur vereinzelte und leichtere sklerotische Veränderungen. Die Nieren klein. Die Oberfläche grobhöckerig.

Das Gehirn wurde in toto eingelegt. Die Gefäße an der Basis waren in mittlerem Grade sklerotisch.

Nach Durchschneidung der gehärteten linken Hemisphäre fand sich ein alter, etwa haselnußgroßer Erweichungsherd derWand des vorderen Seitenventrikels lateral anliegend.

Die frische Blutung der rechten Hemisphäre hat in ihrem vordersten Teil den Kopf des Streifenhügels vernichtet und reicht nach hinten, sich verschmächtigend bis in die Frontalebene, in der Unterhorn und Hinterhorn zusammenfließen. Im ganzen hat der Herd eine eiförmige Gestalt, wobei jedoch auf den Frontalschnitten der transversale Durchmesser kleiner als der vertikale ist. Jener mißt an Stellen, wo der Herd seine größte Ausdehnung hat, etwa 2,5, dieser etwa $4,5 \mathrm{~cm}$.

Der Boden des Seitenhornes ist im vordersten Teile in die blutige Erweichung einbezogen. Weiter nach hinten liegt der Schwanzkern und Züge der inneren Kapsel zwischen Herd und Ventrikel. Trotzdem ist es zu einer irgend erheblichen Blutung in die Hirnhöhle nicht gekommen. Auch Unter- und Hinterhorn enthalten nur ganz wenig Blut.

In den hinteren Abschnitten reicht die Blutung in das Mark des Schläfenlappens hinein und legt sich eine Strecke weit an die laterale Wand des Unterhornes an. Die trennende Markschicht ist hier nur etwa 2, stellenweise nur $1 \mathrm{~mm}$ dick und dazu noch durch kapillare Blutungen erweicht. Aber zu einem Durchbruch ist es nicht gekommen.

An den meisten Stellen hat sich der blutige Inhalt von der Wand der Höhle abgelöst. Am vollkommensten ist das von der hinteren Wand des Herdes geschehen, wo aus dem Frontalschnitte das Blut herausfällt und eine Höhle hinterläßt. An den übrigen Stellen ist fast überall die Trennung vollkommen und nur der medialen, unteren Herdwand haftet die Blutung an. Die Wand ist im allgemeinen glatt, etwas buchtig und nur hier und da ragen Fortsätze von Gewebe in das Innere der Höhle.

In der Wand der apoplektischen Höhle liegen sehr zahlreiche kleinste oft ringförmige und eine Anzahl größere, bis zu Linsengröße anschwellende, Blutungen. Etwas auffallend ist, daß diese Blutungen die laterale Wand des Herdes viel reichlicher durchsetzen als die mediale.

Feine Schnitte durch den vorderen Pol der Blutung zeigen, daß in der Herdwand die Glia verändert ist. Während ihre Struktur in weiterem Abstand von der blutigen Schicht auch bei gewöhnlichen Färbungen gut erkennbar ist, so verschwindet das Netzwerk zwischen den Ringblutungen 
an manchen Stellen, besonders nahe der großen Blutung, oder wird undeutlicher. Das Stützgewebe gewinnt eine mehr gleichmäßig gekörnte, auch wohl mehr homogene Beschaffenheit. Dabei ist es vielfach wabig, und innerhalb der Lücken trifft man oft kugelige oder fädig-körnige Gebilde, die als zerfallene Achsenzylinder angesprochen werden dürfen. Die Zahl der Kerne ist in diesem Gebiete vermehrt. Neben den kleinen Gliazellen, deren Protoplasma oft beträchtlich vermehrt ist, finden sich Leukozyten, ganz unregelmäßig verteilt, oft in der Nähe der Gefäße und zum Teil in Nestern.

Die Mitte der Ringblutungen läßt ein Glianetz nicht mehr erkennen, sondern hat eine mehr körnige Beschaffenheit. Öfter findet sich hier ein kapilläres oder auch etwas gröberes Gefäß, dessen Wandung aber durchweg nicht mehr gut erkennbar ist. Sie hebt sich weder gegen den Inhalt noch gegen die Umgebung deutlich ab und ihre Kerne sind sebr blaß gefärbt. Fibrinfärbung zeigt öfter in diesem zentralen Gefäß wie in seiner Wandung und Umgebung die Einlagerung von Faserstoff. Nur hie und da sieht man einige eingewanderte Rundzellen.

$\ddot{A u B e r s t}$ schwer verändert finden sich in diesen Schnitten auch die kleinen Arterien zwischen den Ringblutungen. Die Wand ist öfters fast unkenntlich und strukturlos geworden.

Die Lichtung kann unverändertes Blut oder auch thrombenähnlichen Inhalt bergen. Von letzterem grenzt sich die Wand meist nicht mehr deutlich ab. Fast immer ist die äußere Begrenzung der eigentlichen Wand unerkennbar. Sie geht unter in einer feinkörnigen, mit Rundzellen in wechselnder Menge durchsetzten, breiten Schicht, die nach außen hin sich scharf absetzt und offenbar durch die Lymphscheide begrenzt wird. Die Elastika, die an normalen, weiter abliegenden Arterien ähnlicher Größe deutlich färbbar ist, läßt sich an diesen Gefäßen kaum noch oder gar nicht nachweisen. Die Abbildungen 10 und 11 geben zwei solcher Gefäßdurchschnitte wieder. Fibrinfärbung zeigt an solchen Arterien hie und da eine Durchsetzung der Wand mit Faserstoff.

Auch die großen Übersichtsschnitte bieten eine Fülle von Stellen, an denen die Wandnekrosen der Gefäße in dem Bereiche des apoplektischen Herdes verfolgt werden können und daneben bieten sie Gelegenheit, festzustellen, daß solche Veränderungen weiter ab von der Blutung im gesunden Hirngewebe nicht vorkommen. Bis etwa $1 \mathrm{~mm}$ von der Zone der Ringblutungen entfernt, findet man noch Gefäßchen, deren Wand hyalin gequollen und hie und da auch von Rundzellen durchsetzt sind. Weiter nach der Peripherie des Gehirnes hin verschwinden diese Dinge und an den groben Arterien finden sich hier die Zeichen ziemlich ausgesprochener Sklërose mit stellenweise starker Verdickung der Intima.

Frontalschnitte vom hinteren $\mathrm{Pol}$ der Blutung zeigen eine längliche, den erweiterten Seitenventrikel außen begleitende Höhle, deren Wand meist von Blut durchtränkt, häufig ganz glatt ist und von der nur hie und da feine fädige Fortsätze in das Innere streben.' Die Gefäße dieser Randschicht sind fast ausnahmslos schwer degeneriert. Schon im Präparat 1 liegt in einer kleinen knopfförmigen, blutigen Ausbuchtung der Wand ein 
solides aneurysmenartiges Gebilde, zu dem in Schnitt 1 und 2 eine kleine Arterie hinzieht, ohne daß in den aufgelegten Präparaten die Vereinigung beider Abschnitte vorliegt. Schnitt 5 liefert ein gutes Beispiel der Gefäßnekrosen. Innerhalb der mit Blutungen durchsetzten Wandschicht liegt eine kleine Arterie auf dem Längsschnitt, deren Charakter nur an ganz wenigen Stellen an vereinzelten Muskelfasern eben erkennbar ist. Die Wandschichten sind miteinander verschmolzen und bilden eine homogene, körnige oder leicht streifige Hülle, die an der dem Herde zugekehrten Gabelung vollkommen nekrotisch, aufgequollen und feinkörnig ist (Fig. 12). Ganz in der Nähe findet sich ein schwer erkennbarer Gefäßrest, an dem sich aber doch noch eine feinkörnige Wand und einzelne Muskelkerne erkennen lassen, eingebettet in ein dichtes Nest von Rundzellen, meist Leukozyten.

Weiter enthalten die Schnitte 9-16 am Rande des großen Blutergusses ein keulenförmiges, nach außen durch eine Membran abgegrenztes Gebilde von teils blutiger, teils rundzelliger Beschaffenheit. Innerhalb desselben sieht man in einigen Schnitten Reste einer Gefäßwand, und in einem ein eben kenntliches zuführendes Gefäß. Auch enthält der Schnitt 15 etwa $5 \mathrm{~mm}$ vom Rande der Blutung entfernt inmitten sonst gesunden Gewebes eine kleine Arterie mit verquollenen Wandungen, die in einen völlig nekrotischen und erweiterten Abschnitt übergeht, in dem die Wand keinerlei Schichtung mehr erkennen läßt, völlig homogen, stark gequollen ist und Eosinfärbung angenommen hat. Dieser Gefäßabschnitt ist von einem starken Rundzelleninfiltrat umgeben und nach einer Seite hin liegt ihm ein kleiner Bluterguß an. Der erweiterte Abschnitt mißt etwa $0,05 \mathrm{~mm}$, während der Durchmesser des zuführenden, annähernd noch normalen Teiles die Hälfte beträgt. Der Bluterguß, der dieses Gefäß umgibt, ist noch nicht einmal stecknadelkopfgroß.

Ähnliches Beweismaterial enthalten die folgenden Schnitte, von denen ich 50 auflegte und näher untersuchte, noch vielfach. Ich verzichte auf eine ausführliche Beschreibung aller Befunde, weil sie dem Gesagten nichts Neues zufügen würden. Vielfach findet man nekrotische Massen in der großen Blutung, die man nicht mit Sicherheit mehr als ehemalige Gefäßwand deuten kann. Manchmal wird dann an einem Nachbarschnitt die Sachlage klar, weil man ein noch leidlich erhaltenes Gefäß seitlich in diese Bildungen einmünden und mit diesen verschmelzen sieht (Präparat 42 bis 44$)$.

Nicht nekrotische Arterien mit gut erhaltener Struktur sind in dem Bluterguß nicht selten nachweisbar. Aber durchgehends finden sie sich nur in Randpartien, nicht in den inneren Schichten der großen Blutung. Sie sind vom Gewebe völlig losgelöst. Selbst von Adventitia ist an ihnen nichts nachweisbar. Nach außen von der Muskelschicht, die meist gut erkennbar, legt sich eng der Bluterguß an. Die Wand ist hie und da von Leukozyten durchsetzt und sklerotisch verändert, d.h. die Intima ist verdickt. Stellenweise ist die Verdickung der Intima so hochgradig, daß die Lichtung fast verschlossen ist.

An diesen großen Schnitten kann man auch sehen, daß die Wand 
des apoplektischen Herdes auf einige Millimeter verändert ist. Sie ist im Hämatoxylinpräparat lichter gefärbt als die entferntere Markschicht und auch das Pal-Präparat zeigt hier eine Aufhellung, die durch einen tropfigen Zerfall der Markfaser bedingt ist. Doch sind die letzteren Präparate nicht zahlreich genug, um Genaueres auszusagen.

Abgesehen von den sklerotischen Arterien ist in dem großen Bluterguß von Gewebe nichts erhalten.

\section{Zusammenfassung und Beurteilung.}

Es handelt sich nach dem Mitgeteilten um eine Frau, die an einer chronischen Nierenentzündung litt, vor Jahresfrist eine Blutung in die linke Hemisphäre erlitten hatte, und nun einer erneuten großen Blutung in die rechte Hemisphäre erlag. Zwischen Insult und Tod lagen 3 Tage.

Über die allgemeineren Verhältnisse des Herdes sei gesagt, daß er im ganzen von eiförmiger Gestalt, in dem. Hemisphärenmark vom Kopfe des Streifenhügels bis über das hintere Ende der Cella lateralis sich hineinzog. Der Boden des Seitenventrikels war in seinem vorderen Teile in die Erweichung einbezogen. Trotzdem war eine Blutung in die Hirnhöhlen am gehärteten Organ nicht nachweisbar. Das Hinterhorn war an der Stelle, wo es mit dem Unterhorn zusammenfließt, erweitert; das Unterhorn dagegen spaltförmig zusammengedrückt.

Es lag also ein ziemlich großer Bluterguß vor. Trotzdem war er der Hemisphäre äußerlich nicht anzusehen, so daß ich bei der Sektion zunächst im $Z$ weifel war, in welcher Hemisphäre er sitzen möchte. Bei der Zerlegung des gehärteten Organes war allerdings eine Verbreiterung des queren Durchmessers der frontalen Schnitte unverkennbar, indem der Grund der Insel nach außen gedrängt war. Immerhin war es wahrscheinlich, daß das Blut nicht allein einen Spalt aufgerissen und die Hirnmasse auseinander gedrängt hatte. Vielmehr waren besondere Teile des vorderen Schenkels der inneren Kapsel und die Vormauer in der Blutung unnachweisbar untergegangen. Daß alle diese Teile durch rein mechanische Kräfte so umgewandelt sein sollten, daß sie unauffindbar würden, kann nicht angenommen werden. Gewiß sind die hier in Betracht kommenden Übersichtsschnitte dick. Sie schwanken zwischen 60-70 Mikren. Aber daß sie für die vorliegende Untersuchung ausreichen, geht schon daraus hervor, $\mathrm{da} \mathrm{B}$ man die Gewebsreste, die im Bluterguß wirklich vorhanden sind, nämlich die feineren und gröberen Arterien, die der Zerstörung entgangen sind, vollkommen deutlich sieht und leicht auifindet. Nimmt man hinzu, daß auch hier in der 
Randschicht des Herdes an kleinen, feinen Schnitten, zwischen und in den zahlreichen Ringblutungen ein Undeutlichwerden der Glia und weiter ein Blaßwerden der Markfasern mit tropfigem Zerfall beobachtet wird, so kann man sich dem Schluß nicht entziehen, daß hier dieselbe Schädlichkeit, nur in geringerer Intensität wie in dem großen Bluterguß, eingewirkt hat. In dem apoplektischen Herde selbst aber hat sie zur Vernichtung und Unkenntlichmachung des Gewebes geführt.

Wie in den vorigen Fällen, so läßt sich auch hier dieser Prozeß der Zerstörung am sinnfälligsten wieder an den Arterien studieren. Augenscheinlich nur deshalb, weil sie die widerstandsfähigsten Gebilde sind. Lediglich aus diesem Grunde sieht man wohl hie und da auch in dem großen Bluterguß noch den Durchschnitt eines wohlerhaltenen Gefäßes und es ist wohl nicht ohne Bedeutung, daß diese ausnahmslos stark verdickte, sklerotische Wand haben. In dem Falle Kistner, bei dem die Arteriosklerose eine sehr nebensächliche Rolle spielte, sah ich sie nicht. Auch das kann nicht zufällig sein, daß in dieser Blutung fast nie Venen oder Kapillaren. nachweisbar sind, deren zarte Wandung der Zerstörung rasch unterliegen mag. Nur da, wo die den Krankheitsprozeß veranlassende Schädlichkeit nicht mehr mit voller Kraft einwirkte; wie in der Herdwand und in den kleinen Blutungen der Wand, ist es nicht zu einer Zerstörung gekommen, die von den Arterien keine Spur mehr übrig ließ, wenngleich die Veränderungen auch so noch schwer genug sind.

Wie in den früheren Fällen, so bestehen diese zunächst in einer Homogenisierung der Wand, die ihre spezifischen Elemente, Kerne und Gewebszellen, elastisches Gewebe, Fibrillen des Bindegewebes einbüßt. Die einzelnen. Wandschichten werden ununterscheidbar. Die scharfe Begrenzung gegen den Inhalt der Lichtung und gegen den immer vorhandenen umgebenden Bluterguß verschwinden, während der letztere oft durch ein feines Häutchen, offenbar die erhaltene Lymphscheide, begrenzt wird. Eine noch schwerere Degeneration wird durch ein Anschwellen der Wand kenntlich, in der schlieBlich jede Andeutung von Gewebsbau verschwindet, so daß der Nachweis, daß überhaupt Gefäßwand vorliegt, nur noch da zu erbringen ist, wo der Zusammenhang mit unversehrter Wand, so z. B. auf längsgetroffenen Gefäßen, erkenubar ist. Der Inhalt solcher degenerierter Gefäße ist öfter Thrombenmasse. Je schwerer die Degeneration wird, um so reichlicher lagern sich Rundzellen um die erkrankten Arterienwandungen.

Bildungen, die zu keulenförmiger Anschwellung der nekrotischen Arterienwand gefïhrt haben und, wenn sie als Zupfpräparat isoliert 
worden wären, wohl als Aneurysmen gedeutet worden wären, habe ich in diesem Falle seltener gefunden, ganz im Einklang mit der Literatur über diesen Gegenstand, in der ja deren Vorkommen auch als recht wechselnd geschildert wird. Das Wesentliche ist zweifellos die Nekrose der Arterienwand. Die Auftreibung und Verbildung derselben, die als Aneurysmen beschrieben wurden, sind ein mehr nebensächliches und zufälliges Ereignis.

Noch ist über die kleineren Blutergüsse der Wand des apoplektischen Herdes ein Wort zu sagen. Nach der Schulmeinung sind sie Nebeneffekte der großen Blutung und durch Kreislaufstörungen, veranlaßt durch jene, zu erklären. Nun präsentiert sich ein großer Teil der kleinsten Blutergüsse hier als Ringblutung, körperlich gedacht, also als kugelschalenförmige Blutung, in deren Mitte das Gewebe eine regressive Metamorphose durchgemacht hat. Es enthält keine Gliakerne, die Gliafaserung ist nicht erkennbar und ist oft von Fibrin durchsetzt. Dazu kommt, daß auch im Bereiche dieser kleinsten Blutungen markhaltige Nervenfasem nur sehr spärlich zu finden sind. Auch das im Zentrum öfter nachweisbare Gefäß, meist eine Kapillare, vielleicht auch eine kleine Vene, ist stets verändert, die Wand schwer erkennbar und die Endothelkerne nur andeutungsweise gefärbt.

Die größeren Blutungen dieser Zone sind von ganz unregelmäßiger Gestalt und lassen innerhalb ihres Bereiches kein Gewebe mehr erkennen, wenn sie nicht eine Arterie enthalten. Aber diese ist fast immer leichter oder schwerer verändert, und zwar immer in der beschriebenen Weise. Daraus erhellt zur Genüge, daß alle diese Blutungen nicht lediglich mechanische Entstehungsursachen haben, sondern daß sie durch denselben Prozeß bedingt sind, wie der Schlaganfall überhaupt.

Es sei aber noch einmal hervorgehoben, daß das Gewebe zwischen diesen Blutungen keineswegs unverändert ist, daß vielmehr Zeichen der Degeneration in Zerfall der Achsenzylinder wie der Markscheiden und Unkenntlichwerden des Glianetzes nachweisbar sind. Nimmt man nun hinzu, daß die Blutergüsse um die schwer veränderten Arterien herum vielfach nur ganz gering sind, so exkennt man, daß die Ergießung von Blut, der man bisher hauptsächlich Beachtung geschenkt hat, überhaupt das Wesen des Prozesses nicht erschöpft. Ebenso wenig kann die Erkrankung der Arterien der allein wichtige Vorgang sein. Offenbar erkrankt vielmehr das Gewebe als ganzes. Alles, Stützgerüst, wie nervöse Substanz und der ganze gefäßführende Apparat, erkrankt mit einem Male, und da, wo die Blutungen, große oder kleine, auftreten, ist 
sicherlich die Masse der Kapillaren vernichtet. Es spricht nichts dafür, daß die Hauptmenge des Blutes aus den Arterien stammen müßte.

Es war zu erwarten, daß in einem Falle, in dem das Leben den Insult drei Tage überdauerte, schon Erscheinungen der Realktion am Gewebe der Herdwand nachweisbar sein würden. Indessen fanden sich Zeichen der Wucherung an den geschädigten Arterien nur selten vor. Intensiver als bei ganz frischen Blutungen, am schwersten um nekrotische Gefäßwandreste, war die Infiltration mit Rundzellen. : Leukozyten fanden sich auch sonst in Nestern von 10-30 Stück im Gewebe der Wand des großen Herdes, ohne daß sich in ihnen immer ein Gefäßrest nachweisen ließ. Sie konnten den Gedanken an einen bakteriell bedingten Prozeß erwecken. Indessen ließen sich mit Methylenblaufärbung derartige Mikŗoorganismen nicht entdecken. Schließlich seien noch die Vorgänge erwähnt, die sich an den Gliazellen der Herdwand fanden. Sie bestanden wesentlich in Zunahme des Protoplasma der kleinen Gliaelemente, wie sie auch schon in den ganz frischen Fällen zu beobachten war.

\section{Achte Beobachtung. 3 Tage alte Blutung.}

Frau B., 66 Jahre alt. Wird am 5. XII. 1916 in benommenem Zustand eingeliefert, nachdem sie vormittags plötzlich mit rechtsseitiger Lähmung vom Stuhl gefallen war. Vorher war sie gesund. Bald trat völlige Bewußtlosigkeit und am 8. XII. der Tod ein.

Die Sektion ergab geringe Arteriosklerose hie und da an den Gefäßen der Hirnbasis. Die Aorta fast frei. Geringe Sklerose an Kranzarterien. Die linke Herzkammer kaum verdickt. Schrumpfniere.

Die Untersuchung des gehärteten Gehirnes ließ an Frontalschnitten folgendes erkennen. Der apoplektische Herd hat seine größte Ausdehnung in dem linken Stirnhirn in der Gegend, wo der vordere Schenkel der inneren Kapsel anfängt den Streifenhügel zu durchbrechen. Lateral von diesem Schenkel ist von der grauen Substanz nur der basale Teil des Streifenhügels erhalten. Dorsal ist der vordere Kapselschenkel durchbrochen und der Ventrikel eröffnet. Hièr wölben sich blutige Massen in das Seitenhorn hinein, das aber nur wenig erweitert ist. Da an den Schnitten das Septum pellucidum erhalten ist, so läBt sich feststellen, daß dieser Abschnitt des Vorderhornes, der zwischen jenem Septum und Schwanzkern liegt, frei von Blut und kaum erweitert ist. Lateral reicht der Herd bis zu dem Markweiß der Insel und an der lateralen Grenze seiner ventralen Ausdehnung springt er bis in das Rindengrau der Insel hinein. Dorsal besonders, wo der Herd den Bezirk der Ausstrahlung der Balkenfasern nicht ganz erreicht, ist er von einer am Pal-Präparat aufgehellten Schicht bedeckt und übrigens fast überall von einem Saume umgeben, in dem zahlreiche kleine Blutungen im Gewebe liegen. 
Wenig weiter kaudal, in der Ebene der vorderen Kommissur, ist der Ventrikelboden unversehrt, wenngleich die Blutung vielfach bis an das Ependym heranreicht. Auch weiter kaudal bleibt die Blutung bis zu ihrem Ende in der Höhe des Pulvinar dicht unter dem Boden des Seitenhornes und breitet sich von da spaltförmig, das äußere Linsenkernglied zerstörend, nach der ventralen Seite aus. Auch hier liegen noch zahlreiche kleinere Blutungen in der Umgebung des Hauptherdes.

Nur an dem hinteren Pol der Blutung findet sich im Gebiete des kaudalsten Abschnittes des Linsenkernes ein Bild, das mikroskopisch der Vorstellung entsprechen würde, wonach der Inhalt des apoplektischen Herdes einen blutigen Hirnbrei darstellt. Hier findet sich nämlich zwischen den roten Blutzellen eine Menge von Marksubstanz, die zum weitaus größeren Teil von den Wandungen aus in den blutigen Herd in Form von dünneren und dickeren Fasern eintaucht, zum Teil aber auch ohne jeden Zusammenhang mit der umgebenden Markmasse inselartig in dem Blute zu liegen scheint. Manche dieser Fasern sind gut erhalten und gefärbt,. andere flaschen- und keulenförmig aufgetrieben oder tropfig zerfallen. Bei einer Minderheit hat die Färbung deutlich abgenommen.

In mehreren der großen Übersịchtsschnitte dieser Gegend finden sich gröbere Arterien innerhalb des blutigen Herdes, die einen mehr oder weniger stark veränderten Eindruck machen. Meist ist die Wandschichtung undeutlicher geworden. Leukozytenansammlung findet sich spärlich in den Wandungen, reichlicher in der Lichtung. Sehnitte, die die größte Ausdehnung des Blutherdes fassen, enthalten in dessen zentralen Teilen keine Gefäße. Wohl aber finden sich in den Randschichten des apoplektischen Herdes solche, die durchweg einen schwer degenerierten Eindruck machen. Manchmal sind sie nur an ihrer Form und an etwa sich abzweigenden Ästen zu erkennen, während das Gewebe ganz oder teilweise nekrotisch und kernlos geworden ist. Außerhalb des Gebietes der Apoplexie ist dagegen das Gefäßsystem durchaus frei von schwereren Veränderungen. Speziell die Äste der Sylvischen Schlagader, die an den Übersichtsschnitten gut geprüft werden können, weisen nirgends erhebliche Veränderungen von Sklerose auf.

Auch von Nervengewebe ist in den zentralen Teilen der Blutung nichts auffindbar.

Wie erwähnt, wird die große Blutung von einer Gewebschicht umgeben, die am gefärbten und ungefärbten Präparat einen lichteren Eindruck macht, in dem sich meist zahlreiche kleine Blutungen finden. In dieser Zone finden sich auch in den nicht blutigen Partien massenhaft die Zeichen des Unterganges nervöser Elemente, zerfallende Markscheiden und gequollene Achsenzylinder, daneben auch einkernige runde Zellen mit reichlicherem, azidophilem Protoplasma, als es den kleinen Gliazellen normalerweise zukommt. Die kleinen Blutungen gehen auch hie und da noch über diese Zone hinaus in ein Gebiet, dessen Elemente weniger geschädigt scheinen.

Ein großer Teil dieser kleinen Blutungen sind nun Ringblutungen. In ihnen ist meist ein kleines Gefäß vorhanden, dessen Wandung sich von

Defutsche Zeitschrift f. Nervenheilkunde. Bd. 61. 
der Umgebung nicht mehr scharf abhebt. Die Umgebung des Gefäßes färbt sich nach van Gieson rot und läßt kaum noch Strukturen normalen Gewebes erkennen. Am Markscheidenpräparat fällt eine ausgesprochene Verminderung der Nervenfasern nicht nur in den Zentren der Ringblutungen, sondern auch zwischen den roten Blutzellen selbst auf. Auch die Schnitte, welche größere Blutungen als diese flohstichartigen enthalten, sind häufig fein genug, um den Schwund von Markfasern auch hier mit voller Sicherheit feststellen zu können.

Auch in denjenigen Blutungen, die größer als die Ringblutungen sind, finden sich vielfach schwer veränderte Gefäße. Interessant ist eine Reihe von Schnitten, die eine etwas über erbsengroße gesonderte Blutung umfaßt. Eine kleine längsgeschnittene Arterie tritt in sie ein, deren Adventitia in dem umgebenden Blute nicht mehr sicher erkennnbar und deren mittlere Haut verquollen ist. Auch die Muskelkerne sind nicht mehr gut zu unterscheiden. Das Endothel ist zwar meist noch erkennbar, aber von der mittleren Haut durch Wanderzellen abgehoben. Diese Arterie spaltet sich nun in den folgenden Schnitten in mehrere Äste, von denen zwei benachbarte $z u$ je einem aneurysmenartigen Gebilde in Beziehung treten. Die Einmündung der Äste in je ein rundliches Gebilde und der stetige Übergang der noch leidlich erhaltenen Wand der zuführenden Arteriolen in eine vollkommen nekrotische, stark gequollene, kernlose Wandung ist zweifelfrei erkennbar. Diese aneurysmenartigen Bildungen umschließen Blut oder auch thrombenartigen Inhalt. Weitere Schnitte fassen nur noch die gequollene Wand, in der niemand, der dieses Gebilde für sich betrachten würde, die ehemalige Arterie wiedererkennen würde (s. Fig. 13 und 14).

Faserstoff läßt sich an den entsprechend gefärbten Präparaten innerhalb der kleinen Blutungen fast gar nicht nachweisen. Nur inmitten der Ringblutungen bleibt in der Umgebung des zentralen Gefäßes eine Zone, die Fibrinfärbung angenommen hat, ohne daß sich sicher entscheiden ließe, ob hier wirklich Fibrin oder Reste von Gliafasern vorliegen.

Auch zwischen den kleinen Blutungen findet man nicht selten kleine Gefäße, die äbnliche Veränderungen aufweisen wie die in den Blutungen selbst gelegenen. Ihre Wandungen sind verquollen, die einzelnen Elemente nicht mehr unterscheidbar. Die Elastika ist am Orceinpräparat nicht mehr nachweisbar und zellige Infiltrate durchsetzen die Wand.

Schnitte in Flemmingscher Lösung fixierter Stücke lassen oft im Gewebe zwischen den Blutungen Zellen erkennen, die reichlich kleine Marktrümmer enthaiten, während solche innerhalb der kleinen Blutungen nur selten erkennbar sind.

Sieht man von dem hinteren Pol der Blutung ab, wo der Übergang des apoplektischen Herdes gegen das gesunde Gewebe durch eine Mischung von Blut und Nervensubstanz gebildet wird, die an der Umgebung noch ziemlich festhaftet, so ist an allen anderen Stellen der blutige Herd von dem umgebenden Hirngewebe losgelöst. Wie schon die Durchschnitte des gehärteten Organes und besser die Schnitte erkennen lassen, werden Inhalt und Wand des Herdes überall durch einen Spalt von 1-2 $\mathrm{mm}$ Breite ge- 
schieden. Die Wand dieses Herdes, von blutigem oder auch nicht blutigem Gewebe gebildet, ist fast durchweg glatt und nus. selten ragen aus ihr zottige Vorsprünge gegen den Inhalt hin.

\section{Zusammenfassung und Beurteilung.}

Bei einer 66jährigen Frau, die an Schrumpfniere litt, war eine Blutung in das linke Stimhirn eingetreten, die den Tod innerhalb von 3 Tagen herbeiführte. Sklerotische Veränderungen an den Arterien waren nur in geringem Maße nachweisbar.

Der apoplektische Herd von rundlicher Form hatte seine größte Ausdehnung im linken Stirnhirn lateral vom Streifenhügel und verbreiterte sich von da bis in die Inselwindungen. Ein Teil des vorderen Schenkels der inneren Kapsel, ein Teil des Linsenkernes, äußere Kapsel, Vormauer und Capsula externa waren durch die Blutung zerstört. Nimmt man an, daß die Zerstörung so zustande kam, daß eine grobe Arterie riß, das austretende Blut einen Spalt wühlte und erweiterte, so wird man den Befund schwerlich erklären können. Man wird nicht annehmen, daß ausströmendes Blut das Gewebe wie ein durchfahrendes Messer trennt, sondern man würde erwarten, daß noch zahlreiche Brücken von Gewebsresten, sei es von Faserbündeln, sei es von derberen Gefäßen, stehen geblieben seien. Davon ist fast nichtsnachweisbar. Die Trennung von Gewebe der Herdwand und blutigem Inhalt ist fast überall so vollkommen, daß am fertigen Präparat meist ein Spalt von $1-2 \mathrm{~mm}$ zwischen beiden bleibt. Die Wand der apoplektischen. Höhle ist meist von auffallend glatter Beschaffenheit. Nur an dem hinteren Pol der Blutung liegt eine Mischung von Nervensubstanz und Blut vor; so daß hier das vorliegende Walten mechanischer Kräfte wahrscheinlich ist.

Weiter ist für die genannte mechanische Erklärung auffällig, daß wohl ein Einbruch in das Seitenhorn, eine größere Blutung in das Höhlensystem des Hirnes aber nicht stattgefunden hat, wie bei dieser Deutung eigentlich zu erwarten.

Hauptsächlich widerstreitet ihr aber der Umstand, daß von allen den zerstörten Bildungen, den Kapseln, soweit sie im Bereiche der Blutung liegen, Linsenkem und Vormauer nichts nachweisbar ist, während man sie, wenn auch vielleicht erheblich verdrängt und von ihren Verbindungen losgelöst, zu erwarten hätte.

Es ist somit fraglos, daß man mit der Annahme, das aus einer oder 
einigen zerrissenen groben Arterien ausströmende Blut habe den ganzen apoplektischen Herd geschaffen, nicht auskommen kann.

Die Annahme, daß der Herd aus zahlreichen kleinen Blutungen zusammengeflossen sei, ist mit dem Ausbleiben einer starken Ventrikelblutung eher vereinbar. Aber auch dann entsteht die Frage, was aus dem zweifellos untergegangenen Gewebe geworden ist. In dem kaudalen Abschnitte des Herdes ist es vorwiegend mechanisch geschädigt, aber doch vorhanden. In den inneren Partien der Blutung aber ist es überhaupt nicht nachweisbar. So drängt sich von selbst der Gedanke auf, daß das Gewebe hier eine ähnliche Veränderung durchgemacht hat, wie sie an den Arterien auch in diesem Falle nachweisbar ist, Veränderungen, die zur völligen Nekrose, zum Untergang und Unkenntlichwerden des Gefäßes führen.

Auch in diesem Falle ist der apoplektisshe Herd von einem Saume umgeben, innerhalb dessen das Gewebe entweder lichter gefärbt oder mit kleineren Blutungen durchsetzt ist. Diese kleinen Blutungen sind wesensgleich der großen Hauptblutung, denn in ihnen sind die nämlichen schweren Arteriendegenerationen nachweisbar, wie sie in den Schlagadern des großen Herdes nachgewiesen wurden. Selbst an kleinen Arterien dieses Saumes, zwischen den kleinen Blutungen ohne direkte Beziehung zu den Blutaustritten, finden sich nekrotische Umwandlungen, Verquellung der Wand, Schwund der Kerne und der Elastika, thrombenartiger Inhalt. Im Zentrum der kleinsten und der ringförmigen Blutungen, wo gröbere Gefäße fehlen, tritt dagegen mehr die Nekrose des Gewebes in die Erscheinung.

Entsprechend diesen schweren Schädigungen des Gewebes, sind auch schon die Zeichen der Reaktion von seiten der Gliazellen in dieser Schicht deutlich.

\section{Neunte Beobachtung. 7 Tage alte Blutung.}

Balthasar N., Ökonomiehandwerker, $38 \mathrm{Jahr}$ alt. Aufgenommen 6. II. 1915, $\dagger$ den 18. VII. 1915. Vor 15 Jahren machte er eine Lungenentzündung durch. Seit 8-14 Tagen fühlt er sich matt, hat Kopfweh, Reißen in den Gliedern, Brechreiz und ist schon länger appetitlos.

Befund: Magerkeit und blasse Schleimhäute. Spitzenstoß im 5. Zwischenrippenraum und etwas außerhalb der Brustwarzenlinie, hebend. Der erste Ton an der Spitze nicht ganz rein, der zweite Aortenton akzentuiert. Puls regelmäBig und hart. Blutdruck über $200 \mathrm{~mm} \mathrm{Hg}$. Im Urin Eiweiß, im Sediment rote Blutkörperchen und vereinzelte hyaline und körnige Zylinder. Augenhintergrund nicht zu ïbersehen wegen älterer Hornhauttrübungen. 
In der Nacht vom 11. auf den 12. VII. wurde er unruhig und bald völlig benommen. Bei der Morgenvisite liegt er völlig reaktionslos da. Die linksseitigen Extremitäten werden bewegt, die rechtsseitigen nicht. Hier erfolgt auch auf Nadelstiche keine Reaktion. Schnarchende Atmung und reaktionslose Pupillen.

Das Bewußtsein hellte sich nicht wieder auf und am 18. VII. trat der Tod ein.

Bei der am selben Tage ausgeführten Sektion fand sich das Gehirn voluminös, die weiche Haut ödematös mit weißlichen Verdickungen. Die Gefäße an der Basis durchweg zart. Bei der Herausnahme schlüpfte aus dem linken Schläfenlappen, dessen Rinde an umschriebener Stelle eine blutige Erweichung zeigte, ein rundliches, etwa walnußgroßes Blutkoagulum. Das Gehirn wurde injiziert und im ganzen gehärtet.

Im Fettgewebe des Herzens zahlreiche kleine Blutungen. Der linke Ventrikel stark verdickt, der rechte weniger. Die Klappen zart. In der Intima der aufsteigenden Aorta nur geringe gelbe Fleckung.

Die Nieren kaum verkleinert. Kapsel ohne Substanzverlust abziehbar. Auf der Oberfläche zahlreiche ältere und frische kleine Blutungen. Die Rinde stellenweise auf dem Durchschnitt nur 2-3 mm breit. In der Schleimhaut des Nierenbeckens beiderseits blutige Infiltrate.

Diagnose: Schlaganfall mit Blutung im linken Schläfenlappen. Chronische hämorrhagische Nierenentzündung mit Hypertrophie des linken Ventrikels.

Das aus dem apoplektischen Herd stammende Blutgerinnsel wurde zum Teil zu frischen Zupfpräparaten verarbeitet, in denen sich nur selten ein kleines Gefäß isolieren ließ. Manchmal war die Lymphscheide eines solchen durch Blutungen abgehoben, so daß die oft beschriebenen Bilder entstanden.

Auf frontalen Ubersichtsschnitten durch das linke Großhirn zeigt sich, daß der apoplektische Herd fast durch den ganzen Schläfenlappen und noch in den angrenzenden Hinterhauptslappen sich erstreckt. Dabei ist das Mark sämtlicher Schläfenwindungen zu einem großen Teil zerstört. Medial reicht er bis in die laterale Wand des Unterhornes, ohne in dieses durchzubrechen. Ebenso tritt er hier in die Nähe des äußeren Linsenkerngliedes und hier werden im Marke der Inselwindung einige kleine Erweichsherde sichtbar, die nicht blutig sind.

Der wichtigste Befund, der sich aus diesen Übersichtsschnitten ersehen läßt, ist, daß die Blutung oder die durch sie entstandene Höhle überall noch von einer Zone umgeben ist, die am Pal-Präparat viel lichter gefärbt ist als die weitere normale Umgebung. Diese Zone ist an manchen Stellen nur angedeutet, an den meisten aber mehrere, bis $6 \mathrm{~mm}$ breit (siehe Fig. 18).

Innerhalb derselben sind die markhaltigen Nervenfasern nur ganz blaß gefärbt und vielfach tropfig entartet. Kernfärbungen zeigen die Gefäße kernreich und zwar auch infolge von Vermehrung der fixen Elemente. In dieser Schicht sind punktförmige Blutungen häufig, meist kompakt, selten in Ringform. In den letzteren kann man dann eine Ver- 
mehrung der Gliakerne erkennen. Selten finden sich auch kleine leicht hämorrhagische zellige Knötchen.

Feine Schnitte durch die Herdwand enthalten zahlreiche Gefäße, deren Wand homogen verquollen ist, während die Kerne der inneren oder Muskelhaut nur stellenweise färbbar sind. Die Adventitia kann durch Blutung abgehoben oder überhaupt unerkennbar sein.

In den Präparaten 1-16 ist ein Teil des der Herdwand anhaftenden Blutergusses erhalten und gerade in ihm tritt eine längsgeschnittene kleine, schwer veränderte Arterie hervor, die sich in verschiedenen Schnitten mit verschiedener Färbung untersuchen ließ. Sie ist in der Fig. 15 und 16 wiedergegeben und beide lassen die Umwandlung der Wand und die teilweise

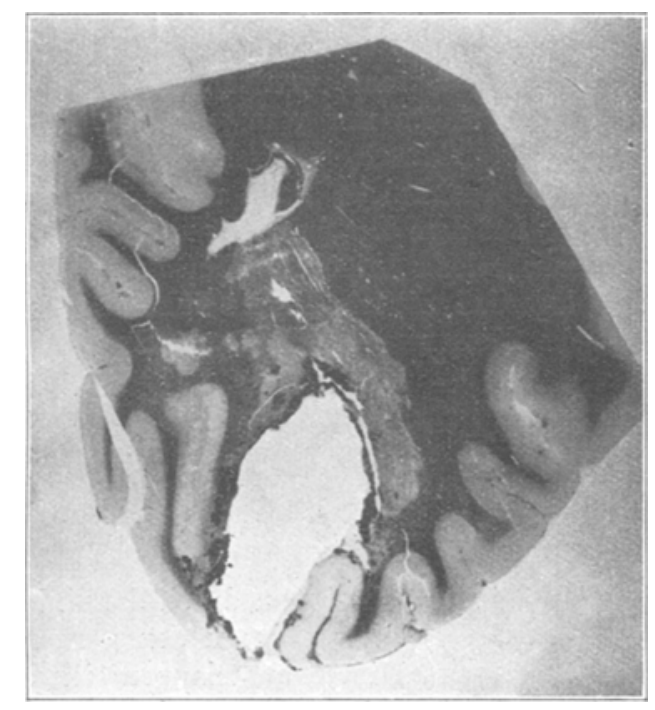

Fig. 18.

Zerstörung der Elastika gut erkennen. Von reaktiven Veränderungen ist an diesem Gefäße nichts zu entdecken. Hier sowohl wie an anderen Schnitten hatte die Gefäßwand öfter einen solchen Glanz, daß ich den Verdacht hegte, es könne Amyloidentartung mit im Spiele sein. Er bestätigte sich aber nicht. Jodreaktion war nicht zu erhalten.

Besonders lehrreich sind auch die Schnitte 60-69, die den vordersten Pol der Blutung fassen. In ihnen finden sich zahlreiche schwer degenerierte Gefäße. Darunter fällt ein großes auf von runder Form, dessen Durchmesser etwas mehr als $0,1 \mathrm{~mm}$ mißt. Die Wand ist bis zur Unkenntlichkeit an den meisten. Stellen verändert und präsentiert sich meist als aufgefasertes streifig-körniges Band, zwischen dessen einzelnen Lamellen rote und weiße Blutkörperchen liegen, während von Gewebskernen nur hie und da etwas zu erkennen ist. Der Charakter des in einen kleinen Bluterguß eingebetteten 
Gebildes könnte fraglich bleiben, wenn nicht für seine Gefäßnatur ein an drei benachbarten Schnitten zu beobachtendes längsgeschnittenes Gefä. $\beta$ spräche, das aus jenem entspringt und dessen Wand in die des beschriebenen Gebildes eingeht. Der Durchmesser dieses längsgeschnittenen Gefäßes beträgt nur etwa den fünften Teil des größeren. Auch sein Gefäßcharakter könnte bei dem Mangel deutlicher Gewebselemente zweifelhaft sein, wenn er nicht aus der ganzen Form des Gebildes und seinen Verzweigungen, die an einem Präparate typisch sind, erhellte. Das größere Gebilde kann nun entweder eine entartete Arterie sein, die vor ihrer Erkrankung annähernd dieselben Dimensionen hatte, oder sie kann einem durch die Erkrankung stark erweiterten Gefäßabschnitt entsprechen.

In den Schnitten dieser Region, dem vorderen Pol der großen Blutung, haben die kleinen Blutungen, die zahlreich in der Herdwand liegen, öfter den Charakter der Ringblutung. Hie und da enthalten sie ein degeneriertes, manchmal nur noch schwer zu erkennendes Gefäß im Innern. Nicht selten erkennt man auch in diesem Zentrum eine zellige Wucherung.

Solche Befunde bilden den Übergang zu kleinen, ebenfalls rundlichen Herden, in denen das Blut ganz zurücktritt und die sich lediglich aus Zellen zusammensetzen. Sie sind schon mit der Lupe kenntlich. Stärkere Vergrößerung zeigt, daß die Zellen große protoplasmareiche Elemente sind. Hie und da liegen zwischen diesen Zellen feine Tröpfchen und Körnchen, die sich mit Hämatoxylin lebhaft färben. Die feinsten erinnern an Mikrokokken, lassen sich aber davon unterscheiden, da sie weder die Anordnung dieser, noch die Gleichmäßigkeit des Kornes haben. Verglichen mit den zahlreichen kleinen Blutungen finden sich die ganz oder vorwiegend zelligen Knötchen nur selten.

Das zwischen diesen kleinen Blutungen liegende Gewebe ist auch, abgesehen von den erwähnten Gefäßerkrankungen, nicht frei von erheblichen Veränderungen. Einmal finden sich vielfach herdförmige Zonen, innerhalb deren das Gewebe fast völlig seine Struktur verloren hat. Weder Nervenfasern, noch Kerne, noch Kapillaren, noch Glia sind erkennbar. Diese Gebiete färben sich blaß mit den sauren Farbstoffen. Dann ist ziemlich gleichmäßig eine Zellwucherung vorhanden, die zur Bildung protoplasmareicher Gliazellen geführt hat. Sie gleichen den Elementen innerhalb der Ringblutungen und in den zelligen Knötchen. Vielfach finden sich Körnchenzellen. Sie sind ziemlich gleichmäßig durch diese Gewebszone verbreitet und zeigen keine besondere Anhäufung um die Gefäße herum. Ferner spielen sich an den Gefäßen, soweit sie nicht nekrotisch sind, lebhafte Wucherungsvorgänge ab. Die Wandungen lassen die ursprüngliche Struktur kaum noch erkennen. Die Wand wird vielmehr gebildet durch dichtliegende, große, protoplasmareiche, ovale Zellen, die meist mehrschichtig die Gefäßwand bilden. In diesen Zellen findet sich nicht ganz selten eine Mitose. Daneben werden die Kerne von Wanderzellen ziemlich spärlich sichtbar und weiter Zellen, in deren Leib Trümmer von Blutkörperchen eingeschlossen sind. Dazwischen finden sich Tropfen von verschiedener Größe, mit Kernfarbstoffen intensiv gefärbt, zum Teil in Zellen eingeschlossen, an denen dann kein Kern mehr erkennbar ist. 
Sie können nur als Reste zerfallender Kerne gedeutet werden. Sie sind in ähnlicher Weise auch in dem Gewebe der Herdwand zu sehen, wie ich sie ja auch schon innerhalb der zelligen Knötchen erwähnt habe. Auch an soliden GefäBsprossen fehlt es nicht.

Die Gliafaserung ist in dieser. Zone bei den gewöhnlichen Doppelfärbungen nur undeutlich wahrzunehmen. Ebenso finden sich auch nur selten Reste von Achsenzylindern. Daß die Markscheiden hier schwer gelitten haben, habe ich schon erwähnt. Es sei noch hinzugefügt, daß die Zahl der markhaltigen Fasern, die durch die kleinen Blutungen ziehen, zweifellos geringer ist als in der Umgebung. Das wird besonders an Präparaten deutlich, die Blutungen auch etwas weiter von dem großen Herde enthalten, in einer Zone, in der die Markfaserung sonst keine schwerere Veränderung mehr aufweist (s. Fig. 17). Besonders kann man hier feststellen, daß in das nicht blutige zellige Zentrum der Ringblutungen nur ganz wenig feine, blasse Fäserchen eintauchen.

Von dem Blutkoagulum, das bei der Sektion aus dem apoplektischen Herde stürzte, wurden eine Anzahl Schnitte aufgelegt. Auch hier fanden sich nicht wenige solcher Gebilde, die mit einiger Sicherheit als nekrotische Gefäßreste gedeutet werden konnten. Immer lagen in und um diese Gebilde reichlich Rundzellen. Im übrigen aber waren Gewebsreste nur sehr spärlich anzutreffen. Besonders waren Kerne, wenn man in Betracht zieht, daß ja durch das ergossene Blut selbst kernhaltige Zellen geliefert werden mußten, lange nicht so reichlich anzutreffen, wie man sie in einem mechanisch zertrümmerten Nervengewebe erwarten sollte. Ebenso fehlen meist Marktrümmer. Diese allerdings keineswegs ganz. Hie und da finden sich nämlich ziemlich dichte Haufen von Marktropfen, alle annähernd von gleicher Größe und von ganz auffallender blasser Färbung. Nirgends aber fand ich Bilder, die auf eine nur mechanische Zertrümmerung der Fasern hinwiesen.

Es ist wichtig, diesen Befund zu vergleichen mit dem, den die großen Übersichtsschnitte bieten. Sie liegen aus drei verschiedenen Ebenen, der vorderen, der mittleren und der hinteren Partie des großen Blutergusses vor und gestatten somit wohl ein Urteil über die ganze Zerstörung, der diese Hirnpartie ausgesetzt war. Man sieht, daß nahezu das ganze Mark des Schläfenlappens ausgefallen ist. Man fragt sich, was daraus geworden ist. Die Blutung hat nicht etwa einen Riß geschaffen und nur das Gewebe zur Seite gedrängt. Ein Blick auf die Schnitte schließt das aus. Es liegt auch nicht etwa ein blutiger Hirnbrei vor, in dem Nervensubstanz und Blut mehr oder weniger innig gemischt wäre. Das ist mikroskopisch leicht festzustellen. Nur spärliche, schwer erkenubare Reste von Gefäßen und Nervenfasern liegen in der Blutung und sicher sind sie nur in den peripherischen Gebieten der Blutung zu finden. Somit ist kein Zweifel möglich: die Hirnsubstanz im Bereiche der Blutung ist so verändert, daß sie sich dem Nachweis mit den mikroskopischen Hilfsmitteln entzieht.

An den großen Übersichtsschnitten kann man sich auch am besten ein Urteil über die Bedeutung bilden, die der Arteriosklerose im vor- 
liegenden Falle zukommt. Sie ist gering. Man muß ziemlich lange suchen, um Arterien mit deutlich verdickter Intima zu finden.

Bei der Zerlegung der rechten Hemisphäre fand sich im Linsenkern eine kleine Blutung, die auf dem Frontalschnitt nur einige Millimeter Ausdehnung hat und in sagittaler Richtung etwa $1 \mathrm{~cm}$ erreicht. Mikroskopisch erweist sich der Herd als eine ältere Erweichung mit reichlichem braunem, zum Teil in Zellen eingeschlossenem Blutpigment, mit deutlichem faserigem Gliagerüst und sehr zahlreichen kleinen Gefäßchen, deren Wand keine Einzelheit mehr erkennen läßt, sich aber diffus und intensiv mit Hämatoxylin gefärbt hat. Sie sind offenbar verkalkt.

Von der Niere brauche ich für den vorliegenden Zweck nur zu erwähnen, daß sie auch mikroskopisch das ausgesprochene Bild der Schrumpfniere gibt. Es finden sich Schrumpfungszüge, die von der Kapsel tief in die Rinde hineinziehen und zahlreiche verödete Glomeruli enthalten. In den Harnkanälchen liegen vielfach Haufen von Erythrozyten und Zylinder. Die gröberen Arterienstämmchen an der Grenze von Rinde und Marksubstanz weisen alle eine ziemlich hochgradige Sklerose mit starker Verdickung der Innenhaut auf.

\section{Zusammenfassung und Beurteilung.}

Der vorstehende Fall, einen 38jährigen Mann betreffend, der einen Schlaganfall 7 Tage überlebte, ist nach mehreren Richtungen von Interesse. Die Nieren wiesen neben anderen schweren Veränderungen eine ziemlich hochgradige Sklerose der Arterien auf. Dahingegen war die Aorta nur sehr wenig verändert und die Gefäße an der Hirnbasis durchaus zart. Ebenso ließ sich auch mikroskopisch an den intrazerebralen Arterien nur ganz wenig von sklerotischen Veränderungen finden. Die schweren Degenerationen, welche sich in Gestalt von Homogenisierung der Arterienwandungen unter Verschwinden der Wandelemente, von körniger Entartung und völliger Nekrose, wahrscheinlich auch von Ausweitung der degenerierten Arterien zu aneurysmenähnlichen Bildungen im ganzen Bereiche der Blutung nachweisen ließen, konnten also unmöglich mit Arteriosklerose in Zusammenhang gebracht werden. Ich kann mich mit diesem Hinweis begnügen und brauche auf die Gefäßnekrosen hier nicht näher einzugehen.

Eine Besonderheit bilden die Ringblutungen, die in der Wand des apoplektischen Herdes vielfach vorkommen. In ihrem Zentrum sind die Spuren des Zerfalles wie der reaktiven Wucherung sichtbar. Die kleinen, im Inneren meist sichtbaren Gefäße sind deutlich nekrotisch und ebenso sind die in die Blutung eintauchenden Nervenfasern vielfach zerfallen. Daneben aber enthalten die Ringblutungen auch oft einen Kern von zelligen Elementen, augenscheinlich gewucherten Gliazellen, 
denen gegenüber hie und da die Blutung ganz zurücktreten kann. Augenscheinlich sind Blutung wie zellige Wucherung auf dieselbe Schädlichkeit zurückzuführen, die auch die große Hämorrhagie geschaffen hat.

Auf einen eigenartigen -Gewebszerfall lassen auch die kleinen areolären Zonen in der Herdwand schließen, innerhalb deren alles Gewebe geschwunden und zu einer homogenen Masse geworden ist.

Ein Zerfall des Gewebes muß auch im Gebiete der großen Blutung in entsprechendem Umfang angenommen werden. Das geht hervor aus dem Befunde, den die Utbersichtsschnitte durch den apoplektischen Herd an die Hand geben. Hätte ein aus einem durchrissenen Gefäß ausströmender Bluterguß fast das ganze Mark des Schläfenlappens samt einem Teile der Rinde mechanisch zertrümmert, so müßten diese Trümmer eben nachweisbar sein. Sie könnten auch nach 7 Tagen, der Zeit, die Patient den Insult überlebte, nicht spurlos verschwunden sein. Arterien, Venen und Kapillaren, Markfasem und Gliakerne, sollte man meinen, müßten in Massen nachweisbar sein. Wäre nicht das bei der Sektion aus dem Herde der Blutung ausschlüpfende Blutgerinnsel konserviert und untersucht worden, so könnte auch die Meinung auftauchen, dieses Koagulum hätte das sequestierte Mark des Schläfenlappens enthalten. Aber die Untersuchung zeigte auch hier, daß von Gewebe nur sehr wenig Reste vorhanden sind und daß diese durchaus andere Veränderungen tragen als solche, die auf mechanische Einwirkung zurückgeführt werden können. Die Gefäße, soweit sie überhaupt noch nachweisbar waren, waren nekrotisch und die spärlichen Reste von Markfasern bestanden in ziemlich gleichmäßigen Tropfen, die sich nur ganz blaß gefärbt hatten. Es bedurfte nur noch einer geringen Herabsetzung der Affinität dieser Tropfen zu Hämatoxylin und die Nachweisbarkeit dieses Nervenrestes war aufgehoben. Enthielt dieses Gerinnsel aber Gefäße und Nerven, dann mußte es natürlich auch Glia enthalten. An deren feineren Nachweis war in einem so schwer zu behandelnden $\mathrm{Ob}$ jekte nicht zu denken. Aber wenigstens die Kerne mußte man erwarten. Auch diese sind von den Lymphozytenkernen des ergossenen Blutes nicht mit Sicherheit zu unterscheiden. Aber soviel läßt sich sagen, daß die Zahl der Kerne überhaupt hinter der zurückbleibt, die in einem durchbluteten, sonst aber nur mechanisch veränderten Gewebe zu erwarten wäre. Alles drängt somit zu dem Schlusse, daß in dem großen Bluterguß große Teile der nervösen Substanz des Schläfenlappens untergegangen sind.

Daß sich dieser Untergang von Nervengewebe auch in den kleinen 
Ringblutungen der Herdwand zeigt (Fig. 17), habe ich eben erwähnt. Es sei aber noch darauf hingeweisen, daß fast die ganze Herdwand in einer Breite von mehreren Millimetern eine diffuse Veränderung zeigte, die sich schon makroskopisch in einer Aufhellung dieser Zone am Schnittpräparat, besonders bei Palscher Färbung, zeigte (Fig. 18). Auch hier kann an eine mechanische Schädigung nicht gedacht werden. Es liegt nicht ein einfaches Ödem vor, wie man wohl vermutet hat, man sieht auch keine Zeichen einer Quetschung. Es handelt sich vielmehr um einen gleichmäßig verbreiteten tropfigen Zerfall der Fasern und um eine Einbuße ihrer Färbbarkeit.

Man wird also nicht fehlgehen, wenn man hier das Wirken derselben Schädlichkeit iil gemildertem Grade sieht, die im Gebiete der großen Blutung mit größter Intensität angreifend das ganze Gewebe rapid zur. Nekrose brachte. In dieser Randzone dagegen blieben die nervösen Elemente vielfach erhalten, wenn auch nicht ungeschädigt. Ebenso starben die Gefäße nur stellenweise ab und waren fähig, einen. ausgedehnten Wucherungsprozeß einzuleiten.

Wie in der sechsten Beobachtung wahrscheinlich wurde, daß die große Kleinhirnblutung durch Zusammenfließen von zahlreichen kleinen und kleinsten Hämorrhagien zustande gekommen war, so ist auch hier der Gedanke naheliegend, $\mathrm{da}$ in dem großen Herde nur eine Summation unzähliger kleinster, wie sie in der Herdwand liegen, zu sehen ist.

Entsprechend dem Umstand, daB der apoplektische Insult das Leben 7 Tage bestehen ließ, sind in diesem Falle die reaktiven Erscheinungen des erhaltenen Gewebes in der Herdwand viel ausgesprochener als in den bisher beschrieben en Fällen. Die Gliazellen sind protoplasmareicher und enthalten viel Lipoide. Besónders kräftig ist an vielen kleinen Gefäßen die Wucherung der Zellen des Gefäßmantels zu erkennen und auch neugebildete Gefäßsprossen werden gegen den Blutergue vorgetrieben.

\section{Zehnte Beobachtung. 14 Tage alte Blatung.}

A. H., 60 jähriger Arbeiter. Aufgenommen den 30. IV., $\uparrow$ den 14. V. 1913. Früher gesund bis auf leichte rheumatische Schmerzen, die bei der Arbeit nicht beachtet wurden. Er stürzte bei der Arbeit plötzlich zusammen mit Lähmung der linksseitigen Extremitäten und konnte zunächst nicht sprechen.

Bei der Aufnahme kurze Zeit nachher ist er klar, gibt auf alle Fragen Auskunft, weiß, daß er einen Schlaganfall erlitten hat und klagt über Kopfweh. 
Bei der näheren Untersuchung am 1. V. besteht leichte Apathie. Fragen werden nicht immer zutreffend und nur zögernd beantwortet. Die Zunge wird gerade herausgestreckt. Lähmung des unteren linken Fazialis. Kein Verschlucken. Pupillen reagieren. Linksseitige alte Hornhauttrübung. Der Augenhintergrund hier nicht zu übersehen. Rechts keine Veränderung. Der linke Arm und linke Hand völlig gelähmt. Pat. kann sich mühsam ohne Unterstützung aufrichten. Das linke Bein ist nicht gelähmt, wird aber mit nur geringer Kraft bewegt. An der ganzen linken Körperseite werden Nadelstiche nicht empfunden.

Kniephänomen beiderseits vorhanden. Urin frei.

In den nächsten Tagen wurde Pat. teilnahmsloser, ließ Stuhl und Urin unter sich. Am 13. V. verschlechterte sich das Schlucken. Die Temperatur ging unter Schüttelfrost auf 40 C. hinauf. Am 14. V. Exitus.

Bei der am selben Tage ausgeführten Sektion fand sich das Schädeldach dick und mit der Dura verwachsen. Die Pia überall zart. Aus einer Verletzung der Rinde des rechten Scheitelläppchens sickert Blut und die ganze Partie fühlt sich weicher an. Die Arterien der Basis sind überall zart. Nur fleckweise am Abgang der A. cerebri media umschriebene Verdickungen. Beide Lungen emphysematös. Die rechte fest verwachsen. Der Unterlappen ödematös und schwer aber frei von pneumonischen Herdchen. In der rechten Spitze eine Narbe. Nirgends käsige Veränderungen. Der rechte Ventrikel hypertrophisch, der linke nicht. Am vorderen Mitralsegel eine kleine Wucherung. Die Aorta ascendens zeigt nur geringe fleckige, gelbe Verdickungen der Intima. Die Milz klein. Die Nieren nicht deutlich verkleinert. Die Kapsel schwer abziehbar. Die Rinde höckrig.

Anatomische Diagnose: Apoplexie mit Bluterguß im rechten Scheitelhirn. Lungenemphysem. Hypertrophie des rechten Ventrikels. Nephritis chronica.

Das Gehirn wurde injiziert und unzerlegt eingelegt. Die angefertigten Frontalschnitte ließen erkennen, daß der apoplektische Herd ungefähr das ganze untere Scheitelläppchen bis in den angrenzenden Hinterhauptslappen zerstört hat. Nach vorn erstreckt er sich am weitesten im Gebiete des Linsenkernes, dessen äußeres Glied fast in seinem ganzen Umfang zerstört ist. Die größte Ausdehnung hat der Herd in einer frontalen Ebene, die durch den hinteren Abschnitt des Sehbügels und die Kniehöcker geht. Hier ist die mediale Grenze der blutigen Erweichung durch die Reste des hier noch angeschnittenen äußeren Linsenkernes gebildet. Alles was lateral davon liegt, ist bis zur Rinde in die Zerstörung einbezogen. Das kann an dieser Stelle nicht allzu viel sein. Außer Stabkranzfasern der benachbarten Hirnteile, Capsula externa und Vormauer, kommt nicht viel in Betracht. Da die Einsenkung der Insel an diesen Schnitten fehlt und der transversale Durchmesser der apoplektischen Höhle fast $3 \mathrm{~cm}$ beträgt, so ist wohl anzunehmen, daß der Bluterguß die Inselwindung, die die äußere Begrenzung derselben bildet, stark nach außen gedrängt hat. 
Schnitte in der Ebene des Balkenwulstes fassen das hinterste Ende des Herdes.

Er ist hier als zapfenartig kaudalwärts vorspringender Fortsatz des großen Herdes nachweisbar, der sich aber an dieser Stelle nicht als blutige, sondern als weiße Erweichung darstellt, in die nur spärlich kleine Blutungen eingestreut sind. Gewebe ist darin wohl kaum noch erkennbar. Nur wenige Gefäße und durchziehende aufgequollene Markscheiden, aber dichtgedrängte Körnchenzellen sind in ihm nachweisbar. Die weitere Umgebung dieses zapfenförmigen Fortsatzes, etwa das ganze Gebiet des unteren Scheitellappens auf dem Frontalschnitt, ist zwar fast frei von Blutungen, aber das Gewebe durch Markzerfall vielfach gelichtet.

Die Übersichtsschnitte geben einen guten Überblick über die Verbreitung sklerotischer Veränderungen an den Arterien. Sie ist im allgemeinen gering. Nur selten findet man ein Gefäß mit Verdickung der Intima, die dann allerdings hochgradig sein kann.

Im übrigen sind die Veränderungen an den Gefäßen zweifacher Art, progressiver und regressiver. Die letzteren Veränderungen bieten ausgesprochen das Bild der Nekrose und finden sich nur innerhalb des Blutergüsses oder in der diesen unmittelbar begrenzenden Wandschicht, manchmal in Gewebszöttchen, die noch in die apoplektische Höhle hineinragen. Diese nekrotischen Gefäße sind nicht immer mit Sicherheit als solche zu erkennen, weil die Umwandlung, die sie durchmachten, eben alles Charakteristische vernichtet haben kann. Am schwersten sind oft mutmaßliche Querschnitte von Gefäßen zu deuten. Leichter kann man öfter in einem, wenn auch völlig kernlos gewordenen Gebilde das Gefäß wieder erkennen, wenn es auf dem Längsschnitt vorliegt und die Abzweigung von Seitenästen erkennen läßt. Solche Wandungen sind entweder homogen oder körnig und haben für die Farbstoffe wenig Affinität. Andere Gefäße lassen noch eine Andeutung ihres Baues erkennen. Sie haben noch ein streifiges Gefüge oder lassen hie und da Gewebskerne erkennen. In den ganz nekrotischen Gefäßen sah ich niemals frisches Blut. In minder schwer veränderten liegen hie und da gut erhaltene rote Blutzellen oder Leukozytenthromben. Die Infiltration mit Rundzellen ist meist nicht bedeutend.

In dem großen Bluterguß sind Reste von Markfasern nicht oft auffindbar. Wo man sie findet, da machen sie nicht den Eindruck von nur mechanisch geschädigten Fasern. So finde ich an einer Stelle in dem peripherischen Teile der Blutung ein längsgetroffenes Bündel von Nervenfasern, das als solches noch wohl erkennbar ist, aber aus sehr dünnen, sehr blaß̊ gefärbten Fäserchen besteht, wie sie ohne Beimischung von gröberen Fasern in der Marksubstanz des Gehirnes wohl nicht vorkommen. Dazwischen liegen blasse Marktröpfchen und Körnchenzellen, die durchweg nur kleine und blasse Tröpfchen enthalten.

Reichlicher finden sich Marktrümmer und Körnchenzellen in der innersten Schicht der Wand des großen Herdes, die sich schon makroskopisch am Pal-Präparat als kaum gefärbter Streifen von der Marksubstanz abhebt. Blutpigment findet sich in den Abraumzellen im ganzen nicht sehr häufig. 
Die Wucherung der Gefäße ist in dieser Schicht sehr rege: Die Wandungen bestehen meist aus einer mehrschichtigen Lage von spindelförmiger Gestalt. Hie und da enthalten sie Blutpigment, oder auch Markreste. Selten wird einmal eine Mitose sichtbar. In einem großen Teil dieser Zellzüge ist ein Lumen oder ein Inhalt nicht zu erkennen. Sie bilden offenbar solide Sprossen.

Der Zerfall des Nervenmarkes beschränkt sich nicht auf die unmittelbare Umgebung des blutigen Herdes, sondern macht sich noch etwas weiter in der Markschicht durch tropfigen Zerfall kenntlich.

Im Marke des Stirnhirnes zwischen Inselwindung und Kopf des Schwanzkernes fand sich noch eine isolierte, etwa linsenkerngroße blutige Erweichung.

In den Nieren fanden sich kleine Schrumpfungszïge, von der Kapsel aus sich in die Rinde senkend, die vielfach verödete Glomeruli umschlossen. Seltener fanden sich zellige Infiltrate in der Umgebung von Glomeruli. An den Nierenarterien sieht man vielfach eine mäBige Wucherung der Intima.

\section{Zusammenfassung und Beurteilung.}

Fin älterer Mann, der an chronischer Nierenentzündung litt, überlebte einen Schlaganfall 14 Tage. Lediglich im Bereiche des großen Herdes fanden sich ausgesprochene Gefäßveränderungen im Sinne der Nekrose. Während an den Gefäßen der Herdwand sehr lebhafte Zeichen der Wucherung sichtbar waren, fanden sich an jenen niemals progressive Veränderungen. Die Zerstörung der Wandelemente war oft so hochgradig, daß der Gefäßcharakter an Querschnitten nicht mehr mit Sicherheit erkannt werden konnte, während er an längsgeschnittenen Objekten noch öfter aus dem Gesamtbilde der Form und den Verzweigungen zu erschließen war. Blut hat in solchen hochgradig veränderten Gefäßen nicht mehr zirkuliert. Es fanden sich im Lumen immer nur entfärbte Erythozyten. Die Wand war dann homogen oder körnig und zeigte auch keine Rundzelleninfiltration. Diese war aber wohl an weniger schwer veränderten Arterien sichtbar, die noch ein streifiges Gefüge der Wand und hie und da Gewebskerne erkennen ließen. In solchen war auch öfter Thrombenbildung zu erkennen. Diese schweren Veränderungen irgendwie mit Arteriosklerose der Hirnarterien in Beziehung zu bringen, ist unmöglich. Dazu waren auch sicher sklerotische Gefäße viel zu selten anzutreffen.

Weiterhin ist von Interesse, daß hie und da in den Randschichten der Blutung Markreste auffindbar waren. Sie machten nicht den Eindruck mechanisch geschäaigten Gewebes. So fand ich ein Bündel Nervenfasern in die Blutung eingebettet, das sich fast ausschließlich 
aus nur sehr blaß nach Pal färbbaren Fäserchen zusammensetzte. Dazwischen lagen nur wenig, ebenfalls blaß gefärbte Marktropfen und Körnchenzellen mit blaß gefärbten feinen Markresten. Die Körnchenzellen fanden sich mit ähnlichem Inhalt auch spärlich in den Zellen der gewucherten Gefäßwände und reichlicher in der Herdwand.

Betrachtet man die frontalen Ubersichtsschnitte, so kommt man zu der Überzengung, daß in dem blutigen. Herde Nervengewebe zugrunde gegangen sein muß, besonders unter Einbuße von Substanz des Putamen und Stabkranzfaserung des Scheitellappens. Aber es ist auch nicht zu übersehen, daß die Größe des Herdes mechanisch durch austretendes, die Gewebe auseinanderdrängendes Blut mitbedingt wird. Vergleicht man einen Frontalschnitt, der durch das hintere Gebiet des Sehhïgels und die Kniehöcker geht, mit einem Normalschnitt, so sieht man sofort, daß die normalerweise sich hier tief medianwärts einsenkende Inselfurche fehlt. Sie kann nur auf das Niveau der Hirnoberfläche hinaufgedrängt sein, was nur durch den Druck des ausströmenden Blutes erklärt werden kann.

\section{Elfte Beobachtung. 15 Tage alte Blutung.}

Frau K., $58 \mathrm{Jahre}$ alt, a ufgenommen den 30. IX. 1914, $t$ den 13. X. 1914. Pat, war früher gesund und ist gestern plötzlich bewußtlos vom Stuhle gefallen. Mäßig tiefe Benommenheit. Augäpfel nach rechts gerichtet. Pupillen ziemlich eng, reagieren auf Licht. Die Nasen-Lippenfalte links flacher als rechts. Leichter Grad von Nackensteifigkeit. Die linksseitigen Extremitäten gelähmt, während die rechtsseitigen bewegt werden. Patellarreflex links gesteigert, Babinski links auslösbar. Herzstoß außerhalb der Brustwarzenlinie hebend. Erster Ton an der Spitze gespalten, der zweite Aortenton akzentuiert. Puls gespannt, regelmäßig, 60. Der Urin enthält Eiweiß und Zylinder.

Die Temperatur stieg schon nach den ersten Tagen gelegentlich über 38 C. und blieb vom 7. X. an dauernd zwischen 38 und 39 C. Dementsprechend wurde die Entwicklung einer Pneumonie im linken Unterlappen deutlich, die am 13. X. das Ende herbeiführte.

Bei der am selben Tage vorgenommenen Sektion wurde das Gehirn injiziert und im ganzen eingelegt. Es zeigte ausgesprochene Sklerose der basalen Arterien. Hypertrophie des linken Ventrikels. Leichte Sklerose an den Mitralsegeln, den Kranzartrien und der Aorta. Ausgedehnte Bronchopneumonie im rechten Unterlappen, weniger im linken. Schrumpfniere.

Bei der Zerlegung des Gehirnes und Untersuchung an Frontalschnitten fand sich in der rechten Hemisphäre ein etwa kleinapfelgroßer Blutherd, dessen größter Umfang in der Region des Stirnhirnes liegt, wo die Faserung des vorderen Schenkels der inneren Kapsel den Streifen- 
hügel durchbricht. Der lateralste Teil des äußeren Linsenkernes ist in die Blutung einbezogen. Lateral reicht diese bis in das Mark der Inselwindung. Ventral wird sie teils durch die vordere Kommissur, teils durch das Mark der Insel begrenzt. Dorsal grenzt sie sich in der Höhe des spaltförmig verengten Seitenventrikels ab und wird von den ausstrahlenden Balkenfasern umfaßt. Daraus geht also hervor, daß in die blutige Erweichung die nicht unbeträchtliche Markmasse eingegangen sein muß, die zwischen Streifenhügel und Insel einerseits, und zwischen vorderer Kommissur und den ausstrablenden Balkenfasern anderseits liegt.

Wenn hier also auch die ganze äußere Kapsel,.-Vormauer und Teile des Putamen vernichtet sind, so ist der ganze blutige Erweichungsherd doch viel größer, als der ausgefallenen Nervenmasse entspricht. $\mathrm{Er}$ hat in diesen Frontalschnitten runde Form mit etwa 2,5 cm Durchmesser. Daraus geht hervor, da ja normalerweise eine Schicht von solcher Mächtigkeit zwischen Putamen und Insel in diesen Ebenen nicht liegt, daß ausströmendes Blut den Herd vergrößert haben muß.

Immerhin war von der in die blutige Erweichung einbezogenen Masse der Hirnfasern noch einiges nachweisbar. Hie und da ist im Pal-Präparat, besonders in den Randschichten der Blutung, ein Faserbündel sichtbar. Es ist schwer verändert. Die meisten Fasern sind sehr fein und meist blaß, nur schattenhaft gefärbt. Andere, meist dickere Fasern haben sich noch gut gefärbt, zeigen aber tropfigen Zerfall. Kerne, die denen der Glia gleichen, sind in solchen Bündeln ziemlich reichlich zu finden.

Der apoplektische Herd wird meist umgeben von einer Zone von wechselnder Breite, in der Markfasern kaum noch auffindbar oder tropfig zerfallen sind und die dementsprechend am Pal-Präparat hell aussieht. Auch tiefer in das Gewebe hinein ist noch Narkzerfall erkennbar.

Arterien finden sich in dem Bluterguß nicht selten. Sie können ihre Struktur bewahrt haben und sind dann meist ausgesprochen sklerotisch. Manchmal ist die äußere Haut durch einen Bluterguß abgehoben und die roten Blutzellen sind oft deutlich im Zerfall. Sehr selten traf ich einen Venendurchschnitt an. Daneben sind aber mehr veränderte Gefäße nachweisbar. Leichtere Grade der Erkrankung machen sich in einer Verwischung der Grenzen der einzelnen Wandschichten kenntlich. Die Adventitia ist häufig durch einen BluterguB abgehoben, die Intima aber von der Media nicht mehr unterscheidbar. Sie sind zu einer faserigen Haut verschmolzen, in der nur vereinzelte Kerne noch färbbar sind. In solchen Gefäßen kann noch anscheinend unverändertes Blut enthalten sein. Hie und da ist neben der faserigen Struktur auch eine hyaline Quellung der Gefäßwand zu beobachten. Von diesem Zustand bis zur schwersten Veränderung, so daß nur der Durchschnitt eines nekrotischen Schlauches übrigbleibt, finden sich zahlreiche Übergänge. Nanche solcher Gebilde sind mit Sicherheit nicht deutbar. Bei anderen ist es nur die ganze Form, besonders bei Längsschnitten die Verästelung, die den Gefäßcharakter klar macht. Manchmal findet man aber in einem Teil solcher Gebilde noch erhaltene Gefäßwandkerne, entweder der Intima oder der Muskelschicht. Die elastische Haut ist fast nirgends mehr in solchen Ge- 
fäßen anzutreffen. Öfter sind es auch neben den kleinen Arterien, an denen, sich hauptsächlich dieser Vorgang abspielt, ganz kleine Gefäße präkapillaren und kapillaren Charakters, die nahezu oder völlig nekrotisch durch das Gesichtsfeld ziehen. Solche schwer veränderte Gefäße haben immer auch veränderten Inhalt. Er kann thrombenartig sein und vorwiegend aus Rundzellen bestehen oder er setzt sich vorwiegend aus geschrumpften, körnig gewordenen, meist mehr oder weniger entfärbten Erythrozyten zusammen. Die Ansammlung von Rundzellen in der Wand und der Umgebung solcher Gefäße ist meist gering.

Die besprochenen Veränderungen waren auf das Gebiet der blutigen Erweichung und die Wand derselben beschränkt. Diese Wand selbst ist von wechselnder Beschaffenheit. Abgesehen von der blutigen Durchtränkung, die sie vielfach darbietet, finden sich in ihr kleine Erweichungsherde mit Lücken im Gewebe, die teilweise mit Körnchenzellen ausgefüllt sind. Auch an anderen Stellen, wo keine eigentliche Erweichung des Gewebes vorliegt, sind die Körnchenzellen reichlich; wenn auch nicht so dicht gelagert zu finden. Sie enthalten entweder Blutpigment oder, soweit dies nach $\mathrm{Pal}$ darstellbar ist, Markreste in Form eines feinen Staubes.

Wucherungsvorgänge an den Gefäßen dieser Schicht sind an vielen Stellen zu beobachten.

\section{Zusammenfassung und Beurteilung.}

Es lag also hier ein Schlaganfall vor, der bei einer 58jährigen, mit chronischer Nierenentzündung behafteten Frau das Leben in 15 Tagen vernichtete.

Die Sklerose der Hirnarterien war an vielen Stellen sehr ausgesprochen und vielleicht war es diesem Umstande zuzuschreiben, daß auch innerhalb des blutigen Frweichungsherdes ziemlich zahireiche noch erhaltene Arterien nachweisbar waren. Man kann sich wohl vorstellen, daß ein stark verdicktes Gefäß nicht so leicht der Auflösung verfällt, wie ein normales. Denn um einen Untergang zahlreicher Arterien und anderer Gefäße handelt es sich zweifellos auch hier. Der Prozeß beginnt mit einer hyalinen oder faserigen Degeneration der Gefäßwand. Manchmal ist beides an einem Gefäß erkennbar. Die äußere Gefäßhaut ist oft abgehoben und durch einen BluterguB von der mittleren Haut getrennt. Dann folgt das Undeutlichwerden und völlige Verschwinden der Kerne. Die elastischen Fasern verschwinden spurlos. Schließlich wird der Durchschnitt der Gefäßwand nur noch durch eine feine Linie angedeutet. Der Inhalt solcher Gefäße besteht, wenn sie schwerer verändert sind, niemals aus gesundem Blut. Die Blutzellen sind entweder geschrumpft, körnig und schlecht färbbar geworden oder der ganze Inhalt ist thrombenartig und enthält reichlich 
Rundzellen. Merkw ürdig ist, daß ebenso wie in der vorigen Beobachtung die nekrotische Gefäßwand selbst nur selten von Rundzellen durchsetzt ist und $\mathrm{da} B$ auch in der nächsten Umgebung keine größeren Rundzellenansammlungen vorkommen.

Einen Teil der beschriebenen Veränderungen, nämlich Kernschwund, fand sich auch an kleinsten und kapillaren Gefäßen, kenntlich besonders an solchen, die auf eine größere Strecke längsgeschnitten deutliche Verzweigung zeigten.

Die Gefäße waren nicht der einzige Gewebsbestandteil, der in dem blutigen Erweichungsherd nachweisbar war. Hie und da, besonders in dem Randgebiet der Blutung, fanden sich auch Bündel von Markfasern, die schwer verändert waren, aber keine sicheren Zeichen mechanischer Schädigung aufwiesen. Sie fielen besonders durch ihre oft blasse, schattenhafte Färbung und ihre ungemeine Verschmächtigung auf. Daneben war auch tropfiger Zerfall erkennbar.

Im übrigen ging jedoch aus den topographischen Verhältnissen der Ubersichtsschnitte hervor, daß die Größe des apoplektisehen Herdes jedenfalls auch durch ausgeströmtes Blut und Auseinanderdrängung der Hirnsubstanz bedingt ist.

Wie meist, wurde anch hier die eigentliche Blutung durch einen Streifen veränderten Gewebes gegen das Gesunde oder relativ Gesunde abgegrenzt, in dem ein starker Zerfall von Markfasern, das Auftreten von Körnchenzellen mit Blutpigment, feinen Markresten und kleinen Erweichungsherden und die Zeichen. regenerativer Tätigkeit an den Gefäßen erkennbar waren.

Zwölfte Beobachtung. 4 Wochen alte Blutung.

Wilhelm M., Schuhmacher, 66 Jahre alt. Aufgenommen den 22. X. 1914, † den 22. XI. 1914.

Pat., der seit vielen Jahren rheumatisch war und öfter geschwollene Unterschenkel hatte, erlitt am 18. X. eine plötzliche Lähmung der linken Seite ohne schwerere Stồrung des Sprach- und Schluckvermögens.

Aufnahmebefund: Etwas fettleibiger, unruhiger und verwirrter Mann. SpitzenstoB fast drei Querfinger außerhalb der Brustwarzenlinie. Nach rechts war die Dämpfung nicht verbreitert. Die Töne rein. Puls hart und regelmäßig. Urin frei von Eiweiß. Der linke Mundwinkel hängt, die Zunge weicht nach links ab. Breites Bein links. Die linksseitigen Extremitäten im Zustand der völligen schlaffen Lähmung. Die Sehnenreflexe erhalten. Die Schmerzempfindung auf der linken Körperseite herabgesetzt.

Augenhintergrund ohne Befund.

Der Verlauf war fieberlos. Pat., der von Anfang an unter sich ließ, 
wurde immer apathischer. In den letzten Tagen Cheyne-Stokessche Atmung.

Sektionsdiagnose: Starke Hypertrophie der linken Herzkammer. Mäßige Sklerose der aufsteigenden Aorta und der Kranzarterien. Schrumpfniere.

Das Gehirn wurde injiziert im ganzen eingelegt. Bei der Zerlegung in frontale Scheiben uhd nach Anfertigung von Übersichtsschnitten ergab sich in der rechten Hemisphäre ein im ganzen rundlicher, kleinapfelgroßer blutiger Erweichsherd, dessen größter Umfang im Gebiete des Sehhügels liegt. In einer frontalen Ebene, die den Kniehöcker faßt, findet sich fast der ganze Sehhügel zerstört, von dem nur der mediale dem dritten Ventrikel anliegende Teil erhalten ist. Lateral reicht der Herd bis zu dem Marke der Insel, hat also äußere Kapsel und was von Vormauer und Linsenkern in diese Ebene noch reichte, zerstört. Dorsal ist der Boden des Seitenventrikels in seinem lateralsten Abschnitt in die Erweichung einbezogen. Trotzdem ist der Ventrikel hier nicht erweitert und Blut in ihm nicht zu sehen. Ventral reicht die Blutung nahe bis zum Hirnschenkelfuß und der Substantia nigra.

In einer weiter kaudal reichenden Ebene liegt der Bluterguß hauptsächlich im Schläfenlappen, und hat das Unterhorn durch Zerstörung seiner medialen Wand eröffnet. Von der Hirnoberfläche im Querschlitz des Hirnes wird er hier nur von der Gefäßplatte getrennt.

Die histologischen Verhältnisse anlangend, so ist ein Teil der gröberen Arterien an der Hirnbasis ausgesprochen sklerotisch und zeigt starke Wucherung der Intima. Dasselbe gilt von den Arterien in der Tiefe der Insel. Weniger ausgesprochen ist der Proze $B$ an den intrazerebralen Ästen und hier auch weniger allgemein. Auch findet man an diesen Gefäßen und fern von dem Herde öfter hyaline Quellung und perivaskuläre Rundzellenansammlung.

Die roten Blutkörperchen innerhalb des großen Herdes sind ihrer Form nach häufig noch erkennbar, aber entfärbt. Zitronengelbes Blutpigment ist vielfach entweder frei oder in Zellen eingeschlossen $\mathrm{zu}$ finden.

Sowohl in den Übersichtsschnitten als in den feineren und kleineren Präparaten lassen sich vielfach Gebilde nachweisen, die nach ihrem ganzen Verhalten nur als nekrotische Gefäße zu deuten sind. Die abgestorbenen Gefäßwände haben manchmal noch scharfe Konturen, manchmal sind sie unscharf, mehr körnig. Sie nehmen meist nur eine schwache Färbung mit sauren Farbstoffen an. Hie und da lief die Wand in Form einer scharf begrenzten faltigen Linie, an eine Elastika erinnernd. Doch ergaben entsprechende Färbungsversuche kein einwandfreies Resultat. Den Inhalt dieser nekrotischen Schläuche bildete niemals frisches Blut, sondern meist dichtgedrängte völlig entfärbte Erythrozyten mit einigen Rundzellen untermischt. In diesen Wandungen selbst fanden sich keine Wanderzellen und auch in der näheren Umgebung nicht.

Während die mittleren Partien der Blutung einen ziemlich gleichmäBigen Eindruck machen, zeigen die Randpartien oft eine Felderung. Sie kommt dadurch zustande, dab Stellen, die entweder von Gewebe und 
Zellen ganz entblößt sind und nur noch ein geronnenes Serum enthalten, oder die dicht gedrängt mit Körnchenzellen ausgefüllt sind, von Gewebszügen umsäumt werden. Diese Züge bestehen entweder aus neugebildeten Gefäßen, kenntlich an ihren saftreichen, spindeligen, zellenreichen Wandungen, oder aus soliden Zellbalken, die ebenfalls aus Spindelzellen zusammengesetzt sind.

In den tieferen Teilen der Blutung hat eine Vaskularisation noch nicht stattgefunden. Die GefäBsprossen durchsetzen nur die Randschicht. Auch erhaltene Arterien, Venen oder Kapillaren mit erkennbarer Struktur und gefärbten Kernen traf ich in den zentralen Schichten nicht, in den peripheren nur selten an.

Markreste fanden sich spärlich in dem Bluterguß, und um so weniger, je mehr man sich von der Randschicht der Blutung entfernt. Sie finden sich als Bündel oder veréinzelte Fasern, selten tief schwarz gefärbt̀, meist blaß, schattenhaft und fein im Pal-Präparat. Eine mechanische Schädigung kann man ihnen nicht ansehen. Selten sieht man tropfig zerfallende Fasern oder einzelne Marktropfen, öfter feinkörnige Markreste in Zellen eingeschlossen.

Stärker ist der Markzerfall noch in der Wand des Herdes ausgebildet.

Die Untersuchung der Nieren ergab eine ausgeprägte Sklerose der Arterien an der Grenze von Rinde und Mark mit starker Verdickung der Intima. Die Glomeruli sind vielfach verödet oder ihre Kapsel streifig verdickt. Von der Nierenkapsel sieht man zahlreiche Schrumpfungszüge in die Tiefe ziehen.

\section{Zusammenfassung und Beurteilung.}

Ein 66jähriger Mann, der an chronischer Nierenentzündung litt, hatte einen Schlaganfall etwa 5 Wochen überlebt. Die linksseitige, mit Herabsetzung der Schmerzempfindlichkeit verknüpfte Lähmung fand ihre Erklärung durch den apoplektischen Herd, der den rechten Sehhügel und auch benachbarte Nervengebiete fast ganz zerstört hatte. Die Betrachtung der Frontalschnitte lehrte, daß nicht eine einfache Zerreißung von Hirnsubstanz stattgefunden hatte. Vielmehr war der größte Teil des Sehhügels, Teile des hinteren Linsenkemes und der Vormauer und die äußere Kapsel zerstört worden.

Von dieser untergegangenen Firnsubstanz war zwar nur wenig nachweisbar, aber sie war doch erkennbar in Form von Bündeln von Nervenfasern und von einzelnen Fasern, die zum Teil noch ganz wohl erhalten waren, zum Teil einen Zerfall erkennen ließen, wie er auch sonst bei Untergang von. Nervengewebe aus anderen Ursachen getroffen wird. Sonst waren Gewebsreste nur noch in Form von schwer degenerierten Gefäßen erkennbar, während Reste von Glia überhaupt nicht nachweisbar waren. Es stimmt mit den übrigen, bei den anderen Beob- 
achtungen gemachten Erfahrungen überein, daß solche Reste in den zentralen Partien der Blutung gar nicht gefunden werden, und daß sie im allgemeinen um so reichlicher zu sehen sind, je mehr man sich den Randschichten nähert. Wenngleich auch in diesen Randschichten solche Gewebsreste spärlich sind, so deuten sie doch auf einen allmählichen Übergang aus dem Zentrum der blutigen Erweichung, in dem alles Gewebe vernichtet ist, nach der noch stark alterierten Wand des apoplektischen Herdes hin an. Der Gedanke liegt nahe, daß dieses Verhalten der Ausdruck einer Schädlichkeit ist, die am intensivsten in den mittleren Schichten der Blutung angreift und hier alles Leben vernichtet, während in der Peripherie sich die gewebezerstörende Kraft nicht mehr in vollem Maße geltend machen kann.

Vergegenwärtigt man sich an der Hand der. Frontalschnitte die topographischen Verhältnisse, wie sie vor der Apoplexie gewesen sein müssen, so kommt man zu dem Schluß, daß der ganze Herd im wesentlichen aus den vorher angeführten Hirnteilen bestanden haben wird, und da. ausströmendes Blut zu seiner Vergrößerung nicht allzu viel beigetragen hat. Überhaupt ist anzunehmen, daß das Blut bei dem Insult aus. den Gefäßen nicht mit sehr großer Gewalt ausgeströmt sein kann. Andernfalls hätte eine schwere Hirnhöhlenblutung nicht ausbleiben können, da ja sowohl ein Teil des Bodens des Seitenventrikels, als ein Teil der medialen Wand des Unterhorns in die blutige Erweichung einbezogen war. Trotzdem fanden sich die Stimhöhlen nicht erweitert und nur im Unterhorn ein mäßiger Bluterguß, und auch dieser letztere hatte den Verschluß dieser Höhle zwischen Ammonshorn und Hirnbasis durch die Gefäßplatte nicht gesprengt und keine Blutung an der freien Hirnoberfläche und in der weichen Hirnhaut zuwege gebracht.

So ist diese Beobachtung wohl nicht anders zu deuten, als daß die Blutung nur unter mäBigem Druck, wahrscheinlich als kapilläre Blutung, erfolgte, und dab sie weniger das Wesen des Schlaganfalles als eine notwendige Begleiterscheinung darstellte.

Entsprechend seinem Alter unterscheidet sich dieser Herd histologisch von den anderen jüngeren. Die Zerstörung und der Schwund der in ihm enthaltenen Gefäße ist so hochgradig, daß die nachweisbaren Reste oft nicht mehr mit Sicherheit zu deuten sind. Anderseits ist die Reaktion, die in Form von zelliger Infiltration der nekrotischen Gefäße in frischeren Fällen sehr ausgesprochen war, wieder fast völlig geschwunden. Die Reaktion in dem Gewebe der Herdwand ist sehr rege. Spindelzellige Bündel und Gefäßsprossen sind in die Randschicht des 
Herdes eingewachsen und haben sie in Felder zerlegt. Der Blutfarbstoff ist aus dem Bluterguß fast völlig entfernt und liegt zum Teil, ebenso wie Markreste, in Körnchenzellen.

Durch altes Gewebe hängt der Herd mit seiner Wand nicht mehr zusammen. Weder Nervenfasern, noch alte, etwa sklerotische, Gefäße sah ich von dem gesunden Gewebe aus in die Blutung tauchen. Der kugelförmige Herd war gänzlich von dem umgebenden Gewebe getrennt, lag sequestriert in dem Gehirn, und erst langsam wird er durch reaktive Wucherung von der Wand aus wieder in Beziehung zu dem lebenden Gewebe gebracht. Ein solches Verhalten ist wohl nicht denkbar, wenn man von der geltenden mechanischen Erklärung der Apoplexie ausgeht. Es ist unverständlich, daß das aus einem oder wenigen zerrissenen Gefäßen ausströmende Blut nicht zahlreiche lebensfähige Verbindungen mit dem gesunden Gewebe hätte stehen lassen sollen, die der Untersuchung nicht hätten entgehen können.

Die vorstehenden zwölf Fälle bieten nicht mein ganzes Untersuchungsmaterial. Ich verzichte aber auf die Besprechung weiterer Beobachtungen, weil ich damit keinen neuen, wesentlichen Gesichtspunkt bringen kann.

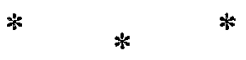

Zusammenfassung der vorstehenden Untersuchungen und Schlußfolgerungen.

Wir haben gesehen, daß nach alter Auffassung der Schlaganfall so zustande kommt, daß eine oder auch mehrere Arterien reißen und das Blut sich in das Hirngewebe ergießt. So soll nach der einen Auffassung ein $\mathrm{Ri} \beta$ entstehen, der eine befallene Hirnpartie zerklüftet. Das ergossene Blut bringt die Wandungen dieser Kluft zum Auseinanderweichen und es enthält selbst wenig oder gar keine Hirnmasse. Nach anderer Darstellung zertrümmert das ausströmende Blut vielfach die nervöse Substanz und mischt sich innig mit ihr, so daß der Inhalt der apoplektischen Höhle nicht lediglich oder doch nicht ganz vorwiegend Blut, sondem ein blutiger Hirnbrei ist.

Wäre die erste Vorstellung richtig, so ist schwer zu verstehen, warum der apoplektische Herd in so vielen Fällen eine rundliche Gestalt annimmt. Eigentlich sollte man erwarten, daß wenigstens in Gebieten, die von einem strangartig angeordneten Fasersystem durchsetzt werden, 
die Blutung sich längs solcher Fasersysteme oder auch innerhalb derselben ausbreitete. Aber ich bezweifle, $\mathrm{d} a ß$ jemand gesehen hat, daß etwa eine Blutung das untere Längsbündel von der Sehstrahlung auf größere Strecken oder diese von dem Tapetum abgelöst hätte oder daß die ausstrahlenden Balkenfasern oder die Pyramidenbahn richtunggebend für den Erguß des Blutes gewesen wären. Auch die wechselnden Widerstände, die ausströmendes Blut an den Grenzen von grauer und weißer Substanz, besonders an den basalen Ganglien, findet, müßten, so sollte man meinen, in der Form des blutigen Herdes zum Ausdruck kommen. Aber von alledem ist nichts zu sehen. Betrachte ich meine Präparate, so finde ich im allgemeinen, daß größere Blutungen einen rundlichen, oft eiförmigen Herd schaffen, an dessen Peripherie freilich sich noch un regelmäßige Fortsätze anschließen können.

Wie man nun aber über die Entstehung des Herdes denken mag, so muß jedenfalls auf Durchschnitten die Verdrängung des Gewebes deutlich zu sehen sein, wenn das ausströmende Blut im wesentlichen nur einen Spalt im Hirn reißt und diesen dann verbreitert. In der Tat ist das auch ganz unverkennbar bis zu einem gewissen Grade der Fall, wie ja auch schon äußerlich die von der Blutung befallene Hemispäre meist durch ihre Vergrößerung auffällt. Betrachtet man aber Frontalschnitte durch eine Hemispäre, die die Blutung mitfassen und denkt man sich den Bluterguß hinweg und die Wandungen des Herdes wieder aneinandergelegt, so kommt man keineswegs immer auf die natürliche Form und Größe der gesunden Hemisphäre. Sie würde vielmehr meist zusammengefallen und verkleinert erscheinen und der SchluB wird unabweisbar, daß hier Gewebe, Fasermassen und Ganglien zugrunde gegangen sein müssen. Ist es gelungen, den Bluterguß in solchen Schnitten zu erhalten, so vermißt man in der Tat unter Umständen leichter erkennbare Strukturen, wie der basalen Ganglien, der Vormauer, der inneren oder äußeren Kapsel, die ganz oder teilweise verschwunden sind. Das war besonders in dem Falle 8 deutlich.

Auf der anderen Seite ist nicht zu leugnen, $\mathrm{da}$ h auch in den blutigen Massen hie und da Trümmer von Nervengewebe nachweisbar sind. Aber diese Trümmer sind keineswegs so regelmäßig auffindbar, wie sie bei der mechanischen Erklärung des Vorganges erwartet werden müßten.

Nimmt man ferner an, daß die apoplektische Höhle einfach durch gewaltsam ausströmendes Blut aufgerissen werde, dann wird man auch überall unregelmäBig vorspringende Gewebsfetzen erwarten, die in Gestalt von Nervenbündeln und Gefäßresten in die blutigen Massen 
eintauchen. Nun kann man sich ja in der Tat überzeugen, daß solche Fasem oft nachweisbar sind und die Charcotsche Methode der Untersuchung auf miliare Aneurysmen fußt ja auf dem Vorhandensein dieser unter dem Wasserstrahl flottierenden Fasern, die die Wand des Herdes besetzen. Aber man trifft sie keineswegs immer und überall an. Oft sind, wie ich den Čbersichtsschnitten entnehmen kann, die Wände auf größere oder geringere Ausdehnung völlig glatt. Der Rand der Höhle kann an den Schnitten so scharf wie mit dem Messer durchtrennt aussehen. Man hat hier gar nicht den Eindruck, daß ein mechanisches Wirken die Trennung vollzogen hat und anderseits beweist natürlich der Befund von fetzigen Fortsätzen der Wand die mechanische Entstehung noch keineswegs sicher, denn an Abszeßwandungen kann man sie oft genug sehen.

Eine andere Schwierigkeit für die in Rede stehende pathogenetische Auffassung bieten besonders unregelmäßig gestaltete Herde. Die Quelle einer Blutung wird man zunächst da suchen, wo der Herd seine größte Ausdehnung hat. Von da aus, wird man annehmen, hat sich das Blut zu kleineren Fortsätzen des Herdes, seine mechanische Kraft allmählich erschöpfend, weitergewühlt. Nun betrachte man die nach Photographien des in Formalin fixierten und in Frontalscheiben zerlegten Hirnes der Beobachtung 1 hergestellten Abbildungen. Abbildung 1 zeigt das proximale, Abbildung 3 das kaudale Ende der Blutung, die zweite ungefähr die größte Ausdehnung der Blutung. War hier die Quelle der Blutung, so begreift man nicht, daß die den Ventrikel eröffnende Blutung sich nicht rasch erschöpfte, indem sie das Höhlensystem des Gehirnes ad maximum mit Blut erfüllte. Statt dessen wühlte sie sich in den Schläfen- und Hinterhauptlappen, während das vordere Seitenhorn auf den. Schnitten eng und frei von Blut gefunden wurde.

Der Vorgang wird nicht verständlicher, wenn man die Quelle der Blutung neben dem Hinterhorn sucht. Auch hier bleibt es unverständlich, wie die Blutung bis zum Kopf des Schwanzkernes gelangen konnte und sich nicht vorher durch Durchbruch in das Seitenhorn oder auch an die Hirnoberfläche in der sylvischen Grube erschöpfte.

Prüt man die vorkommenden Apoplexien unter diesem Gesichtspunkte, so wird man die dargelegte Schwierigkeit oft finden. Denn so selten die genannte Apoplexia ventricularis sein mag, bei der massenhaft ergossenes Blut die Höhlen beider Hemisphären ausfüllt, so häufig wird man finden, daß eine gewöhrliche Hirnblutung die Ventrikelwand an irgend einer kleineren oder größeren Stelle blutig erweicht oder direkt 
zerstört hat, und das ohne nachfolgende erhebliche Blutung in die Hirnhöhle. Freilich muß man zu dieser Feststellung oft das Gehirn härten und näher untersuchen.

Ganz ähnliche Verhältnisse bot der Fall 7. Die gröBte Ausdehnung hat der Herd im Gebiete der. Stammganglien und der Kopf des Schwanzkernes war bis in seine obersten Schichten in die blutige Erweichung einbezogen. Trotzdem war eine erheblichere Blutung in die Stimhöhlen nicht eingetreten. Der Seitenventrikel in seinem hinteren Abschnitt und das Unterhorn waren nisht einmal erweitert. Auch ist von Interesse, daß an Frontalschnitten durch die Gegend des hinteren Balkenabschnittes die Blutung der lateralen Ventrikelwand in der Ebene, wo. Unter- und Hinterhorn zusammenfließen, anliegt. Der apoplektische Herd hat hier in vertikaler Richtung eine Ausdehnung von $3,5 \mathrm{~cm}$. Die Schicht, welche Blutung und Ventrikel scheidet, ist stellenweise sehr dünn, dazu auch noch von kleinen Blutungen durchsetzt, so daß das Fehlen des Durchbruches einem von starker mechanischer Gewalt vorgetriebenen Blutstrom gegenüber auffallend ist.

Lehrreich ist auch der Fall 5. Von der mechanischen Auffassung ausgehend, würde man die Quelle der Blutung in der Kleinhirnhemisphäre da suchen, wo sie die größte Ausdehnung hat und mit schmaler Brücke durch den Wurm auch auf die andere Hemisphäre übergreift. Es ist schon merkwürdig, daß das Blut, welches an verschiedenen Stellen auch die Rinde infiltriert, sich nicht in den Maschen der weichen Haut weitergewühlt und hier umfangreiche Blutungen gesetzt hat. Statt dessen schritt es im mittleren Kleinhirnschenkel proximal fort, verwandelte hier den linken Bindearm in eine blutige Masse, so daß in den hinteren Abschnitten dieses Organ kaum noch zu erkennen ist. Weiter nach vorn stellt sich die ventrale Partie dieses Organes wieder her, während die dorsale stark geschwollen und blutig erweicht in den Ventrikel hineingedrängt ist. Obwohl an diesen Stellen das Epithel zerstört ist, fehlt wiederum jedes stärkere Blutextravasat im 4. Ventrikel und im Äquadukt. Vollends in die Großhirnhöhlen ist gar kein Blut gelangt.

Es ist einleuchtend, daß Blutungen, die aus zahllosen kleinen und kleinsten Herden zusammengeflossen sind, jede beliebige Gestalt annehmen können, daß ein solcher Herd nicht notwendigerweise eine rundliche Form annehmen muß. Die oben hervorgehobene Schwierigkeit aber, warum Herde, die den Ventrikelboden oder die Hirnrinde zerstört haben, so selten eine größere Blutung in die Hirnhöhlen oder 
auch in die Maschen der Arachnoides setzen, bleibt bestehen, auch wenn man den Herd aus zahlreichen kleinen geplatzten Arterien ableiten will. Denn mit Blutungen in die Arachnoides bei der Apoplexie steht es wie mit der Ventrikelblutung. Sie ist häufig in geringem Grade vorhanden und weist auf den verborgenen Herd hin. Aber es ist wohl eine große Seltenheit, daß größere Blutmengen in die weiche Haut ergossen werden oder da $\dot{B}$ sie gar die Maschen der Spinnewebhaut durchbrechen und der Erguß frei im Subduralraum liegt.

Daß nun wirklich der apoplektische Herd durch den Zusammenfluß zahlloser kleinerBlutungen entstehen kann, das machen zahlreiche meiner Präparate wahrscheinlich. Und manche lassen überhåupt keine andere Deutung zu. In der Beobachtung 3 z. B. zeigen die frontalen Übersichtsschnitte zwar eine kompakte große Blutung im Marke des Stimhirnes, deren Entstehung nicht ohne weiteres erkennbar ist. Kaudal aber löst sich diese größere Blatung in kleinere oder vielmehr Gruppen von kleinen Blutungen auf, die ihren Hauptsitz im Sehhügel, Linsenkern, Hirnschenkelhaube und der Brücke haben. Besonders die im Sehhügel gelegenen kleinen Blutungen lassen vielfach scheinbar unverändertes Gewebe zwischen sich, and wenn jemand die kleinen und kleinsten diskreten Hämorrhagien in der Brücke für sich betrachtet, so wird er zunächst glauben, eine Encephalitis haemorrhagica vor sich zu haben, die aber völlig auszuschließen ist.

In sehr ausgeprägter Weise ist auch in der 6. Beobachtung der Hauptherd von einer ausgedehnten und mehrere Zentimeter dicken Schicht umgeben, in der unzählige kleine Blutungen in der Rinde der Kleinhirnwindungen und der Pia zwischen diesen lagen. Zahllose der kleinsten sind nur mit der Lupe erkennbar. Andere begleiten spritzerförmig die kleinen Arterien oder fließen an der Grenze von Rindengrau und Körnerschicht oft zu flächenhaft ausgebreiteten Hämorrhagien. zusammen.

Diese kleinen Blutungen in der Umgebung des apoplektischen Herdes fehlen wohl in keinem Falle gänzlich. Meist umgeben sie in wechselnder Menge den großen Herd, treten in dem einen Teil der Wand zurück und finden sich massenhaft in anderen. Diese kleinen Herde bereiteten der Erklärung stets eine Schwierigkeit. Man nahm an, daß sie eine Folge der durch den großen Herd gesetzten. Kreislaufstörungen sein müßten. Träfe das zu, so müßten sie jünger sein als der große Herd. Das ist aber wohl sicher nicht der Fall.

In Wirklichkeit löst sich vielfach der apoplektische Herd in seiner 
Peripherie in eine große Zahl von kleinen und kleinsten Blutungen auf, die auf demselben Wege wie jener zustande gekommen sind. Gerade die Untersuchung kleiner, etwa stecknadelkopf- bis erbengroßer Hämorrhagien ist sehr lehrreich. In ihnen wies ich wiederholt dieselben schweren Veränderungen an den Arterien nach wie in dem großen Herd. Die Abbildungen 6-8 der 1. Beobachtung und 14 und 15 der 8. Beobachtung geben diese nekrotischen Arterien innerhalb kleiner umschriebener Blutungen wieder.

Berücksichtigt man das, so wird man auch den kleinsten, flohstichähnlichen Blutungen keine andere Ätiologie zuschreiben, nur da $B$ man in ihnen natürlich nicht den Nachweis gröberer erkrankter Gefäße erwarten kann. Diese kleinsten Blutungen weisen nicht selten ein Merkmal auf, das von Interesse ist, sie können als Ringblutungen auftreten. Solche fanden sich in größerer oder geringerer Zahl in der 5., 7., 8. und 9. Beobachtung.

In letzter Zeit sind die Ringblutungen wiederholt studiert worden, und besonders hat sich M. B. Schmidt ${ }^{1}$ ) in seiner Arbeit über die Enzephalitis mit ihnen beschäftigt. Die Himpurpura, wie Schmidt die Erscheinung von kleinen, flohstichartigen Blutungen nennt, fand er unter verschiedenen Bedingungen, so daß sich seine Fälle in drei Gruppen von Erkrankungen sondern, in die der spontanen Hirnpurpura und in solche septisch pyämischer und traumatischer Herkunft. Die Mehrzahl dieser kleinen Purpurablutungen trugen nun den Charakter der Ringblutungen.

Sieht man von den traumatischen Ekchymosen, die eine etwas abweichende histologische Beschaffenheit haben, ab, so bieten die beiden anderen Gruppen gleiche mikroskopische Beschaffenheit. Ein Gürtel von roten Blutzellen umschließt ein hyalines, kernarmes oder kernloses Zentrum und zwischen beiden findet sich eine Zone, in der große Zellen liegen. Das Zentrum färbt sich nach van Gieson rot und weist Schollen, Körner, plumpe Spindeln, Keulen und Bänder, alle von. hyaliner Besehaffenheit und homogen oder von kleinen Vakuoleı durchsetzt auf. Alle diese Gebilde sind nichts anderes als gequollene Achsenzylinder, wie daraus hervorgeht, daß manche dieser Gebilde durch den Blutwall hindurch in einen Achsenzylinder von normaler Beschaffenheit übergehen und $\mathrm{da} \beta$ in manchen Regionen, wie der des Balkens, die Anordnung dieser Degenerationsprodukte dem parallelen Faserverlauf

1) Zieglers Beiträge 1905, Supplementbd. 7. 
entspricht. Auch konnte Schmidt einigemal an frischen Objekten um solche kolbige Gebilde eine Myelinscheide nachweisen. Um die Gefäße sind oft Fibrinfäden und in den Bluturgen, nicht aber in den Zentren, Markscheiden nach W eigert nachweisbar. In den großen Zellen, die zum größten Teil oder sämtlich Gliazellen sind, fanden sich öfters Mitosen. Wichtig ist ferner, daß Schmidt in einem Falle (6) auch Herdehen fand, die der Blutung gan $z$ entbehrten und nur ein nekrotisches Zentrum, umgeben von den großen Zellen, darstellten.

Alle diese Herde sind um eine erweiterte Kapillare entwickelt. In der Lichtung liegen rote Blutzellen einzeln oder konglutiniert. Leukozyten kommen in wechselnder Menge vor und können auch ganz fehlen. Sie können einen Ring um das in der Achse des Herdes gelegene Gefäß bilden oder auch in wechselnder Menge in dem Kranze großer Zellen liegen. Niemals aber kann von ein er eitrigen Infiltration die Rede sein.

Schmidt fügt hinzu, daß man im Hinblick auf die großzellige Wucherung diese Ekchymosen als hämorrhagische Entzündungsherde bezeichnen könnte, aber sie sind nicht Teilerscheinung einer diffusen Entzündung, sondern eingesetzt in ein Gewebe, welches in der Regel ganz unverändert ist. Nur in einem Falle (5) fand er zwischen besondërs dicht stehenden Purpuraflecken im Hirngewebe polynukleäre Leukozyten.

Schließlich wird noch bemerkt, daß an den weichen Häuten in diesen Fällen keine Veränderungen, besonders keine Thromben, nachweisbar waren.

Schmidt sieht in diesen Ringblutungen Diapedeseblutungen und in der Entfernung der roten Blutzellen vom GefäB das sichere Zeichen, daß letztere nicht durch Ruptur aus den Kapillaren ausgetreten sind, sondern die Wand gleichzeitig mit einem Transsudationsstrom passiert haben und durch denselben vom Gefäß ins Gewebe fortgetragen worden sind. Kann man in einem ganz frühen Stadium untersuchen, wie dieser Autor in seiner ersten Beobachtung, so findet man noch keine Ringblutung. Die Blutkörperchen liegen den Gefäßen noch eng an.

Schmidt erklärt den ganzen Vorgang dieser Purpurabildung mit der Annahme, daß eine gemeinsame toxische Schädlichkeit bisweilen nur auf das Gewebe wirkt, dann entstehen die Herdchen ohne Blutring, meist auf das Gewebe und die Kapillare, dann tritt zur Nekrose die Diapedese und bisweilen das Blut selbst, dann kommt die Konglutination der roten Blutkörperchen in dem zentralen Gefäß hinzu. 
Die Vermehrung der großen Zellen an der inneren Grenze des blutigen Ringes wird für einen reaktiven Vorgang gehalten.

Von großer Wichtigkeit ist schließlich, daß Schmidt auch in unkomplizierten traumatischen Hirnblutungen im Mark unter den geschädigten Rindenpartien Ringblutungen fand. In ihnen aber fehlte das nekrotische Zentrum, die scholligen verdickten Achsenzylinder. Nur sind die Gliafasern in der Nähe der Kapillare starr und glänzend und die Zellkerne vermehrt. Diese Veränderung der Gliafasern betrachtet Schmidt als den Ausdruck eines lokalen Odems, das seinerseits durch Zirkulationsstörungen hervorgerufen wurde.

Es ist von Bedeutung, daß nach den Untersuchungen von Grön$\left.\mathrm{d} a h 1^{1}\right)$ Ringblutungen bei der Fettembolie des Gehirnes häufig sind. Auch hier findet sich um das zentrale, den Fettropfen enthaltende Gefäß ,eine nekrotische Zone von gequollenen, nekrotischen Myelinmassen, die durch Weigerts und Fränkels Markscheidenfärbung nicht tingiert werden und um diese herum liegen die roten Blutkörperchen". DerErklärung Schmid.ts stimmt der Autor nicht zu. Er faßt das Ganze auf als einen kleinen Infarkt mit zentraler anämischer Partie. Den Blutring leitet er aus einer Rückstauung und Blutung aus den umgebenden Kapillaren ab. Es kommt bei der Fettembolie weiter auch zu miliaren Erweichungen, denen die Blutung fehlt, während zentrales Gefäß und nekrotische Umgebung sich wie in den kleinen Blutungen verhalten.

Die Entstehung der kleinen Blutungen wird also ganz mechanisch aufgefaßt. So naheliegend und gewissermaßen selbstverständlich diese Deutung auch erscheinen mag, so ist sie doch nicht die einzig mögliche. Es ist auch auffallend, daß nach Gröndahls Angabe die Fettembolien von Odem, Blutungen und miliaren Erweichungen nur dann begleitet sind, wenn sie älter als 50 Stunden sind. Man sollte meinen, die Zirkulationsstörung träte mit der Embolie in der Regel gleichzeitig ein und dementsprechend begänne auch sehr bald die Auswanderung der roten Blutkörperchen. Man kann doch nicht annehmen, daß der das Gefäß verlegende Fettembolus niemals direkt einen Verschluß bewirkte, sondern daß ein solcher immer erst durch langsam sich anschließende Thromben zustande käme. Von solchen ist ja auch in der Beschreibung keine Rede. Da darf man wohl an die Möglichkeit denken, daß der Embolus allmählich chemischen Umwandlungen unterworfen wird oder

1) Untersuchungen über die Fettembolie. Zeitschr. f. Chir. 1911, Bd. 3. 
da $\beta$ er sie in seiner Umgebung hervorruft und da $\beta$ diese so entstandénen Produkte an der Herdbildung beteiligt sind.

In viel allgemeinerer Weise und gestützt auf ein großes Untersuchungsmaterial, das Fälle verschiedenster Krankheiten enthält, hat Oeller ${ }^{1}$ ) die Himblutungen lediglich aus mechanischen Prinzipien abzuleiten versucht. Er läßt die traumatische und apoplektische Blutung außer Betracht und untersucht Hirnhämorrhagien, die sich bei verschiedenen Erkrankungen ausgebildet haben und die, in zwei großen Gruppen untergebracht, als Blutungen bei Zirkulationsstörungen der Gehirn- und Gehirnhautvenen einerseits und der Hirnarterien anderseits betrachtet werden.

Unter der ersten Gruppe finden sich zunächst Fälle mit entzündlichen Veränderungen der Meningen, besonders auch mit tuberkulöser Hirnhautentzündung. Nachgewiesene Venenthrombose gestattete in diesen Fällen, die Blutungen im Gehirn von diesen Gefäßverschlüssen abzuleiten. Es wird darauf hingewiesen, daß die Thrombose über den ursprünglichen Entstehungsbereich hinauswachsen kann, daß als Folge dieser Venenthrombose eine Diapedesis der Erythrozyten aus den Kapillaren eintritt, daß unter Umständen die Stainung durch diesen Vorgang nicht behoben wird und daß es dann zu der Diärese kleiner Gefäße kommen kann, ein Begriff, der durch Marchand wieder in die Pathologie eingeführt wurde. Bei der Diapedesis bleibt die Schädigung des Gewebes gering, bei der Diärese lrommt es zur Zertrümmerung von Hirnsubstanz und durch beide Vorgänge können auch große Blutungen zustande kommen.

Eine verwandte Rolle wie diesen Veränderungen wird bei der Leukämie den Leukozytenthromben in Hirnvenen zugeteilt, die ebenfalls zu kleinen und größeren Blutungen Anlaß geben sollen.

In ähnlicher Weise werden die Blutungen bei arteriellen Kreislaufstörungen erklärt. Es wird darauf hingewiesen, daß zwar der Verschluß größerer und kleinerer arterieller Aste im Gehirnmark die weiße Erweichung bedingt, daß aber der Verschluß kleiner Schlagadern in der Großhirnrinde und den Zentralganglien anders wirkt. Die Arterien der weichen Hirnhaut und die die Rinde versorgenden Stämme sind keine Endarterien im strengen Sinne wie die Schlagadern der Markes. Sie besitzen vielmehr kleine Anastomosen mit den Nachbargefäßen. Ein

1) Pathol.-anatomische Studium zur Frage der Entstehung und Heilung von Hirnblutung. Deutsche Zeitschr. f. Nervenheilkunde 1913, Bd. 47/48. 
Embolus wird daher zunächst einen Stillstand in dem versorgten Gefäßgebiet hervorbringen. Alsbald aber wird von den seitlichen Zuflïssen eine immer stärker werdende Füllung dieses Stromgebietes eintreten und in einem großen Teile des Kapillargebietes eine Stase sich ausbilden, die derjenigen bei der venösen Stase ganz entspricht. Fis bilden also solche nach Arterienverschluß auftretenden hämorrhagischen Infarkte nur eine besondere Art der Stasenbildung. So gedeutete Rindenblutungen fanden sich in einem Falle von schwerer Arteriosklerose der Aorta. Besonders wurden hyaline Thromben in den kleinen Arterien der weichen Hirnhaut und der Rinde mit Blutungen im Gebiete der letzteren gefunden.

Daß diese Erklärung für die kleinen Blutungen in der Marksubstanz bei arteriellen Störungen nicht obne weiteres brauchbar ist, hebt der Autor selbst hervor. Besonders bei der Fettembolie finden sich die kleinen Blutungen vorwiegend in der Marksubstanz des Großhirns, während sie in der Rinde selten sind. Anderseits sind dabei weiße Erweichungen im Marke selten. Der Autor hilft sich hier mit der Annahme, daß das in die Arterien gelangende Fett nicht definitiv in den kleinen Arterien, wo es z. B. von Gröndahl nachgewiesen wurde, stecken bleibt, $\mathrm{da}$ es vielmehr bei seiner weichen Beschaffenheit in kleinste Teilchen allmählich zerlegt in die Kapillaren gelangt, wo es dann infolge des geringeren Druckes liegen bleibt. Der Reichtum an Haargefäßen. in der Rinde gleicht weiterhin die Störung aus, während bei den ungünstigeren Bedingungen im Marke multiple Kapillarembolien Blutungen bewirken sollen.

Freilich kommt Oeller nicht für alle Fälle mit der rein mechanischen Erklärung völlig aus. Für eine Reihe von Purpurafällen, bei denen an embolische Vorgänge nicht gedacht werden kann, die Gerinnungen innerhalb der Blutbahn oder Konglutination der Frythrozyten bewirken können, nimmt er lokal und multipel wirkende toxische Einflüsse an. Durch Thrombose kleinster Gefäße und durch kapilläre und venöse Stase läßt er dann die kleinen Blutungen entstehen. Aber der Typus der Ringblutung ist auch hier nicht als der Ausdruck toxischer Schädigung des Gewebes zu, deuten, da sich ihr histologischer Charakter nicht von dem der sicher mechanisch, z. B. durch Fettembolie entstandenen unterscheidet. Sie entwickeln sich aus Diapedeseblutungen und neben dem Transsudationsstrom ist es eine Verquuellung des um die Kapillare liegenden, mechanisch geschädigten Gewebes, das die roten Blutkörperchen in die Peripherie drängt. Das hyaline Zentrum besteht aus 
einem weitmaschigen, starren Glianetz mit glänzenden Tropfen, in dem Achsenzylinder und Markscheiden zugrunde gegangen sind. Auch die Gliazellen, falls sie in dem Gebiete der Ringblutung vorkommen, zeigen ausgesprochene Zerfallserscheinungen. Ebenso sind degenerative Vorgänge an den zentralen Kapillaren nachweisbar. Schließlich entwickelt sich an der Peripherie des kleinen Herdes eine reaktive Wucherung der Gliazellen. Das Ganze aber wird nur als der Ausdruck rein mechanischer Schädlichkeiten aufgefaßt, welche das Gewebe während der Blutung selbst erlitten hat.

So richtig es methodisch nun sein mag, zur Erklärung dunkler Vorgänge von den einfachsten mechanischen Prinzipien auszugehen, so werden sie doch nicht ausreichen, um alle Blutungen und die mit ihnen verbundenen Veränderungen des Hirngewebes überall und restlos verständlich zu machen. Für eine Anzahl Purpurafälle hat ja Oeller selbst auf die Mitwirkung toxischer Kräfte zurückgreifen müssen. Anderseits finden sich in der Literatur, so bei Vorpahl ${ }^{1}$ ), Halff, Dickert, Mitteilungen, die bezeugen, daß gelegentlich ausgedehnte Thrombosen, der Gehirnsinus und zahlreicher einmündender Venen kein e Blutúngen in der Hirnsubstanz gesetzt haben. Ich selbst hatte noch kürzlich die Gelegenheit, bei multipler Tuberkulose eines Kindes eine wohl als marantisch zu deutende 'Thrombose des Sinus longitudinalis und transversus sinister und zahlreicher Venen auf der Konvexität des Großhirns zu untersuchen. Auch hier fehlen Blutungen durchaus und waren auch mikroskopisch nicht nachweisbar. Allerdings soll dabei nicht verschwiegen werden, daß, worauf Oeller Gewicht legt, die intergyralen Venen meist frei von Thromben waren.

Erhebliche Schwierigkeiten erwachsen der mechanischen Erklärung aber gerade bei der Deutung der Ringblutungen.. Bei der Apoplexie kennt man, was bei anderen Purpuraerkrankungen nicht immer der Fall ist, das Alter der kleinen Blutungen genau, da sie zweifellos mit dem großen Herde gleichalterig sind. Da ist es nun auffallend, daß auch bei ganz frischen Blutungen die Markfasern im Bereiche der kleinen Herde fast ganz geschwunden sind. Man findet nur wenig Reste von ihnen und die vorhandenen lassen an ihrer schlechten Färbbarkeit erkennen, daß sie nicht allein mechanisch geschädigt sein können.

Ebenso hatte ich bei Untersuchungen der Ringblutungen bei perni-

1) Über Sinusthrombosen usw. Z. Beiträge z. Anatomie 1913, Bd. 55. 
ziöser Anämie ${ }^{1}$ ) gefunden, daß auch hier die Markscheiden innerhalb der kleinen Herde zugrunde gehen und daß die Achsenzylinder nach Ströbe sich nicht darstellen ließen. Später hat dann Wohlwill' ${ }^{2}$ gezeigt, daß in vier Fällen von Hirnpurpura, die sich im Anschluß an Bakteriämie, Diphtherie und Pneumonie entwickelt hatte, Achsenzylinder nach Bielschowsky innerhalb der Herdchen zur Anschauung. gebracht werden konnten und daß sie sich in dem Zerfall des nervösen und gliösen Gewebes relativ am besten erhalten hatten. Zwischen diesen Befunden und den meinigen braucht kein unlösbarer Widerspruch angenommen werden, da ja mit $\mathrm{K}$ aplan angenommen wird, daß die Färbung der Achsenzylinder etwas anderes darstellt als die Silberimprägnation.

Wenn sich aber nun innerhalb der Purpurafleckchen die Markscheiden anders verhalten sollten als die Achsenzylinder, diese resistenter sind als jene, so erwächst der mechanischen Erklärung nur eine neue Schwierigkeit. Daß eine chemisch wirkende Schädlichkeit auf die Markscheide anders wirken mag als auf den Achsenfaden, hat nichts Befremdendes und wir dürfen annehmen, daß ein solches Verhalten bei der multiplen Sklerose zutrifft. Wie aber einer mechanisch wirkenden Kraft eine ähnliche Wirkung zugesprochen werden könnte, ist weniger ersichtlich.

Für die bei Malaria vorkommende Hirnpurpura ist neuerdings Dürk ${ }^{3}$ ) der Meinung Schmidts beigetreten, daß nicht der Blutaustritt, sondern ein entzündlicher Vorgang das Wesentliche an der Erscheinung ist.

Von größter Bedeutung ist ferner, daß bei vielen Purpuraformen auch zellige Knötchen in wechselnder Anzahl vorkommen, in deren Bereiche die roten Blutkörperchen entweder ganz fehlen oder doch zurücktreten. Ich habe sie besonders zahlreich in manchen Fällen von perniziöser Anämie gefunden. In ihrem Zentrum waren sie ebenso beschaffen wie die Ringblutungen. Die Nekrose des Gewebes mit Schwund der Markscheiden war meist deutlich nachweisbar. Ja, es waren weiterhin auch kleine Stellen in der Marksubstanz dieser Gehirne nachweisbar, in der nur eine wabige Beschaffenheit des Gewebes, eine

1) Zur Pathologie der Encephalitis acuta. Deutsche Zeitschr. f. Nervenheilkunde 1914, Bd. 50.

2) Über amöboide Glia. Virchows Arehiv 1914, Bd. 216.

3) Über die bei Malaria perniciosa contagiosa auftretenden Veränderungen des Zentralnervensystems. Archiv f. Schiffs- u. Tropenhyg. 1917, Bd. 21. 
hyaline Verquellung der Glia mit Schwund der Markscheiden und tropfigem Zerfall der Achsenzylinder erkennbar waren, während. Blutaustritt und zellige Wucherung fehlten.

Es ist unabweisbar, daß diese Veränderungen unter einem gemeinsamen Gesichtspunkte zu betrachten sind und daß sie mechanisch nicht erklärbar sind. Augenscheinlich bilden die zuletzt erwähnten kleinen umschriebenen Nekrosen des Hirngewebes die primäre und wesentliche Veränderung. Die Blutung kann hinzutreten oder fehlen und an der Peripherie der nicht ganz frischen Herdchen tritt eine Wucherung gliöser Elemente auf. Ob. zellige Wucherungen, die bei anderen Purpuraformen vorkommen, in ähnlicher Weise zu bewerten sind, kann hier

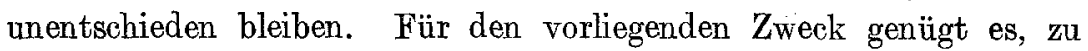
wissen, daß wenigstens bei der perniziösen Anämie kleine Gehirnblutungen vorkommen, die durch schwere Gewebsveränderungen veranlaßt sind, und daß diese Gewebsveränderungen keineswegs allein die GefäBe oder auch nur vorwiegend die Gefäße betreffen.

Auch bei der Apoplexie finden sich nun in der Umgebung des großen Herdes Ringblutungen, und sie waren in meinem Material in 4 Fällen, also in 33 Proz., nachweisbar. Auch in diesen Fällen war der Schwund der Markfasern innerhalb der kleinen Herde immer nachweisbar (s. Abb. 17) und im Zentrum war öfter ein verquollenes und wohl auch von Fibrin durchtränktes Gefäßchen erkennbar. Das Zentrum des Herdchens trägt kein deutliches Glianetz mehr, sondern hat körnige Beschaffenheit. Die Zeichen reaktiver Gliawucherung fehlen nicht in Fällen, in denen das Leben länger erhalten blieb.

Unzweifelhaft sind auch in den kleinen Blutungen, die die Ringblutungen an Größe übertreffen und die in der verschiedensten Form und Größe den apoplektischen Herd begleiten, die nämlichen zerstörenden Kräfte wirksam, wie in dem großen Herde. Hier trifft man nicht selten gröbere Arterien an, deren Wand gerade so der Nekrose verfallen ist, wie das an den Schlagadern des Hauptherdes nachweisbar ist (s. Abb. 6-8 und 13-14).

$\mathrm{Zu}$ alledem kommt noch ein Weiteres. Während bei der reinen Hirnpurpura die kleinen Hirnblutungen meist in einem unveränderten Hirngewebe liegen, ist das bei der Apoplexie anders. Dieses Hirngewebe ist weder zwischen den kleinen Blutungen noch auch überhaupt in der Umgebung des großen Herdes unverändert. Nur selten scheidet sich dieser scharf gegen gesundes Gewebe. Meist ist er von diesem getrennt durch eine Schicht von wechselnder, bis zu einigen Millimetern betra- 
genden Dicke, in der das Gewebe aufgehellt ist. Bei der 7 Tage alten Blutung der 9. Beobachtung zeigt ein Blick auf die Photographie des Pal-Präparates den lichter gefärbten Saum, der die Blutung umgibt. Mikroskopisch finden sich darin Markfasern in tropfigem Zerfall und solche, deren Färbbarkeit herabgesetzt ist. Auch die kleinen Zonen, innerhalb deren das Gewebe ganz homogen geworden, jede Struktur verloren hat, die sich in mehreren Fällen in dieser Schicht fanden, weisen auf den degenerativen Prozeß hin.

Diese Veränderung der Randzone kann nicht etwa lediglich als sekundär bètrachtet werden. Sie findet sich vielmehr auch bei ganz frischen Fällen, in denen das Leben durch die Blutung in wenigen Stunden vernichtet wurde. Besonders deutlich trat das in der ersten Beobachtung hervor, weil hier ein Teil der Blutung in der Brücke, und zwar vorwiegend in der Schleifenschicht einer Seite, gelegen war. Der symmetrische Bạ des Organes und der Vergleich mit der Schleife der gesunden Seite machten den Faserausfall auch dem unbewaffneten Auge schon sehr deutlich. Ebenso war in der 3. Beobachtung diese degenerierte Randschicht an manchen Stellen schon bei makroskopischer Betrachtung der Übersichtsschnitte deutlich erkennbar, wie auch mikroskopisch Ausfall von Fasern und tropfiger Zerfall leicht $z u$ sehen war. An anderen Stellen fehlte diese Zone. Der Ubergang zum gesunden Gewebe war unvermittelt oder durch eine blutige Schicht, in der Einzelheiten nicht mehr erkennbar waren, gegeben. In den anderen frischen Fällen trat diese aufgehellte Zone mehr zurück oder fehlte überbaupt, und auch bei älteren Fällen ist sie nicht immer nachweisbar, zum Teil vielleicht auch deshalb, weil in dieser Zone später lebhafte Wucherungsvorgänge einsetzen und der dann vorhandene Kernreichtum ein anderes Bild schafft. Daß sich in einer Beobachtung (Fall 10) der hintere Pol des apoplektischen Herdes nicht im Zustande blutiger, sondern weißer Erweichung befand, sei hier noch besonders erwähnt.

Somit betrachte ich als erwiesen, daß auch die kleinen und kleinsten Blutungen bei der Apoplexie nicht einfach mechanisch durch Gefäßruptur zustande kommen, sondern daß auch in ihnen die Gefäße einem nekrotisierenden ProzeB unterworfen sind und $\mathrm{d} a \beta$ das Gewebe zwischen den Blutungen ebenfalls die Zeichen sehwerer Schädigung trägt.

Innerhalb der blutigen Massen des großen Herdes selbst fand sich in meinen Fällen nur wenig von Gewebsresten vor. Das mag ein Zufall sein. Denn man mag sich den apoplektischen Herd entstanden denken, 
wie man will, durch eine Blutung aus einem großen oder aus zahlreichen kleinen Gefäßen, immer ist es denkbar, daß er mehr oder weniger erhaltenes Hirngewebe umschließt, und tatsächlich finden sich auch in der Literatur Hinweise auf ein solches Verhalten. Indessen liegen doch keine näheren Untersuchungen über das mikroskopische Verhalten solchen Gewebes vor. Nach meinen Präparaten kann ich folgendes sagen: Eine Mischung von. Blut und Nervengewebe findet sich hauptsächlich an manchen Randpartien apoplektischer Herde. Hier senken sich oft Bündel von Markfasern in die Blutung ein und sind von roten Blutzellen durchsetzt und machen manchmal durchaus den Eindruck, nur mechanisch auseinander getrieben zu sein. Häufig sind die Fasern auch bei ganz frischen Blutungen in Tropfen und Tröpfchen zerfallen und, was noch wichtiger ist, sie färben sich manchmal nur schattenhaft und werden um so schwerer kenntlich, je tiefer sie in den Herd eintauchen. Je näher man den inneren Lagen der Blutung kommt, um so weniger findet man von Nervengewebe. Liegt die Blutung in der grauen Substanz, so findet man auch hie und da Ganglienzellen, die ihre Färbbarkeit eingebüßt haben. Von dem Stützgewebe ist innerhalb der Blutung niemals etwas zu finden.

Ähnlich wie die Markfasern verhalten sich die Gefäße. Selten findet man eine erhaltene Arterie und noch seltener eine erhaltene Vene in den zentraleren Teilen des Herdes. Findet man eine solche Arterie, so ist sie stark sklerotisch. Man hat den Eindruck, daß sie durch ihre verdickten Wandungen der Zerstörung entgangen ist, der andere anheimfielen. Reichlicher finden sich Gefäße in den Randschichten der Blutungen. Sie sind in der großen Mehrzahl schwer degeneriert, meist völlig nekrotisch und oft nur schwer erkennbar.

Kapillaren wurden zwischen den Blutkörperchen meist völlig vermißt. Nur an den Herdwandungen sieht man hie und da einmal vereinzelte Haargefäße gegen den apoplektischen Herd hinziehen.

Nach meinen Untersuchungen stellt sich die Erkrankung der Arterien folgendermaßen dar. Die inneren Häute sind nicht mehr gut gegeneinander abgrenzbar. Sie erscheinen häufig gequollen. Die Kerne werden undeutlich. Besonders verschwinden die der Muskelschicht, während das Endothel der Intima öfters noch hie und da erhalten bleibt. Mit der Quellung gewinnen diese Häute oft eine hyaline Beschaffenheit. Sie können dann am ungefärbten Präparat einen solchen Glanz zeigen, daß man Amyloid vor sich zu haben glaubt, ohne daß aber darauf gerichtete Färbungen ein positives Resultat geben. Wenn diese hyaline 
Beschaffenheit ausgeprägt vorhanden ist, so sind meist alle Kerne in der Muskelschicht und Innenhaut geschwunden. Auch die Elastikd erhält sich an solchen Stellen nicht. Ist der Prozeß nicht zu hochgradig, so kann man manchmal die Adventitia noch erhalten sehen. Häufig ist sie durch eine Schicht roter Blutzellen von der Muskelhaut abgehoben. In anderen Fällen verschmilzt sie untrennbar mit der letzteren. Gewöhnlich wird die aus der Verquellung and Verschmelzung der einzelnen Häute hervorgegangene Wand völlig homogen, seltener streifig oder körnig. Häufig schwillt ein so erkranktes Gefäß kolbig an, was man: natürlich nur an Längsschnitten sehen kann. Dí Deutung der Querschnitte der hochgradig veränderten Gefäße kann schwierig oder unmöglich werden. Sie fallen meist zunächst auf durch eine Ansammlung von Rundzellen in und an der Wand. Oft bergen sie auch thrombenartigen Inhalt mit zahlreichen Rundzellen. Unverändertes Blut enthalten schwer veränderte Gefäße nur in rasch tödlich verlaufenden Fällen.

Die Ausdehnung des Prozesses, die man an den einzelnen Gefäßen findet, ist verschieden. Trifft man sie auf Längsschnitten, die den apoplektischen Herd and seine Wand umfassen, so sieht man wohl die Arterie wenig verändert aus der Wand nach dem Herde hinziehen. Je näher sie ihm kommt, desto schwerer werden die Veränderungen, bis das Gefäß nur noch ein nekrotischer Schlauch ist. Gelegentlich findet man aber auch Arterien, die zum größten Teil intakt sind und an denen die schwere Veränderung nur einen umschriebenen Teil der Wand einnimmt.

Die kolbige Anschwellung, die ein großer Teil der erkrankten Arterien auf Längsschnitten aufweist, ist oft wohl nur Folge der Quellung der Wand. Nicht selten aber kommt eine Ausweitung der Lichtung hinzu, wozu auch spindelförmige oder kugelige oder sackförmige Anschwellungen des Rohres entstehen, die Miliaraneurysmen Charcots. Diese Bildungen sind immer vollkommen strukturlos. In ihnen nachweisbare Kerne gehören Wanderzellen an. Oft wird die Begrenzung solcher Gefäßstücke ganz unscharf. Weder gegen die Umgebung noch gegen den thrombenartigen Inhalt, wenn solcher das Lumen ausfüllt, setzt sich die Wand scharf ab. Manchmal, aber durchaus nicht oft, läßt sich nachweisen, daß sie mit Fibrin durchsetzt ist. Manchmal kann man an längsgeschnittenen Gefäßen, die aus der Herdwand in die Blutung eintauchen, die Lymphscheide erhalten sehen, die von einer Blutsäule abgehoben, das erkrankte Gefäß begleitet. Auf der Höhe der An- 
schwellung oder wenn die aneurysmenartige Bildung fehlte, in der Umgebung des ganz homogen und kemlos gewordenen Gefäßes, war sie meist in der blutigen Umgebung nicht mehr nachweisbar.

Diese Arterionekrose findet sich ausschließlich im Gebiete des apoplektischen Herdes, innerhalb dieses aber nicht etwa nur in der großen Blutung, sondern auch in den kleinen isolierten Hämorrhagien, die den großen Herd stets begleiteten.

Vergleicht man meine Befunde an den kranken Gefäßen mit denen der früheren Autoren, so finden sich zwar erhebliche Meinungsverschiedenheiten, aber einige wichtige Punkte werden doch allgemein anerkannt. Dahin gehört besonders der Vorgang, der sich in einem Schwinden der zelligen Elemente der Häute kundgibt und in einem Verschmelzen der Wandschichten miteinander. Mehrfach wird hervorgehoben, daß diese Wand dann streifig oder körnig oder homogen werden kann und daß sie im letzteren Falle einen starken Glanz gewinnen kann. Am schärfsten unterscheidet Lö wenfeld diese verschiedenen Befunde. Indessen glaube ich nicht, daß diese Unterscheidung einen besonderen Wert hat. Das Wesentliche aller dieser Vorgänge gibt sich in der endlichen Wirkung kund und diese ist der Untergang der Gefäßwand, die Zerstörung ihrer besonderen Bestandteile. Für die heutige Technik ist es nicht zweifelhaft, daß die schwerer erkrankten Gefäßgebiete der Nekrose verfallen, die sich gleichmäBig auf innere und mittlere Haut erstreckt und auch die Adventitia nicht verschont.

Hier erhebt sich nun sofort die Frage nach dem Verhältnis dieser schweren Degeneration zu der Arteriosklerose, eine Frage, zu der alle Bearbeiter des Gegenstandes Stellung genommen haben, indem sie den Zusammenhang teils behaupteten, teils ablehnten. Nun ist von vornherein klar, daß man bei einem Leiden, bei dem so häufig die Arterien des ganzen Hirnes sklerotisch gefunden werden, natürlich auch oft sklerotische Gefäße in und um den apoplektischen Herd finden muß. Ich verfüge über Präparate, die sklerotische Arterien längsgeschnitten aus dem gesunden Gewebe in den apoplektischen Herd eintauchend enthalten.' Sieht man da die cklerotischen Veränderungen des peripheren Abschnittes der Arterie in nekrotische übergehen, die der in die Blutung eintauchende Abschnitt aufweist, so liegt natürlich der Gedanke nahe, daß der letztere Prozeß nur ein höherer Grad des ersten sei. Wie kommt es dann aber, daß der gleiche Prozeß in anderen Organen nicht vorkommt? Niemand hat doch bislang diese eigentümlichen aneurysmenartigen Bildungen an nekrotischen Arterien in anderen Organen be- 
schrieben und doch findet man in den. Nieren der Schlagflüssigen so gut wie immer die Arterien sklerotisch und häufig in höherem Grade sklerotisch als in dem Gehirn.

Von entscheidender Bedeutung ist aber der Umstand, daß man in einer Minderzahl von Apoplexien überhaupt keine Arteriosklerose der Himarterien nachweisen kann, oder daß sie in einem so geringen Grade vorhanden ist, daß man sie unmöglich als ursächlich für die nekrotisierende Entartung der Gefäße des apoplektischen Herdes betrachten kann. Die Anfertigung großer Übersichtsschnitte erleichtert das Urteil sehr, ob sklerotische Arterien im Gehirn vorhanden sind oder nicht.

Weiter muß ich, im Gegensatz zu anderen Autoren, hervorheben, daß die Gefäßnekrosen und aneurysmenartigen Bildungen lediglich im Bereiche des apoplektischen Herdes vorkommen. Dem stehen allerdings einige Angaben, besonders die von Charcot, entgegen. Aber ich muß doch betonen, daß das Zupfpräparat ungeeignet ist, diese Frage zu entscheiden. Bei dem Auszupfen sklerotischer Gefäße werden leicht Kunstprodukte zu Trugbildern führen. Andere Arbeiten, bei denen zahlreiche M.-A. sicher nachgewiesen wurden, nehmen eine Ausnahmestellung ein. In dem Falle von Paulicki z. B. sind wohl zahlreiche Aneurysmen in der Pia und an der Hirnoberfläche gefunden, aber hier lag, soweit der Bericht erkennen läßt, überhaupt keine'Apoplexie vor und die Auffassung des ganzen Falles ist zweifelhaft. Meine eigenen Präparate lassen mir keinen Zweifel, daß die Gefäßnekrosen mit und ohne aneurysmenartige Bildungen lediglich im Bereiche des apoplektischen Herdes vorkommen.

Daß man zunächst auch außerhalb dieses Bereiches nach Aneurysmen auf das eifrigste suchte, war natürlich genug. Man nahm an, daß die Arteriosklerose oder eine andere ihr nahestehende Erkrankung in diffuser Weise die Arterien des Gehirnes befallen hatte, daß sie an einer oder einigen wenigen Stellen des Gehirnes aus unbekannten Ursachen eine besonders schwere Entwicklung nahm und so zum Bersten von Gefäßen und zur Bildung des apoplektischen Heerdes führte. Besonders Charcot hat diese Ansicht ausgesprochen, wenngleich er den schädigenden Prozeß an den Gefäßen von der Sklerose scharf schied und erklärte, daß seine M.-A. niemals außerhalb der Schädelhöhle gefunden würden. Wenn er aber seine M.-A. in einem Gehirn fand, das frei von Blutung war, so betrachtet er dieses als prädestiniert für die Apoplexie. Diese Bildungen mußten also der Blutung vorausgehen und eine unbestimmte Zeit lang bestanden haben. 
Dagegen wendet nun Pick mit Recht ein, dab diese sogenannten Aneurysmen kurzlebige Erscheinungen sein müßten, denn es fehlen in ihrer Umgebung, was Charcot freilich an seinen Zupfpräparaten nicht feststellen konnte und was auch den späteren Untersuchern entgangen ist, alle Zeichen der Reaktion.

Diesen Satz kann ich bestätigen und dahin erweitern, dab nicht allein die aneurysmenartigen Bildungen, sondern überhoupt die nekrotischen Arterien in ihrer Umgebung die Zeichen der Reaktion vermissen lassen. Der Grund ist freilich einfach der, daß das die nekrotischen Arterien umgebende Gewebe meist selbst abgestorben ist. Die Reaktion wird also in der Regel nur von der überlebenden Gefäßwand erfolgen können. Sieht man sich aber nach solchen Vorgängen um, so findet man in der Tat an den Gefäßen frischer Blutungen noch gar keine hier in Betracht kommenden Veränderungen. Blutungen, die mehrere Wochen alt sind, geben wieder mit ihrem Kernreichtum in der realitiven Zone ein wenig übersichtliches Bild. Wohl aber fand ich bei einer neun Tage alten (hier nicht näher besprochenen) Apoplexie interessante Bilder, die wohl nur als Wucherung von äußerer und innerer Gefäßhaut mit Umfassung nekrotischer Gefäßwandreste zu deuten sind. Doch bedarf dieser Vorgang noch näherer Untersuchung. Jedenfalls aber kann ich bestätigen, daß die Arterionekrose der frischen Apoplexie einem akuten Prozeß der jüngsten Vergangenheit ihr Dasein verdankt. Nichts spricht dafür, daß sich diese Gebilde langsam und allmählich entwickeln und dem Schlaganfall längere Zeit vorausgehen müßten.

Vergegenwärtigt man sich alles, was über den apoplektischen Herd gesagt ist, $\mathrm{da} ß \mathrm{~B}$ inm nur selten erhaltenes Nervengewebe gefunden wird und daß auch dieses, selbst in frischen Fällen, Schädigungen aufweist, die nicht allein mechanischer Natur sein können, betrachtet man, daß Arterien, Venen und Kapillaren zugrunde gehen, nimmt man hinzu den Gewebszerfall in der Wand des Herdes, im Bereiche der kleinen und kleinsten Blutungen, so wird klar, daß die mechanische Theorie ganz unzureichend zur Erklärung des Schlaganfalles ist. Sicherlich liegt in der Auffassung Rochoux', die die Blutung als Folge eines unbekannten Erweichungsvorganges auffaßt, eine nicht beachtete Wahrheit.

Eine nähere Vorstellung über diesen Vorgang zu gewinnen, ist freilich auch heute noch sehr schwer, wenn auch nicht ganz so aussichtsIos wie zu Zeiten Rochoux'. Die festgestellten Tatsachen drängen aber zu folgenden Schlüssen. Eine unbekannte, mit äußerst wirksamen chemischen Kräften ausgestattete Schädlichkeit befällt plötzlich einen 
umschriebenen Hirnbezirk. Innerhalb dieses greift sie diffus oder in zahllosen, meist zusammenfließenden Herden das gesamte Gewebe an und vernichtet Glia, Nervenfasern, Ganglienzellen, Kapillaren und Venen. Von den Arterien entgeht ein Teil dem Untergang, und zwar um so eher, je mehr die Wände durch die so häufig vorhandene Sklerose verdickt und besonders widerstandsfähig geworden sind. Nicht immer und überall fließen die kleinen Herde zusammen. Sie können erhaltenes Gewebe einschließen. Immer stehen sie weniger dicht an der Peripherie des Herdes. Diese Schicht, die zur Wand des Herdes wird, enthält zwar die kleinen Blutungen mehr vereinzelt, läßt aber die Wirkung derselben nur nicht so intensiv wie in den zentralen Partien angreifenden Schädlichkeit erkennen. Das ergossene Blut stammt wohl vorwiegend aus Venen und Kapillaren. Die Arterien sind vielfach durch Thromben geschlossen. Die Blutkörperchen sind die einzigen Elemente, die unter der Schädlichkeit nicht leiden. Das meist unter geringem Druck aussickernde, oft mit umgewandelter Hirnmasse innig gemischte Blut neigt zur Gerinnung, obwohl in diesen weich geronnenen Massen Faserstoff meist nicht nachweisbar ist. Der geringe Druck des aussickernden Blutes und die Neigung zur Gerinnung machen es verständlich, daß trotz häufiger Zerstörung der Ventrikelwandungen eine starke Blutung in das Hirnhöhlensystem meist nicht exfolgt.

Es erwächst nun die Aufgabe, die eben besprochene Auffassung von dem Wesen der Apoplexie unseren allgemeinen pathologischen Anschauungen einzuordnen. Die Schwierigkeit liegt hierbei vornehmlich in der großen Bedeutung, die einer perakut einsetzenden Nekrose zugeschrieben wird, die nicht nur umfangreiche Teile eines Organes viernichtet, sondern dabei auch die verschiedensten Gewebe angreift.

Allgemein läßt sich zunächst wohl sagen, daß die Bedeutung der nekrobiotischen Vorgänge in neuerer Zeit entschieden höher eingeschätzt wird als früher. Ich verweise dabei auf die neueste Arbeit von Neu$\operatorname{mann}^{\mathbf{1})}$ über das Verhältnis der Entzündung zur Regeneration. Unter Beziehung auf die Arbeiten Weigerts über die Pockeneffloreszenz, auf die von Fürst und Rischlpeter über die Einwirkung von Wärme- und Kältereizen auf die äußere Haut, auf die Arbeiten Unnas über den Herpes zoster und die Varizellen wird die Nekrose der Retezellen als der primäre Vorgang anerkannt, der erst die Entzündung im Gefolge hat. Daß die Ansammlung mancher pathogener Spaltpilze auch in inneren Organen zunächst zu einer umschriebenen Nekrose Veranlassung

1) Beiträge zur pathol. Anatomie 1917, Bd. 64, Heft 1. 
gibt, ist wobl allgemein zuzugeben. Von Streptokokken und Staphylokokken war es lange bekannt, während die Kenntnis der Muskelnekrosen. beim Gasbrand jünger ist. Auf die Arbeit von E. Fränkel ${ }^{1}$ ), nach der in der Wand der kleinen Hautarterien in den Roseolon Fleckfieberkranker und in den Patechien bei Genickstarre Nekrosen nachweisbar sind, darf hier Bezug genommen werden.

Auch toxische Schädigungen nicht infektiöser Natur können Zellen zum Absterben bringen. So berichtete Schopper ${ }^{2}$ ) auf der Wiener Naturforscherversammlung über herdförmige Nekrosen in den Leberläppchen, die durch Alkoholvergiftung bei Kaninchen erzeugt waren. Ebenda sprach Hein richsdorf über degenerative Prozesse in der Leber, die sich im Anschluß an toxische oder infektiöse Einflüsse neben einer Stauung entwickelten. Sie sollen innerhalb des Leberläppchens als zentrale Verfettung beginnen und unter Umständen zu hämorrhagischer Nekrose führen können. Von verschiedenen Seiten wurde über ähnliche Erfahrungen berichtet.

Uber schwere alkute Muskeldegenerationen in Form der Zenkerschen Degeneration haben Benecke und seine Schüler berichtet. Es hatte sich gezeigt, daß bei Kaninchen, die mit brasilianischem Schlangengift getötet waren; wachsartige Degeneration der Muskel eingetreten war und die Vergiftung hatte ż einem tiefen Temperatursturz geführt. Diese Erkenntnis führte dazu, auch die Muskeln anaphylaktischer Tiere za untersuchen und es zeigte sich, daß bei ihnen in wenigen Minuten eine schwere Entartung der Muskelfibrillen, besonders des Zwerchfelles, zustande kommt ${ }^{3}$ ). Den gleichen Befund erhob Benecke ${ }^{4}$ ) an der Leiche eines Mannes, der im Anschluß an eine Punktion einer großen Echinokokkuszyste der Leber rasch zugrunde gegangen war. Die Verletzung einer Vene in der Zystenwand ließ sich nachweisen und damit der Ubertritt von Zystenflüssigkeit in die Blutbahn sehr wahrscheinlich machen. Ähnliches fand Stemmler ${ }^{5}$ ) bei verschiedenen Infektionen.

1) Zur Fleckfieberdiagnose. Münchn. med. Wochenschr. 1915 und Über petechiale Hauterkrankung bei epidemischer Gerickstarre. Beiträge zur patholog. Anatomie 1916, Bd. 63.

2) Zentralblatt f. allg. Pathologie 1913, Bd. 24, Nr. 21.

3) Steinschneider, Die sessilen Rezeptoren bei der Anaphylaxie. ReichsMed.-Anzeiger 1913.

4) Weitere Beobachtungen über wachsige Muskeldegeneration nach anaphylaktischen Vergiftungen. Beiträge z. pathol. Anatomie 1917, Bd. 63.

5) Die wachsartige Degeneration der Muskulatur bei Infektionskrankheiten. Virchows Archiv 1914, Bd. $2 \mathrm{I} 6$. 
Bei der Dysenterie kommt es zur Bildung von Leberabszessen und von Lebernekrosen. Die ersteren sind oft steril und die Nekrosen werden ąuch ohne räumliche Beziehungen zu den Abszessen gefunden. Abszesse und Nekrosen konnte Mühlman $n^{1}$ ). in der Leber durch Einspritzung von Dysenterietoxin in die Pfortader von Kaninchen erzielen.

Von noch größerem Interesse sind hier die Versuche von Lotmar ${ }^{2}$ ). In einer umfangreichen Versuchsreihe konnte er bei Kaninchen, denen er Aufschwemmungen abgetöteter Dysenteriebazillen subkutan oder ein Filtrat der Bouillonkultur intravenös beibrachte, perakut entstehende myelitische und enzephalitische Herde erzeugen. In ihnen erwies sich das meso- wie elktodermale Gewebe schwer verändert. Neben kleinen Blutungen kam es an der Gefäßwand neben geringen, anscheinend progressiven auch zu regressiven Veränderungen und bis zum völligen Untergang der Gefäßwand. Die nervösen Bestandteile reagieren auf das Gift rasch mit Verflüssigung der Ganglienzellen und Schwund der Nervenfasern. Das Glianetz schwindet zum Teil, während die Gliazellen je nach der Intensität der Schädigung der Umwandlung in amöboide oder in proliferierende Glia anheimfallen.

Immerhin wirken bei diesen schweren Schädigungen der Gewebe immer exogene Schädlichkeiten ein. Es fragt sich, ob solche auch endogen entstehen können. Die Zahl der anzusprechenden Tatsachen ist hier gering.

Bekannt ist, daß bei der Gicht Nekrosen in den Nieren, Sehnen und Bändern, im Knorpel und selbst im Knochen vorkommen. Wie es zur Ausbildung dieser Nekrosen kommt, ob dieselben, wie Ebstein wollte, primär entstehen und dem sich abscheidenden harnsauren Natron eine Stätte bereiten, ist zwar noch unentschieden, kann aber auch hier unerörtert bleiben. Weiter können hier die Leberveränderungen bei der Eklampsie herangezogen werden. Doch ist trotz vielfacher Bearbeitung des Gegenstandes noch keine Einigung erzielt, ob die Nekrosen lediglich durch Blutungen infolge von Verlegung von Venen durch Thromben entstehen oder ob vielmehr eine besondere Giftwirkung vorliegt, die die Lebensfähigkeit zelliger Elemente, und zwar des Endothels und der Leberzellen, schädigt (Konstantinowitsch).

1) Zur Ätiologie und Pathogenese der dysenterischen Ieberabszesse. Beiträge z. patholog. Anatomie 1914, Bd. 57.

2) Zur Wirkung des Dysenterietoxins auf das Zentralnervensystem. Zeitschr. f. d. ges. Neurol. u. Psych. 1912, Bd. 8, und Beiträge zur Histologie und der akuten Myelitis und Encephalitis. Nissl und Alzheimer, Hist. u. histopath. Arbeiten 1913, Bd. 6, Heft 2. 
Von großer Bedeutung würde es sein, wenn über die Entstehung der Netzhautblutung bei der Nephritis und die Retinitis albuminurica mehr Klarheit bestände. Die auch in der Retina vorkommenden angeblichen Miliaraneurysmen scheinen für dïe Blutungen keine größere Bedeutung zu haben. Die Veränderungen der Netzhaut bei Nierenerkrankungen bestehen, abgesehen von Hämorrhagien, in einer sero-fibrinösen Infiltration und Exsudation, in varikösen Verdickungen der marklosen Nervenfasern, in Fettinfiltration mit Auftreten von Körnchenzellen und in Wucherungen der Neuroglia. Leber ${ }^{1}$ ), dessen Darstellang ich hier vor Augen habe, möchte dies alles aus einer eigenartigen Zirkulationsstörung erklären, läßt aber doch die Möglichkeit offen, daß eine infolge der Niereninsuffizienz geänderte Blutbeschaffenheit die Gewebe schädigen möge. Die Annahme, daß im Verlaufe der Nierenentzündung und besonders bei der Urämie giftige Stoffwechselprodukte wirksam werden, ist ja allgemein und in der Tat wohl kaum zu entbehren. Aber unsere histologischen Kenntnisse über die primären Veränderungen bei der urämischen Entzündung der serösen Häute und besonders über diejenigen, die den Blutungen bei der hämorrhagischen Diathese, durch die eine Urämie nicht ganz selten kompliziert wird, zugrunde liegen; sind noch wenig entwickelt.

Er wäre durchaus möglich, daß weitere Untersuchungen hier sowohl für die Blutungen als die Entzündungen nekrotisierende Gewebsschädigungen aufdeckten. Hat doch schon Ceelen ${ }^{2}$ ) bei chronischen, mit Herzhypertrophie verlaufenden Nierenentzündungen Degeneration der Ganglienzellen im Gebiete des vasomotorischen Systems am Boden der Rautengrube nachgewiesen. Er führt diese Degeneration, die bis zur Nekrose führen kann, auf im Blut kreisende Toxine zurück. Das Studium aller bei der chronischen Nierenentzündung vorkommenden Organveränderungen wird aber für unsere Kenntnis von der Entstehung des Schlaganfalles von großer Bedeutung sein, denn es ist nicht zweifelhaft, daß dieses Leiden in erster Linie den Boden bereitet, auf dem die Apoplexie eintritt. Die Beziehungen zwischen beiden Krankheiten sind seit langer Zeit bekannt, aber die Häufigkeit des Vorkommens der chronischen Nierenentziundung bei dem Schlaganfall wird bei den älteren Statistiken doch sehr verschieden angegeben. Löwenfeld fand sie in

1) Gräfe-Sämisch-Hess, Handbuch d. ges. Augenheilkunde. 2. Aufl. 1915, Bd. 7 .

2) Zur Ätiologie der Herzhypertrophie bei Nierenkranken. Berliner klin. Wochenschr. 1917. 
60 Fällen von Schlaganfall elfmal verzeichnet. Andere von ihm angegebene Beobachter kommen zum Teil zu höheren Prozentsätzen, aber ich glaube, daß auch diese nicht die tatsächliche Häufigkeit der Nierenentzündung beim Schlaganfall richtig wiedergeben. Diese Zählungen bedürfen durchaus einer Nachprüfung, bei der man sich nicht auf den bloßen Anblick der Niere bei der Sektion beschränkt oder auf die Angabe, daß während des Lebens Albuminurie bestand oder fehlte, um die Nephritis anzunehmen oder auszuschließen. Es ist ja nicht zweifelhaft, daß Apoplexien auch bei einer Nierenentzündung nicht selten sind, die noch gar keine Beschwerden gemacht hat. Ich habe eine Anzahl von Schlaganfällen beobachtet, bei denen die betreffenden Personen bis auf eineBlutdrucksteigerung, die $160 \mathrm{~mm} \mathrm{Hg}$. nicht überschritt, keine weiteren Symptome boten und auch kein Eiweiß ausschieden. Ich habe solche Leute auch in der Folge des Schlaganfalles sterben sehen. Bei der Sektion sah dann die Niere durchaus normal aus, während sie bei der mikroskopischen Unterscuhung sichere Zeichen der chronischen Nephritis bot. Diese mikroskopische Untersuchung ist in den alten Statistiken sicherlich meist unterlassen und neue Zählungen gibt es leider nicht. Aber schon aus der kleinen Reihe meiner Beobachtungen, die hier mitgeteilt ist, geht hervor, daß die Nephritis eine sehr große Rolle spielt. Sie ist elfmal nachgewiesen und hätte wahrscheinlich auch in dem übrigbleibenden Falle sich nachweisen lassen, wenn die mikroskopische Untersuchung ausgeführt worden wäre.

In welcher Weise aber nun die erkrankte Niere die Breitschaft für den Schlaganfall schaffen mag, das ist noch durchaus unklar. Nur das eine darf man sagen, daß weder die Erhöhung des Blutdruckes noch die so häufig vorhandene Arteriosklerose die Disposition erklärt. Tritt doch der Schlaganfall oft genug, wie schon erwähnt, bei geringer Drucksteigerung ein und überrascht er doch nicht selten den Patienten im Zustande völliger Ruhe, mitten im Schlafe, wo auch von einer vorübergehenden Blutdrucksteigerung gar nicht die Rede sein kann. Ohne die Annahme, daß in dem unter dem Einfluß der Nierenentzïndung geänderten Stoffwechsel plötzlich fermentativ wirkende Kräfte frei werden, die in kurzer Zeit ganze Hirnteile zu vernichten und chemisch wie morphologisch umzuwandeln vermögen, wird man nicht auskommen können. Nur die Analogie mit den erwähnten fermentativen Prozessen, wie man sie bei der Wirkung des Dysenterietoxins auf das Nervensystem annehmen muß, und wie sie sich auch bei der Nekrose des Pankreas und des Fettgewebes zeigt, vermag die stürmische Zerstörung von Hirn- 
gewebe, wie sie bei dem Schlaganfall eintritt, unserem Verständnis näher zu bringen.

Für die weitere Untersuchung ergeben sich damit alsbald neue Gesichtspunkte und neue Fragen. Lassen sich bei Apoplektikern im Blut und in der Zerebrospinalflüssigkeit Fermente nachweisen, die auf Hirngewebe einwirken? Indessen werden solche Untersuchungen nur von einem Arbeiter erfolgreich in Angriff genommen werden können, der über die entsprechende Schulung verfügt. Ich selbst kam über tastende Versuche nicht hinaus.

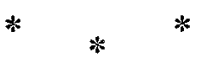

Zum Schluß fasse ich meine Ansicht über die Entstèhung der Apoplexie in folgenden Sätzen zusammen:

1. Die mechanische Theorie reicht nicht aus, um die Zerstörung völlig zu erklären, der das Hirngewebe bei dem Schlaganfall anheimfällt. Schon die Form des apoplektischen Herdes läßt sich häufig nur gezwungen auf lediglich mechanisch wirkende Kräfte zurückführen. Von mechanisch geschädigtem Hirngewebe ist meist nur wenig nachweisbar.

2. Die kleinen und kleinsten Blutungen, die in der Umgebung des großen Herdes angetroffen werden, sind mit diesem wesensverwandt. Sowohl an den Gefäßen in ihrem Innern als auch an dem nervösen Gewebe sind nekrotisierende Vorgänge nachweisbar.

3. Innerhalb des großen apoplektischen Herdes geht ein grosser Teil des gesamten Gewebes, also Nervenfasern und Zellen, Glia und Gefäßsystem, zugrunde und macht eine Umwandlung durch, wodurch es verflüssigt, jedenfalls dem morphologischen Nachweis entzogen wird. Von den Gefäßen erhalten sich nur wenige Arterien and diese um so eher, je dickwandiger und sklerotischer sie sind.

4. In und an der Wand des Blutergusses sind die abgestorbenen Arterien leichter nachweisbar als im Innern. Die sogenannten Miliaraneurysmen sind eine mehr nebensächliche Form, unter der der abgestorbene Gefäßschlauch auftreten kann.

5. Die abgestorbenen Arterien sind häufig durch Thromben verschlossen. Es ist anzunehmen, daß die Blutung vorwiegend. aus den massenhaft vernichteten Kapillaren und Venen stammt.

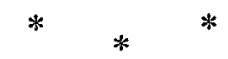


Die reiche Ausstattung der Arbeit mit farbigen Tafeln wurde mir durch Unterstützung aus der Gräfin-Bose-Stiftung in Marburg ermöglicht. Ich spreche dafür auch an dieser Stelle meinen verbindlichsten Dank aus.

\section{Erklärung der Abbildungen.}

Beobachtung 1. Abb. 1-3 Photographien des in Formalin fixierten und in Frontalscheiben zerlegten Hirnes. Sie zeigen die Ausdehnung des Blutergusses in verschiedenen Ebenen. Text Seite 54 u. 55.

Abb. 4 (Winkel Obj. 1, Ok. 2) und 5 (Winkel Obj. 3a, Ok. 4) geben eine kleine längsgeschnittene Arterie wieder, die in ein aneurysmenartiges Gebilde a übergeht. m Muskelschicht, L Lymphscheibe, Färbung van Gieson. Text S. 55.

Abb. 6-8. Nekrotisches aneurysmenartiges Gebilde mit noch erkennbaren Resten der Arterienwand innerhalb eines kleinsten Blutergusses. Färbung Hämatoxylin-Eosin. Winkel, Obj. 3a, Ok. 4. a Reste der Arterienwand. n nekrotische Gefäßwand. Text S. 56.

Beobachtung 2. Abb. 9. d.a. Degenerierte Arterie in einem keulenförmigen Blutergu $B$ untergehend, der sich von der Umgebung überall abgrenzt. Seibert Obj. 00, Perisk. Ok. 3. Hämatoxylin-Eosin. Text S. 64.

Beobachtung 7. Abb. 10 und 11. Zwei kleine, in der Wand des apoplektischen Herdes gelegene Arterien. Die Wand zum Teil völlig verquollen, die Lymph. scheide L abgehoben. Orcein-Hämat. Winkel Ob. 3a, Ok. 4. Text S. 91.

Abb. 12. Längsgeschnittene Arterie in der Wand des apeplektisches Herdes. Nur noch wenig erhaltene Muskelzellen. An der Stelle der Teilung bei $\mathrm{n}$ körnignekrotischer Zerfall der Wand. Winkel Obj. 3a, Ok. 4. Hämt.-Eosin. Text S. 92.

Beobachtung 8. Abb. 13 und 14 zeigen eine kleine, schwer degenerierte Arterie und das nekrotische aneurysmenartige Gebilde n. Winkel. Obj. 1, Ok. 4. Hämt.-Eosin. Text S. 98.

Beobachtung 9. Abb. 15 (Hämt.-Eosin) und 16 (Orcein-Methylenblau) zeigen dieselbe längsgeschnittene Arterie innerhalb des Blutergusses. Die Wand schwer entartet und Muskelkerne hier und da und E Elastica teilweise erhalten. Winkel Obj. 4a, Ok. 2. Text S. 102.

Beobachtung 9. Abb. 17. Pal-Präparat. Seibert Obj. 00, Periskop. Ok. 2. Kleine, zum Teil ringförmige Blutungen, innerhalb deren Markfasern nur selten zu sehen sind. Text S. 104.

Beobachtung 9. Abb.18. Photographie eines Pal-Präparates, die lichte Zone in der Umgebung des apoplektischen Herdes zeigend. Text S. 101. 